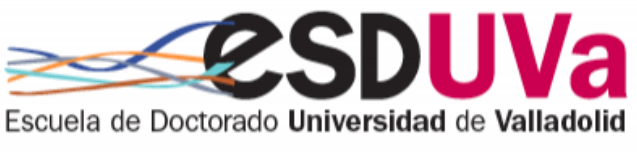

Universidad deValladolid

PROGRAMA DE DOCTORADO EN ESPAÑOL: LINGÜÍSTICA, LITERATURA Y COMUNICACIÓN

TESIS DOCTORAL:

\title{
UNIDADES FRASEOLÓGICAS SOMÁTICAS: ANÁLISIS CONTRASTIVO ESPAÑOL - RUMANO Y APLICACIÓN A E/LE
}

Presentada por Marius Laurențiu Rădoi para optar al grado de Doctor por la Universidad de Valladolid

Dirigida por:

Nieves Mendizábal de la Cruz 


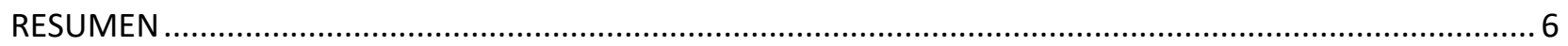

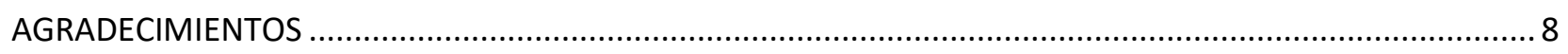

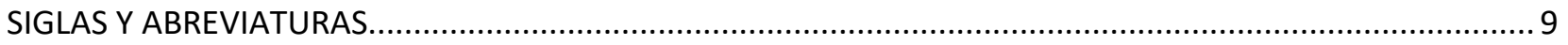

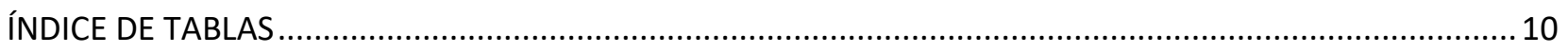

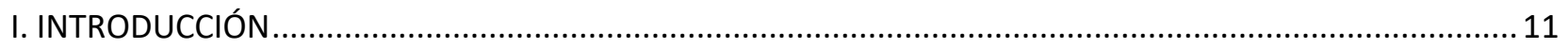

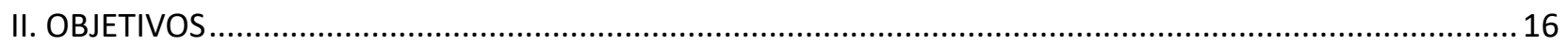

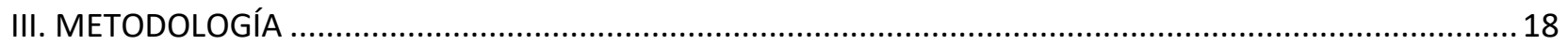

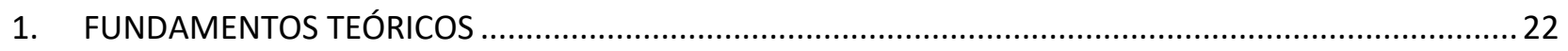

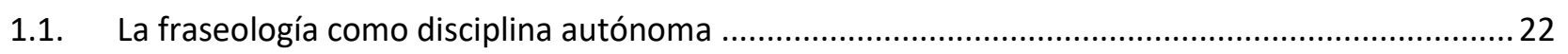

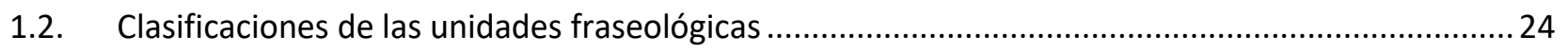

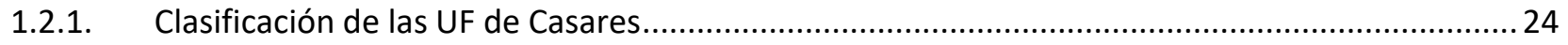

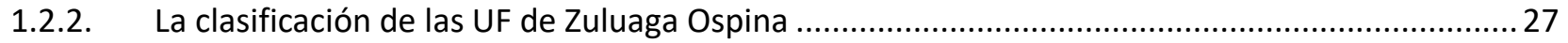

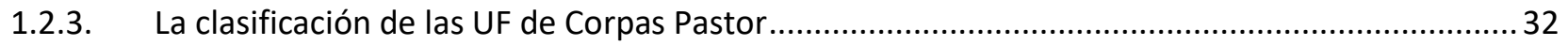

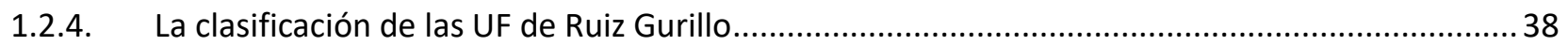

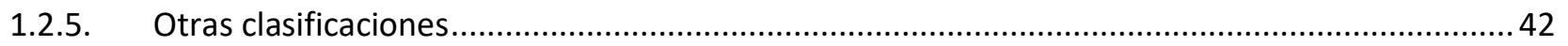

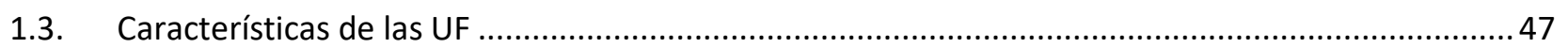

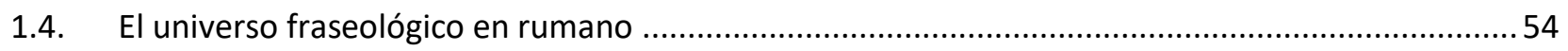

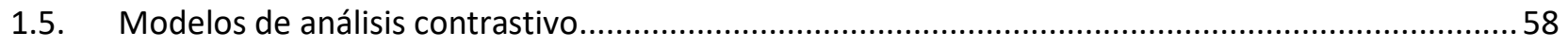

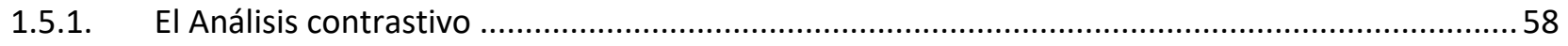

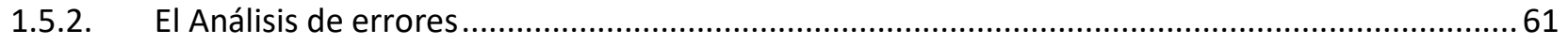

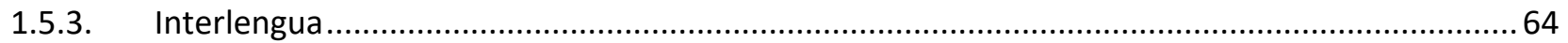

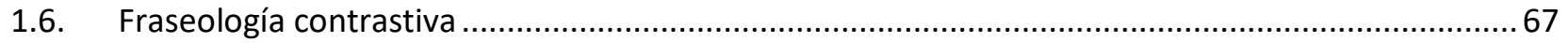

1.7. Estudios y fuentes fraseológicas contrastivas (español-rumano) ……........................................... 70

1.8. Traducción y equivalencias fraseológicas: técnicas de traducción ...............................................73

2. PARALELISMOS LINGÜÍSTICOS EN UNIDADES FRASEOLÓGICAS SOMÁTICAS: ELABORACIÓN Y ANÁLISIS DEL CORPUS ESPAÑOL/RUMANO Y RUMANO/ESPAÑOL...................................................... 78

2.1. Creación del corpus: selección de criterios............................................................................... 79

2.2. Consideraciones morfosintácticas y léxicas interlinguales ........................................................ 81

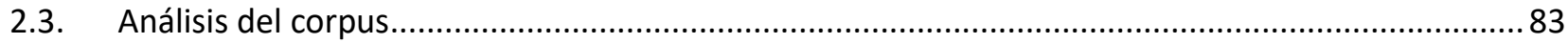

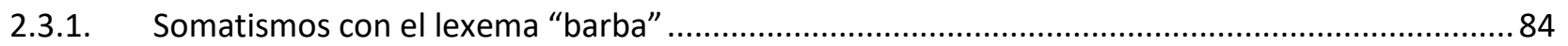

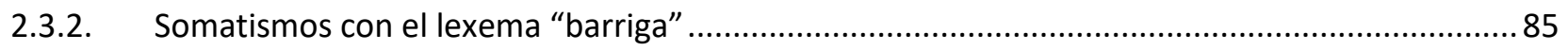




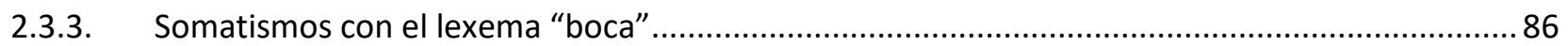

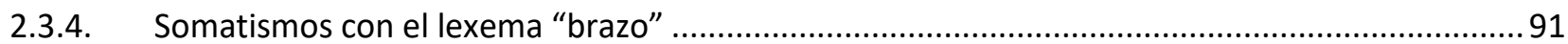

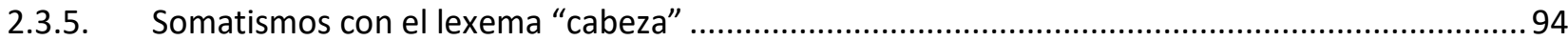

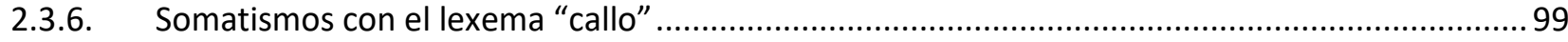

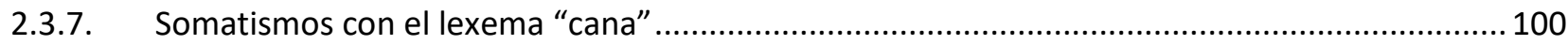

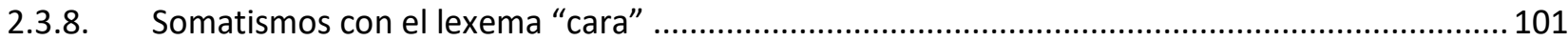

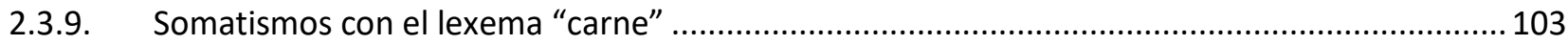

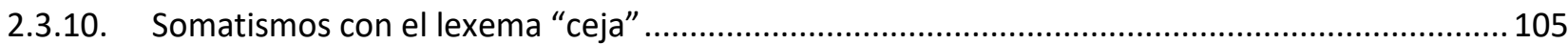

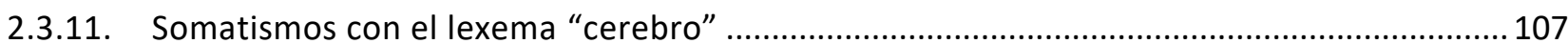

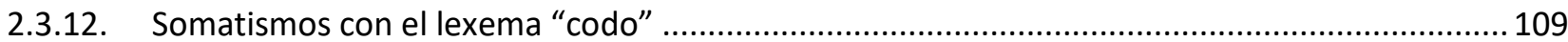

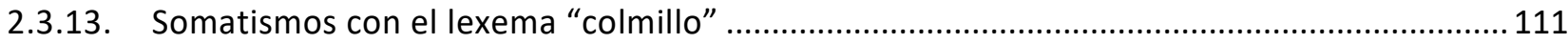

2.3.14. Somatismos con el lexema "corazón ....................................................................................112

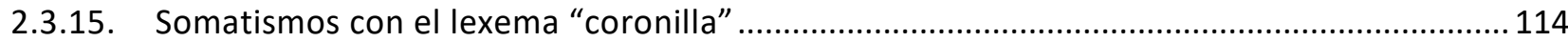

2.3.16. Somatismos con el lexema "cuello" ..................................................................................... 115

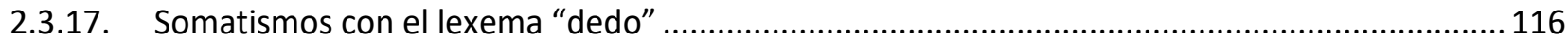

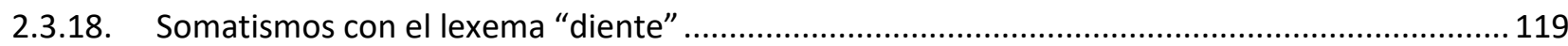

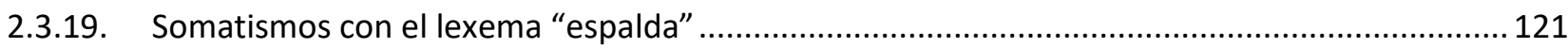

2.3.20. Somatismos con el lexema "estómago" ....................................................................................... 122

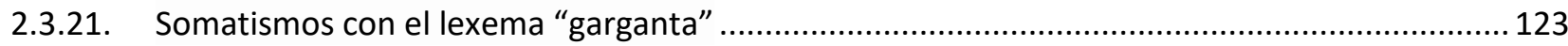

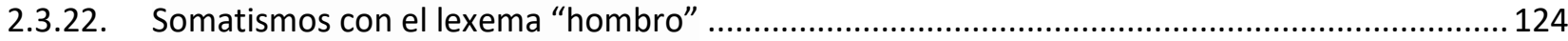

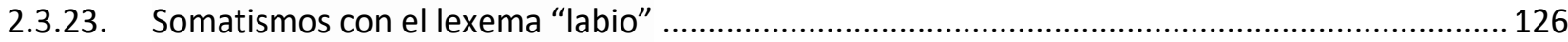

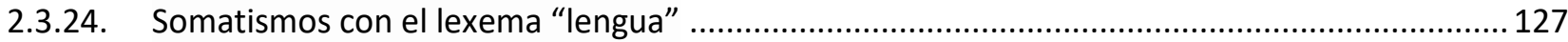

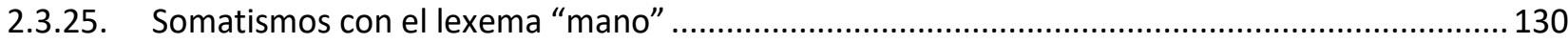

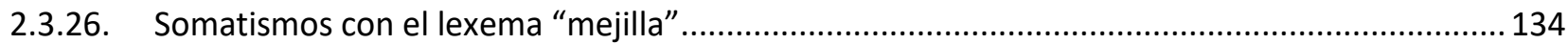

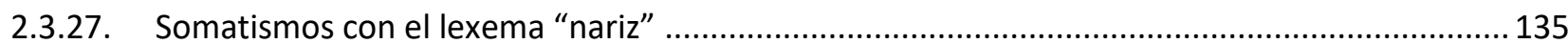

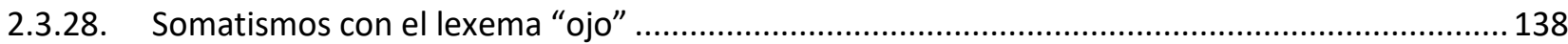

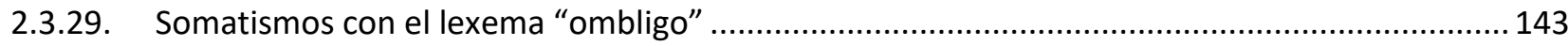

2.3.30. Somatismos con el lexema "oreja" ...................................................................................... 145

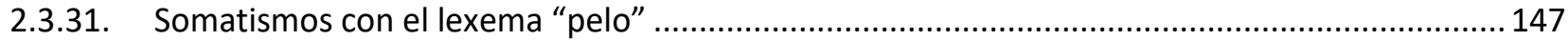

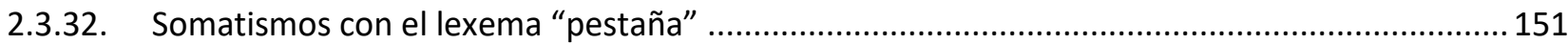

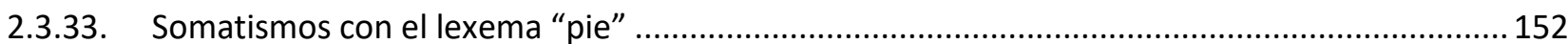

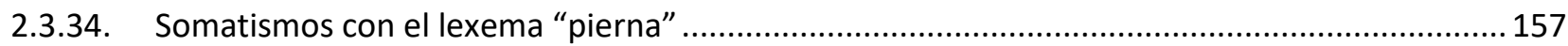

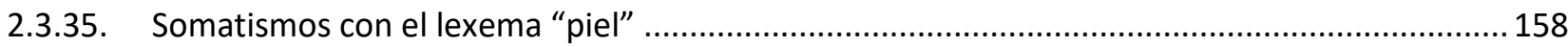




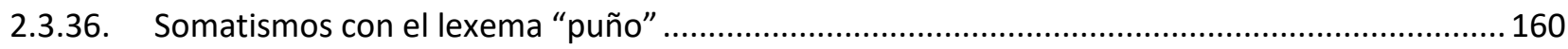

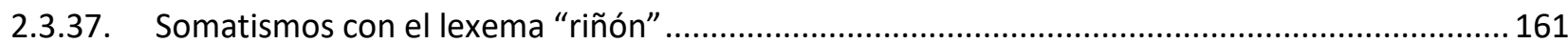

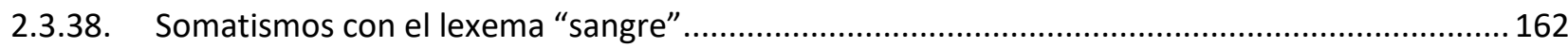

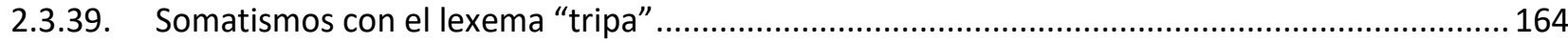

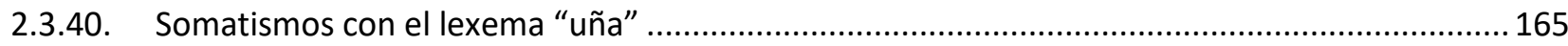

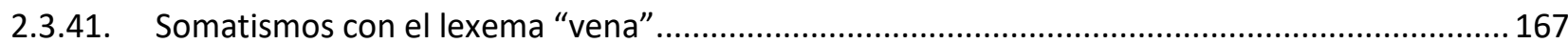

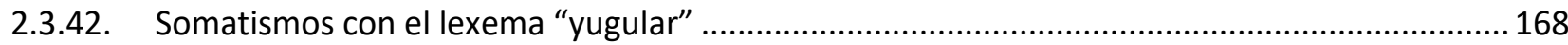

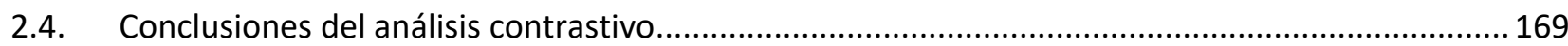

3. FUNDAMENTOS CURRICULARES DE LA FRASEOLOGÍA: LA FRASEODIDÁCTICA...............................175

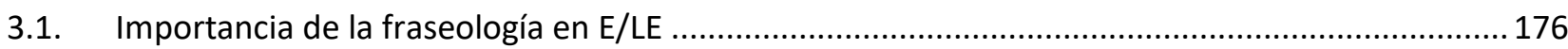

3.2. MCER: pautas para una mayor unidad curricular ................................................................... 179

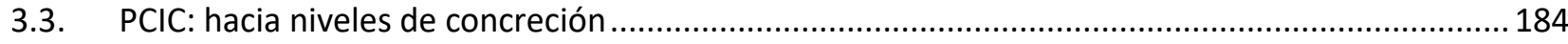

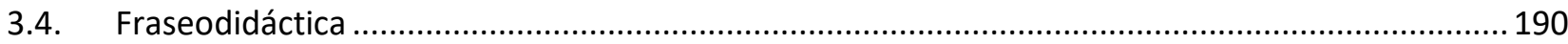

4. EL ENFOQUE LÉXICO Y EL COMPONENTE FRASEOLÓGICO: REVISIÓN CRÍTICA DE RECURSOS EN LÍNEA

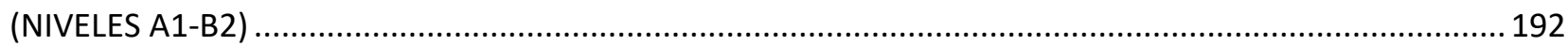

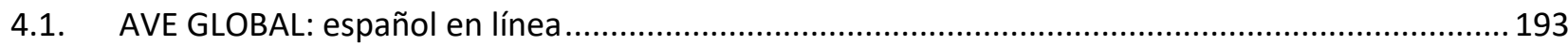

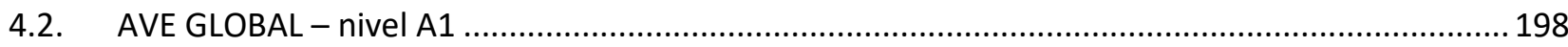

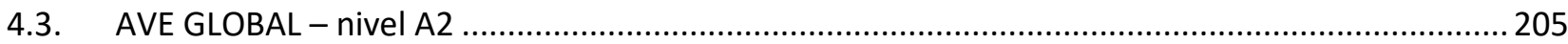

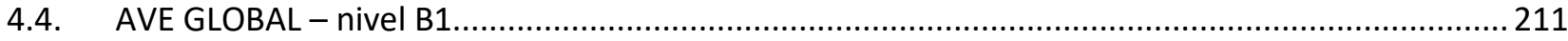

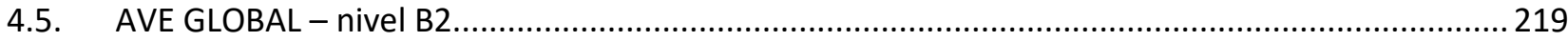

5. PROPUESTA DE APLICACIÓN DIDÁCTICA DE LAS UNIDADES FRASEOLÓGICAS A ALUMNOS RUMANOS

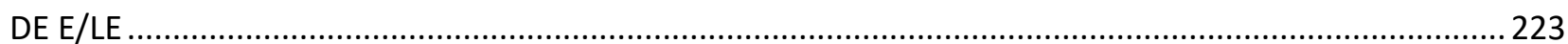

5.1. La fraseología en el aula de E/LE para alumnos rumanos: retos didácticos .................................224

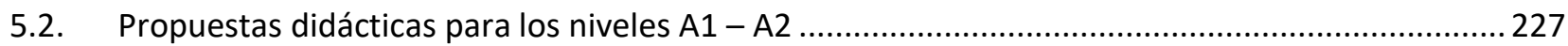

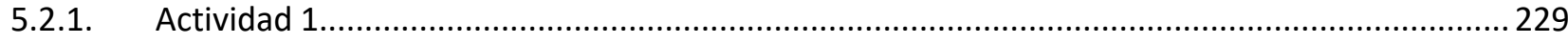

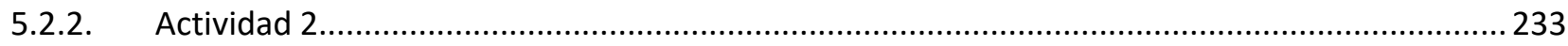

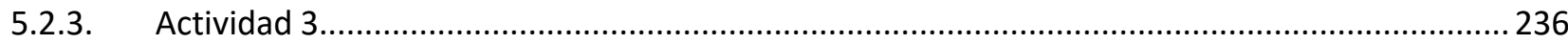

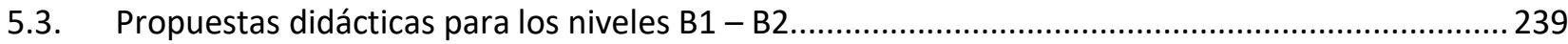

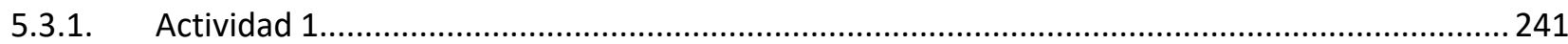

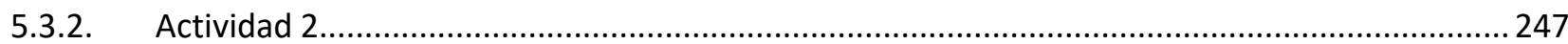

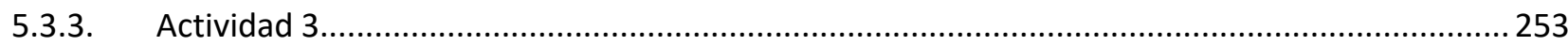

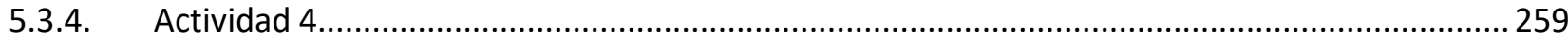

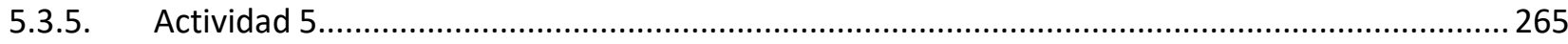

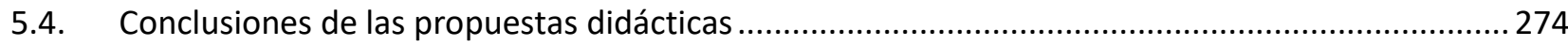




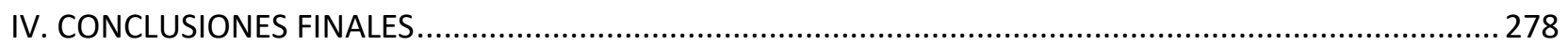

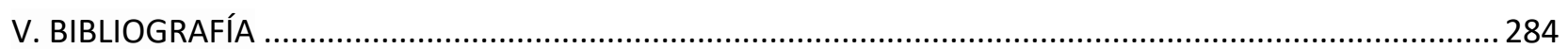

VI. ANEJOS 


\section{RESUMEN}

Dentro del panorama de la lingüística contrastiva y aplicada, la fraseología ocupa un lugar destacado en los trabajos publicados en los últimos años. A pesar de este creciente interés, son escasos los estudios teóricos, aplicados y basados en corpus que analizan convergencias y divergencias entre los sistemas lingüísticos español y rumano. Esta tesis doctoral aborda los paralelismos estructurales a nivel morfosintáctico y lexicológico, a partir del análisis contrastivo de un corpus formado por locuciones verbales somáticas. La elección de este campo onomasiológico se debe fundamentalmente a dos factores: se trata de un universal lingüístico que refleja la visión que cualquier ser humano tiene sobre el universo con el que se relaciona, independientemente de su pertenencia a un mundo cultural determinado y, desde la perspectiva del proceso de enseñzanza/aprendizaje de una lengua extranjera, el cuerpo humano constituye una parcela léxica motivadora que no suele plantear ninguna dificultad translémica. Como categoría gramatical, las locuciones no presentan la vaguedad nocional y los límites difusos de las colocaciones ni la complejidad estructural y las numerosas restricciones de los elementos parémicos y representan una herramienta de comunicación extremadamente eficaz. Analizamos a fondo la teoría fraseológica (delimitaciones, conceptos, taxonomías), abordamos los aspectos teóricos del análisis contrastivo y del análisis de errores y destacamos los trabajos más relevantes que resaltan, analizan, resumen y sistematizan la fraseología contrastiva entre el español y el rumano. Nuestro análisis contrastivo se centra en aspectos formales, niveles de correspondencia, contornos sintácticos, estructuras actanciales y funciones comunicaticas que cubren las unidades fraseológicas (UF) seleccionadas. Con ello pretendemos aportar una descripción exhaustiva de cada locución, a fin de reforzar su conocimiento morfosintáctico y pragmático en ambos idiomas. Como instrumento de trabajo hemos recurrido al software colaborativo en la nube airtable.com, un híbrido de base de datos y hoja de cálculo, con tablas y filas similares a Excel, pero enfocado a compartir la información con otras personas, herramienta que ha servido para volcar y analizar las UF en ambos idiomas. Consideramos la competencia fraseológica como parte fundamental de competencia comunicativa. En este sentido, analizamos la perspectiva desde la que enfocan el lenguaje idiomático el Marco Común Europeo de Referencia: aprendizaje, enseñanza, evaluación (2001) y el Plan Curricular del Instituto Cervantes (2006), que desarrolla, en términos de objetivos y contenidos de enseñanza y aprendizaje, las pautas marcadas por el MCER y llevamos a cabo un estudio centrado en la plataforma AVE GLOBAL. Prestamos especial atención a la presencia del componente fraseológico en las primeras etapas del proceso de enseñanza-aprendizaje, como firmes defensores de la necesidad de acometer su estudio desde niveles iniciales. Finalmente, se aportan materiales e ideas para la enseñanza/aprendizaje de los SO analizados en los capítulos previos, teniendo en cuenta los fundamentos curriculares y las carencias detectadas en las propuestas existentes en la plataforma AVE GLOBAL, siguiendo un enfoque de la lengua postmétodo.

Palabras clave: Fraseología, unidad fraseológica, somatismo, Español como Lengua Extranjera, fraseología contrastiva 


\section{ABSTRACT}

Within the panorama of contrastive and applied linguistics, phraseology occupies a prominent place in the works published in recent years. Despite this growing interest, there are few theoretical, applied and corpus-based studies that analyze convergences and divergences between the Spanish and Romanian linguistic systems. This doctoral thesis addresses structural parallels at a morphosyntactic and lexicological level, based on the contrastive analysis of a corpus made up of somatic verbal phrases. The choice of this onomasiological field is fundamentally due to two factors: it is a linguistic universal that reflects the vision that any human being has about the universe with which he is related, regardless of his belonging to a specific cultural world and, from the perspective of the process of teaching and learning a foreign language, the human body constitutes a motivating lexical segment that does not usually pose any translemic difficulty. As a grammatical category, phrases do not present the notional vagueness and fuzzy limits of collocations or the structural complexity and the numerous restrictions of the parameic elements, and they represent an extremely effective communication tool. We thoroughly analyze phraseological theory (delimitations, concepts, taxonomies), address the theoretical aspects of contrastive analysis and error analysis, and highlight the most relevant works that highlight, analyze, summarize and systematize the contrastive phraseology between Spanish and Romanian. Our contrastive analysis focuses on formal aspects, levels of correspondence, syntactic contours, actantial structures and communication functions that cover the selected phraseological units (FU). With this we intend to provide an exhaustive description of each phrase, in order to reinforce their morphosyntactic and pragmatic knowledge in both languages. As a work instrument we have used the collaborative software in the cloud airtable.com, a hybrid of database and spreadsheet, with tables and rows similar to Excel, but focused on sharing information with other people, a tool that has served to dump and analyze the UF in both languages. We consider phraseological competence as a fundamental part of communicative competence. In this sense, we analyze the perspective from which the Common European Framework of Reference: learning, teaching, evaluation (2001) and the Instituto Cervantes Curricular Plan (2006) approach language, which it develops, in terms of objectives and contents of teaching and learning, the guidelines set by the CEFR and we carried out a study focused on the AVE GLOBAL platform. We pay special attention to the presence of the phraseological component in the early stages of the teachinglearning process, as strong defenders of the need to undertake its study from initial levels. Finally, materials and ideas are provided for the teaching-learning of the $\mathrm{SO}$ analyzed in the previous chapters, taking into account the curricular foundations and the deficiencies detected in the existing proposals on the AVE GLOBAL platform, following a post-method language approach.

Key words: Phraseology, Phraseological Unit, Somatic Idiom, Spanish as a Foreign Language, Constrastive Phraseology 


\section{AGRADECIMIENTOS}

Son muchas las personas que podrían y deberían figurar en las siguientes líneas. Todas y cada una de ellas han aportado su granito de arena en la realización de este trabajo.

No obstante, este apartado solo puede tener un nombre propio: mi directora de tesis, dra. Nieves Mendizábal de la Cruz, a la que quiero expresarle mi más sincero y eterno agradecimiento. Su profesionalidad, disponibilidad, paciencia y empatía no solo me han enseñado a ser mejor docente e investigador, sino mejor persona.

Han sido cinco largos años de búsquedas y cambios constantes, una tesis "accidentada" que ha cruzado océanos y ha vivido un inesperado confinamiento. Sin la ayuda, la energía y la entrega de mi directora no habría sido posible llevar a cabo esta investigación. En todo momento me ha transmitido confianza y me ha corregido con increíble delicadeza.

Gran amante de los deportes, siempre me he preguntado por qué, tras una importante victoria, los ganadores miran, se dirigen y abrazan a sus entrenadores antes que a familiares y amigos. Ahora sé que nadie conoce mejor tus dudas, frustraciones y altibajos que la persona que te acompaña en ese esfuerzo diario común.

Gracias, Nieves, por haber vivido esta tesis con intensidad, por tu confianza y por tu amistad. 


\section{SIGLAS Y ABREVIATURAS}

\begin{tabular}{|c|c|c|}
\hline$A C$ & - & Análisis Contrastivo \\
\hline $\mathrm{AE}$ & - & Análisis de Errores \\
\hline AVE & - & Aula Virtual de Español \\
\hline CVC & - & Centro Virtual Cervantes \\
\hline DELS & - & Dicţionar de Expresii, Locuţiuni şi Sintagme ale Limbii Române \\
\hline DEX & - & Diç̧ionar Explicativ Român \\
\hline DFDEA & - & Diccionario Fraseológico Documentado del Español Actual \\
\hline DFE & - & Diccionario de Fraseología Española \\
\hline DFSR & - & Dicţionar Frazeologic Spaniol - Român \\
\hline DILEA & - & Diccionario de Locuciones Idiomáticas del Español Actual \\
\hline DLVES & - & Diccionario de Locuciones Verbales para la Enseñanza del Español \\
\hline DRAE & - & Diccionario de la Real Academia Española \\
\hline DSR & - & Dicţionar Spaniol - Român \\
\hline DSREL & - & Dicţionar Spaniol - Român de Expresii şi Locuţiuni \\
\hline E/LE & - & Español como Lengua Extranjera \\
\hline $\mathrm{IL}$ & - & Interlengua \\
\hline LE & - & Lengua extranjera \\
\hline LM & - & Lengua meta \\
\hline LO & - & Lengua (de) origen \\
\hline MCER & - & $\begin{array}{l}\text { Marco Común Europeo de Referencia para las lenguas: aprendizaje, } \\
\text { enseñanza, evaluación }\end{array}$ \\
\hline $\mathrm{PCIC}$ & - & Plan Curricular del Instituto Cervantes \\
\hline SO & - & somatismo; somatismos \\
\hline UF & - & unidad fraseológica; unidades fraseológicas \\
\hline
\end{tabular}




\section{ÍNDICE DE TABLAS}

Tabla 1. Clasificación de las locuciones de Casares

Tabla 2. Diferencia entre frase proverbial y refrán

Tabla 3. Clasificación de las UF de Zuluaga, según los rasgos de estructura interna

Tabla 4. Clasificación de las UF de Zuluaga, según su función

Tabla 5. Clasificación de las UF de Zuluaga. Criterio de estructura dependiente o independiente

Tabla 6. Clasificación de las esferas de Corpas Pastor

Tabla 7. Clasificación de las colocaciones de Corpas Pastor

Tabla 8. Clasificación de las locuciones de Corpas Pastor

Tabla 9. Clasificación de las fórmulas rutinarias de Corpas Pastor

Tabla 10. Clasificación general de grupos graduales de Ruiz Gurillo

Tabla 11. Clasificación funcional de las locuciones de Ruiz Gurillo

Tabla 12. Clasificación de las locuciones de García-Page

Tabla 13. Clasificación de las UF de Pamies

Tabla 14. Distribución porcentual de lexemas analizados

Tabla 15. Distribución de las UF según las funciones comunicativas

Tabla 16. Distribución de las UF por nivel

Tabla 17. Tipo de equivalencias de las UF analizadas

Tabla 18. Competencia lingüística general

Tabla 19. Riqueza de vocabulario

Tabla 20. Distribución de UF por nivel

Tabla 21. Descripción y objetivos de curso 


\section{INTRODUCCIÓN}

Esta tesis doctoral se enmarca dentro del área de las investigaciones de la lingüística románica, más concretamente en el campo de la fraseología aplicada. El estudio que conforman las siguientes páginas se encuentra a caballo entre la lingüística contrastiva, la lingüística del corpus, la fraseodidáctica, la traductología y la pragmática.

El impulso que lo motiva es profundizar en la lingüística contrastiva y fraseológica entre el español y el rumano y aportar herramientas necesarias para el estudio y la enseñanza de las unidades fraseológicas (en adelante UF) a alumnos rumanos de E/LE, partiendo de los postulados del análisis contrastivo, la lingüística del corpus y la fraseodidáctica.

A pesar de que en los últimos años observamos un interés creciente por este campo, todavía carecemos de estudios de gran envergadura o de novedades relevantes en el mercado editorial, menos aún si nos referimos a los trabajos de corte contrastivo y didáctico entre el español y el rumano.

Este trabajo está estructurado en cinco capítulos.

En el primer capítulo se asientan los fundamentos teóricos de la fraseología: su aparición y desarrollo como disciplina dentro de la lingüística, los incesantes intentos de definir sus límites, la taxonomía y las aportaciones de los investigadores españoles y rumanos. Asimismo, consideramos un buen punto de partida una presentación del universo fraseológico del rumano y de los estudios contrastivos más relevantes entre el español y el rumano.

Emprender una tarea de análisis contrastivo interlingüístico sin delimitar previamente el área de interés puede desembocar en fracaso, por lo que hemos decidido centrar nuestro estudio en un campo semántico concreto, ya que "la fraseología exhibe una variedad extraordinaria de vocabulario hasta el punto de poder imaginarse que cualquier parcela de la realidad o de la experiencia encuentra un lugar en el léxico locucional" (García-Page 2008:371). Identificamos nombres de profesiones, colores, instrumentos musicales, arte culinario y gastronomía, flora y productos agrícolas, animales, minerales y piedras preciosas, objetos del hogar, prendas de vestir, nombres relativos a la climatología, la astrología y los fenómenos naturales, topónimos, antropónimos y gentilicios, nombres relacionados con el mundo del deporte y de la lidia, con el lenguaje marinero, la automoción y el transporte, la religión, las letras, el sistema monetario, las armas o las unidades lingüísticas.

De todos estos campos semánticos nos hemos limitado a las locuciones que incluyen en su estructura una parte del cuerpo: las así llamadas "locuciones somáticas o 
somatismos" que son, según Čermák (2000), las que más interés despiertan. Los fraseologismos somáticos o corporales reflejan la visión que tiene cualquier ser humano sobre el universo con el que se relaciona, independientemente de su pertenencia a un mundo cultural o lingüístico determinado. Se trata, en resumidas cuentas, de un universal lingüístico y "al parecer, en todas las lenguas del mundo existe una estructuración de nuestra experiencia directamente vinculada al cuerpo humano o animal y a la manera en que se interactúa con el entorno" (Nénkova 2006:109). La elección de este campo onomasiológico también responde a factores de índole más académica: las partes del cuerpo son de las primeras palabras que se enseñan y se aprenden en una clase de lengua extranjera y no suelen plantear ninguna dificultad translémica.

Dentro de esta categoría analizaremos exclusivamente las que contengan un sintagma verbal, considerando que, gracias a su fuerza, el núcleo verbal es la categoría gramatical más motivadora para un aprendiz de LE. Fernández Ramírez (1986), Rojo Sánchez (1986), Bosque (1989) o Gutiérrez Araus (1995) se detienen para analizar esta categoría gramatical plena desde una perspectiva teórica, pero al mismo tiempo aportan ideas valiosas de índole más aplicada a profesores y estudiantes de E/LE, que les permiten avanzar y progresar en la comprensión de sus múltiples facetas: temporalidad lingüística, aspecto, planteamientos pragmáticos, etc. El objetivo último de la lingüística aplicada a la didáctica de una LE (que el aprendiz extranjero se exprese con más fluidez y corrección en la lengua meta) pasa inevitablemente por los postulados teóricos que arrojan luz sobre la competencia lingüística del ser humano, por lo que "la interacción entre la teoría gramatical y las disciplinas que confluyen en el estudio de la enseñanza y la adquisición de las lenguas extranjeras puede ser fructífera para ambos ámbitos" (Brucart 2009:27).

Del vasto campo fraseólogico hemos acotado el presente trabajo al estudio de las locuciones porque desde una perspectiva didáctica no presentan la vaguedad nocional y los límites difusos de las colocaciones ni la complejidad estructural y las numerosas restricciones de los elementos parémicos. Asimismo, las locuciones representan una herramienta de comunicación extremadamente eficaz. Según Timofeeva,

los hablantes nativos procesan las locuciones significativamente más rápido que las combinaciones libres de palabras, lo que, unido a su riqueza semántica, les confiere la capacidad de comunicar una gran variedad de valores y matices a través de una forma compacta (Timofeeva 2017:680).

En el segundo capítulo describiremos el procedimiento para la creación del corpus y explicaremos detenidamente los criterios manejados y los filtros aplicados para elaborar 
la base de datos. Consideramos que seleccionar e inventariar acertadamente las UF es una condición imprescindible para que el análisis llevado a cabo produzca datos concluyentes, para que se puedan extraer conclusiones acertadas y formular observaciones pertinentes, a fin de alcanzar nuestro propósito: el de servir de herramienta de interés para la aplicación práctica en la enseñanza/aprendizaje de estas estructuras.

Asimismo, este segundo capítulo incluye el análisis contrastivo español-rumano propiamente dicho de las UF inventariadas, el apartado más consistente de este trabajo y nuestra aportación original más importante. Analizamos en cada UF aspectos formales, niveles de correspondencia, contornos sintácticos y estructuras actanciales y con ello aportaremos una descripción exhaustiva de cada UF, que reforzará el conocimiento morfosintáctico de cada locución en ambos idiomas, objetivo primario de nuestra investigación.

Resumiremos los resultados obtenidos y aportaremos datos estadísticos que nos darán claves más precisas respecto a la distribución porcentual de los somatónimos analizados, las funciones comunicativas que cubren las UF, las dificultades que plantean y los niveles asignados, el tipo de equivalencia y los rasgos gramaticales. Los elementos formales derivados del análisis estadístico (como gráficos y diagramas) nos ayudarán a sintetizar y a comprender mejor cada apartado. Mientras el análisis cualitativo (tanto léxico como morfosintáctico) es fundamental para llevar a cabo el contraste interlingüístico, el análisis cuantitativo centraliza los datos extraídos y aporta una visión global, ofrece información matizada y abarcadora y corrobora las hipótesis de partida.

En el tercer capítulo nos centraremos en el documento fundamental para la enseñanza de las lenguas extranjeras en Europa, el Marco Común Europeo de Referencia: aprendizaje, enseñanza, evaluación (2001) -en adelante MCER-y en el Plan Curricular del Instituto Cervantes (2006) -en adelante PCIC- que desarrolla, en términos de objetivos y contenidos de enseñanza y aprendizaje, las pautas marcadas por el MCER. Haremos especial hincapié en la perspectiva desde la que enfocan el lenguaje idiomático estos documentos que "constituyen algunas de las principales hojas de ruta en el diseño curricular que (...) han trazado buena parte de las prácticas docentes, así como de la elaboración de libros de texto para la enseñanza del español" (Muñoz-Basols 2015:448). Aclararemos conceptos como competencia lingüística, competencia comunicativa, competencia fraseológica o fraseodidáctica, con el objetivo de crear un marco metodológico de actuación de cara al capítulo final, en el que elaboramos actividades didácticas basadas en la aplicación de estos principios metodológicos. Este capítulo generalista, que analiza los fundamentos curriculares, tiene identidad propia porque también aporta la base metodológica y didáctica para la elaboración de la aplicación práctica de los resultados obtenidos a raíz del estudio contrastivo de las dos lenguas. 
En otros estudios similares al nuestro hemos notado el interés por el análisis de la presencia del componente léxico en general y de la fraseología en particular en los materiales de E/LE, abarcando todos los niveles de estudio. Aunque la revisión de materiales no puede constituir el eje central de un trabajo de esta índole, consideramos que un breve acercamiento a ciertos recursos puede arrojar luz sobre el tratamiento que reciben las UF en el marco global de la eseñanza del español. Prestaremos especial atención a la presencia del componente fraseológico en las primeras etapas del proceso de enseñanza-aprendizaje, como firmes defensores de la necesidad de acometer su estudio desde niveles iniciales.

En este sentido, en el capítulo cuatro llevaremos a cabo un estudio centrado en la plataforma AVE GLOBAL (curso de español en línea diseñado por el Instituto Cervantes). Justificamos esta elección por el hecho de tratarse de una herramienta versátil, moderna y de manejo intuitivo, que engloba todos los niveles contemplados por el MCER. Además, reúne (desde el enfoque comunicativo) actividades, tareas y recursos didácticos muy completos que activan destrezas y habilidades de pensamiento y expresión.

Haremos una profunda revisión de las actividades disponibles creadas especialmente para la adquisición de la competencia léxica y trataremos de comprobar nuestra hipótesis de partida: que la presencia de la fraseología en los niveles A1-A2 es muy escasa, aunque anticipamos una paulatina incorporación de elementos idiomáticos en los niveles más avanzados.

El capítulo cinco pretende ser un punto de encuentro que unifique la presente investigación con la práctica docente, implementando todas las conclusiones de este trabajo. El marco teórico aportado, las taxonomías de diversos estudiosos, el análisis contrastivo y la herramienta informática que alberga el corpus de somatismos con todas sus peculiaridades conformarán la base para la creación de materiales que faciliten la adquisición contextualizada de UF españolas por parte de aprendices rumanos. Por lo tanto, didactizaremos los SO analizados en los capítulos previos, aportando materiales e ideas a los docentes que precisen herramientas necesarias para la enseñanza de las UF, teniendo también en cuenta los fundamentos curriculares analizados en profundidad (MCER y PCIC) y las posibles carencias detectadas en las propuestas existentes en la plataforma AVE GLOBAL.

Nos situamos en la misma senda metodológica que investigadores como Leal Riol (2011), Julià Luna y Ortiz Rodríguez (2012) o Saracho (2015) y abogamos por la introducción temprana del componente idiomático en la clase de E/LE, al tratarse de "una parte de la lengua fundamental que sirve al hablante para expresarse con corrección y para sentirse partícipe de las convenciones de una sociedad" (Saracho 2015:163). 
Somos conscientes de las limitaciones que entraña este estudio, en el que hemos limitado el análisis a UF somáticas pertenecientes a la variante estándar del español peninsular. Además de esta restricción en el plano diatópico, hemos operado también con una restricción distrática (al prescindir de locuciones etiquetadas o consideradas como vulgares) y con una restricción diacrónica (dado que hemos decidido prescindir de muestras de UF arcaicas o en desuso). Creemos que estos filtros resultan inevitables para alcanzar los propósitos de este estudio: elaborar y analizar un corpus que se ciña a los niveles A1-B2 y que sea relevante y rentable para un aprendiz rumano de E/LE. No obstante, nos parece interesante explorar futuras líneas de investigación a las que el presente estudio abre el camino. Cabe la posibilidad de ampliar el corpus de locuciones a otros campos semánticos, abarcar todos los niveles de estudio o incluir nuevas lenguas para el estudio comparativo y contrastivo. Este modelo de descripción y, sobre todo, la herramienta de trabajo colaborativo que utilizamos, podrían dar pie a la creación de un clúster para que la comunidad científica avance en el análisis interlingual y en la creación de materiales para la enseñanza de las UF.

Para concluir, ofreceremos una síntesis de nuestro trabajo y aportaremos la transcripción íntegra del corpus.

En cuanto a la organización de la bibliografía, la hemos estructurado en dos apartados distintos, con el fin de agilizar la consulta. El primero contiene exclusivamente los repertorios fraseológicos (diccionarios monolingües y bilingües tanto en formato papel como en línea) y el segundo incluye los estudios teóricos y los artículos de corte didáctico que hemos consultado a lo largo de la elaboración de este trabajo.

Hemos prestado especial atención a los aspectos formales y, en este sentido, hemos seguido las normas de estilo en la redacción de trabajos académicos APA, con su adaptación al español, y las actualizaciones publicadas en su séptima edición (2020). 


\section{OBJETIVOS}

En las siguientes líneas trazamos los objetivos generales y los objetivos específicos de esta tesis.

El objetivo general del presente trabajo es llevar a cabo un análisis lingüístico contrastivo entre unidades fraseológicas somáticas del español y del rumano. Dicho análisis abarcará múltiples aspectos, como rasgos estrictamente gramaticales (morfosintácticos), estructuras actanciales y, sobre todo, lo que constituye uno de los pilares de la fraseología comparada, la búsqueda de las correspondencias interlingüísticas (formales, semánticas, pragmáticas), con el fin de identificar y describir aquellas áreas que pudieran provocar errores interlinguales. Para lograr este primer objetivo, consultaremos varias fuentes lexicográficas, diccionarios monolingües (generales y fraseológicos) en ambas lenguas, diccionarios bilingües y otros repertorios especializados.

Otro objetivo general consiste en elaborar una base de datos en línea donde se recojan y actualicen las UF somáticas, incorporando todas sus características morfosintácticas, léxicas y pragmáticas (en español y en rumano). Aprovecharemos, por lo tanto, el auge de las nuevas tecnologías y las herramientas digitales disponibles. El propósito de dicha base de datos en formato electrónico es su posible revisión permanente, la aplicación de múltiples criterios de búsqueda y el espacio ilimitado en la nube para ir aportando datos referentes a variantes de uso, correspondencias, sinónimos - cualquier información adicional que se considere de interés, de cara a su implementación como recurso para los docentes rumanos de E/LE.

Para alcanzar con éxito los objetivos generales y a fin de dotar el estudio empírico de solidez investigadora, nos proponemos como objetivo específico aportar un andamiaje teórico-metodológico. El estado de la cuestión abarca desde los albores de la fraseología hasta las taxonomías manejadas en el siglo XXI, determinando de manera clara las características principales de nuestro objeto de estudio (las UF). Asimismo, haremos especial hincapié en los estudios contrastivos entre el español y el rumano y trataremos de aclarar los conceptos fundamentales con los que opera la fraseodidáctica.

Un objetivo específico de este estudio tiene una vertiente más práctica, como consecuencia directa de los datos obtenidos a raíz del análisis llevado a cabo en los capítulos precedentes: diseñar materiales significativos para la enseñanza de unidades fraseológicas a alumnos rumanohablantes cuyo nivel es inferior al $\mathrm{C} 1$ (dominio operativo eficaz). Partimos de la premisa de que, equivocadamente, en los manuales de $E / L E$ la presencia de la fraseología es muy escasa en los niveles A1-B2, relegando a niveles muy altos la presentación y la sistematización de todas las estructuras pluriverbales prefabricadas. Saracho (2015) trata de identificar las causas de esta ausencia, entre las que señala la falta de preparación teórica del profesorado y los manuales de E/LE que 
carecen de actividades sistematizadas y coherentes para la enseñanza-aprendizaje del componente idiomático. Reiteramos nuestra convicción de que un aprendiz de E/LE y, extrapolando, de cualquier lengua extranjera, debería contar con input y actividades para que la adquisición correcta, equilibrada y contextualizada de UF se lleve a cabo desde las etapas iniciales de su proceso de aprendizaje.

Para contrarrestar esa previsible falta de recursos, otro objetivo específico es elaborar una serie de materiales significativos para la enseñanza-aprendizaje de UF gracias al análisis contrastivo previamente llevado a cabo. Asimismo, basándonos en la experiencia docente, en la intuición como hablante nativo de rumano, pero, sobre todo, en el marco teórico y en nuestra propia investigación, anticiparemos cuáles serían las áreas de mayor dificultad para los aprendientes de E/LE. Tendremos en cuenta el equilibrio entre las destrezas reflexivas y productivas y la integración de contenido funcional y cultural, fomentando la interacción en el aula.

En resumidas cuentas, este trabajo avanza en la línea de la fraseología contrastiva entre el español y el rumano y aporta como novedades el análisis delimitado a un campo semántico concreto (las partes del cuerpo) y una vertiente práctica, de aplicación inmediata en el aula de E/LE puesto que viene a cubrir un hueco existente tanto a nivel teórico como didáctico.

En las páginas precedentes hemos trazado los objetivos generales y específicos de esta tesis doctoral. Los objetivos principales son la creación de un corpus relevante de locuciones verbales somáticas, acotado para aprendices rumanos de E/LE (niveles A1B2), y su posterior análisis pormenorizado. Los objetivos específicos son: a) realizar un sólido estado de la cuestión que sitúe nuestro análisis en unas coordenadas teóricas; b) llevar a cabo un análisis de materiales desde un enfoque léxico fraseológico; c) diseñar materiales significativos para la clase de E/LE a partir de los somatismos analizados, teniendo en cuenta los datos obtenidos. 


\section{METODOLOGÍA}

La creación del corpus para nuestro estudio ha supuesto un largo proceso de reflexión y acotamiento, cruzando diferentes fuentes y consultando a especialistas (filólogos, antropólogos, docentes, periodistas, etc.) tanto rumanos como españoles, hablantes nativos (bilingües o no), con el objetivo de dar con aquellas locuciones somáticas imprescindibles y rentables.

Las UF que conforman la base de datos para este estudio proceden de varios repertorios lexicográficos. Para la elaboración del corpus consultamos, entre otros, los siguientes registros fraseológicos monolingües españoles: Diccionario de locuciones idiomáticas del español actual (2019), Diccionario fraseológico documentado del español actual (2017), Diccionario de fraseología española (2007) y Diccionario de locuciones verbales para la enseñanza del español (2002).

Asimismo, tomamos como referentes el anejo de la tesis de Saracho La fraseología en español: una propuesta de didactización para la clase de ELE basada en somatismos (2015) y el índice alfabético de unidades fraseológicas del libro La enseñanza de la fraseología en español como lengua extranjera. Estudio comparativo dirigido a estudiantes anglófonos de Leal Riol (2011). En cuanto a los diccionarios generales monolingües, usamos la versión en línea del Diccionario de la lengua española de la RAE (23를 edición actualizada).

Para el idioma rumano utilizamos como fuente principal el diccionario Dicţionarul de expresii, locuţiuni şi sintagme ale limbii române (2010), que tiene como ventaja ser la obra de referencia más reciente que goza de mayor prestigio dentro de la comunidad científica. Asimismo, cabe señalar que nos apoyamos en otro corpus ya elaborado para el estudio comparativo entre el rumano y el francés, recogido en Corpul omenesc în expresii: domeniul român-francez (2011). Para las consultas de carácter más general recurrimos a la versión en línea del Dicţionar explicativ român.

Finalmente, señalamos las principales fuentes lexicográficas bilingües que nos garantizan una mayor seguridad a la hora de encontrar equivalencias formales de las UF analizadas: Dicţionar frazeologic spaniol-român (2008), Dicționar spaniol-român de expresii și locuțiuni (2002) y Dicționar spaniol-român (1992).

De todas estas fuentes, tras una laboriosa etapa de recopilación hemos extraído más de mil unidades fraseológicas que contienen un somatónimo, lexema denominativo de una parte del cuerpo humano (o animal) que actúa fundamentalmente como base de la UF. 
Hemos optado por recopilar únicamente locuciones pertenecientes a la variedad del español estándar hablado en España. Por lo tanto, descartamos todas aquellas UF dialectales, arcaicas o en desuso o cuyo significado es desconocido por la totalidad de los hablantes nativos. Al igual que Penadés (2019), nos centramos en aquellas producciones de uso actual, aunque es muy discutible el periodo de tiempo comprendido bajo este término. Sin embargo, a diferencia de los filtros con los que opera su diccionario (DILEA), nosotros excluimos también el registro vulgar y la jerga. Por lo tanto, han quedado fuera de nuestro estudio entradas que contienen lexemas como "culo", "coño", "cojón", etc., a pesar de que generan un número elevado de UF y tienen un uso activo en la lengua. Consideramos que en los materiales didactizados y propuestos para el diseño curricular de nivel inicial e intermedio no se justifica la presencia de estos somatónimos porque los aprendientes no dominan todavía los registros de habla (norma culta, registro formal, informal, etc.). Por lo tanto, estos elementos vulgares entrañan el riesgo de que cometan errores de índole pragmática, en futuras producciones orales o escritas.

En esta misma línea, optamos por incluir en el corpus el somatónimo "cabeza", pero debido a las razones anteriormente expuestas (al encontrarse fuera del registro estándar), prescindimos de sus sinónimos "mollera", "coco" o "pelota". En un caso idéntico se hallan "tranca" (eliminado a favor de "pierna"), "jeta" (únicamente incluimos "cara") o "morro" (descartado frente al neutro "labio"). En cuanto a las sustancias (sólidas, líquidas o gaseosas) que genera el cuerpo humano, decidimos incluir el somatónimo "sangre" debido a su frecuencia de uso, pero eliminamos otros lexemas como "bilis","pis", "caca", "pedo", etc. Tampoco es objeto de nuestro estudio el uso figurado, por lo que no incluimos UF como "hablar la misma lengua" o las que contienen el lexema "alma".

Hemos echado en falta estudios fidedignos sobre la recurrencia de las UF en español y/o en rumano. En su ausencia, tuvimos que elaborar nuestros propios criterios para la selección más bien empírica del corpus puesto que, tras comprobar las dificultades surgidas a la hora de manipular una base de datos de esas dimensiones, se hacía patente aplicar varios filtros que aligeraran el análisis contrastivo y que generaran resultados relevantes.

Durante el proceso llevado a cabo (tras una minuciosa selección acotamos el corpus a 206 UF), comprobamos lo que aseveran los estudios teóricos: la dificultad de delimitar el objeto del estudio y la heterogeneidad de los criterios manejados. Coincidimos plenamente con las afirmaciones del tipo "el hecho de que no exista uniformidad hace que resulte más compleja la identificación de este tipo de unidades, sobre todo para un hablante no nativo, que no dispone de competencia fraseológica suficiente" (Mendizábal y Sastre 2017:52).

Esta falta de coherencia provoca que un alumno de E/LE se halle desamparado y titubeante ante los recursos lexicográficos existentes. Por lo tanto, decidimos plasmar el 
corpus pensando precisamente en los investigadores, los traductores, los docentes y los aprendices de E/LE que son, en el fondo, los principales destinatarios de este trabajo.

A medida que la base de datos iba tomando forma, en lugar de columnas paralelas de somatismos contrastivos que manejábamos en una fase inicial, el corpus se iba acotando en número de entradas e iba desarrollándose en horizontal. Añadimos columnas con el lema (como entrada principal), la UF, su definición, sus equivalencias en rumano (si procede), explicaciones de uso y de registro, grado de transparencia, aclaraciones de orden morfosintáctico, restricciones, nivel recomendado para su enseñanza y otras observaciones.

Ninguno de estos apartados ha estado exento de polémica. A pesar de que Leal Riol (2011), en su amplia base de datos titulada FIDIE (Fijo, Idiomático, Español), propone que la unidad fraseológica constituya la entrada del corpus, nosotros optamos por ir de menos a más, esto es, partir del lexema somático hacia la UF. En cuanto a la presentación del significado, tras analizar los diccionarios explicativos, llegamos a la conclusión de que muchas veces las definiciones proporcionadas superan en dificultad al propio somatismo, a veces más transparente, explícito o sugerente. Como ejemplo, aportamos el caso de "abrir la cabeza" (explicado como "descalabrar") o "subirse el humo a la cabeza" (definido con lexemas tan difíciles como "envanecerse", "ensoberbecerse"). No es, desde luego, una crítica dirigida a los lexicógrafos, ya que los destinatarios de estas explicaciones son los hablantes nativos. No obstante, un aprendiz de E/LE que se expone a este tipo de definiciones podría perder la motivación y sentir frustración. Es nuestro deber, por lo tanto, ejercer de intermediarios, adaptar el input y proporcionar definiciones más claras, esclarecedoras $\mathrm{y}$, en la medida de lo posible, contextualizadas.

Tras una larga reflexión, decidimos que en la base de datos la UF aparecerá "desnuda", desprovista de actantes no lexicalizados, sin aditamentos y sin información sintáctica. Seguimos en este sentido las sugerencias de Mendizábal y Sastre (2017) y tratamos de evitar que un aprendiz de E/LE se enfrente a presentaciones exhaustivas e integradoras lingüísticamente, pero fuera de su alcance o comprensión. Presentamos en este sentido dos ejemplos recogidos del anejo de la tesis doctoral de Saracho (2015: 354): "hablar [una pers.] para el cuello de la (o su) camisa o no oír [a una pers.] ni el cuello de la (o su) camisa, o no oírse [la voz de una pers.] más allá del cuello de la (o su) camisa" con el significado de "hablar [esa pers.] en voz muy baja" y "poner [alguien] en (por o sobre) los cuernos de la Luna (o levantar[le] hasta los cuernos de la Luna)" con el significado de "alabar[le] extraordinariamente".

No sería de extrañar que, ante unas UF como las anteriores, el alumno optara directamente por seguir utilizando los verbos explicativos, "hablar (bajo)" o "alabar (mucho)". Sin embargo, no cabe duda de que los aprendientes necesitan herramientas a fin de construir su andamiaje lingüístico. Por esta razón hemos creado en la base de datos una casilla titulada "estructura argumental o actancial", con la que pretendemos ofrecer 
un modelo de uso más sencillo y práctico: "<alguien> habla para el cuello de su camisa". En el apartado dedicado a "otras consideraciones" presentamos unidades fraseológicas sinónimas, usos frecuentes o aportamos información referente al registro de habla.

Antes de emprender el análisis propiamente dicho, hemos reflexionado sobre el método de trabajo más apropiado, sencillo y didáctico, y nos decantamos por presentar las UF siguiendo el orden alfabético de los somatónimos que constituyen la entrada del corpus. La lengua de la que partimos es el español, puesto que constituye la lengua meta para las aplicaciones didácticas finales de este trabajo.

Como instrumento de trabajo elegimos la herramienta colaborativa en la nube airtable.com, software creado en 2012 en EE.UU. Se trata de un instrumento de trabajo virtual muy versátil, de fácil acceso y con un manejo muy intuitivo. Airtable es un híbrido de base de datos y hoja de cálculo, con tablas y filas similares a Excel, pero enfocado a compartir la información con otras personas. Tenemos la fuerte convicción de que es imposible concebir hoy en día una base de datos que no sea virtual. Autores como González y Mogorrón Huerta (2011:10-11) ya advertían de la:

necesidad de elaborar bases de datos lingüísticas informatizadas, según criterios diversos, que faciliten el manejo de la información de forma aceptable y, por las condiciones de la herramienta, agilizar el proceso de asignación de una mejor equivalencia en cada caso, bien consultándolas bien por medio del tratamiento automático del lenguaje (TAL).

Posteriormente, plasmamos todos los elementos vertidos en la base de datos en un análisis contrastivo, justificando en todo momento las decisiones tomadas en cuanto a la selección operada en la creación del corpus (UF seleccionadas vs. UF descartadas) y niveles de estudio recomendados, siempre desde nuestra perspectiva bilingüe. Asimismo, apuntamos las pertinentes traducciones contrastando las fuentes léxicas mencionadas anteriormente, aportamos nuestra visión crítica y proporcionamos el contexto cultural, en el caso de que alguna UF lo requiera.

Centralizamos los resultados obtenidos y elaboramos gráficos que arrojan más luz sobre el análisis llevado a cabo. Los datos estadísticos nos darán claves respecto a la distribución porcentual de los somatónimos analizados, las funciones comunicativas que cubren las UF, las dificultades que plantean, el tipo de equivalencia y los rasgos gramaticales. 


\section{FUNDAMENTOS TEÓRICOS}

Conscientes de la imposibilidad de abarcar en un capítulo la complejidad de toda una disciplina, en el siguiente epígrafe trataremos de acercarnos al universo fraseológico y de esbozar sus coordenadas teóricas imprescindibles.

\subsection{La fraseología como disciplina autónoma}

Aunque el término "fraseología" fue acuñado por Bally ${ }^{1}$ a principios del siglo XX, cuando inició el estudio sistemático de las combinaciones de palabras con significado determinado, podríamos afirmar que el nacimiento como disciplina teórica con autonomía propia se produjo en la década de los cuarenta del pasado siglo en la antigua Unión Soviética, principalmente gracias a las aportaciones de Vinogradov (1947).

Suárez Cuadros (2007), en una revisión crítica de las aportaciones de la lingüística soviética al desarrollo de la fraseología y sus conexiones con el estructuralismo europeo, destaca la importancia de Vinogradov y Šaxmatov (1941) en los albores de la fraseología. Vinogradov introduce muchos de los conceptos y aspectos más relevantes de la fraseología: a) la motivación del signo, base sobre la que se sustenta la mayor parte de los estudios soviéticos; b) la determinación semántica; c) la frecuencia de uso; d) la fijación; e) la idiomaticidad, entendida como irregularidad sintáctica y semántica; f) el establecimiento por vez primera, en 1946, del término "unidad fraseológica" (Фразеологическая единица), entendida como

las combinaciones fijas de la lengua, que pasan de una generación a otra, se reproducen en la práctica de la comunicación por tradición, diferenciándose de esta forma de las combinaciones libres de palabras, que se organizan en el lenguaje a voluntad del hablante (Suárez Cuadros 2007:1002).

Años más tarde, el mismo autor, siguiendo criterios semánticos, presentaría una clasificación de unidades fraseológicas en varias clases, según el tipo de significado que desarrollen: a) unión fraseológica (un grupo de palabras indivisibles); b) combinación fraseológica (una de las palabras tiene un sentido recto, lo que posibilita el uso de sinónimos); y c) unidad fraseológica (entendida en un sentido amplio y que acaba por incluir las construcciones de las dos primeras). Asimismo, Vinogradov (1955) llamó la

\footnotetext{
1 " $\mathrm{Si}$, dans un groupe de mots, chaque unité graphique perd une partie de sa signification individuelle ou n'en conserve aucune, si la combinaison de ces éléments se présente seule avec un sens bien net, on peut dire qu'il s'agit d'une locution composée. C'est l'ensemble de ces faits que nous comprenons sous le terme général de phraséologie" (Bally, Traité de stylistique, 1921:65-66).
} 
atención sobre la dificultad que puede plantear el intento de delimitar el campo de la fraseología.

Sus palabras fueron premonitorias, ya que, efectivamente, tras aquellos trabajos pioneros, hemos sido testigos de un sinfín de intentos de definir la fraseología. A pesar de su estatus de disciplina científica independiente, siempre se ha percibido como una "categoría de frontera" (Ruiz Gurillo 1997), hallada en un cruce de caminos donde convergen la estilística, la lexicología, la semántica, la sintaxis e incluso la sociolingüística o la antropología. En esta misma línea, Ruiz Gurillo (1997) se pregunta retóricamente "¿es la fraseología una disciplina independiente?” y “¿ocupa la fraseología una posición interdisciplinar?", para concluir que

a la hora de hablar de fraseología deberán abordarse cuestiones de morfología, de sintaxis, de lexicología y semántica, de pragmática e, incluso, de sociolingüística y psicolingüística, etc., de un modo similar a como propugnaba una parte de la lingüística soviética, es decir, de forma integrada dentro de una disciplina independiente. Desde esta perspectiva, no perderá su idiosincrasia frente a otras disciplinas, a pesar de que manifiesta evidentes relaciones con algunas de ellas (Ruiz Gurillo 1997:27).

En nuestra opinión, y desde una perspectiva estrictamente didáctica, es precisamente esta interdisciplinariedad de la fraseología lo que la convierte en un activo tan valioso en el aula de LE, su complementariedad, su versatilidad y la relación que entabla con otras ramas lingüísticas u otras ciencias.

Un aspecto fundamental es determinar los mecanismos internos de la fraseología y delimitar las unidades que la conforman, así como sus características y peculiaridades. Saracho (2015) señala "la dificultad de estudiar los signos fraseológicos debido a su carácter no discreto, puesto que no funcionan como los demás signos lingüísticos. (...) La fraseología se resiste a establecer una frontera clara entre lo léxico (la palabra) y lo sintáctico (el sintagma libre)" (Saracho 2015:48). Desde esta perspectiva, la fraseología se puede concebir de forma ancha o de forma estrecha. Como acertadamente subraya Sosiński (2006:23), "adoptar uno u otro punto de vista conlleva consecuencias cuantitativas en la elaboración de las taxonomías". Las clasificaciones que parten de la concepción ancha incluyen colocaciones, locuciones, paremias, refranes, proverbios, aforismos y fórmulas rutinarias, mientras que los investigadores partidarios de la concepción estrecha se centran exclusivamente en las unidades pluriverbales cuyo funcionamiento se asimila al de las palabras o al de los sintagmas. Por lo tanto, en su visión, las locuciones representan las únicas unidades plenas del ámbito fraseológico, descartando todas las demás. 
La caracterización de las UF se puede llevar a cabo desde distintas perspectivas: forma, significado, función comunicativa, etc. Las clasificaciones de corte formal se centran en el tipo de estructura de las expresiones, en los rasgos internos de fijación e idiomaticidad o en la clase de elementos constituyentes que integran dichas UF. El análisis de tipo funcional se elabora teniendo en cuenta las funciones que la UF pueden desempeñar en el discurso (locuciones nominales, locuciones verbales, locuciones adverbiales, etc.), mientras que el criterio semántico se basa en el significado de la UF. Algunos lingüistas señalan que el plano semántico es menos relevante en la lingüística moderna, que prefiere conceder un lugar privilegiado a los criterios formal y sintáctico. No obstante, "se recurrirá a él para completar la descripción de las diferentes clases de UFs establecidas en función de otros criterios y también para hacer distinciones que serían imposibles de introducir tomando como base solo la forma o la función" (Sosiński 2006:24). Atendiendo a las propiedades características de las UF, se puede llevar a cabo una clasificación según sus rasgos internos (examinando las propiedades de fijación e idiomaticidad que presenten) o efectuar un análisis estilístico (entre el significado de los componentes y el significado global de las UF).

Observamos, por tanto, que la tarea de clasificar las UF constituye un problema intrincado y complejo. Según los rasgos analizados y el posicionamiento dentro de la disciplina, se han formulado numerosas teorías y propuestas de taxonomías.

\subsection{Clasificaciones de las unidades fraseológicas}

En las siguientes páginas trataremos de presentar las clasificaciones más relevantes para el estudio de la fraseología en lengua española, siguiendo un orden cronológico, sin pretensión de exhaustividad.

\subsubsection{Clasificación de las UF de Casares}

Figura polifacética, Julio Casares es unánimemente considerado el principal iniciador de varias disciplinas lingüísticas en España, entre las que destacan la lexicografía y la fraseología modernas. Según Sevilla Muñoz (2018), los trabajos de Casares, que siguen mostrando su vigencia, constituyen una referencia fundamental para los investigadores.

Una de sus aportaciones más importantes es la primera clasificación de las unidades fraseológicas, a las que también denomina "expresión pluriverbal" o "fórmula pluriverbal". Asimismo, distingue tres tipos fundamentales de UF: locución, frase proverbial y refrán, estableciendo entre ellas unos límites más bien borrosos. Define la locución como una "combinación estable de dos o más términos, que funciona como 
elemento oracional y cuyo sentido unitario consabido no se justifica sin más, como una suma del significado normal de los componentes" (Casares 1950:170) y los refranes como "una frase completa e independiente, que en sentido directo o alegórico y por lo general en forma sentenciosa y elíptica, expresa un pensamiento - hecho de experiencias, enseñanza, admonición, etc. - a manera de juicio, en el que se relacionan por lo menos dos ideas" (1950:192). Entre estos dos polos, las locuciones y los refranes, se hallan las frases proverbiales, que carecen de definición propia y cuyas características se pueden trazar entre el territorio reservado a las demás categorías restantes. En su afán por encontrar un término que abarque todos estos fenómenos, Casares baraja el concepto de "modismo", que clasifica desde un punto de vista traductológico en los que presentan una correspondencia total en otra lengua, los que no tienen correspondencia de forma y los que, teniendo la misma forma, presentan significados diferentes. No obstante, tras una profunda reflexión teórica, ya no considera apropiado el concepto porque no corresponde a una figura lingüística definible $y$, por consiguiente, "propone con buen criterio su destierro de la nomenclatura fraseológica" (Montoro del Arco 2004:223).

Las unidades mejor caracterizadas por Casares son, sin duda, las locuciones. En este sentido, establece una primera distinción morfológica entre aquellas compuestas por palabras sin significado conceptual y las que contienen al menos una palabra cargada de significado. Siguiendo este criterio funcional, contaríamos con locuciones significantes y locuciones conexivas (que sirven exclusivamente como nexo sintáctico). Dentro de la categoría de locuciones significantes, Casares distingue entre locuciones nominales, adjetivales, verbales, participiales, adverbiales, pronominales y exclamativas, mientras que divide las conexivas en conjuntivas y prepositivas. Asimismo, profundiza en el análisis de las locuciones nominales, al agruparlas en denominativas, singulares e infinitivas.

\begin{tabular}{|c|c|c|c|c|c|}
\hline & & & donominativac & geminadas & tren botijo \\
\hline & & nominglos & Genomintativas & complejas & tocino del cielo \\
\hline & & nominales & singulares & la carabina & Ambrosio \\
\hline & & & infinitivas & coser y can & \\
\hline & cianifinantoc & adjetivales & de brocha gord & & \\
\hline & Sigminicantes & verbales & tomar el olivo & & \\
\hline Locuciones & & participiales & hecho un brazc & de mar & \\
\hline & & adverbiales & en un santiamé & & \\
\hline & & pronominales & cada quisque & & \\
\hline & & exclamativas & ¡Ancha es Cas & lla! & \\
\hline & & conjuntivas & con tal que & & \\
\hline & vomexivas & prepostivas & en pos que & & \\
\hline
\end{tabular}

Tabla 1. Clasificación de las locuciones de Casares. Fuente: Casares (1950) 
En cuanto a la categoría intermedia de las frases proverbiales, estas no funcionan como elemento oracional, pero tampoco tienen la estructura plurimembre propia de los refranes y, para diferenciarlas de estos, recurre a unos criterios más bien artificiosos.

\begin{tabular}{|l|l|}
\hline \multicolumn{2}{|c|}{ Estructuras unimembres con modalidad no exclamativa } \\
\hline $\begin{array}{l}\text { Un texto que tiene una tradición de } \\
\text { ejemplaridad por consenso de una } \\
\text { comunidad lingüística }\end{array}$ & $\begin{array}{l}\text { Un pensamiento, a manera de juicio, en el } \\
\text { que se relacionan por lo menos dos ideas }\end{array}$ \\
\hline \multicolumn{1}{|c|}{ Frase proverbial } & \multicolumn{1}{c|}{ Refrán } \\
\hline
\end{tabular}

Tabla 2. Diferencia entre frase proverbial y refrán. Fuente: Casares (1950)

A pesar de los justificados reproches, entre los que mencionamos los criterios manejados y la inclusión de las estructuras exclamativas dentro de las locuciones, Casares tuvo el gran mérito de haber abierto el camino de las investigaciones en español. Basándose en una visión ancha de fraseología (inclusión de paremias, refranes y otras unidades capaces de funcionar como enunciados independientes en el discurso), propuso definiciones y taxonomías que gozaron de aceptación y respeto dentro de la comunidad científica, a pesar de cierta falta de claridad en la diferenciación de los tipos generales de expresiones pluriverbales. Coincidimos con Rakotojoelimaria en que

el hecho de que Casares haya hecho una clasificación morfológica y funcional de las combinaciones fijas de palabras, sin llegar a discernir otros aspectos como el semántico o el pragmático, encuentra una explicación en el poco tiempo que llevaba desarrollándose la investigación fraseológica española en aquella época (Rakotojoelimaria 2004:34-36). 


\subsubsection{La clasificación de las UF de Zuluaga Ospina}

Siguiendo la senda de Casares, Zuluaga Ospina se sitúa en la concepción ancha de la fraseología y analiza combinaciones de más de dos palabras, pero que no sobrepasan el nivel de una oración y que presentan la fijación de carácter fraseológico. Para denominar estas estructuras elige los términos "expresión fija" y "unidad fraseológica" $(1980: 15)$ y trata a fondo los aspectos relacionados con su estructura interna y su funcionamiento en el discurso.

En relación con la estructura interna de las UF, Zuluaga menciona y consagra dos rasgos definitorios fundamentales, la fijación y la idiomaticidad. Por fijación fraseológica entiende la propiedad de ciertas expresiones de ser reproducidas en el habla como construcciones ya existentes (desde la perspectiva del hablante) y de infringir alguna regla de la combinación de los elementos del discurso (desde la perspectiva lingüística). Emulando la distinción operada por Coşeriu (1962), menciona también que las combinaciones libres se producen en cada acto lingüístico, mediante reglas gramaticales, mientras que las UF pertenecen al nivel de la norma; se reproducen en bloque, en una repetición que no altera la forma de la combinación reproducida.

Desde la perspectiva lingüística, Zuluaga detecta cuatro tipos de fijación: la fijación del orden de los componentes; la fijación de categorías gramaticales (de tiempo verbal, de persona, de número, de género); la fijación del inventario de los componentes (inseparabilidad e insustituibilidad de los componentes e imposibilidad de insertar o de suprimir componentes); la fijación transformativa. De estos, destaca como más importante la insustituibilidad de los componentes y justifica su teoría aplicando a las UF pruebas y operaciones que comprueban la imposibilidad de la variación.

Otro rasgo fundamental que Zuluaga detecta en las UF es la idiomaticidad, definida como "rasgo semántico propio de ciertas construcciones lingüísticas fijas, cuyo sentido no puede establecerse a partir de los significados de sus elementos componentes ni del nivel de su combinación" (1980:123). En una UF, los elementos constituyentes pierden su identidad semántico-funcional para construir una nueva unidad de sentido. Zuluaga otorga una especial importancia a las palabras diacríticas, elementos únicos que no existen en el sistema de manera libre o autónoma y solo tienen cabida dentro del sintagma fijo. Este funcionamiento exclusivo en la expresión pluriverbal es símbolo inequívoco de la idiomaticidad de la UF.

La idiomaticidad está también vinculada a la motivación, entendida como la relación entre el significado literal y el significado global. Dicha relación genera UF motivadas en mayor grado (cuando hay un nexo evidente entre los significados) o menor grado (si la motivación remite a una explicación etimológica o a una justificación histórica).

Asimismo, el autor detecta un grupo de UF semiidiomáticas, cuyo significado fraseológico se basa en una imagen sensible, es decir son expresiones con una "motivación figurada" (1980:134), frente a los casos de idiomaticidad absoluta. Entre estos dos límites señala que hay una amplia zona de UF idiomáticas con un grado de motivación variable. 
Zuluaga (1980) propone dos clasificaciones importantes. Según los rasgos de la estructura interna, distingue varios grupos de combinaciones lingüísticas: combinaciones no fijas o libres y combinaciones fijas (con algunas subcategorías: no idiomáticas, semiidiomáticas e idiomáticas). Dentro de estas UF idiomáticas da un paso más y establece cinco subgrupos: UF mixtas, UF idiomáticas con elementos únicos, UF con anomalías estructurales, UF con elementos metalingüísticos o autodesignativos y UF idiomáticas con estructura sintáctica regular, aunque cabe destacar que estos subgrupos no se excluyen mutuamente.

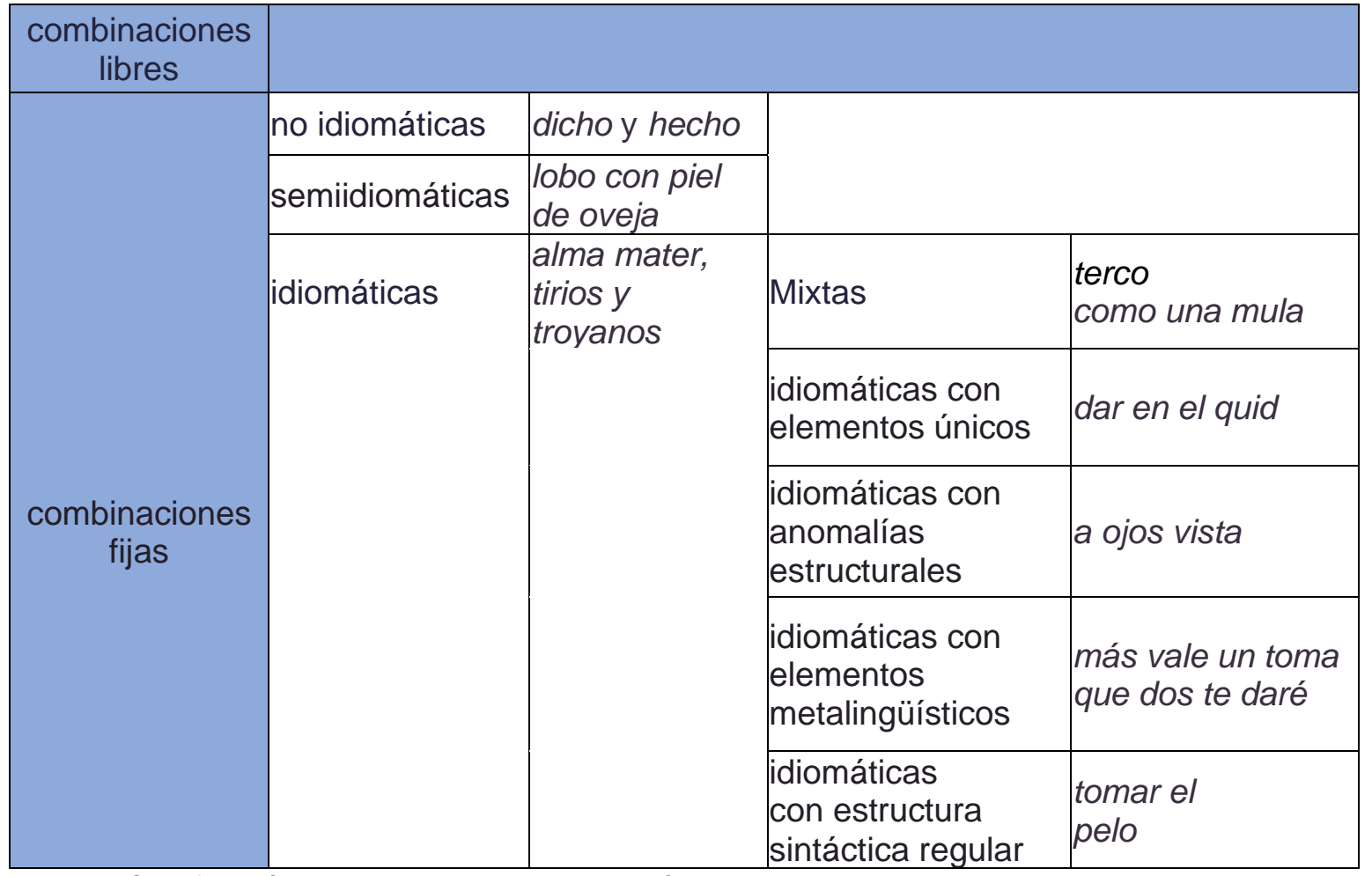

Tabla 3. Clasificación de las UF de Zuluaga, según los rasgos de estructura interna. Fuente: Zuluaga (1980)

Otra clasificación que propone está basada en criterios pragmáticos, en el valor funcional de las UF. Desde esta perspectiva, distingue dos grandes grupos: locuciones (unidades inferiores a la oración) y enunciados fraseológicos. El autor clasifica las locuciones en instrumentos gramaticales que carecen de significado léxico: locuciones prepositivas y locuciones conjuntivas (categorías que también encontramos en la taxonomía de Casares) y, como elemento novedoso, las locuciones elativas (instrumentos relacionales que intensifican lexemas) y locuciones como unidades léxicas (nominales, adnominales, adverbiales y verbales).

Los enunciados fraseológicos los divide a su vez en frases (fórmulas, clichés y dichos) y textos (refranes).

Dentro de los instrumentos gramaticales, siguiendo un criterio de estructura dependiente 0 independiente, Zuluaga (1980:145) lleva a cabo otra clasificación y 
distingue tres tipos de locuciones: prepositivas, conjuntivas y elativas (con verbos, con sustantivos y con adjetivos). Las locuciones equivalentes a unidades léxicas las divide en nominales, adnominales, adverbiales y verbales.

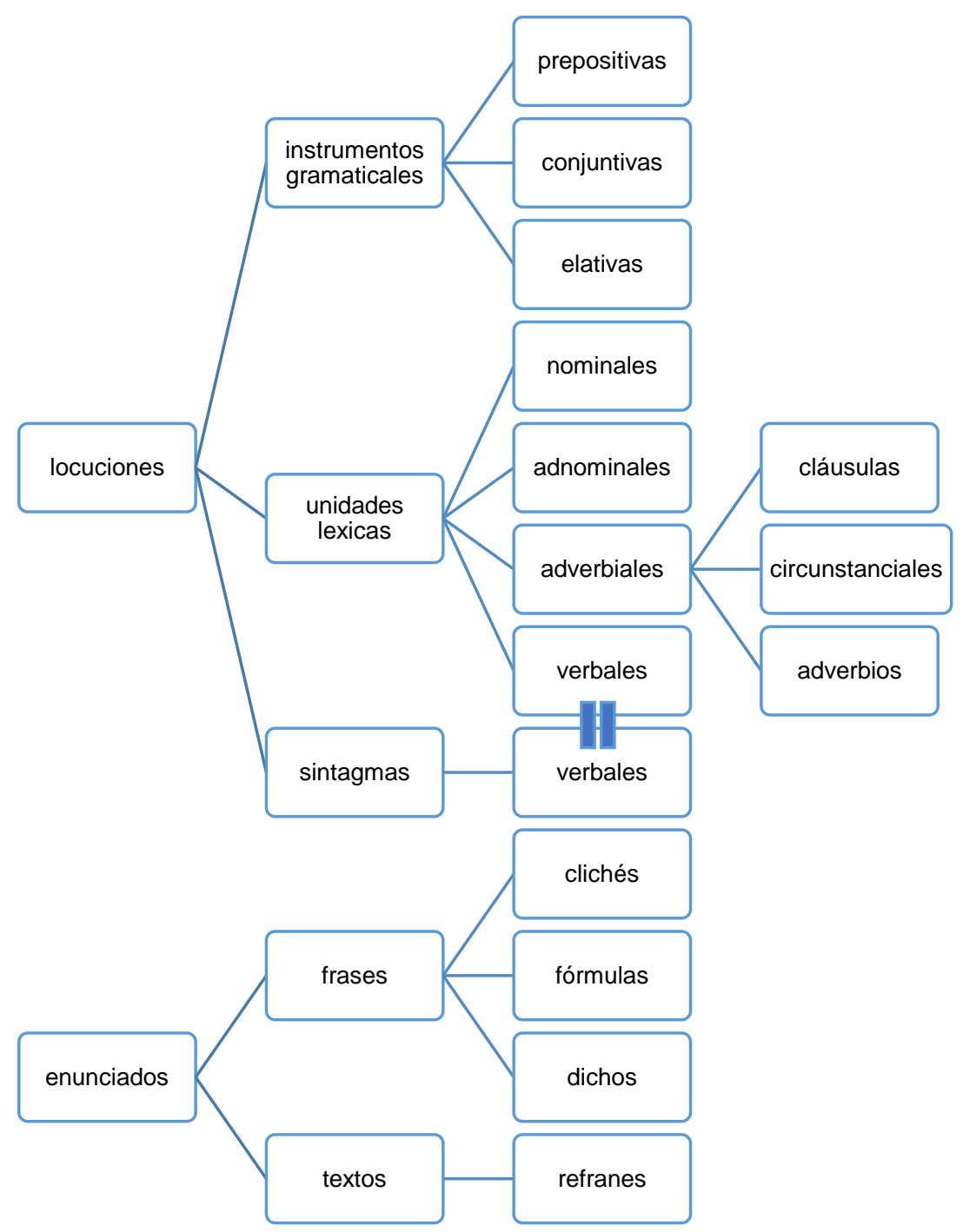

Tabla 4. Clasificación de las UF de Zuluaga, según su función. Fuente: elaboración propia, basada en Zuluaga (1980).

Otro gran grupo fraseológico está constituido por los enunciados fraseológicos, definidos como una unidad de comunicación mínima que no precisan de un contexto verbal inmediato para construir una expresión de sentido completo.

Zuluaga agrupa los enunciados en tres grandes bloques: los fijos de sentido literal, los semiidiomáticos y los idiomáticos, estos últimos formados por una sola palabra, por un sintagma nominal, por una oración simple (nominal o verbal), por una oración compuesta o representados por citas (introducidas por el verbo o interrogativas con respuesta). Para 
Zuluaga, estos cuatro últimos tipos son conocidos como wellerismos y dialogismos, pero se pueden considerar también refranes.

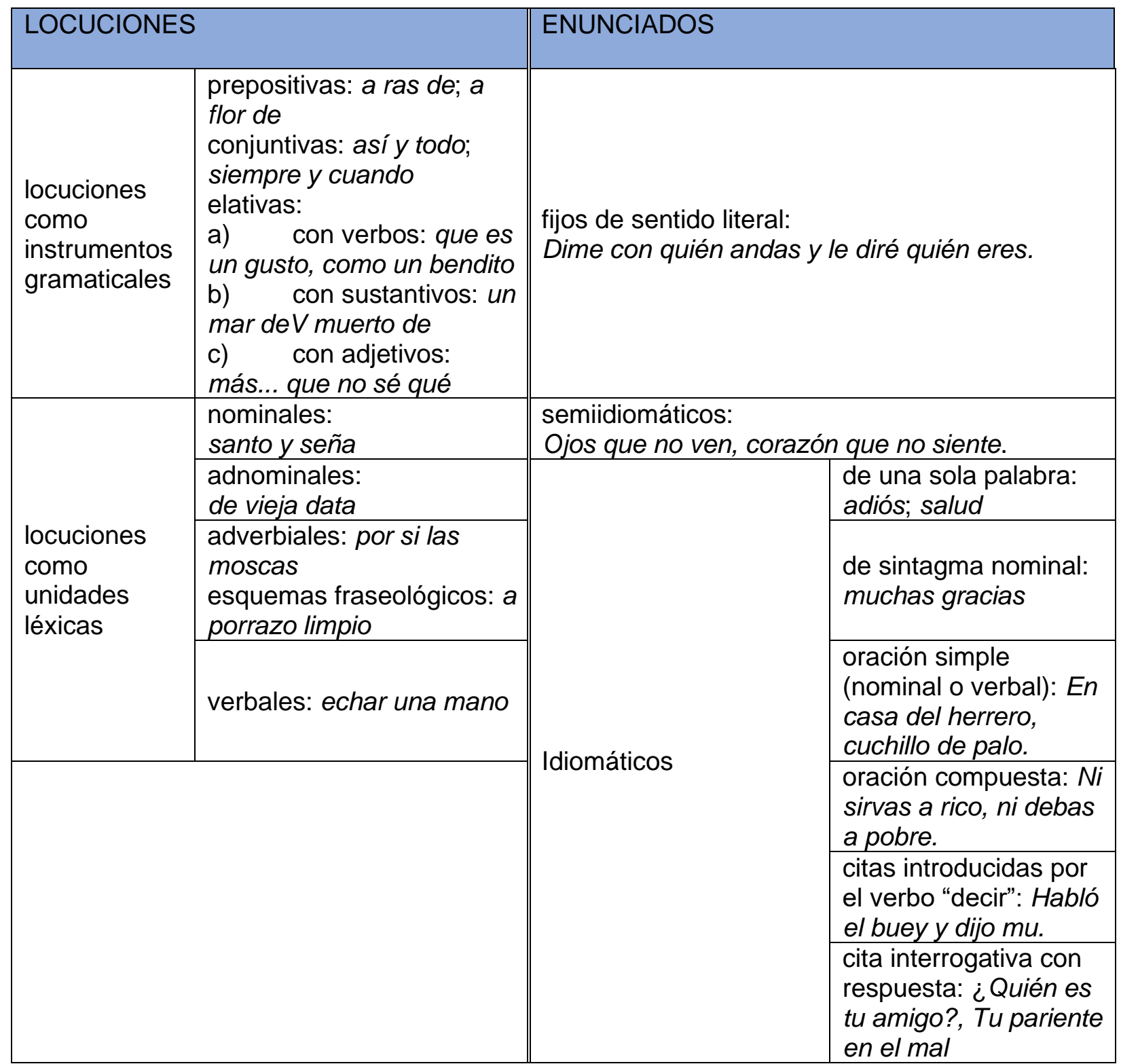

Tabla 5. Clasificación de las UF de Zuluaga. Criterio de estructura dependiente o independiente. Fuente: Zuluaga (1980)

Conviene señalar que Zuluaga no otorgó la misma importancia a las taxonomías propuestas.

La clasificación según los rasgos de la estructura interna está supeditada a la clasificación según el funcionamiento de las UFs en el discurso. Este hecho se comprueba en la misma estructura del libro, donde como punto de partida se toma precisamente la clasificación funcional para luego comentar con más detalle la aparición de la fijación y de la idiomaticidad (Sosiński 2006:47). 
Visto desde una perspectiva E/LE, este enfoque nos parece beneficioso y acertado, puesto que en la enseñanza moderna los componentes lingüísticos están supeditados a las funciones comunicativas.

La importancia del estudio de Zuluaga (1980) es fundamental para la fraseología española y representa la primeraran obra científica dedicada exclusivamente a analizar y a clasificar las UF. 


\subsubsection{La clasificación de las UF de Corpas Pastor}

Situándose también en la concepción ancha de la fraseología, Corpas Pastor (1996) elabora quizás la clasificación más sólida, relevante y esclarecedora en el ámbito de la fraseología española. Se decanta también por el tecnicismo "unidad fraseológica", definida como

unidades léxicas formadas por más de dos palabras gráficas en su límite inferior, cuyo límite superior se sitúa en el nivel de la oración compuesta. Dichas unidades se caracterizan por su alta frecuencia de uso, y de coaparición de sus elementos integrantes, por su institucionalización entendida en términos de fijación y especialización semántica; por su idiomaticidad y variación potenciales (Corpas Pastor 1996:20).

Toma como punto de partida para su taxonomía dos criterios distintos: el enunciado, definido como "una unidad de comunicación mínima, producto de un acto de habla que corresponde generalmente a una oración simple o compuesta, pero que puede constar de un sintagma o de una palabra" (1996:51) y la fijación en la norma, en el sistema o en el habla, siguiendo los niveles lingüísticos propuestos por Coşeriu (1962). Asimismo, estructura el universo fraseológico en "esferas": en la esfera I se encuentran las colocaciones, en la esfera II entran las locuciones y en la esfera III los enunciados fraseológicos. Las UF que no pueden funcionar como enunciados y están fijadas en el sistema son las locuciones, definidas como "unidades fraseológicas del sistema de la lengua con los siguientes rasgos distintivos: fijación interna, unidad de significado y fijación externa pasemática. Estas unidades no constituyen enunciados completos $y$, generalmente, funcionan como elementos oracionales" (1996:88). Mientras tanto, las UF que no pueden funcionar como enunciados y están fijadas en la norma son las colocaciones, "aquella propiedad de las lenguas por las que los hablantes tienden a producir ciertas combinaciones de palabras entre una gran cantidad de combinaciones teóricamente posibles" (1996:66). Las UF que pueden funcionar como enunciados se denominan enunciados fraseológicos y están fijados en el habla. Son "enunciados completos en sí mismos, que se caracterizan por construir actos de habla y por presentar fijación interna (material y de contenido) y externa (1996:132). 


\begin{tabular}{|l|l|l|}
\hline Enunciado & Tipo de fijación & \multicolumn{1}{c|}{ ESFERA } \\
\hline \multirow{2}{*}{ No } & en la norma & I (colocaciones) \\
\cline { 2 - 3 } & en el sistema & II (locuciones) \\
\hline \multirow{2}{*}{ Sí } & en el habla & $\begin{array}{l}\text { III (enunciados } \\
\text { fraseológicos) }\end{array}$ \\
\hline
\end{tabular}

Tabla 6. Clasificación de las esferas de Corpas Pastor. Fuente: Corpas Pastor (1996)

En las siguientes líneas, pasamos a detallar las clasificaciones que opera en las tres esferas acotadas.

En primer lugar, destacamos el acierto de Corpas Pastor en el detallado y novedoso tratamiento de las colocaciones a las que, como acabamos de ver, considera elementos de la norma. Se trata de combinaciones de dos unidades léxicas, unidas por una relación sintáctica que suele presentar una relación semántica peculiar, establecida entre la base y el colaborativo. La base es el colocado semánticamente autónomo y determina con qué palabras puede combinarse, mientras que el colectivo es el elemento determinado que aparece a menudo con una acepción figurativa o abstracta. Las restricciones de combinaciones se establecen por el uso y representan una propiedad de las lenguas por la que los hablantes tienden a producir un número limitado de combinaciones de palabras entre una enorme cantidad tóricamente posible. La relación de subordinación que se establece entre los dos elementos (el colocado selecciona en el colocativo una acepción especial) recuerdan el concepto de "solidaridad léxica" acuñado por Coşeriu (1977) o la noción de "funciones léxicas" de Mel'čuk (1993), que permiten describir la coaparición restringida de palabras.

Inspirada en las taxonomías de Benson et. al. (1986) y Hausmann (1979), Corpas Pastor distingue seis tipos de colocaciones.

\begin{tabular}{|c|l|}
\hline \multirow{3}{*}{$\begin{array}{c}\text { ESFERA I } \\
\text { COLOCACIONES }\end{array}$} & sustantivo (sujeto) + verbo: correr un rumor; estallar una guerra \\
\cline { 2 - 3 } & verbo + sustantivo (objeto): asestar un golpe; dar una paliza \\
\cline { 2 - 3 } & $\begin{array}{l}\text { sustantivo + preposición + sustantivo: rebanada de pan; diente de } \\
\text { ajo }\end{array}$ \\
\cline { 2 - 2 } & verbo + adverbio: negar rotundamente; dormir profundamente \\
\cline { 2 - 2 } & adjetivo + adverbio: estrechamente ligado; diametralmente opuesto \\
\hline
\end{tabular}

Tabla 7. Clasificación de las colocaciones de Corpas Pastor. Fuente: Corpas Pastor (1996) 
En las colocaciones de tipo $\mathrm{V}+\mathrm{S}$ (sujeto), que incluye también las construcciones con verbos pronominales, el verbo expresa una acción característica ejecutada por la persona o cosa que designa el sustantivo.

Las colocaciones de tipo verbo + sustantivo (objeto) presentan varios grados de fijación. En este apartado incluye también las colocaciones compuestas por verbos delexicalizados y sustantivos que aportan la carga semántica y que suelen tener un sinónimo en forma de unidad léxica simple.

En el grupo de de colocaciones constituidas por un adjetivo + sustantivo incluye también combinaciones de dos sustantivos (donde uno modifica al otro).

En las colocaciones formadas por sustantivo + preposición + sustantivo incluye unidades que designan el grupo al que pertenece el sustantivo o una unidad de la que forma parte el elemento más pequeño.

El subtipo de las colocaciones que consta de verbo + adverbio expresan modo o intensidad.

Finalmente, en la unión adjetivo + adverbio uno de los elementos componentes es un participio en función con valor adjetival.

Las UF que conforman la esfera II son las locuciones, la categoría que más interés presenta para nuestro estudio. Corpas Pastor sigue el criterio de la función oracional que desempeñan estas unidades y, en el caso de las locuciones plurifuncionales, integra el criterio formal y el funcional, al centrarse en el núcleo del sintagma correspondiente. Esta elección nos parece muy acertada y al mismo tiempo con aplicabilidad al ámbito del E/LE, ya que "la división en tipos de sintagmas (nominal, adjetival, etc.) conduce a que los estudiantes indaguen en una parte del significado de las unidades, el gramatical, aspecto que se deberá aplicar en ejercicios o actividades de fraseodidáctica" (Saracho 2015:116).

A la hora de distinguir los diferentes tipos de locuciones, sigue principalmente el criterio de la función oracional que desempeñan estas unidades, aunque en ocasiones recurre también al criterio formal. Encontramos, por lo tanto, locuciones nominales, locuciones adjetivas, locuciones adverbiales, locuciones verbales, locuciones prepositivas, locuciones conjuntivas y locuciones clausales.

\begin{tabular}{|c|c|}
\hline \multirow{7}{*}{$\begin{array}{c}\text { ESFERA II } \\
\text { LOCUCIONES }\end{array}$} & locuciones nominales: flor y nata; tira y afloja; coser y cantar; cada quisque \\
\hline & locuciones adjetivas: de padre y muy señor mío; sano y salvo \\
\hline & locuciones adverbiales: en un santiamén; con pelos y señales \\
\hline & locuciones verbales: hacérsele la boca agua; costar un ojo de la cara \\
\hline & locuciones prepositivas: detrás de; con respecto a \\
\hline & locuciones conjuntivas: a fin de que; a medida que \\
\hline & $\begin{array}{l}\text { locuciones clausales: salir el tiro por la culata; irse el el santo al cielo; como } \\
\text { Dios manda }\end{array}$ \\
\hline
\end{tabular}

Tabla 8. Clasificación de las locuciones de Corpas Pastor. Fuente: Corpas Pastor (1996) 
Las locuciones nominales, cuya función oracional equivale a la de un sustantivo, abarcan diversos patrones: sustantivo + adjetivo; dos sustantivos unidos por una preposición; dos sustantivos unidos por la conjunción copulativa "y"; locuciones formadas por infinitivos; cláusulas sustantivadas; expresiones deícticas sin significado léxico.

Las locuciones adjetivas suelen estar formadas por un adjetivo/participio +preposición + sustantivo; dos adjetivos unidos por la conjunción copulativa "y"; adjetivo + como + sustantivo o más + adjetivo + que + adjetivo /sustantivo, estructuras que se reflejan en las comparaciones estereotipadas.

Las locuciones adverbiales incluyen sintagmas prepositivos, sintagmas cuyo núcleo es un adverbio, sintagmas sustantivos y sintagmas adjetivos.

Las locuciones verbales forman predicados y pueden tener una estructura muy diversa: dos verbos unidos por la conjunción copulativa "y"; verbo copulativo + atributo; verbo + complemento circunstancial (de diferentes tipos: circunstancial, objeto directo o suplemento); verbo + pronombre; verbo + partícula con complementación opcional.

Las locuciones prepositivas (que no equivalen a meras preposiciones agrupadas) pueden estar formadas por un adverbio + una preposición o por un sustantivo + una preposición.

Las locuciones conjuntivas se dividen en coordinantes y subordinantes, que a su vez están clasificadas en subapartados, siguiendo las pautas del Esbozo para una nueva gramática de la lengua española (1973): coordinantes (distributivas o disyuntivas, adversativas) y subordinantes (condicionales, concesivas, consecutivas, finales, modales, etc).

Finalmente, las locuciones clausales pueden estar formadas por varios sintagmas, de los cuales por lo menos uno es verbal, si bien no constituyen oraciones completas. Dentro de este tipo de locuciones también se incluyen las formadas por cláusulas enteras que carecen de fuerza ilocutiva.

A la tercera y última esfera pertenecen las paremias y las fórmulas rutinarias, agrupadas bajo un término inspirado de las taxonomías de Casares, "enunciados fraseológicos". Se trata de "enunciados completos en sí mismos, que se caracterizan por construir actos de habla y por presentar fijación interna (material y de contenido) y externa" (Corpas Pastor 1996:132). Las paremias son unidades dotadas de autonomía textual y significado referencial, mientras que las fórmulas rutinarias tienen un significado social, expresivo y discursivo.

A fin de distinguir varios tipos de paremias, Corpas Pastor (1996:136) aplica los criterios propuestos por Arnaud (1991) - lexicalización, autonomía sintáctica y textual, valor de verdad general y carácter anónimo - e identifica enunciados de valor específico, citas y refranes. El grupo de los enunciados de valor específico está formado principalmente por lo que Casares (1950) llama "frases proverbiales", eslóganes, algunas citas que no tienen valor de verdad general (y cuyo autor es desconocido), consignas de carácter político o publicitario, en definitiva, elementos que comparten el rasgo de la institucionalidad. Las citas, en cambio, tienen autor reconocible. Los refranes son 
paremias que, además de cumplir con los requisitos planteados por Arnaud (1991), presentan características adicionales: significado metafórico, particularidades fónicas, anomalías sintácticas.

Desde la perspectiva de la didáctica del E/LE, nos concierne más el grupo formado por las fórmulas rutinarias, debido a su mayor frecuencia e importancia en el discurso (se usan en conversaciones diarias y cumplen fines sociales), rasgo que también destaca Corpas Pastor (1996:170): "fórmulas de interacción social habituales y estereotipadas que cumplen funciones específicas en situación predecibles, rutinarias, y hasta cierto punto, ritualizadas". Combina criterios semánticos con criterios funcionales y considera relevantes los rasgos definidos por Wilss (1990): repetición, dependencia de la situación, carácter predecible, (mono-) funcionalidad pragmática y normatividad individual.

\begin{tabular}{|c|c|c|c|}
\hline \multirow{8}{*}{$\begin{array}{l}\text { ESFERA III } \\
\text { FORMULAS } \\
\text { RUTINARIAS }\end{array}$} & \multirow{2}{*}{$\begin{array}{c}\text { fórmulas } \\
\text { discursivas }\end{array}$} & $\begin{array}{l}\text { fórmulas de apertura y } \\
\text { cierre }\end{array}$ & Buenos días; Hasta luego \\
\hline & & fórmulas de transicion & Vamos a ver \\
\hline & \multirow{6}{*}{$\begin{array}{c}\text { fórmulas } \\
\text { psico-sociales }\end{array}$} & fórmulas expresivas & Perdone que le moleste \\
\hline & & fórmulas comisivas & Te doy mi palabra \\
\hline & & fórmulas directivas & ¿En qué quedamos? \\
\hline & & fórmulas asertivas & No faltaba más \\
\hline & & fórmulas rituales & Buenos días, ¿Qué hay? \\
\hline & & miscelánea & Más claro, agua \\
\hline
\end{tabular}

Tabla 9. Clasificación de las fórmulas rutinarias de Corpas Pastor. Fuente: Corpas Pastor (1996)

Tal como se desprende del esquema anterior, el primer grupo está constituido por las fórmulas discursivas de apertura y cierre, dentro de las que también incluimos las fórmulas que establecen o confirman las relaciones sociales y de transición, utilizadas para estructurar los intercambios conversacionales, "regulando la interacción, organizado y precisando lo que se dice, resaltando alguna parte, enlazando unos tópicos con otros y permitiendo a los interlocutores tomar la palabra, mantener el turno u orientar el cambio de este" (Corpas Pastor 1996:189-190).

En cuanto a las fórmulas psicosociales, las define como

formas establecidas convencionalmente para realizar determinados actos de habla, (...) persiguen primordialmente fines sociales y facilitadores de la interacción. En su mayoría sólo tienen efecto ilocucionario, pues se limitan a construir la expresión de sentimientos y actitudes canalizados socialmente 0 la realización verbal adecuada para encuentros ritualizados (Corpas Pastor 1996:275). 
Dentro de este grupo, las fórmulas expresivas indican sentimientos y actitudes del emisor y, a su vez, están divididas en subtipos: fórmulas de (pseudo)disculpa, de consentimiento, de recusación, de agradecimiento, etc. Entre las fórmulas comisivas encontramos las que sirven para prometer y amenazar (muchas de ellas pertenecientes al lenguaje infantil). Las fórmulas directivas agrupan las fórmulas de exhortación y las fórmulas que se emplean para animar, alentar o apaciguar a nuestro interlocutor. Las fórmulas asertivas constituyen actos de habla informativos, las fórmulas rituales están estrechamente vinculadas con la apertura y el cierre del acto comunicativo, mientras que el grupo misceláneo engloba aquellas fórmulas imposibles de recoger en ninguno de los apartados anteriores.

Nos hemos detenido en la segmentación del universo fraseológico operada por Corpas Pastor porque consideramos su exhaustivo tratamiento de las UF un enorme paso adelante respecto a las taxonomías previas. Este entusiasmo surge fundamentalmente desde la perspectiva docente, puesto que proporciona una solución razonada para ordenar elementos idiomáticos a los que no se les había prestado una atención especial en español, como es el caso de las fórmulas rutinarias y, sobre todo, de las colocaciones, que reciben un tratamiento coherente y sistemático. 


\subsubsection{La clasificación de las UF de Ruiz Gurillo}

A diferencia de los enfoques anteriores, Ruiz Gurillo (1997) prefiere una concepción más estrecha de la fraseología y se limita a segmentar solo el grupo de las locuciones. La autora recurre a los mismos criterios que Zuluaga (1980) y se inspira en la clasificación planteada por Wotjak (1983), aplicando a su propuesta el concepto de centro y de periferia de la Escuela Lingüística de Praga. Opta también por el tecnicismo "unidad fraseológica" en detrimento de otros términos como "expresión fija" o "frase hecha" y aporta su propia definición del concepto: "una combinación fija de palabras que presenta algún grado de fijación y eventualmente de idiomaticidad" (1997:14).

En su visión, las unidades fraseológicas prototípicas (el centro) son las que presentan las características de la fijación y de la idiomaticidad en el grado más alto (incluyen alguna palabra diacrítica y/o muestran una anomalía estructural), mientras que las que presenten esos rasgos en menor medida se encontrarán en la periferia de la fraseología.

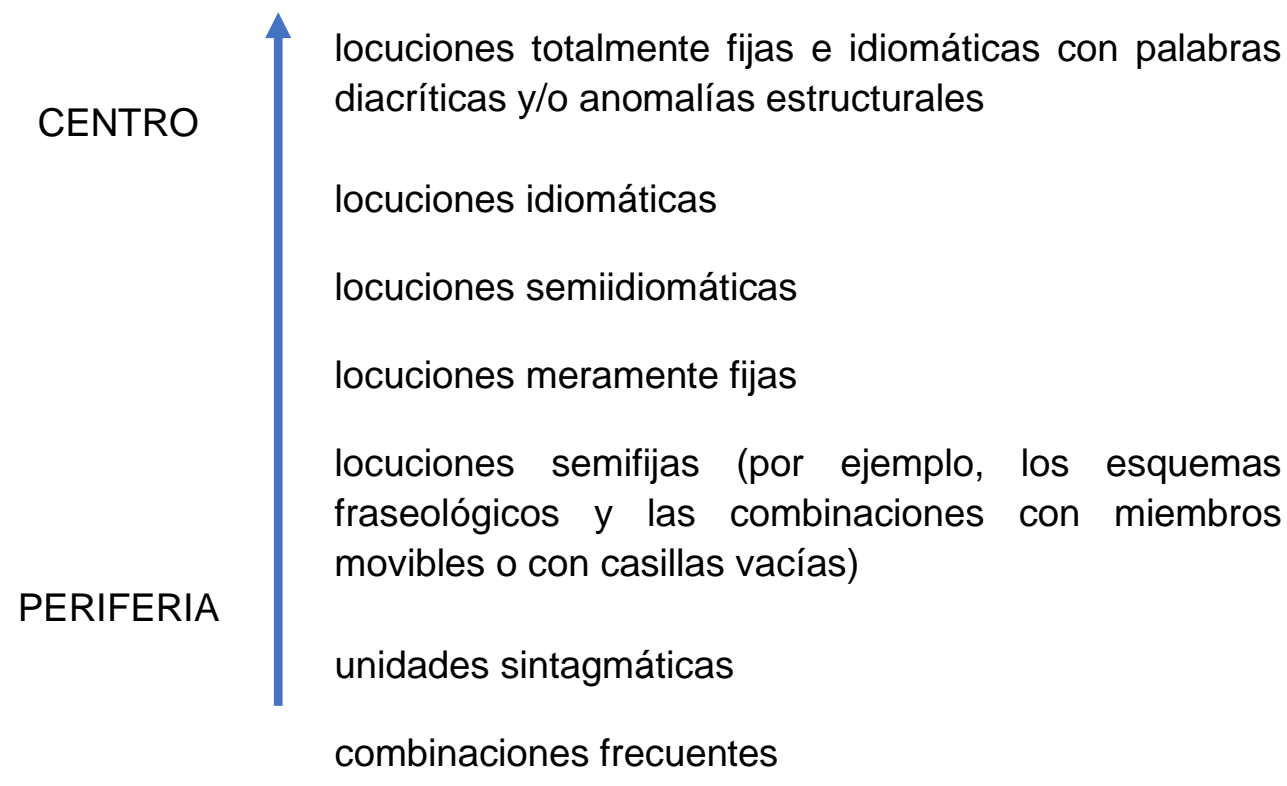

Tabla 10. Clasificación general de grupos graduales de Ruiz Gurillo. Fuente: Ruiz Gurillo (1997)

Como podemos comprobar en la tabla anterior, dibuja "ciertos grados de fraseologización, escalones de un camino continuo de combinaciones ubicadas entre el sintagma y el lexema" (1997:66), "una progresión que va desde la irregularidad a la regularidad, de la improductividad a la productividad, de la fraseología a la sintaxis, pero, ante todo, constituye una diferenciación artificial que responde a un continuum de difícil segmentación" (1997:76).

En una primera taxonomía, parte de un criterio formal que "permite observar con mayor nitidez tanto las diferencias internas como las que se derivan de su relación con 
otras clases de sintagmas" (1997:66) y propone una clasificación no discreta de las UF adscritas a tres sintagmas distintos (nominal, verbal y prepositivo).

Dentro de los sintagmas nominales fraseológicos incluye las colocaciones nominales que constituyen unidades fraseológicas periféricas, creadas empleando procedimientos regulares, propios de la sintaxis libre; las unidades fraseológicas que presentan una parte fija y otra idiomática; las locuciones nominales con algún grado de idiomaticidad y grados mayores de fijación; las locuciones prototípicas. Asume, no obstante, que "las fronteras entre locuciones nominales y compuestos se rozan de tal modo que resulta complejo desgajar ambas categorías" (1997:66), y que se ha guiado por las diferencias de índole formal: "los elementos integrantes de los compuestos manifiestan unidad gráfica, mientras que los de las locuciones acostumbran a aparecer separados en la escritura, manteniendo de este modo su independencia formal" (1997:67). Asimismo, ha recurrido al rasgo de la idiomaticidad para discernir entre colocaciones y locuciones nominales.

Dentro de los sintagmas verbales fraseológicos incluye colocaciones; unidades sintagmáticas verbales periféricas; locuciones con variantes; locuciones fijas; locuciones con una parte meramente fija y otra idiomática; locuciones con idiomaticidad intermedia; locuciones semiidiomáticas; locuciones totalmente idiomáticas; locuciones prototípicas. Se trata de sintagmas que

representan UFS de distinta complejidad que se sitúan en diversos lugares de la escala fraseológica que va del centro a la periferia. Algunos de ellos pueden ser considerados, gracias a las propiedades de fijación e idiomaticidad y a los rasgos que manifiestan, como unidades prototípicas de la fraseología. Otros, en cambio, representan grados de fijación escasos y nula idiomaticidad, por lo que habrán de adscribirse a la periferia (1997:69).

En cuanto a los sintagmas prepositivos fraseológicos, descarta las combinaciones frecuentes que revelan libertad sintáctica, pero incluye esquemas fraseológicos; creaciones locucionales analógicas; locuciones con casillas vacías; locuciones con variantes; locuciones meramente fijas; locuciones parcialmente fijas e idiomáticas en diversos grados; locuciones totalmente fijas e idiomáticas; locuciones prototípicas. Considera que

la peculiar estructura de estas locuciones, la del sintagma prepositivo, deja a priori sin efecto algunos de los rasgos (...) como el de componentes no extraíbles, la invariabilidad de persona y de tiempo o los rasgos que aluden a la fijación transformativa, como la posibilidad de aparición en pasiva o de nominalización (1997:73). 
Además de esta taxonomía gradual, en un trabajo ulterior (2001) propone una nueva clasificación, siguiendo un criterio categorial.

\begin{tabular}{|l|l|l|}
\hline \multirow{4}{*}{ LOCUCIONES } & nominales & el año de la pera \\
\cline { 2 - 3 } & adjetivales & de pacotilla \\
\cline { 2 - 3 } & verbales & tomar las de Villadiego \\
\cline { 2 - 3 } & adverbiales & sin tapujos \\
\cline { 2 - 3 } & marcadoras & sin embargo \\
\cline { 2 - 3 } & prepositivas & a cambio de \\
\cline { 2 - 3 } & clausales & salir el tiro por la culata \\
\hline
\end{tabular}

Tabla 11. Clasificación funcional de las locuciones de Ruiz Gurillo. Fuente: Ruiz Gurilo (2001)

Por otra parte, Ruiz Gurillo (1997:48) desglosa a fondo los rasgos de las UF tomando como criterio los niveles fonético-fonológico, morfológico, sintáctico, léxico-semántico y pragmático.

En el nivel fonético-fonológico distingue la separación en la escritura de los elementos, la reducción fonética y otra amplia serie de rasgos fonéticos que agrupa bajo el nombre de "peculiares": aliteración, rima consonante, rima asonante, figura paronomástica, disposición rítmica, gradación silábica, repetición de fonemas y/o de palabras, fórmulas apofónicas.

En el nivel morfológico destaca las relaciones con la derivación y composición y, sobre todo, la presencia de las palabras diacríticas o que presentan ciertas anomalías estructurales, así llamadas ill formed (Weinreich 1966), caracterizadas por el orden sintáctico anómalo o la concordancia irregular.

En el nivel sintáctico distingue dos grandes rasgos: la fijación entendida como complejidad y estabilidad de forma, que tiene carácter gradual (puesto que determinadas expresiones presentan una mayor estabilidad que otras) y la fijación entendida adicionalmente como defectividad combinatoria y sintáctica. La autora indaga a fondo en esta defectividad que se manifiesta bajo múltiples aspectos: a) componentes léxicos invariables (de número, género, determinante, persona o tiempo verbal); b) componentes léxicos no conmutables; c) componentes no permutables (imposible, por lo tanto, su topicalización o la extracción de algún elemento constitutivo); d) componentes léxicos no separables (incluida aquí la imposibilidad de la elipsis o la inserción de un elemento extraño a la UF); e) fijación transformativa (imposibilidad de pasivización, nominalización o referencia a otras estructuras profundas).

En el nivel léxico-semántico hace especial hincapié en un aspecto fundamental, recogido por numersos lingüistas, desde Bally (1921) hasta García-Page (1990): la UF se 
concibe como una unidad léxica y la conmutación solo es posible en su conjunto. Menciona también la no composicionalidad semántica, la motivación y la tropología, entendida como la presencia de las figuras retóricas estrechamente vinculadas a la idiomaticidad: metáfora, hipérbole, metonimia, sinécdoque.

Finalmente, en el nivel pragmático hace referencia a la memorización en bloque de estos elementos, lo que facilita su reproducción. Además, el reconocimiento a nivel colectivo hace posible la aposiopesis, sobre todo en las estructuras bimembres, ya que se trata de UF compartidas por la comunidad de hablantes, no de una competencia comunicativa individual. En cuanto a la frecuencia de uso, apunta que las UF "representan un alto porcentaje de las expresiones que existen en una lengua" (1997:51) y que, en caso de contar con un elemento fijo, los hablantes optan por una UF en detrimento de la combinación libre de palabras. La iconicidad es también otro aspecto relevante debido a que el empleo del componente idiomático potencia las funciones del lenguaje e imprime mayor fuerza expresiva, apelativa, ilocutiva o perlocutiva. Las UF conllevan valores sociolingüísticos, están institucionalizadas y adscritas a distintas variantes diastráticas o diafásicas.

Consideramos muy acertada esta minuciosa disección de los rasgos de las UF, que acabamos de resumir. En cuanto a sus taxonomías, destacamos la inclusión de las colocaciones dentro del campo de la fraseología y la preponderancia de la idiomaticidad como criterio clasificador. No obstante, desde la perspectiva de la lingüística aplicada a la didáctica, nos parecen demasiado borrosos los límites que establece entre distintas zonas (centro, transición, periferia). 


\subsubsection{Otras clasificaciones}

García-Page (2008), en una obra esencialmente descriptiva, no descuida la proyección teórica. Contrasta opiniones, toma postura en controvertidos aspectos fronterizos, formula sus propias hipótesis y propone una taxonomía, en la misma línea de la visión restringida de la fraseología. En este sentido, señala que las colocaciones son elementos que atañen a la sintaxis, mientras que el estudio de los refranes debería llevarse a cabo desde la paremiología.

Toma como punto de partida la clasificación de las locuciones propuesta por Corpas Pastor (1996) y aporta como mayor novedad la ampliación del campo de la estructura oracional $^{2}$. En su segmentación distingue locuciones nominales, pronominales, adjetivales, verbales, adverbiales, prepositivas, conjuntivas y oracionales, tal como se refleja en el siguiente esquema:

${ }^{2}$ En trabajos anteriores (1995:79) ya había mostrado su interés por esta categoría de UF que había definido en los siguientes términos: "parece presentar autonomía gramatical y semántica, en el sentido de que la propia expresión fija - a semejanza del refrán y el proverbio- constituye un enunciado completo que no necesita la concurrencia de otros términos gramaticalmente complementarios. Todos los signos que componen el modismo están fijados históricamente por el uso repetido en una forma léxica determinada y con esa forma aparecen en el discurso cuando el modismo es empleado. A tales secuencias las llamaremos "fraseologismos o locuciones oracionales". 


\begin{tabular}{|c|c|}
\hline \multicolumn{2}{|r|}{ LOCUCIONES } \\
\hline Nominales & $\begin{array}{l}\text { noche toledana; cuento chino; el más allá; coser y cantar } \\
\text { (infinitiva para Casares), todo dios; el que } \\
\text { más o el que menos (las dos últimas pronominales para } \\
\text { otros autores) }\end{array}$ \\
\hline Pronominales & cada quisque \\
\hline Adjetivales & \multirow{2}{*}{$\begin{array}{l}\text { largo de manos (cualitativas) } \\
\text { de andar por casa; para tomar pan (infinitiva para } \\
\text { Casares) } \\
\text { la mar de historias; un porrón de discos } \\
\text { (intensificadoras) }\end{array}$} \\
\hline $\begin{array}{l}\text { cualitativas } \\
\text { intensivas }\end{array}$ & \\
\hline Verbales & $\begin{array}{l}\text { cantar las cuarenta; } \\
\text { pedir peras al olmo (infinitiva para Casares) }\end{array}$ \\
\hline Adverbiales & $\begin{array}{l}\text { a salvamano; } \\
\text { al correr de la pluma (de infinitivo inflexible) }\end{array}$ \\
\hline Prepositivas & en pos de \\
\hline Conjuntivas & para que \\
\hline Oracionales & \multirow{2}{*}{$\begin{array}{l}\text { caérsele la baba; írsele el santo al cielo (clausales en } \\
\text { Corpas1996) }\end{array}$} \\
\hline semioracionales & \\
\hline $\begin{array}{l}\text { de estructura autónoma } \\
\text { interjectivas y fórmulas }\end{array}$ & $\begin{array}{l}\text { La procesión va por dentro; Llueve sobre mojado; Las } \\
\text { paredes oyen (enunciados de valor especifico de Corpas } \\
\text { 1996) }\end{array}$ \\
\hline pragmáticas & $\begin{array}{l}\text { ¿Quien me lo iba a decir!; ;Tengamos la fiesta en paz!; } \\
\text { ¡Hasta ahí podíamos Ilegar!; ;Tanto da!; ;Anda ya! }\end{array}$ \\
\hline
\end{tabular}

Tabla 12. Clasificación de las locuciones de García- Page. Fuente: García-Page (2008)

Prácticamente, García-Page no se aleja demasiado de la clasificación de Corpas Pastor (1996), por lo que, a fin de no caer en la redundancia, no trataremos a fondo las locuciones nominales, pronominales, adjetivales, verbales, etc. Únicamente nos detendremos en sus aportaciones respecto a las locuciones oracionales, consideradas una clase bastante heterogénea que

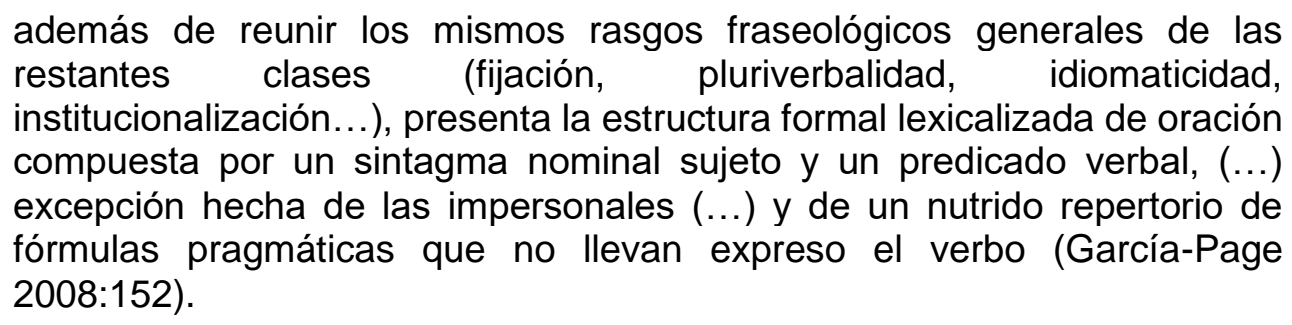

Distingue dos grupos distintos: las locuciones semioracionales o clausales y las oraciones propiamente oracionales (entre las que incluye las fórmulas). La primera categoría estaría formada por locuciones descartadas como verbales, puesto que siguiendo un criterio puramente gramatical, las construcciones contienen un sujeto léxico 
y presentan la estructura de una oración. Esta categoría ya había sido vislumbrada por Carneado Moré (1983) o Corpas Pastor (1996), que advirtieron de la necesidad de una mejor segmentación de las estructuras que incluyen un sujeto fijo y se adelantaron con rótulos terminológicos como "fraseologismos propositivos" o "locuciones clausales", respectivamente. García-Page traza mejor los límites de este subapartado, injustamente considerado un "cajón de sastre" al que se habían desterrado todas aquellas construcciones que difícilmente encajaban en categorías mejor asentadas y separa los fraseologismos semioracionales de los propiamente oracionales, que presentan todos los argumentos - externos e internos - realizados léxicamente.

En nuestra opinión, más que una taxonomía novedosa, Gacía-Page aporta una mirada crítica global de los trabajos de clasificación previos. Beneficiándose de un corpus ilimitado en la red, ejemplifica con numerosos ejemplos esclarecedores su construcción teórica y da muestra de un profundo y preciso conocimiento de la fraseología, a la que describe con atención y acribia.

Finalizamos este recorrido por las clasificaciones de las UF con las teorías de Pamies (2007). Tras reformular en clave crítica los ragos fundamentales de las UF, descarta el concepto de "palabra" y, en la senda de Martinet (1967), opta por el sintagma, en detrimento del monema. En este sentido, opera con un concepto hallado en un espacio intermediario, el sintema: unidad lingüística cuyo comportamiento sintáctico es idéntico al del monema, pero que puede ser concebido como formado por elementos semánticamente reconocibles. Esta categoría le permite "no desperdiciar" ciertos compuestos léxicos, construcciones onímicas o fraseotérminos.

Si en vez de multilexicalidad recurrimos a la multlexematicidad (fijación de lexemas no de palabras) tenemos un rasgo que es igual de aplicable a compuestos que a locuciones, pero que es objetivo y estable. Los sintemas son siempre multilexemáticos y se distinguen del sintagma por funcionar como un lexema único. En este sentido, los sintemas son pseudo-sintagmas (Pamies 2007:185).

La clasificación multicriterial que propone, además de los sintemas y de los sintagmas, incluye también los enunciados. 


\begin{tabular}{|c|c|c|c|}
\hline \multicolumn{2}{|c|}{ unidades multilexemáticas fijas } & no idiomáticas & Idiomáticas \\
\hline \multirow{11}{*}{ SINTEMA } & compuesto léxico & Sacacorchos & Matasuegras \\
\hline & $\begin{array}{l}\text { compuesto } \\
\text { sintagmático }\end{array}$ & máquina de escribir & luna de miel \\
\hline & locución nominal & apretón de manos & cero a la izquierda \\
\hline & locución adjetival & en blanco y negro & de medio pelo \\
\hline & locución verbal & poner en remojo & tomar el pelo \\
\hline & locución adverbial & sin dudarlo un instante & a toda leche \\
\hline & locución conjuntiva & con la condición de que & a pesar de que \\
\hline & locución prepositiva & encima de & en nombre de \\
\hline & "phrasal verb" & $\begin{array}{l}\text { to run after } \\
\text { ("perseguir") }\end{array}$ & to mess around ("tontear") \\
\hline & construcción onímica & República Italiana & América Latina \\
\hline & fraseotérmino & fonética experimental & células asesinas \\
\hline \multirow{5}{*}{ SINTAGMA } & $\begin{array}{l}\text { comparación } \\
\text { esterotipada }\end{array}$ & negro como el carbón & $\begin{array}{l}\text { más chupado que la pipa } \\
\text { de un indio }\end{array}$ \\
\hline & coloc. $\mathrm{N}+\mathrm{Adj}$. & enfermedad grave & enemigo mortal \\
\hline & coloc. V+Adv. & enfermar gravemente & despreciar olímpicamente \\
\hline & coloc. $\mathrm{V}+\mathrm{N}$ & pedir permiso & entablar amistad \\
\hline & coloc. $\mathrm{N}+$ Prep $+\mathrm{N}$ & rebaño de ovejas & banco de peces \\
\hline \multirow{3}{*}{ ENUNCIADO } & fórmula & ¡Cumpleaños feliz! & ¡Que te den morcilla! \\
\hline & $\begin{array}{l}\text { apotegma no } \\
\text { sentencioso }\end{array}$ & $\begin{array}{l}\text { No mandé mis naves a } \\
\text { combatir los elementos }\end{array}$ & La maté porque era mía \\
\hline & paremia & $\begin{array}{l}\text { No dejes para mañana } \\
\text { lo que puedes hacer } \\
\text { hoy }\end{array}$ & $\begin{array}{l}\text { Quien siembra vientos } \\
\text { recoge tempestades }\end{array}$ \\
\hline
\end{tabular}

Tabla 13. Clasificación de las UF de Pamies. Fuente: Pamies (2007)

Pamies destaca la importancia de la idiomaticidad, "mecanismo semántico universal de gran rentablilidad" (2007:185) y concluye que "la fijación no siempre implica idiomaticidad, pero sí inversamente, de modo que la presencia de idiomaticidad implica la fijación que a su vez implica la multi-lexematicidad" (2007:189). 
En este subcapítulo hemos presentado las propuestas teóricas que consideramos más relevantes a la hora de clasificar de manera coherente los elementos que configuran la fraseología. Desde los albores de la disciplina, numerosos lingüistas han tratado de abarcar y estructurar las UF. Algunos reinterpretan, reformulan o revisan propuestas anteriores. Trabajos loables de la escuela soviética, del mundo anglosajón o del espacio hispano no se analizan a fondo en nuestro estudio, si bien se reflejan de manera indirecta, a través de citas, referencias o influencias las aportaciones de Aničkov (1964), Carneado Moré y Tristá Pérez (1985), Mel'čuk (1998), González Rey (2002), Álvarez de la Granja (2002), Granger y Paquot (2008), entre otros.

Como breve conclusión a este recorrido por las taxonomías, opinamos que a pesar de cierta ambigüedad en la nomenclatura (que afecta principalmente las obras lexicográficas de consulta), existe cada vez más coherencia en las clasificaciones, consenso que también se ve reflejado en los rasgos definitorios de las UF, como comprobaremos más adelante. 


\subsection{Características de las UF}

Los lingüistas se han referido a las UF con una multitud de términos (fraseologismo, modismo, expresión idiomática, frase hecha, etc.) y todavía hay debates y discrepancias en torno a la delimitación interna del concepto y del campo de estudio de la disciplina. No obstante, señalamos un relativo consenso en cuanto a las características que individualizan las UF, teniendo en cuenta aspectos formales, peculiaridades de significado y condicionantes de uso. García Rodríguez considera que "la diversidad de cualidades que se pueden hallar en los fraseologismos no hacen más que enriquecer el universo fraseológico" (2019:48), mientras que otros especialistas optan por aunar rasgos como la estabilidad, la traductibilidad reducida o la no composicionalidad semántica bajo el paraguas de la "fraseologicidad".

Los criterios definitorios del concepto de UF, recogidos por numerosos lingüistas, desde Weinreich (1969), Rey (1976) o Coşeriu (1977), hasta Gross (1996), Mejri (2003), Gurrutxaga y Alegría (2013) son, sin duda, la fijación y la idiomaticidad.

La fijación se refiere a la propiedad que tienen las UF de ser reproducidas como combinaciones previamente elaboradas, al igual que "las estructuras prefabricadas, en la arquitectura" (Zuluaga 1975:230). Los hablantes las reproducen sin alterarlas ni descomponerlas en elementos constituyentes, hasta que acaban convirtiéndose en un bloque indisoluble, solidificado por el uso. Para García-Page

La fijación se entiende como el resultado de un proceso histórico-diacrónico, evolutivo, de la conversión paulatina de una construcción libre y variable en una construcción fija (estable), invariable, sólida, gracias a la insistente repetición literal; una forma analítica libre llega a adquirir, en un punto de la historia, un significado traslaticio o específico hasta concebirse como un todo, un estereotipo, una fórmula memorizable, estando así disponible para su empleo (para su repetición) cuando, en el proceso discursivo, quisiera expresarse un contenido que ya está condensado en ella. En este sentido, una locución es, ante todo, una combinación de palabras fija o estable (García-Page 2008:25).

Aunque hay investigadores (Donalies 2009) que rechazan el criterio de la repetición o reproducibilidad como una característica intrínseca de la fijación, coincidimos con Strohschen (2016:10) en que

para la didáctica, la repetición o reproducibilidad juega un papel importante por su influencia en el proceso de aprendizaje, ya que es parte imprescindible de la estrategia de memorización y sirve, por tanto, para consolidar el saber y la información adquirida. El hecho de que las UF se repitan y reproduzcan una y otra vez con las mismas estructuras morfosintácticas y léxicas tiene como resultado su almacenamiento en nuestro lexicón mental como un todo, es decir, como un monolexema junto 
con su significado. Esta lexicalización de la forma fija junto con su significado en nuestra memoria lingüística se considera como la 'fijación psicolingüística', la cual posibilita el acceso directo y el reconocimiento de una UF, sin tener que descomponerla en sus lexemas.

Hemos recopilado distintos tipos de fijación. Según los rasgos que presente la estabilidad, hablamos de fijación interna, centrada en los aspectos formales de las UF, y de fijación externa, ubicada en el nivel pragmático. La fijación interna se subdivide, a su vez, en fijación material (a nivel sintáctico) y fijación de contenido (a nivel semántico). Mientras tanto, dentro de la fijación externa se han distinguido una fijación situacional (relacionada con el uso de las UF en una situación determinada), una fijación analítica (relacionada con el uso de una UF en detrimento de otra), una situación pasémica (centrada en el papel que posee un hablante en un determinado acto comunicativo) y una fijación posicional (que hace referencia al lugar que ocupan ciertas unidades).

Quizás resulte un tanto complicado navegar por esta amplia variedad de términos y tipologías. Nosotros tomamos como referencia el amplio estudio que Zuluaga (1975) dedica a este rasgo y que representa un punto de partida para otros trabajos de esta índole en la fraseología española. Zuluaga (1975) señala que la fijación "fraseológica" puede manifestarse de distintas maneras, entre las que enumera: a) la insustituibilidad de los elementos componentes; b) la inalterabilidad del orden de los componentes: c) la invariabilidad de alguna categoría gramatical (género, número, tiempo verbal, etc.); d) la inmodificabilidad del inventario de los componentes o la cohesión absoluta entre los componentes.

Ruiz Gurillo (1998) parte de este modelo y detalla el esquema, dando un paso más respecto a la propuesta de Zuluaga (1975): en el nivel sintáctico sitúa la fijación entendida exclusivamente como complejidad y estabilidad de forma y la fijación entendida adicionalmente como defectividad combinatoria y sintáctica. Esta última se divide en: a) los componentes léxicos invariables (que incluye la invariabilidad de determinante y de persona); b) los componentes léxicos no conmutables; c) los componentes léxicos no permutables; d) la imposibilidad de extracción de los componentes de una UF; e) los componentes léxicos no separables: y f) la fijación transformativa.

Corpas Pastor (1996:23) opta por utilizar el término "estabilidad" en vez de fijación, ya que el término "sirve para abarcar tanto los fenómenos de institucionalización como los de lexicalización" y propone varias operaciones lingüísticas para concluir si nos encontramos ante una UF: permutaciones, inserciones, sustituciones o cambios gramaticales y sintácticos.

Según Pamies (2007), la fijación se define desde una triple perspectiva: la restricción formal de los ejes sintagmático y paradigmático (restricciones morfosintácticas, imposibilidad de inserción de complementos, etc.), la mayor estadística de ocurrencia y la alteración valencial. Desde estos ángulos, hace un alegato a favor de las palabras compuestas (compuestos gráficamente separados o no) que son intrínsecamente fijas, al 
compartir este rasgo en sus tres vertientes: "la palabra compuesta (...) incluso es más fija que las UF, que al fin y al cabo conservan una variabilidad relativa y pueden ser manipuladas y desautomatizadas. Las palabras compuestas, en cambio, son a menudo invariables, incluso cuando su categoría sintáctica permite teóricamente la flexión de género y número (Pamies 2007:175).

Resumiendo los apartados anteriores, hemos presentado brevemente el primer rasgo que vertebra a las UF, característica definitoria que encontramos presente bajo distintos nombres (frozeness, figement, Starrheit) en todos los estudios fundamentales de fraseología. Mellado subraya que

La estabilidad, fijación o petrificación es uno de los rasgos formales definitorios más concluyentes en Fraseología. Ciertamente, los FR son cadenas predeterminadas que el hablante aprende y utiliza en bloque y que su fijación ha sido tradicionalmente concebida como el resultado directo de uso repetido dentro de una determinada comunidad lingüística (Mellado 2004:153).

No obstante, hay autores como García-Page (2008) que señalan que este rasgo, aunque importante, no es netamente distintivo de las UF y destacan su fragilidad o escasa estabilidad. A pesar de ello, consideramos la fijación como un elemento clave y el primer paso en el así llamado proceso de "fraseologización".

La otra característica relevante relacionada con la estructura interna de la UF es la idiomaticidad, definida como "aquella propiedad semántica que presentan ciertas UF, por la cual el significado global de dicha unidad no es deducible del significado aislado de cada uno de sus elementos constituyentes" (Corpas Pastor 1996:26). En una UF idiomática sus componentes pierden total o parcialmente su identidad semántico-funcional y pasan a formar una identidad de sentido. No obstante, aunque la idiomaticidad siempre se ha tratado como uno de los rasgos esenciales de las UF, el concepto tampoco está exento de controversia, ya que, al igual que en el caso de fijación, se detectan distintos grados de idiomaticidad: "(...) ni todos los componentes llegan a "perder" su identidad, ni a veces lo hace ninguno de ellos, de ahí que se plantee el problema de cómo se manifiesta realmente este rasgo» (González Rey 1998:61). Por lo tanto, no todos los elementos constituyentes de una UF tienen que convertir su significado literal en idiomático e, incluso, existen UF que no presentan el rasgo de la idiomaticidad (véase el caso de las colocaciones); basta que uno de los componentes de una UF funcione de forma idiomática para que el significado global sea idiomático. En este sentido, se subraya la importancia de los elementos únicos o "palabras diacríticas" (Zuluaga 1980), cuya presencia en una UF es señal de idiomaticidad. Estas palabras solo tienen significado dentro de las unidades fraseológicas y carecen de autonomía semántica ("mondo y lirondo", "en un plis plas", "de lo lindo y de lo galindo", "toma y daca", etc.). 
La idiomaticidad de las UF está estrechamente vinculada al concepto de motivación del signo, que se refiere a la relación entre el significado literal y el significado global de una unidad. Dicha relación puede resultar evidente (en este caso estamos ante UF motivadas en mayor o menor grado) o no tan manifiesta (la motivación se remonta a una especie de justificación histórica o explicación etimológica). En este sentido, Zuluaga (1980:127) señala la arbitrariedad de las expresiones idiomáticas, teoría que "se refiere a su constitución y funcionamiento, y que quiere decir que su motivación no es natural, sino histórica y finalística".

En lo que concierne al objetivo de este estudio, las locuciones verbales somáticas, coincidimos con Strohschen, cuando afirma que

\begin{abstract}
Un ejemplo muy claro de motivación son los casos de kinegramas o somatismos, los primeros reflejando un gesto humano con un simbolismo interno, culturalmente condicionado, y los segundos de un elemento léxico perteneciente al cuerpo humano. Muchos somatismos son ejemplos prototípicos de la motivación, la cual indica en qué medida el significado de una expresión puede ser entendida desde el significado libre de sus componentes. Es, por consiguiente, la motivación como parte de la idiomaticidad, la que condiciona directamente la transparencia o la opacidad de la UF (Strohschen 2016:17-18).
\end{abstract}

Según el grado de opacidad semántica que presenten las UF, pueden diferenciarse tres tipos de idiomaticidad: UF idiomáticas, UF semiidiomáticas y UF no idiomáticas o transparentes. El primer apartado incluye las UF cuyo significado global no se puede deducir a partir de la suma de significados de sus componentes. Son las que se consideran los "prototipos" de las UF en un sentido estricto y las más difíciles de comprender por un estudiante de LE, que carece de conocimiento lingüístico y contexto cultural para comprenderlas. Las UF que constituyen la segunda categoría contienen un componente que mantiene el significado que tendría en una combinación libre de palabras, lo que facilita la comprensión del significado global de la UF, no del todo opaco. En cuanto a las UF no idiomáticas o transparentes, tal como se desprende de su denominación, favorecen la comprensión debido a su transparencia.

Olza (2009) subraya la idea de que "lo idiomático" representa un fiel reflejo de la cultura de una sociedad, de una manera propia de concebir la realidad. En este sentido, las UF más opacas serán las que presenten una mayor carga de motivación cultural.

(...) resultan más opacas para el hablante actual, y más aún, para un hablante no nativo, cuya lengua materna poseerá, a su vez, otros "idiomatismos" característicos. A pesar de ello (...), no se debe rechazar la posibilidad real en muchos de los casos, a una comprensión cabal de los mecanismos semánticos que intervinieron en la creación de la esta clase de unidades, pues incluso aquellas cuya motivación parece más difícil de rastrear hoy en día, tendrán de seguro base en alguna experiencia humana 
o en algún esquema de conocimiento que permita acceder de algún modo a su significado (Olza 2009:36-37).

La idiomaticidad sigue siendo objeto de numerosas investigaciones, desde distintos enfoques. Para Pamies (2007) representa un rasgo esencial de las UF, entendido como no-composicionalidad semántica y reitera la idiomaticidad de los elementos compuestos:

Ni la llave inglesa es "inglesa", ni la estrella de mar es una "estrella", por no
hablar de pez luna, pájaro del sol, galán de noche, matasuegras,
madreselva o matagallegos. El significado global de estos compuestos
tampoco se deduce del de sus componentes y, aunque solo una parte de
los compuestos sean idiomáticos, lo mismo ocurre con las UF, para las que
la idiomaticidad tampoco es una condición indispensable (Pamies
$2007: 175)$.

Prodromou (2008) destaca la creatividad favorecida por la idiomaticidad (creative idiomaticity) y la ingeniosa manipulación de las UF que genera sutiles variaciones, con fines pragmáticos. Los mecanismos a los que recurren los hablantes abarcan desde el uso de las figuras retóricas (metáfora, hipérbole, repetición, etc.) o el cambio de registro, la creación de fórmulas híbridas hasta la co-construcción del discurso.

\begin{abstract}
While it is true that much of phraseology is routine and repetitive $(\ldots)$, there are significant areas of phraseology that are constantly reformed in original ways in everyday discourse. Conversational creativity extends beyond the ability to manipulate idiomatic language in inventive ways: creativity is an inherent quality in everyday speech, not the preserve of linguistically gifted individuals (Prodromou 2008:225).
\end{abstract}

Asimismo, Mejri (2004), Wray (2005) y Peguret (2009) subrayan el carácter dinámico de la idiomaticidad; la producción lingüística necesita de una interacción continua entre los conjuntos prefabricados de la lengua (especialmente entre las combinaciones semilibres) y la novedad, con el propósito de enfrentar los requisitos formales y funcionales de las situaciones de comunicación. Todas estas aportaciones son especialmente útiles en la didáctica de la fraseología porque indagan en aspectos de psicolingüística y de adquisición de una LE: "idiomaticity is not like a coat of paint that can be applied to all learners uniformly for a uniform effect. Idiomaticity is not the top layer, but rather is intrinsically tied into the bottom layers" (Wray, A. y Fitzpatrick, T. 2006:55).

Además de estos rasgos esenciales, mencionamos la multilexicalidad, conocida también como plurilexicalidad o pluriverbalidad. Muchos lingüistas le han otorgado a esta característica una especial importancia. Para Corpas Pastor (1996) es una condición sine qua non, que ni siquiera necesitaría explicarse, por ser tan obvia, mientras que Montoro del Arco (2005) la ve como una característica fundamental de las UF. No obstante, otros 
no consideran esta "perogrullada" (Pamies 2007) un criterio tan evidente. Pamies señala los límites de este rasgo, critica la definición que propone Corpas Pastor (1996:20) para las UF: "(...) unidades léxicas formadas por dos o más palabras en su límite inferior" y se lamenta de la ineficacia del concepto de "palabra", que no dispone de una definición operativa en la lingüística moderna.

De ser así, tela de araña sería una UF, frente a telaraña, que sería una palabra, artificial distinción que favorece la grafía en detrimento tanto de la semántica como de la sintaxis. Aunque la separación gráfica es una herramienta rentable para la praxis lexicográfica, es insostenible como criterio teórico, en la medida en que añade la dependencia de la convencionalidad de la escritura a las incertidumbres del propio concepto de palabra. Además, elige a menudo caprichosamente entre la grafía unimembre, plurimembre y el guion intercalado, habiendo incluso varias grafías admitidas por la Academia para una misma secuencia (Pamies 2007:176).

No obstante, aunque cuestionado y tal vez limitado, este rasgo tiene su utilidad, sobre todo en el proceso de aprendizaje de las UF en una clase de LE, puesto que los aprendices podrán identificar, comprender y memorizar mejor estos elementos.

Las características secundarias, que complementan los rasgos principales 0 directamente derivan de ellos, abarcan numerosas facetas de las UF. No obstante, señalamos cierta imprecisión en cuanto a su delimitación y, sobre todo, un amplio abanico terminológico.

La institucionalización de las expresiones idiomáticas, también conocida como "reproducción" (Larreta Zuluategui 2001), "reproductibilidad" (Zuluaga 1980) o "reproducibilidad" (Pamies 2007), sugiere que las UF no se construyen en el habla, sino que se memorizan como si fueran palabras, criterio que las diferencia de los sintagmas libres. Corpas Pastor (1996) relaciona este con la frecuencia de aparición, el uso y la repetición. La institucionalización representa, en el fondo, el reconocimiento por parte de una comunidad lingüística concreta de una UF, asentada por la repetición y por el uso constante, durante un proceso temporal.

La desautomatización es un mecanismo que devuelve a los componentes de una UF "cierta transformabilidad sintáctica y autonomía semántica" (Pamies 2007:178), potencia la creatividad del hablante y mejora la eficacia en la comunicación, con fines lúdicos, aclarativos, aclaratorios, etc.

Una unidad fraseológica (UF) es una criatura lingüística muy curiosa. Nace con el fin de denominar algo para lo que los lexemas simples no son suficientes, pero en su comportamiento discursivo busca asemejarse a esos lexemas. Con el tiempo fija su significado complejo que pasa a formar parte del patrimonio lingüístico de una comunidad de hablantes. Sin embargo, ese significado supuestamente fosilizado de pronto se convierte en la materia prima para nuevas creaciones lingüísticas (Timofeeva 2009:249). 
Mena (2003) señala que cualquier modificación de una UF no genera una desautomatización inmediata y propone una serie de requisitos para que la modificación sea considerada desautomatización: la modificación debe presentar un cambio ocasional, voluntario e intencionado del hablante; la modificación debe desviarse lo suficiente de la forma originaria para que el cambio sea percibido; la unidad originaria debe ser reconocible y recuperable con ayuda de los elementos conservados e inalterados, o mediante el contexto. Mientras tanto, Timofeeva (2009) indaga en los mecanismos transgresores e identifica una desautomatización formal, una desautomatización semántica y una desautomatización discursiva.

Desde la perspectiva didáctica, la desautomatización constituye un rasgo muy valioso, una herramienta efectiva en el aula de LE y un recurso para motivar, crear y divertir. En actividades significativas y, sobre todo, colaborativas, los aprendices disfrutan descomponiendo el lenguaje idiomático para combinar, sustituir, omitir y añadir elementos nuevos ("ama de cama", "Sangría Familia", "máquina tragapelas", etc.).

Desde el punto de vista de la didáctica de las UF, la traductibilidad reducida 0 intraductibilidad, rasgo vinculado a la idiomaticidad, nos interesa de manera especial. Castillo Carballo (1997) opina que las dificultades de traducción se pueden explicar por la motivación histórica o concreta de la fijación de las UF. A un aprendiz de LE le resultará muy difícil comprender su sentido, memorizarlas y reproducirlas adecuadamente debido a la opacidad del significado.

Otros rasgos secundarios que hemos recopilado son la expresividad o valoración subjetiva, que alude al carácter emocional (positivo o negativo) de las UF, la variación o variabilidad fraseológica (relacionada con la libertad que tiene el hablante de elegir y modificar una determinada combinación de elementos finitos en una situación comunicativa dada) o la presencia de componentes únicos o palabras diacríticas.

Consideramos que en muchos casos se trata de rasgos que se solapan o que se desprenden de las principales características comúnmente aceptadas de las UF, la fijación y la idiomaticidad.

En este apartado hemos querido reunir las propiedades principales (incuestionables, intrínsecas o sumamente obvias) de las UF y otras secundarias (que complementan las primeras y se encuentran en distintas escalas de gradación). No obstante, cabe destacar ante todo la interdependencia de los rasgos de las UF, puesto que todo este conjunto determina la fraseologización, proceso por medio del cual se constituye una UF. 


\subsection{El universo fraseológico en rumano}

Las primeras preocupaciones fraseológicas en la lingüística rumana se remontan a principios del siglo XIX, gracias a autores como Golescu y Pann, que dejaron una rica colección paremiológica. Siguiendo esa misma senda, Zanne (1895) amplía sus investigaciones hacia los estudios folklóricos y publica una obra monumental de "proverbe, zicători, povăţuiri, asemănări, idiotisme" (proverbios, refranes, dichos, moralejas, idiotismos) recogidos de todas las comarcas habitadas por rumanos.

La fraseología rumana moderna surge como una subdisciplina lingüística, a caballo entre la lexicología y la sintaxis, rozando aspectos de estilística funcional; no obstante, hay que esperar hasta 1980 para que "este fenómeno lingüístico que ha experimentado una rápida evolución" sea considerado una "disciplina autónoma” (Dumistrăcel 1980:132).

Los primeros intentos de crear un marco teórico sólido se los debemos a Hristea (1980), que proporciona dos definiciones distintas de la fraseología: "disciplina lingüística cuyo objeto de investigación lo constituyen las unidades fraseológicas de una lengua determinada o de un grupo de lenguas (1984:138)" y "conjunto o totalidad de unidades fraseológicas de una determinada lengua" (1984:138).

Hristea reitera la legitimidad de "una disciplina lingüística independiente" (1984:140) que analiza las UF, compartimento diferente al léxico y, sobre todo, a la sintaxis. Distingue entre la combinación de palabras que los hablantes crean con total libertad y la combinación fraseológica, que cuenta con una existencia previa en la lengua y es consagrada por el uso. Asimismo, establece una delimitación clara entre UF, "combinaciones estables de palabras dentro de las cuales los elementos constitutivos guardan independencia semántica", y expresiones idiomáticas (o idiotismos), cuyos elementos componentes están tan estrechamente vinculados que ya no se pueden separar. "El significado de tales expresiones no se puede deducir a partir de la suma de los partes componentes; por eso su traducción ad litteram a otras lenguas es, en la mayoría de los casos, imposible (1980:143)".

Descarta del campo de estudio de la fraseología las máximas, las sentencias, los refranes y los dichos, a los que agrupa bajo el paraguas de las "unidades frásticas" y trata de identificar las fuentes de la fraseología: las creaciones internas (derivación fraseológica y cristalización de sintagmas históricos y culturales), los préstamos de otras lenguas y los calcos fraseológicos.

Dumistrăcel (1980) sitúa la metáfora en el centro de sus estudios sobre fraseología, destacando su rol de soporte afectivo que se desgasta por el uso y se convierte, en

sincronía, en signo (arbitrario, no motivado). Las expresiones idiomáticas están presentadas junto con las metáforas porque comparten la misma función estilística, la expresividad. 
Clasifica las expresiones idiomáticas basándose en la relación entre la función comunicativa y la función expresiva, haciendo especial hincapié en la dicotomía de la función expresiva: el momento de génesis de una expresión y el momento de su utilización. Según el momento de aparición, se distinguen dos categorías de expresiones idiomáticas: las "imaginarias" y las que son "copias de la realidad". Las imaginarias tienen una función estilística no motivada y se caracterizan por el hecho de que buscan provocar un efecto uniendo elementos incompatibles o imaginando acciones imposibles. Mientras tanto, las expresiones copias de la realidad son imágenes de la experiencia común, fórmulas que parten de un hecho real y que inicialmente tuvieron una función objetiva de comunicación. A su vez, estas expresiones se dividen entre las que no llevan una marca precisa de la época en la que se engendraron y las expresiones marcadas temporalmente (grupo que suele incluir arcaísmos y neologismos).

Iordan (1975) recupera de Philippide (1894) dos términos importantes: "idiotismo", entendido como fórmula fija que se transmite por tradición y que se mantiene inalterada tanto a nivel formal como en el significado y "aislamiento", sintagma cuyo valor estilístico surge de la relación entre ciertos elementos lingüísticos. No obstante, para lordan, tanto las taxonomías como la delimitación y etiquetado de concepto carecen de interés. Considera que las clasificaciones son arbitrarias y que, en muchas ocasiones, se solapan. Utiliza indiscriminadamente términos como "locución", "expresión", "fórmula expresiva", "refrán", "proverbio", etc., sin delimitar estrictamente estas nociones, puesto que todas se encuentran en un mismo plano y sirven para satisfacer la misma necesidad, la expresividad: "dau vorbirii populare şi familiare plasticitate, culoare, viată, aşa cum figurile de stil însufleţesc limbajul poetic (1975:267)", esto es "otorgan al habla popular y familiar expresividad, color, vida, al igual que las figuras de estilo animan el lenguaje poético".

A diferencia de lordan, Dimitrescu (1958) opta por delimitar claramente entre "locuciones" y "expresiones". Para ella, la locución es "un ansamblu de cuvinte mai mult sau mai puţin sudat, cu un înţeles unitar determinat, care se comportă din punct de vedere gramatical ca o singură parte de vorbire" (1958:32), esto es "conjunto de palabras más o menos fijo, con un significado unitario determinado, que se comporta desde el punto de vista gramatical como un único lexema". Mientras tanto, las expresiones representan "îmbinări de cuvinte încărcate cu conținut afectiv, proprii unei anumite limbi", es decir,"la unión de palabras cargadas de contenido afectivo, propias de una determinada lengua". Los rasgos comunes entre las locuciones y las expresiones derivan del hecho de que ambas representan conjuntos fraseológicos con un sentido general relativamente independiente del significado individual de los elementos constituyentes considerados por separado y que son intraducibles. La mayor diferencia consiste en la posibilidad que tienen las expresiones de ser "disociadas gramaticalmente", ya que representan exclusivamente "hechos de léxico", mientras que las locuciones son también "hechos de gramática" (1958:67). Según su teoría, las expresiones se caracterizan por variabilidad, 
expresividad y novedad en cuanto a la unión de palabras, mientras que las locuciones son "agrupamientos de palabras de carácter permanente, dotados de función gramatical unitaria (1958:84)". La categoría de las expresiones abarca refranes, aforismos, citas famosas, prácticamente todas las estructuras dotadas de expresividad.

Dimitrescu presenta también un modelo de organización de las UF por categoría, prefigurando el modelo centro-periferia de Fleischer (1997): las estructuras aparecen representadas bajo forma de esferas concéntricas, que reúnen a) centro (categoría I): estructuras totalmente gramaticalizadas o definitivamente fijadas; b) nivel intermedio (categoría II): estructuras que han perdido expresividad, pero han ganado desde el punto de vista gramatical; c) estructuras muy expresivas, con función gramatical unitaria, pero que no están completamente gramaticalizadas.

Colţun (2000) distingue entre locuciones y "fraseologismos", siguiendo varios criterios: a) semántico: las locuciones están formadas por elementos con sentido individual denotativo y se caracterizan por composicionalidad semántica, mientras que los fraseologismos están constituidos por elementos con sentido individual figurado, pero con un alto grado de solidez semántica; b) estructural: las locuciones son intercambiables por lexemas simples, mientras que los fraseologismos son equivalentes a otras UF o a una combinación libre de palabras; c) morfológico: las locuciones tienen el mismo valor que la palabra que sustituyen, mientras que el valor gramatical de los fraseologismos depende de la palabra dominante (nocional) de su estructura; d) sintáctico: ambas categorías cumplen la función sintáctica de las construcciones que sustituyen pero, a diferencia de las UF, las locuciones que tienen un menor grado de fijación se pueden descomponer y analizar por separado; e) formal: como resultado de su uso intensivo, las locuciones SE pueden fusionar, creando palabras compuestas.

Resumiendo estas distinciones, Colţun define las locuciones como "grupos de mayor o menor fijación, constituidos por al menos dos lexemas, de los cuales uno es nocional, mientras que los demás no lo son" (2000:25), a diferencia de los fraseologismos, que contienen dos palabras nocionales.

Para la clasificación de los fraseologismos, Colţun aplica dos criterios. Según el grado de idiomaticidad, hay UF con fusión semántica total y UF con fusión semántica parcial; según la estructura gramatical, hay UF similares a la unión de palabras, UF equiparables a una oración y UF que siguen el modelo de construcción de la frase.

Más recientemente, Groza (2011) se dedica al estudio de la fraseología, disciplina que clasifica en "teórica" o "general" (si analiza las combinaciones de palabras de una lengua o de grupo de lenguas) y "especial" (si estudia únicamente un segmento fraseológico determinado de una lengua: las colocaciones, las unidades terminológicas, etc.). Asimismo, distingue entre la fraseología diacrónica (cuando se sigue la evolución histórica, bajo aspectos formal y semántico, de las uniones de palabras existentes en 
una lengua) y fraseología sincrónica (cuyo objetivo es la descripción del campo fraseológico desde la perspectiva de la evolución histórica, aunque fuese de manera parcial). Además, menciona un aspecto importante para este estudio, el de la fraseología contrastiva (que se encarga de comparar la fraseología de diferentes lenguas) y señala que la aplicación de las teorías estructurales determinó la aparición de la fraseología "generativo-transformacional (2011:20)".

Resulta un tanto complicado navegar a través de las distintas taxonomías y la heterogeneidad de los criterios manejados, al tratarse de una disciplina relativamente joven, de un campo de investigación amplio y dinámico. Como hemos comprobado, son varias las opiniones expresadas en torno a los criterios de definición y clasificación de las UF y su delimitación en relación con otras unidades: palabra, palabra compuesta, sintagma, refrán.

Una mera revisión terminológica de lo que relevantes lingüistas rumanos entienden por "fraseologismo" da fe de ello: "asociación metafórica", "elemento metafórico", "expresión metafórica" (Şăineanu 1887), "idiotismo" (Philippide 1894), "expresión perifrástica" (Puşcariu 1940), "conjunto fraseológico" (Dimitrescu 1958), "asociación de palabras indivisibles" (Dragomirescu 1995), "expresión figurada" (Slave 1966), "grupo sintáctico estable" (Asan 1967, Ciobanu 1967), "expresión idiomática” (Andriescu 1977), "asociación de palabras fijadas" (Dumistrăcel 1980), "asociación estable" (Dimitriu 1984), "idiom" (Avădanei 2000), etc.

Como ya hemos comprobado, lordan utiliza indiscriminadamente varios términos, quizás en un intento involuntario de relativizar la preocupación por la denominación y centrar el foco en el trabajo práctico.

Podríamos concluir que en Rumanía el interés por la fraseología se ha manifestado principalmente en la elaboración de diccionarios fraseológicos (sobre todo de corte paremiológico), tradicción que sigue vigente y que inspira la aprición de nuevos trabajos: Dicţionar de expresii, locuţiuni şi sintagme ale limbii române (DELS) de Mărănduc (2010), Marele dicţionar de expresii româneşti (2012) de Bucă, Dicţionar de expresii româneşti in contexte (DERC) de llincan (2015). Observamos también que recientemente llegan propuestas desde el mundo de la didáctica, como Dicţionar de comunicare, morfologie, corectitudine, expresii generative de Pereş (2011) o Dicţionar de expresii şi locuţiuni străine de Papuc (2015).

Asimismo, contamos con varios estudios teóricos que tratan el estatus de la disciplina, delimitan su objeto de estudio, proponen diferentes taxonomías, analizan aspectos traductológicos o contrastivos interlinguales: Zafiu (2000), Şodolescu-Silvestru (2002), Căpăţână (2007), Sasu (2011). 


\subsection{Modelos de análisis contrastivo}

Llegados a este punto en nuestro recorrido por el concepto de la UF, sus definiciones, rasgos y taxonomías y tras haber escaneado el panorama de las preocupaciones (antiguas y actuales) por la fraseología rumana, consideramos que es el momento idóneo para ampliar el marco teórico hacia un horizonte relevante en este estudio. Tal como el mismo título de esta tesis indica y como ya hemos mencionado entre los objetivos principales de este trabajo, llevaremos a cabo un análisis contrastivo. Necesitaremos por lo tanto herramientas téoricas que nos sitúen mejor en este campo lingüístico y que sirvan como elemento de enlace entre este marco general y el estudio práctico que emprenderemos.

La lingüística contrastiva surge en los años cuarenta del siglo XX como rama de la lingüística aplicada y, según Jackson,

is a branch of linguistics which seeks to compare (the sounds, grammars and vocabularies of) two languages with the aim of describing the similarities and differences between them. Such a description may be carried out for its own sake, or its purpose may be to contribute to task of foreign-language teaching (Jackson 1981:195).

Su definición tiene especial relevancia para nuestro trabajo, puesto que abarca tanto la vertiente teórica (la comparación entre los sistemas lingüísticos de dos lenguas) como las aplicaciones prácticas en el campo de la metodología de una LE, destacando una clara finalidad didáctica.

La lingüística contrastiva cuenta con tres modelos distintos de análisis: el Análisis contrastivo, el Análisis de errores y la Interlengua, diferenciados entre sí por los principios metodológicos en los que se basa cada uno, por el corpus que utilizan, por los resultados obtenidos y, por consiguiente, por las implicaciones pedagógicas.

\subsubsection{El Análisis contrastivo}

El Análisis contrastivo nace como fruto de una constante preocupación didáctica por los errores en el proceso de aprendizaje de una lengua extranjera y por el intento de evitarlos. Ancla sus raíces teóricas en el estructuralismo norteamericano (como teoría lingüística) y en la psicología conductista (como teoría del aprendizaje), considerando que el comportamiento humano se reduce a un proceso mecánico de estímulo y respuesta y, por lo tanto, la adquisición de una LE equivaldría al aprendizaje de un conjunto de hábitos lingüísticos. Sostiene que una comparación sistemática de dos lenguas en todos los niveles lingüísticos generaría predicciones sobre las áreas de dificultad de aprendizaje de la lengua meta, ya que de los resultados se podrían extraer consecuencias metodológicas dirigidas a facilitar el proceso de aprendizaje en el alumno. 
En la versión débil del análisis contrastivo surge el concepto de "distancia interlingüística”, que sugiere que aquellos elementos de la LE equivalentes o análogos a los de la lengua materna serán más fáciles de confrontar y asimilar, mientras que aquellos diferentes serán más difíciles. Por consiguiente, a mayor diferencia estructural entre las lenguas, mayores las potenciales áreas de interferencia y dificultad en el aprendizaje. Resulta relevante el concepto de "interferencia", entendido como "fenómeno que se produce cuando un individuo utiliza en una lengua meta un rasgo fonético, léxico, morfológico o sintáctico característico de su lengua nativa" (Santos Gargallo 1993:17).

Puede ocurrir que la similitud entre los sistemas facilite la adquisición de la L2 (transferencia positiva) o que la diferencia constituya las áreas de dificultad y los posibles errores (transferencia negativa o interferencia), puesto que los estudiantes, en su mayoría, construyen hipótesis sobre la lengua que están aprendiendo, tienden a transferir las estructuras y el vocabulario de su lengua materna.

Los aprendices que se enfrentan a una LE descubren que

those elements that are similar to the native language will be simple (...) and those elements that are different will be difficult. The teacher who has made a comparison of the foreing language with the native language of the students will know better what the real learning problems are and can better provide for teaching them (Lado 1957:2).

El Análisis contrastivo se sirve de los principios de la teoría psicológica conductista. Skinner (1957) postula que todo comportamiento verbal se explica en términos de estímulo, respuesta, refuerzo y hábito. La adquisición de la lengua materna se desarrolla a través de la imitación de las producciones de los adultos y a través del refuerzo de las respuestas positivas o negativas, creándose así los hábitos lingüísticos. El mismo proceso se da en el aprendizaje de la L2, donde las diferencias existentes entre los hábitos de la L1 y la L2 generarán interferencia. Solo persistirán aquellas producciones o estructuras que la comunidad de usuarios de la lengua acepte y recompense (refuerce). Se concibe la mente de los humanos como una tabula rasa en la que se van estampando las asociaciones entre varios estímulos del ambiente y las respuestas elegidas desde fuera del organismo, mediante el reforzamiento.

La versión fuerte del Análisis contrastivo, creada por Wardhaugh (1970), estriba en que el sistema de la lengua nativa y el sistema de la lengua segunda son comparables tanto en la fonología como en la sintaxis. De acuerdo con dicha comparación, es posible predecir las dificultades con las que se encontrarán los estudiantes de una LE, por lo que habría que diseñar material pedagógico que les ayude en el proceso de adquisición de la L2, con especial énfasis en dichas dificultades. 
El mismo Wardhaugh evaluaría esta versión fuerte del Análisis contrastivo y llegaría a la conclusión de que la teoría lingüística y los lingüistas no tienen disponible un conjunto de universales lingüísticos formulados en una teoría global capaz de tratar de modo adecuado tanto la sintaxis como la semántica y la fonología. Por esta razón, muchos lingüistas optaron por la débil, que exigía únicamente la realización de un análisis a posteriori de los errores cometidos, junto con unas sugerencias acerca del modo en que pudieran explicarse.

La meta del Análisis contrastivo de dos sistemas es construir una nueva gramática contrastiva. De esta forma, se podrá establecer una jerarquía de correspondencia en los distintos niveles de análisis lingüístico, para graduar las dificultades en el aprendizaje y las posibilidades de interferencia. La comparación ha de realizarse en todos los niveles del sistema: fonológico, gramatical, léxico y pragmático, siguiendo un procedimiento establecido: descripción estructural de L1 y L2, cotejo de las descripciones, elaboración de un listado preliminar de estructuras no equivalentes, reagrupación de las mismas estableciendo una jerarquía de dificultad, predicción y descripción de las dificultades y preparación de los materiales didácticos. La propuesta permitirá, finalmente, evaluar los contenidos de los libros de texto empleados en la instrucción, preparar nuevos materiales, reemplazar los materiales inadecuados y diagnosticar las dificultades.

Sin embargo, el Análisis contrastivo resultó insuficiente, al constatarse que no todos los errores procedían de la interferencia con la lengua nativa, sino que había muchos otros factores, como las propias estrategias de los aprendices, la deficiencia de la enseñanza o la interferencia intralingüística. Además, hace descripciones normativas considerando que la posición del aprendiente con respecto a la lengua meta es estable e ignora el componente pragmático y el psicológico.

A pesar de estas críticas, el Análisis contrastivo sirvió para iniciar una tendencia investigadora centrada en el aprendiz y en su proceso de aprendizaje. Además, abrió el debate en torno a materiales y metodologías, con vistas a una mejora de la práctica docente. 


\subsubsection{El Análisis de errores}

Una vez superado el modelo del AC debido a sus limitaciones, surge una metodología diferente, el Análisis de errores. La mayor diferencia reside en el concepto del error, que deja de ser un fenómeno negativo para convertirse en uno de sus elementos más necesarios, por ser muestra fiable de cómo se lleva a cabo el proceso de aprendizaje.

Desde esta perspectiva, Corder (1967:168) afirmaba que los errores no se describen solamente como consecuencia de la interferencia con la lengua materna, sino también como resultado de procesos mentales independientes "they are best not regarded as the persistence of old habits, but rather as signs that the learner is investigating the systems of the new language."

El alumno, por lo tanto, aplica estrategias de aprendizaje y los errores no representan una muestra de su fracaso, sino de las hipótesis que formula sobre la LM, siendo este proceso igual al de los niños que adquieren su lengua materna. Se trata de elementos que aportan información más precisa concerniente a la "competencia transitoria" del aprendiz, demuestran su progreso, sus estrategias, sus técnicas y tácticas involucradas.

El Análisis de errores se centra en las producciones reales del aprendiz, en lo que el alumno hace realmente, sin prestar ninguna atención a lo que hará, a diferencia del Análisis contrastivo, que procura predecir los errores potenciales. Esto lleva a replantear las teorías psicolingüísticas, puesto que el concepto facilidad-dificultad en el proceso de aprendizaje de una L2 no es exclusivamente lingüístico. Aparte de la causa única que induce a cometer errores, el Análisis de errores obtendría de esta manera una rica fuente para su explicación. En este sendido, Corder (1967) distingue entre "falta" (error de actuación) y "error" (error sistemático que afecta a la competencia del aprendiz y que es propiamente idiosincrásico).

Las faltas se deben a fallos de memoria, estados físicos concretos o condiciones psicológicas (nervios, agotamiento), en otras palabras, a las circunstancias accidentales, y de las cuales somos conscientes y capaces de corregir. No tienen demasiada relevancia en el proceso de aprendizaje de la lengua, por lo cual no son contabilizables. En el polo opuesto, los errores sistemáticos son aquellos de los que el aprendiz no es consciente y presentan ciertas idiosincrasias que los alejan de la norma lingüística. Por lo tanto, son signo de incompetencia en relación con la lengua que se aprende. Corder (1971) lo denomina "dialecto idiosincrásico", "dialecto transitorio", "sistema de compromiso" o, con un término sugerido por Nemser (1971), "sistema aproximativo".

En la distinción propuesta por Corder se evalúa también la gravedad del error y, con un propósito pedagógico, se busca la posible terapia de intervención sobre él. El hecho innovador de considerar los errores como parte del proceso de adquisición es clave 
en el proceso de la adquisición-aprendizaje de la lengua, ya que conduce a la pérdida del miedo frente al error.

Uno de los objetivos fundamentales del Análisis de errores fue establecer un inventario de los errores más frecuentes, con el objetivo de señalar las áreas de dificultad en el aprendizaje de una segunda lengua para un determinado grupo de estudiantes con idéntica lengua nativa.

Dependiendo del objetivo del análisis, se determinan e implantan tipologías y clasificaciones. Los criterios manejados pueden ser lingüísticos, pedagógicos, etiológicos, gramaticales y comunicativos.

Teniendo en cuenta el criterio lingüístico o descriptivo, los errores se clasifican según la forma en que se ve alterada la estructura superficial de las instancias. De esta manera, habrá errores de omisión (ausencia de vocablos, morfemas o fonemas), errores de adición (presencia injustificada de vocablos, morfemas o fonemas), doble marca (redundancia incorrecta), hipergeneralización de la regla (falsas analogías), simples adiciones, formaciones erróneas, ausencia de orden u orden incorrecto.

Según el criterio pedagógico, encontraremos errores transitorios, causados generalmente por una falta de adecuación de las técnicas de enseñanza o en el orden de presentación de las estructuras, y errores sistemáticos que reflejan un mal conocimiento de las reglas que se manifiesta en un grupo de estudiantes.

El criterio etiológico se fundamenta en el concepto de transferencia lingüística, es decir en el impacto de un sistema de reglas sobre otro. Habrá, por lo tanto, errores interlingüísticos, causados por interferencia con la lengua materna del estudiante o con otras lenguas que conoce o está aprendiendo simultáneamente, y errores intralingüísticos, efecto que la lengua meta en sí misma tiene sobre el proceso de aprendizaje.

El criterio gramatical distingue las categorías afectadas por el error: fonética, ortografía, sintáctica, léxica, semántica, pragmática.

El criterio comunicativo clasifica los errores según el efecto que tiene desde la perspectiva del oyente, tratando de evaluar el grado en que impiden la transmisión del mensaje. Por consiguiente, habrá errores locales que afectan a elementos particulares o individuales de la oración, pero sin provocar la ruptura de la comunicación, y errores globales que, por su alto nivel de inaceptabilidad e impropiedad, causan una ruptura en la comunicación. Estos errores pueden abarcar desde conectores, conjunciones coordinadas y subordinadas o relativos hasta incoherencia temporal. Desde el punto de vista de la comunicación, los errores locales y globales pueden provocar efectos de ambigüedad (con respecto al mensaje), de irritación (con respecto al interlocutor) o de estigmatización (con respecto al emisor). 
A pesar de representar un adelanto frente al Análisis contrastivo, el Análisis de errores tiene también sus limitaciones, lo que provoca una serie de críticas: confusión entre explicación y descripción de los errores, falta de precisión en la descripción de las categorías, simplismo en la subcategorización de los errores o fragmentariedad de los resultados. Además, consideramos que el mayor fallo es limitar el enfoque únicamente en la actuación equivocada del aprendiz y no saber valorar también sus logros. 


\subsubsection{Interlengua}

En el aprendizaje de una LE, el alumno hace uso de un sistema lingüístico que no llega a identificarse ni con el de la lengua materna ni con el de la LM, puesto que tiene entidad propia. En la búsqueda de nuevas vías de análisis, Selinker (1972), apud. Santos Gargallo (1993:127), acuña para ese sistema el concepto de "interlengua", al que define como "sistema lingüístico autónomo sobre cuya existencia podemos hacer hipótesis en el output de un estudiante, al intentar producir la norma de la lengua meta".

La mayor aportación de este concepto es que la interlengua engloba no solo los errores, sino también estructuras correctas, gracias a las que se puede hacer una descripción de la evolución del aprendiz. En otras palabras, la interlengua es un sistema lingüístico internamente estructurado, recreado por cada aprendiz para enunciar en la lengua meta aquello que podría formular en su lengua materna. Para lograrlo, acude en ocasiones a las estrategias de transferencias o se plantea hipótesis (correctas o no) sobre la lengua meta. Estamos ante un sistema evolutivo, continuo y dinámico, entre la lengua materna y la lengua meta, con rasgos prestados de ambas, muestra de la competencia comunicativa transitoria del aprendiz. La complejidad se va incrementando en un proceso creativo que atraviesa sucesivas etapas marcadas por las nuevas estructuras y vocabulario que el alumno adquiere.

Selinker (1972) propone una serie de principios teóricos a partir de los cuales se pueda determinar qué datos son importantes para elaborar una teoría psicolingüística del aprendizaje de LE. En este sentido, sigue las ideas de Lenneberg $(1967)^{3}$ y de Chomsky (1957), que sostienen la existencia en la mente de una estructura latente del lenguaje que posibilita la adquisición de la lengua materna, una ordenación ya formulada en el cerebro, base biológica de la gramática universal.

En el proceso de adquisición de su lengua materna el niño transforma esa estructura latente en una estructura concreta de una lengua particular, a través de una serie de etapas de maduración. Junto a ella, Selinker propone la existencia de una estructura psicológica latente que se activa cuando el adulto trata de comprender y producir oraciones en una L2.

Selinker sugiere que hay cinco procesos principales que se sitúan en esa estructura psicológica latente para el aprendizaje de una LE: la transferencia lingüística, la transferencia de instrucción, las estrategias de aprendizaje de la L2, las estrategias de comunicación en la L2 y la hipergeneralización del material lingüístico de la lengua meta.

\footnotetext{
${ }^{3}$ Lenneberg (1967) propone la existencia de una dotación biológica especificada para el lenguaje, que hace posible la adquisición del lenguaje en los niños, pero se anula o deja de funcionar en el periodo crítico de la pubertad. Con esta propuesta, el aprendizaje de las lenguas extranjeras por parte de adultos sería un proceso cognitivo diferente al de los niños.
} 
La transferencia lingüística es un fenómeno que suscribe todos aquellos vocablos, reglas y subsistemas fosilizables que tienen lugar en la interlengua, como resultado de la influencia de la lengua nativa. Hay dos tipos de transferencia: transferencia positiva (cuando uno o varios elementos de la lengua materna o tercera lengua aprendida anteriormente interfieren en el proceso de aprendizaje haciéndolo más fácil) y transferencia negativa (cuando el uso de un vocablo o estructura de la lengua materna 0 de una L2 lleva al estudiante a incurrir en un error).

La transferencia de instrucción subscribe todos aquellos subsistemas fosilizables que pueden ser identificados como resultado de los procedimientos de práctica de las nuevas estructuras y se debe a las confusiones producidas por la utilización de metodologías o materiales incorrectos.

Las estrategias de aprendizaje subscriben aquellas reglas, vocablos y subsistemas fosilizables que son resultado de la complejidad del propio corpus lingüístico que va a ser aprendido por el estudiante. Es la tendencia del estudiante a reducir el sistema de la lengua modelo a un sistema más simple, evitando categorías que no considera necesarias, como los artículos o el morfema del plural.

Las estrategias de comunicación son un fenómeno que subscribe aquellas reglas, vocablos y subsistemas que son identificables como soluciones a problemas de comunicación (paráfrasis, acuñación de un vocablo nuevo, reestructuración, estrategias de cooperación y estrategias no lingüísticas).

Finalmente, la hipergeneralización de las reglas es un fenómeno que subscribe aquellas reglas, vocablos y subsistemas que son generados por analogía con otros elementos de la gramática a través de una generalización errónea de las reglas de la lengua meta. Entre los casos más frecuentes destacamos el uso de formas verbales irregulares como si fueran regulares.

Coincidimos con Galindo Merino (2004:46) cuando afirma que la Interlengua representa "la culminación de los trabajos iniciados por Fries y Lado y la superación del análisis de errores, habiendo contribuido al establecimiento de una metodología de investigación que tiene en cuenta no solo los errores de los aprendices, sino también sus aciertos." Además, consideramos que todos estos modelos de análisis están interrelacionados y que representan herramientas que el docente tiene a su alcance.

Nuestro estudio está anclado principalmente en la versión débil del Análisis contrastivo, dado que compara en español y en rumano un corpus compuesto por unidades fraseológicas somáticas, tratando de anticipar transferencias negativas, lagunas fraseológicas y otros errores de índole traductológica. Por nuestra experiencia docente con alumnos hablantes nativos de rumano, hemos constatado que los errores que cometen o pueden cometer en el aprendizaje del lenguaje idiomático se circunscriben principalmente a los componentes semánticos y/o pragmáticos. 
Por tanto, no tendremos en cuenta únicamente los parámetros morfosintácticos, sino que también centraremos el análisis interlingüístico en esos componentes semánticos y pragmáticos, a fin de evitar producciones como *hacer con el ojo (por "guiñar el ojo", "decir verde en cara (por "decir a la cara"), "dejar con los ojos en sol (por "dejar plantado"), etc.

Aunque no trabajamos con muestras reales (y por tanto no contamos con input auténtico), coincidimos con la opinión que sostiene que el error es un elemento de progreso, que es inevitable y que forma parte del aprendizaje. Por lo tanto, en un aspecto tan complejo como la fraseología hay que ser especialmente tolerantes ante el error y animar a los aprendices a seguir produciendo enunciados que engloben UF. Según Martín Peris (1988:17),

la ausencia de errores indicaría que o bien el alumno no hace un uso creativo de la nueva lengua que está aprendiendo, o bien que el uso que hace está tan planificado, tan monitorizado, que en definitiva está obstaculizando lo que Krashen denomina aprendizaje.

En el contexto de la fraseología, Leal Riol apunta que sería conveniente distinguir entre errores de carácter transitorio, errores de carácter sistemático, errores interlingüísticos y errores intralingüísticos. Emulando los postulados de Selinker, señala que "el carácter sistemático de muchos de estos errores nos conduce a la idea de que existe una competencia fraseológica transitoria, que tiene lugar en la interlengua" (Leal Riol 2011:245). Más que una simple corrección, habría que indagar en los mecanismos de aprendizaje subyacentes, puesto que permitirían averiguar el conocimiento interiorizado que el aprendiz tiene sobre el léxico del español.

La selección de las UF con la que vamos a operar tendrá también en cuenta todos los aspectos presentados en este apartado. Las locuciones complejas tan predispuestas a generar errores interlinguales, las descartamos de la base de datos que elaboremos o las relegamos a niveles superiores, preparando propuestas didácticas especialmente diseñadas para que los aprendices incidan en los aspectos contrastivos más relevantes y eviten así los errores generados por transferencia negativa, interferencia con una L3 o hipercorrección. 


\title{
1.6. Fraseología contrastiva
}

Si la fraseología se consolidó como disciplina lingüística independiente relativamente tarde respecto a otros campos de investigación lexicológica, la fraseología comparada solo empezó a despertar el interés de los especialistas en la década de los setenta del pasado siglo.

Los primeros trabajos pioneros que surgen se dedican principalmente a las comparaciones fraseológicas entre el inglés, el alemán y el sueco y entre el ruso y el alemán. El congreso de Mannheim (1981), la creación de la Sociedad Europea de Fraseología (EUROPHRAS) y las conferencias organizadas bajo sus auspicios consolidan la fraseología contrastiva, que pasa a desempeñar un papel cada vez más relevante. Muestra de ello son las numerosas ponencias, publicaciones y proyectos de investigación. No obstante, tanto su objeto de estudio como el nombre que se le atribuye a la disciplina no están exentos de polémica. Colson (2008:194) señala que "anyone studying set phrases across languages needs to be aware that several interpretations of the term contrastive are possible". En este sentido, se barajan opciones alternativas como "fraseología comparada", "fraseología interlingual" o "fraseología interlingüística", que en modo alguno tratan de cubrir mejor el término cross-linguistic, aplicado en los estudios de lengua inglesa.

\begin{abstract}
A possible view is to consider contrastive and cross-linguistic as synonyms. In that case, any kind of comparison between languages from the point of view of their set phrases will be considered as contrastive phraseology. However, contrastive in the narrow sense implies that a really systematic comparison is achieved between two or more languages, on the basis of all their differences and similarities. Finally, a more restricted interpretation of contrastive is also possible, in which only differences between languages are taken into account (Colson 2008:194).
\end{abstract}

Colson (2008) subraya que todavía no se ha determinado con exactitud si la investigación contrastiva en el campo de la fraseología equivale o no a la investigación interlingual y presenta tres posibilidades de interpretación: una sinonimia completa entre fraseología contrastiva y fraseología interlingual (cualquier estudio comparativo sobre algún fraseologismo o aspecto fraseológico de dos o varias lenguas pertenece a la fraseología contrastiva), una sinonimia parcial (solo pertenecen a la fraseología contrastiva aquellos estudios que presentan y comparan la fraseología de dos lenguas desde un punto de vista sistemático, no en base a casos aislados) y una divergencia de sentido (la fraseología contrastiva solo trata de las diferencias entre dos sistemas fraseológicos, mientras que la comparación interlingual puede abarcar tanto similitudes, como diferencias). 
Aunque comprendemos y aceptamos la validez de su enfoque, seguimos optando por el término "fraseología contrastiva" (ya consolidado en las investigaciones de lingüística hispánica) y consideramos que "el contraste" no descarta automáticamente los casos de similitud. Nénkova (2006:97) refleja la misma idea cuando afirma que "la fraseología contrastiva persigue la determinación de las semejanzas y las diferencias que existen entre los sistemas fraseológicos de dos o más lenguas. Su objetivo es la búsqueda de fraseologismos universales, el establecimiento de correspondencias, así como también de equivalencias y divergencias fraseológicas".

Dentro del marco de la fraseología contrastiva, como análisis comparativo de las UF de dos sistemas lingüísticos, se han concretado dos opciones metodológicas: la sistémica y la pragmática. La primera se establece a nivel de lengua: utiliza un corpus formado exclusivamente por unidades fraseológicas de las lenguas comparadas y sostiene que la fraseología contrastiva ha de comparar los fraseologismos como unidades de sistema y no como unidades textuales, puesto que en este caso se trataría de equivalencias comunicativas y traductológicas. Los lingüistas que optan por este tipo de enfoque, entre los que destacan Sosiński (2006) y Navarro (2007), recurren a fuentes lexicográficas y señalan que este método asegura una validez completa de los resultados porque no depende de contextos y realizaciones específicas.

La otra tendencia en la fraseología contrastiva no traza una separación tan firme entre la lengua como sistema y la lengua como producción textual y contempla también el recurso a otros procedimientos lingüísticos (que se establecen generalmente en el habla), aceptando que una expresión idiomática puede tener como equivalente un lexema, una palabra compuesta o una paráfrasis, según los criterios del texto en el que está insertada.

Una importante línea de investigación es el establecimiento de los universales fraseológicos, que abarcan las relaciones de homonimia, polisemia, sinonimia, antonimia, las escalas graduales de idiomaticidad y las restricciones combinatorias.

Según Corpas Pastor (2000),

la tendencia a denotar fenómenos que marcan una experiencia emocional intensa o simpatía externa en grado máximo, las valoraciones negativas, la universalidad del concepto o la imagen subyacentes y las operaciones de pensamiento universales que determinan la interpretación de una unidad fraseológica ilustran los universales determinados extralingüísticamente 0 semántico-culturales (Corpas Pastor 2000).

La universalidad de la metáfora es una fuente de inspiración en la fraseología contrastiva, interpretada desde la perspectiva de la semántica cognitiva. Dobrovol'skij y Piirainen (2005) proponen la teoría del lenguaje figurado convencional, a modo de pauta, para entender tanto los fundamentos cognitivos de las metáforas y de las expresiones 
idiomáticas como la relación que existe entre estas. Esta teoría se centra en la idea de imagen como estructura conceptual específica fundamental para las unidades figuradas y elemento relevante para su significado.

Lakoff y Johnson (1980) proponen los términos "metáforas universales" y "sistematicidad de los conceptos metafóricos". El origen de muchas UF responde a una motivación que nos ayuda a descodificarlas. Las expresiones idiomáticas que muestran de forma más clara la metáfora subyacente resultan más transparentes (por lo tanto, más fácil de interpretar, enseñar y aprender) que aquellas opacas, en las que es más difícil rastrear la metáfora. La idea principal que se extrae de la teoría de las metáforas de Lakoff y Johnson (1980) es que "los mecanismos que rigen los procesos metafóricos no residen en el propio lenguaje, sino que se hallan en nuestro sistema conceptual, sin el cual están entreverados los rasgos característicos de nuestra cultura" (Leal Riol 2011:45).

La lingüística del corpus también desempeña un papel muy importante en el uso de las UF, pues un análisis muy detallado de los fenómenos léxicos y de coocurrencia en el corpus es muy útil para la resolución de problemas teóricos como el papel de la semántica y de la sintaxis y su interferencia con la fraseología (Colson 2008:199).

Hemos podido comprobar que la fraseología contrastiva es un ámbito altamente interdisciplinario, relacionado con la lexicología, la sintaxis, la pragmática y la semántica, pero también con la semiótica y la teoría de la traducción. La amplia diversidad de las teorías en las cuales se fundamenta la fraseología contrastiva puede constituir una ventaja, pero también puede generar aspectos polémicos, dado que aún no se ha desarrollado una metodología unánimemente válida y aceptada. 


\subsection{Estudios y fuentes fraseológicas contrastivas (español- rumano)}

En las siguientes páginas trataremos de esbozar el panorama de los estudios comparativos y contrastivos (español-rumano) en el ámbito de la fraseología. No pretendemos llevar a cabo un análisis exhaustivo y pormenorizado de los trabajos publicados, sino que prestaremos especial atención a los más relevantes y haremos hincapié en los más recientes.

Como punto de partida, volvemos a destacar la primera obra lexicográfica bilingüe importante, Dicţionar spaniol-român de expresii şi locuţiuni de Pisot, Mahalu y Teodorovici (2002) a la que le correspondió una versión "en el espejo", Diç̧ionar român-spaniol de expresii şi locuţiuni (2005) de los mismos autores. Se trata de un trabajo cuyo gran mérito fue cubrir las necesidades de un número cada vez más elevado de aprendientes, debido a factores de índole social ${ }^{4}$ y cultural y que abrió el camino a futuras investigaciones basadas en corpus. El diccionario incluye equivalencias semánticas y funcionales entre unidades consideradas de mayor vitalidad en ambas lenguas, seleccionadas en torno a núcleos semánticos.

Resulta también útil el amplio estudio introductorio bilingüe (Mahalu, Pisot y Teodorovici 2002), que incluye reflexiones en torno al concepto de UF y una presentación detallada de sus rasgos sintácticos y léxico-semánticos significativos, como también los criterios de selección y ordenación.

La inexistencia de estudios de frecuencia en el ámbito de las unidades fraseológicas nos ha obligado a llevar a cabo una selección subjetiva de todo el material a partir de seis diccionarios (...), eligiendo aquellas 3.000 unidades que, a nuestro juicio, se consideran más representativas de acuerdo a un criterio intuitivo de frecuencia (Pisot, Mahalu y Teodorovici 2002:73).

Los procedimientos llevados a cabo, la organización en torno a redes semánticas y el estudio comparado de las UF han sido plasmados por Pisot (2005) en una tesis doctoral que gira en torno a la creación de un diccionario fraseológico bilingüe (español-rumano).

Bajo los auspicios de la Academia Rumana y del Instituto de Lingüística "lorgu lordan - Al. Rosetti", se publicó Diç̧ionar frazeologic spaniol-român (2008), un amplio trabajo que cuenta con unas 15.000 entradas, que se autodefine como "el primer diccionario de este

\footnotetext{
${ }^{4}$ La inmigración rumana en España experimentó un auge importante a principios del siglo XXI, realidad social que se vio reflejada en un mayor interés por el aprendizaje del español y que coinicidió con la publicación de un considerable número de manuales, métodos y fuentes lexicográficas. Hoy en día la comunidad rumana representa la segunda nacionalidad extranjera de España, con una cifra de unos 700.000 habitantes censados oficialmente (2019).
} 
tipo en Rumanía y uno de los pocos diccionarios fraseológicos bilingües (español - otra lengua) dentro de la bibliografía de la especialidad."

En el prólogo se aporta información sobre la selección del corpus (que engloba unidades fraseológicas del español estándar, descartando expresiones anticuadas o en desuso, regionalismos americanos, dialectalismos peninsulares o expresiones que pertenecen a terminologías especializadas, como el español jurídico o militar).

Asimismo, contamos con algunas aclaraciones de orden teórico, como la definición de la unidad fraseológica, entendida, en un sentido amplio, como "cualquier construcción (expresión, locución, sintagma) cuyo contenido semántico no se puede deducir (o solo se puede deducir parcialmente) a partir del significado de sus componentes" (2008:6). Destacamos el empeño que las autoras ponen en aclarar matices de significado, aportando ejemplos contextualizados e indicaciones necesarias para el uso adecuado al registro. Estas constantes aclaraciones de orden semántico en detrimento del equivalente en la lengua meta hacen pensar más bien en diccionario explicativo que en una obra exclusivamente bilingüe.

De menor extensión, Culegere de expresii frazeologice sinonime (română, engleză, spaniolă), de Birtalan, Dumbrăvescu y Rădoi (2018), es una herramienta práctica de corte didáctico destinada a estudiantes de filología hispánica e inglesa interesados en aspectos de fraseología contrastiva. El trabajo proporciona equivalencias entre UF agrupadas temáticamente en los tres idiomas y destaca el valor connotativo de las entradas multilingües. En la misma línea se inscriben Culegere de expresii frazeologice antonime (română, engleză, spaniolă) de Buzea y Dumbrăvescu (2018) y Culegere de expresii frazeologice în română, engleză şi spaniolă cu ilustrări din opere literare, de Birtalan y Dumbrăvescu (2019).

En cuanto a los trabajos de índole teórica en la fraseología comparada, el camino lo abre Tudorică (1968) con algunas consideraciones fraseológicas rumano-españolas. Dumitrescu (1980) explora la fraseología contrastiva en una obra imprescindible que abarca aspectos teóricos y prácticos, listados de falsos amigos (totales y parciales) y modelos de traducciones acompañados de aclaraciones. Sitúa las UF dentro del apartado dedicado a las "dificultades de orden léxico semántico" y señala el peligro de las transferencias negativas y de la tentación de la reproducción literal, lo que conllevaría una pérdida de significado.

Más recientemente, destacamos las tesis doctorales de Rădulescu (2006) y de Duţă (2014) y numerosos artículos que tratan las comparaciones léxicas, sintácticas y semánticas entre el español y el rumano y la búsqueda de correspondencias. En este sentido, nos parecen significativas las aportaciones de Oprica $(2013,2014)$ que, a partir de los corpus que elabora y como fruto de su experiencia docente, analiza el fondo cultural que conllevan UF agrupadas según criterios semánticos, "con el fin de averiguar, por un lado, si es posible transferir el sentido de un idioma a otro; y, por otro, si hay similitudes, 
equivalentes o estructuras imposible de transferir" (2014:188). Los intereses de Rădulescu $(2006,2009)$ giran en torno al sintagma verbal y analiza desde una perspectiva contrastiva plurilingüe (que además del español y del rumano incluye en numerosas ocasiones UF del inglés) construcciones idiomáticas centradas en verbos soporte.

Si bien no trata específicamente el tema de la fraseología contrastiva (pero sí la adquisición de la competencia léxica), incluimos en este apartado el trabajo doctoral de Roesler (2010) en el ámbito de la sociolingüística hispánica, más concretamente sobre las lenguas española y rumana que actualmente se encuentran en contacto debido a la inmigración de decenas de miles de rumanos a España. Sus intereses giran en torno a la problemática de las lenguas en contacto, la lingüística comparada y la evolución de las lenguas románicas.

El auge de la enseñanza de E/LE en Rumanía en los últimos años se ha visto también reflejado en una serie de trabajos a caballo entre la investigación, la reflexión y la práctica docente. En este sentido, destacamos el TFM sobre falsos amigos de Sava (2009), la tesis doctoral de Cecovniuc (2016) que gira en torno a las interferencias interlingüísticas y, sobre todo, las constantes aportaciones de Dumbrăvescu $(2012,2015$, 2019).

No obstante, salvo escasas excepciones, son todavía muy tímidos los intentos de acercar la fraseología y el mundo del E/LE. Los trabajos que hemos analizado surgen mayoritariamente del mundo académico universitario o de los institutos de lingüística y no suelen contar con una vertiente práctica. Faltan, por lo tanto, las propuestas didácticas que engloben UF o materiales especialmente diseñados para su adquisición.

Nosotros recogemos la estela de este interés por los estudios de fraseología contrastiva en Rumanía, pero en esta tesis doctoral pretendemos aportar una nueva visión: por un lado, crear una nueva herramienta metodológica para comparar UF desde distintas perspectivas, contrastando el componente idiomático; y, por otro lado, proponer una visión más actualizada respecto a la enseñanza de las UF a rumanohablantes y materiales modernos, conformes con los postulados más recientes de la enseñanza de lenguas extranjeras. 


\subsection{Traducción y equivalencias fraseológicas: técnicas de traducción}

Las UF plantean problemas complejos a la hora de su traducción, puesto que no se trata exclusivamente de una actividad lingüística de transcodificación, sino de una búsqueda de relaciones de correspondencias interlinguales o de "equivalencias".

El concepto de "equivalencia" no significa únicamente una correspondencia estructural o una identidad semántica, sino "una noción funcional y relacional, de carácter histórico y dinámico" (Wotjak 1995:93). Se trata, por lo tanto, de encontrar en la LM una UF con la misma función comunicativa que en la lengua fuente, no de optar por una interpretación literal, que puede conducir al error y entrañar pérdidas de orden semántico. La función comunicativa de una UF es polifacética y "engloba el estilo de lengua al que pertenece, su uso diatópico, el tipo de situaciones comunicativas en que se utiliza, su frecuencia de uso y varias subclases de funciones comunicativas, como la apelativa o la fática" (Rakotojoelimaria 2004:158).

Además, como ya hemos señalado, los rasgos primordiales de la UF son la fijación morfosintáctica y la idiomaticidad semántica, por lo que deberíamos situarnos en el plano del discurso, esto es, traducir el sentido global de la UF en un contexto determinado.

El contexto cobra especial importancia en el caso de las UF que plantean dificultades de traducción de orden cultural, puesto que "la adquisición de la fraseología de la una lengua extranjera está restringida por unos esquemas mentales dependientes de la cultura y la lengua materna del aprendiz, de un lado, y del otro, por la asimilación de conceptos de la cultura de la lengua en proceso de adquisición" (Leal Riol 2011:63).

Afortunadamente, entre lenguas que comparten un acervo cultural similar (como es el caso del español y del rumano) existe una relación de interdependencia, reflejada a nivel fraseológico por préstamos y calcos que tienen un denominador común. Se trata de los así llamados "internacionalismos fraseológicos" (Zholobova 2005) o "europeísmos" (Corpas Pastor 2000), corpus fraseológicos con rasgos comunes, compartido por muchas lenguas. No obstante, el carácter idiosincrático de ciertas UF (como las que proceden del mundo de los toros) imposibilita su traducción, al carecer la LM de referencias culturales equivalentes.

Son muy numerosos los estudios que tratan las equivalencias lingüísticas, que siguen despertando interés y creando polémica: Larreta Zulategui (2001), López Roig (2001), Richart Marset (2008), Pisot (2009), Corpas Pastor (2000), Timofeeva (2012). Tras comparar múltiples puntos de vista y taxonomías, en este trabajo hemos optado por seguir las pautas de Corpas Pastor (1997) y de Mellado (2000), puesto que sus obras constituyen apotaciones teóricas fundamentales en el campo de las equivalencias translémicas entre el español y otra L2 y referencias para los demás autores.

Corpas Pastor (1997), en un estudio contrastivo español-inglés, propone cuatro grados de equivalencia translémica para las locuciones. La equivalencia total aparece cuando las locuciones de ambas lenguas presentan los mismos niveles diastráticos, 
diafásicos y diatópicos y el mismo significado denotativo y connotativo (resultado de compartir fuentes comunes como la Biblia, la literatura universal o la historia). La equivalencia parcial aparece cuando las locuciones presentan diferencias de significado denotativo o connotativo o cuando pertenecen a una variedad (diastrática, diafásica y diatópica) distinta. La equivalencia nula supone que no existe en la LM una expresión adecuada a la locución de la lengua de origen, debido a razones lingüísticas, culturales 0 históricas. Finalmente, la equivalencia aparente se produce entre locuciones que presentan similitud formal con respecto a sus elementos constitutivos, pero divergen en cuanto a sus significados. En este caso estamos ante los así llamados falsos amigos fraseológicos.

A su vez, al comparar los somatismos cinésicos en alemán y en español, Mellado (2000) destaca cuatro grandes casos de equivalencia que, a su vez, subdivide en varios apartados. Identifica una equivalencia funcional cuando la pareja de UF en ambos idiomas tiene el mismo significado fraseológico. Esta equivalencia puede abarcar todos los aspectos, desde el significado literal y fraseológico, estructura morfosintáctica y componente pragmático, pero también pueden aparecer casos en los que para una UF de la lengua fuente se recurre a una unidad léxica simple. Aparte de esta equivalencia plena, encontramos casos de equivalencia parcial cuando uno de los somatismos cinésicos comparados es polisémico o tiene otro homónimo con significado y composición actancial diferentes. El tercer grupo está formado por los SO que no tienen equivalente en el otro idioma y que, por tanto, han de ser parafraseados. Asimismo, señala el caso de los falsos amigos, expresiones que presentan correspondencia en el nivel literal y morfosintáctico, pero no en el significado fraseológico ni en el componente pragmático.

En un trabajo posterior, Mellado (2015) establece una diferenciación entre la equivalencia en el nivel sistémico (que genera escalas de gradualidad), lexicográfico y textual (de tipo funcional comunicativo) de las UF y señala una serie de parámetros.

Los parámetros operativos para definir las equivalencias interlingüísticas son múltiples y reflejan la complejidad formal y semántica de las UF: parámetro semántico (significado fraseológico, imagen, componentes léxicos); parámetro morfosintáctico (valencia sintáctica, función sintáctica y posibilidades de modificación morfosintácticas como la nominalización o la pasivización); parámetro pragmático (componentes culturales, restricciones diasistemáticas, frecuencia, preferencias de género textual, modificaciones, implicaturas del hablante). El grado de equivalencia interlingüística (total, parcial o nula) se verá afectado por la batería de paramétros aplicados, dado que "cuantos más parámetros sean tenidos en cuenta para determinar el grado de equivalencia en un binomio dado, más improbable será que aparezca" (Mellado 2015:158). En nuestro trabajo comprobamos también que muchas UF, candidatas a la equivalencia total (incluyendo los internacionalismos), resultaron parciales tras aplicar los parámetros mencionados anteriormente.

En cuanto al nivel lexicográfico, los parámetros de mayor relevancia son: los componentes léxicos que son elementos constituyentes de una UF, la estructura 
actancial, la imagen en la que se apoya el significado literal, la extensión y estructura semántica y el componente connotativo-pragmático.

De todos estos parámetros heterogéneos, nos detendremos en la imagen base, cuyo grado de similitud en las UF comparadas puede variar desde la coincidencia plena hasta la divergencia total. Desde esta perspectiva, podemos catalogar los siguientes tipos: UF que presentan el mismo significado, la misma imagen base y aproximada composición léxica; UF que presentan el mismo significado fraseológico, imagen aproximada y estructura interna aproximada; UF sin significado coincidente, con base metafórica y estructuras internas que no son totalmente iguales; UF que tienen el mismo significado denotativo conceptual, pero distinto significado literal compositivo.

Afirma Mellado (2015:162) que la imagen no es determinante a la hora de encontrar equivalencias, sino que lo realmente importante es que "se mantenga la expresividad, y esta se garantiza siempre que exista idiomaticidad, aunque se consiga mediante imágenes diferentes". La no convergencia de imágenes se debe a distintos factores: para conceptualizar una misma realidad extralingüística, cada lengua se inspira en distintos objetos o acciones ofrecidos por la naturaleza y el entorno inmediato (dominio fuente); una de las lenguas o ambas lenguas puede acudir a culturemas o elementos idiosincrásicos de cada cultura (objetos típicos, anécdotas o personajes históricos reales o ficticios); factores prosódicos de rima que condicionan la elección de una determinada imagen en una de las lenguas.

En el caso concreto de los somatismos fraseológicos, que representan el objeto de estudio en este trabajo, podemos afirmar que nos hallamos en una situación privilegiada puesto que, por sus características semánticas, realmente hay pocos SO totalmente opacos en los binomios analizados. García-Page afirma que

la presencia de un sustantivo que designa una parte del cuerpo favorece la transparencia del fraseologismo y, por tanto, su analizabilidad semántica, gracias, fundamentalmente, a la posibilidad de establecer una asociación entre la parte del cuerpo y una de sus propiedades o funciones (biológica, fisiológica, psicomotriz, física...), la actividad externa para la que está capacitada, el lugar donde está ubicada o el gesto o ademán que pueda acompañar su enunciación (somatismo cinésico) (García-Page 2008:363).

La frecuencia de uso, la fijación y la idiomaticidad han servido como criterios para definir las UF y precisamente esos rasgos fundamentales provocan la mayor dificultad a la hora de traducirlas. Richart Marset (2008), al referirse al lugar destacado que ocupan las UF dentro de la teoría de la traducción y en la enseñanza de una LE, aporta un término que consideramos muy acertado ("resistencia" a la traducción), mientras que Baker (1992) señala que 
the main problems that idiomatic and fixed expressions pose in translation relate to two main areas: the ability to recognize and interpret an idiom correctly; and the difficulties involved in rendering the various aspects of meaning that an idiom or a fixed expression conveys into the target language (Baker 1992:65).

Además, las dificultades surgen también del hecho de que una UF está dotada de una gran carga de información que hay que transportar a otra expresión correspondiente, relativamente corta, condensada e idiosincrática. En esta misma línea, Corpas Pastor (2003) señala que la complejidad interna de las unidades fraseológicas que encierra una serie de componentes complejos e interrelacionados hace difícil reproducir en la LM el valor global aportado por la unidad fraseológica origen. Un problema añadido puede surgir cuando la UF de la lengua de origen sufre una desautomatización (o manipulación creativa), en el sentido de que el autor del texto de origen efectúa algún juego de palabras con la UF, a través de varias operaciones: acotamiento de su forma, sustitución de algún elemento componente o actualización del significado literal y figurado a la vez.

A continuación, presentaremos brevemente algunos procedimientos técnicos para la traducción de las UF.

La equivalencia (método utilizado para traducir refranes, dichos y locuciones) es la herramienta más frecuente, descrita como "using an idiom of similar meaning, but dissimilar form" (Baker 1992:74). Eso viene a decir que en la LM existe una expresión idiomática con un significado equivalente a la expresión de la lengua fuente, pero que utiliza elementos léxicos distintos. No obstante, Fernando y Flavell (1981) critican el empeño de muchos traductores de buscar una expresión idiomática en la lengua meta, por muy inadecuada que esta fuera. A su vez, Corpas Pastor (2001) apunta que la equivalencia semántica fraseológica no garantiza una solución adecuada, aun cuando la expresión haya sido reconocida e interpretada en su co-texto y una subcompetencia defectuosa por parte del traductor podría llevar a la infratraducción o sobretraducción de los aspectos semántico-pragmáticos actualizados por una determinada expresión.

La compensación es otra técnica de traducción que se aplica en el caso de las UF que presentan una equivalencia parcial. A la expresión (o palabra) por la que se opta en la LM se le quita o añade fuerza comunicativa respecto a la UF de la lengua de origen y, posteriormente, se añaden otros elementos que compensen este cambio.

La paráfrasis es una estrategia empleada cuando el concepto al que hace referencia la UF no está lexicalizando en la LM debido a factores de índole lingüística, histórica o cultural o cuando el uso de un lenguaje idiomático resulta inadecuado en el texto meta, debido a las diferencias entre las lenguas de origen y de destino en cuanto a las preferencias estilísticas. En el caso de las lagunas léxicas que se traducen mediante paráfrasis, Leal Riol (2011:53) subraya la pérdida de "alusiones, aspectos figurativos y valores connotativos presentes en la lengua original". 
El calco es un procedimiento que reproduce el esquema semántico-conceptual de la UF original en el texto meta, manteniendo una imagen evocadora de la cultura original.

Finalmente, la omisión (la anulación o la eliminación) se aplica cuando la UF en el texto original se considera insignificante en la LM o porque presenta problemas de descodificación o transcodificación insolubles para el traductor.

Como hemos podido comprobar, el complejo trabajo del traductor es valorar la aportación global de la UF en el texto origen, con el objetivo de reproducir el mismo efecto en el texto meta, en la lengua que está traduciendo o que está adquiriendo. Anticipamos que en las fuentes lexicográficas consultadas en nuestro estudio encontraremos muchas de estas técnicas y procedimientos.

Desde la perspectiva del proceso de enseñanza-aprendizaje de E/LE, consideramos que se debe fomentar la búsqueda de equivalencias funcionales y evitar la interpretación literal y el abuso de calcos, omisiones y otras estrategias de compensación que, en el fondo, reflejan una falta de competencia fraseológica.

Este primer capítulo dedicado a los fundamentos teóricos representa los pilares que sustentan esta tesis, a modo de declaración filosófica/filológica: "quiénes somos, de dónde venimos y adónde vamos". Hemos aportado un panorama global de la fraseología como disciplina autónoma, desde sus albores hasta el siglo XXI, la unidad fraseológica, con sus intentos de definición, etiquetado y clasificación, el universo fraseológico en rumano y, sobre todo, en el mundo hispano, donde contamos con estudios de gran valía. Asimismo, este capítulo incluye el andamiaje teórico que nos proporciona bases y modelos de análisis contrastivo, de gran importancia para el estudio comparativo de las UF que llevaremos a cabo en el segundo capítulo de esta tesis. Nos apoyamos en herramientas teóricas para analizar el componente idiomático en distintas fuentes lexicográficas, desde el punto de vista de su traducción/equivalencia. Esta perspectiva crítica sobre las correspondencias interlinguales nos ayudará a tomar decisiones respecto a la creación y el análisis del corpus.

El estado de la cuestión es también un indicador de los caminos a seguir y de las vías que quedan por explorar; y, por lo tanto, nos da pautas para sustentar nuestras propuestas, siguiendo la estela del interés por los estudios fraseológico de corte contrastivo. 


\section{PARALELISMOS LINGÜÍSTICOS EN UNIDADES FRASEOLÓGICAS SOMÁTICAS: ELABORACIÓN Y ANÁLISIS DEL CORPUS ESPAÑOL/RUMANO Y RUMANO/ESPAÑOL}

El propósito de este capítulo consiste en detallar el procedimiento de selección del corpus constituido por UF somáticas para aprendientes rumanos de E/LE de niveles A1B2 y realizar un análisis pormenorizado de SO aplicando los postulados de la lingüística contrastiva.

Justificamos los criterios aplicados y las razones que nos han llevado a descartar de la base de datos múltiples entradas y argumentamos de forma sistemática las decisiones tomadas. Asimismo, en diferentes apartados llevamos a cabo un detallado análisis contrastivo de cada locución seleccionada. Aunque más tradicional, en este primer acercamiento al lenguaje formulaico hemos optado por un modelo de comparación contrastivo de las estructuras lexemáticas que tienen las dos lenguas. La elección de este modelo descriptivo de corte clásico, estructuralista, se debe a que una UF es (también) un conjunto, un andamiaje de elementos constituyentes que juntos cobran sentido; pero, sobre todo, con este enfoque clásico pretendemos respetar el estilo de aprendizaje de los alumnos rumanos de $E / L E$, educados en una tradición lingüística funcionalista, anclada en el concepto de la lengua como sistema. 


\subsection{Creación del corpus: selección de criterios}

La elaboración de la base de datos ha supuesto un sinfín de inventarios, anotaciones, consultas de fuentes lexicográficas, cruce de datos y comparaciones de registros fraseológicos en ambas lenguas. Aunque la lengua meta es el español, hemos considerado más eficaz operar con dos bases de datos distintas: la primera incluye los somatónimos en español, ordenados alfabéticamente, y los SO que generan, y la segunda, en el espejo, está constituida por entradas lexemáticas en rumano, con sus respectivas locuciones. Optamos por esta separación para evitar el riesgo de contagio, en el sentido de que en un estudio comparativo que implica equivalencias translémicas es mejor tomar cierta distancia para no caer en la tentación de proporcionar calcos inexistentes. No obstante, en esta ocasión el corpus en rumano no sobrepasa el estatus de una base de datos "en la sombra", de trabajo interno y de consultas. Habría resultado incómodo manipular dos documentos tan complejos como los que hemos creado y quizás los resultados conseguidos a raíz de este cruce un tanto redundantes, pero abrimos la puerta a futuras líneas de investigación, como la enseñanza-aprendizaje de UF rumanas a aprendientes hispanos.

Tras las primeras recogidas de somatónimos, resultó claro que era inviable manejar una base de datos que superara las mil locuciones. Para acotarla, aplicamos una serie de filtros: tomamos en consideración exclusivamente las locuciones verbales, descartamos las UF dialectales, arcaicas o en desuso, el registro vulgar, las jergas o las muestras del español de Hispanoamérica.

Hemos echado en falta estudios sobre la recurrencia de las UF tanto en español como en rumano, que habrían supuesto un verdadero apoyo en nuestro empeño. Penadés (2019) señala también la compleja cuestión de la frecuencia de uso de las locuciones. No obstante, basándose en el número de ejemplos encontrados en cada locución, utiliza en su diccionario en línea DILEA varias marcas de frecuencia que también consideramos de interés para nuestro estudio:

+f. (más frecuente): acepción o variante más frecuente de una locución en relacion con otras acepciones o las otras variantes registradas;

-f. (menos frecuente): acepción o variante menos frecuente de una locución en relación con las otras acepciones o las otras variantes registradas;

mf. (muy frecuente): locución de la que se tiene documentado un número superior a 10 ejemplos, obtenidos de las fuentes lingüísticas de DILEA;

pf. (poco frecuente): locución de la que solo se tienen documentados 3 ejemplos, lo que ha supuesto no incluir en el diccionario aquellas locuciones de las que no se cuenta ningún ejemplo o se dispone tan solo de $1 \circ 2$, a pesar de que algún diccionario las registre. 
Otro criterio importante que manejamos ha sido de índole pragmática, buscando abarcar el mayor abanico posible de funciones comunicativas, con el fin de dotar a los aprendices de herramientas que les permitieran desenvolverse con eficacia y llevar a cabo con éxito actos de habla. Por esta razón descartamos varias UF que vienen a cubrir necesidades pragmáticas idénticas (como expresar amenaza, expresar hartazgo; expresar indiferencia; expresar inactividad; expresar esfuerzo) por lo que resultarían redundantes. No obstante, en futuros trabajos trataremos de distinguir entre destrezas productivas y destrezas receptivas, lo que permitiría ampliar el número de UF presentadas (los aprendices serán capaces de comprender un elevado número de somatismo, pero utilizar menos en sus producciones).

El número final de SO incluidos en el corpus fue de 206, correspondiente a 39 lexemas: barba (1), barriga (4), boca (23), brazo (9), cabeza (21), callo (2), cana (1), cara (11), carne (6), ceja (4), cerebro (2), codo (3), colmillo (1), corazón (5), coronilla (1), cuello (1), dedo (9), diente (3), espalda (6), hombro (3), labio (3), lengua (7), mano (13), mejilla (1), nariz (9), ojo (13), ombligo (2), oreja (6), pelo (7), pestaña (1), pie (10), piel (4), puño (1), riñón (1), sangre (4), tripa (1), uña (5), vena (1), yugular (1).

Como se puede observar, prescindimos de entradas que expresan sustancias que genera el cuerpo humano ("moco", "baba", "caca", "pis"), cualquier elemento léxico vulgar ("cojón, "chocho", "coño"), los somatónimos que no producen locuciones relevantes ("músculo", "pulmón", "sobaco") o que no designan una realidad concreta ("alma"). Asimismo, descartamos numerosos sinónimos coloquiales en detrimento del registro neutro ("morro" vs. "labio", "coco" vs. "cabeza", "jeta" vs. "cara") y lexemas que denominan rasgos específicos de un somátonimo ("melena", "rizo", "cabellera", "tupé"). En este aspecto, nuestro trabajo se distingue de otros, ya que los filtros que aplicamos son mayores y, por consiguiente, el corpus resultado de tamaño más reducido. Si en el pasado primaba la dimensión del corpus (mientras mayor fuera, más aumentaban las posibilidades de análisis de la lengua), hoy en día "se priman los criterios de diseño, es decir, el tamaño solo es importante en la medida en que así lo exija la finalidad del corpus" (Villayandre 2008:341). Leal Riol (2011:238) subraya también este importante aspecto de las listas de UF y señala que "el número de entradas no debe exceder un margen razonable, con el fin de no sobrecargar de información al estudiante y dificultar así su asimilación"; en consecuencia, hemos optado por primar la cohesión frente a la extensión. 


\subsection{Consideraciones morfosintácticas y léxicas interlinguales}

Antes de proceder al análisis propiamente dicho, consideramos importante esbozar algunos aspectos contrastivos entre los sistemas lingüísticos del español y del rumano que sirvan de apoyo para una mejor comprensión de este estudio y como elemento facilitador de nuestro objetivo final, la enseñanza/aprendizaje de español a hablantes nativos de rumano.

La metáfora más recurrente que encontramos respecto a la lengua rumana $(\mathrm{y}$, por extensión, al carácter de la gente que la habla) es "una isla de latinidad en medio de un mar eslavo". Escuchamos también frecuentemente referencias al curioso caso de la antigua Dacia, provincia étnicamente heterogénea, hallada en una encrucijada de caminos y conquistada por el emperador Trajano en el año 106 d.C. "La herencia latina de la lengua rumana ha sido siempre considerada un signo distintivo de su individualidad" (Niculescu 1977:284). La conservación de la latinidad de la lengua representa un acto de fidelidad ante la historia y una manera de conservar la existencia nacional y estatal.

Al usar un alfabeto latino, el rumano se diferencia de todas las lenguas de su alrededor (griego, lenguas eslavas), idiomas que indudablemente tienen una influencia, pero que no consiguen modificar su identidad. El rumano se resiste a esas influencias extranjeras, pero también es capaz de integrar en su estructura elementos no latinos gracias a su fuerza asimiladora. Asimismo, conserva del latín características gramaticales desaparecidas en otras lenguas románicas como el neutro, el vocativo o la declinación nominal.

A diferencia del español, el rumano cuenta con varias grafías más: ă, $\hat{a}, \hat{\imath}$ corresponden a dos fonemas vocálicos, mientras que $s ̧$ y $t$ corresponden a dos fonemas consonánticos. En el alfabeto español encontramos la $\tilde{n}$, inexistente en rumano, aunque registramos el uso dialectal del fonema, en el oeste del país. Solo utiliza el acento gráfico en escasas situaciones, para marcar diferencias de significado en palabras homógrafas.

Como ya hemos señalado, la lengua rumana posee tres géneros (masculino, femenino y neutro), lo que constituye una fuente de transferencias negativas, incluso si el lexema es fácilmente reconocible en ambas lenguas (el sustantivo masculino "problema" en español es femenino en rumano, o problemă - două probleme; el sustantivo "brazo" es masculino en español y neutro en rumano, un braţ - două braţe, etc.). No obstante, las características definitorias del sustantivo rumano frente al español son la existencia de cinco casos (nominativo, acusativo, genitivo, dativo y vocativo) y la declinación del sustantivo, lo que genera múltiples formas, surgidas a raíz del cruce entre estos rasgos.

Ambos idiomas cuentan con dos formas de artículo (definido e indefinido), aunque, en el caso del artículo determinado, en rumano va detrás del sustantivo, formando una sola parabra con este: codo - cot, el codo - cotul; carne - carne, la carne - carnea.

En cuanto al pronombre sujeto, su uso en español y en rumano coincide plenamente, puesto que en ambas lenguas el verbo tiene terminaciones que ponen de relieve la 
persona y el número, una característica común de las lenguas románicas. Por lo tanto, su uso no es obligatorio; únicamente tiene una función enfática, permite marcar contrastes, reforzar el sujeto o deshacer la ambigüedad cuando las terminaciones de diferentes personas coinciden.

En el sintagma verbal la mayor diferencia es la presencia de una conjugación más en rumano, donde encontramos cuatro, según la vocal temática del infinitivo. Además, los infinitivos rumanos se reconocen por llevar antepuesta la preposición a, que corresponde al to del inglés: hacer - a face.

Teniendo en cuenta lo anterior y desde una perspectiva contrastiva orientada a la enseñanza-aprendizaje, podríamos anticipar que para un estudiante rumano de E/LE los mayores escollos lo representan los tiempos verbales (el rumano cuenta con menos tiempos verbales en subjuntivo), las perífrasis verbales inexistentes en rumano (que no tiene aspectos) y la selección adecuada entre los verbos "ser" y "estar" (el rumano opera con un verbo único, a fil). Además, señalamos posibles errores interlinguales en el uso de las preposiciones, entre las que destacan "por" y "para", ya que "mientras el rumano presenta una menor especialización de sus preposiciones y una gran flexibilidad a la hora de expresar estas nociones, el español cuenta con significados sumamente parcelados" (Madrona y Pisot 2009:129). Mientras tanto, consideramos que para un hispanohablante el mayor reto lo constituye la flexión nominal.

Ambos idiomas comparten la característica de presentar numerosas alternancias vocálicas y consonánticas en su tema de presente indicativo y subjuntivo y en el pretérito indefinido.

En cuanto a los aspectos estrictamente léxicos, señalamos que Sala (1998), al referirse al peso del léxico latino en rumano, considera que no es muy copioso (unas 2000 voces), pero resalta su importancia en los campos semánticos que abarca (entre los que enumera el de mayor interés para este estudio: el cuerpo humano).

Entre las influencias en el léxico rumano destacan las lenguas eslavas, el húngaro, el griego, el alemán y el inglés. 


\subsection{Análisis del corpus}

En las siguientes páginas emprenderemos el análisis contrastivo de las UF seleccionadas, abarcando los puntos de intersección señalados anteriormente. Las casillas que conforman este estudio son el lexema denominativo del cuerpo humano (siguiendo el orden alfabético), la expresión, su definición, el equivalente rumano (si procede), el tipo de equivalencia (total, parcial, nula), la estructura argumental, la función comunicativa, el nivel sugerido para su enseñanza-aprendizaje y otras consideraciones.

Cabe destacar la interdependencia de todos estos aspectos, totalmente interrelacionados: la opacidad, la nula equivalencia o un complejo contorno sintáctico relegan una UF a niveles superiores, mientras que la presencia de una metáfora motivada, un internacional fraseológico o una equivalencia total en rumano justifican su presencia en etapas iniciales de enseñanza. En este sentido, tomamos como simples referencias los niveles sugeridos por el PCIC, puesto que basamos nuestras decisiones finales en los datos obtenidos, resultados del constraste concreto entre el español y el rumano. 


\subsubsection{Somatismos con el lexema "barba"}

El lexema español "barba" tiene una transparencia total en rumano, donde encontramos las formas "barbă" (sin artículo) y "barba" (con artículo definido).

Esta cercanía (debida también a una etimología latina común) presagiaba un elevado número de UF similares en ambas lenguas. No obstante, comprobamos que existe un número bastante limitado de UF (tanto en rumano como en español) en cuya estructura haya un sintagma verbal y que muchas de estas UF españolas están en desuso: "temblar la barba" ('tener miedo'), "tener (una mujer) buena barba" ('ser bien parecida'), "echar a la buena barba" ('señalar a alguien para que pague lo que él y sus compañeros han comido o gastado'), "andar con la barba por el suelo" ('ser muy anciano o estar decrépito').

Los SO en rumano también son escasos: "a se trage de barbă (cu cineva)" (lit. tirarse de las barbas con alguien) con el significado 'ser muy íntimo con alguien' está también en desuso, abandonada a favor de "a se bate pe burtă cu cineva" (lit. tocarse la barriga con alguien), con idéntico significado. Finalmente, ninguna de estas UF forma parte del corpus.

Dudamos a la hora de incluir en el corpus la UF más transparente "mentir por la barba" ('mentir con descaro') con su equivalente parcial en rumano "a pune/a trage bărbi" (lit. poner / tirar barbas), pero tras comprobar el escaso grado de aceptación entre los hablantes nativos, la eliminamos de nuestro análisis.

Por consiguiente, la única entrada seleccionada ha sido "subirse a las barbas" ('perder el respeto al superior'). En rumano contamos con una UF con equivalencia parcial, "a se urca în cap", con la variante "a se sui în cap". Ambas conservan los verbos "a urca" o "a sui" (subir - montar) y un somátonimo contiguo, "cabeza". El contexto de uso es idéntico: se suele aplicar en el ámbito familiar (con hijos, nietos, sobrinos que no obedecen órdenes) y en el ámbito laboral (con subalternos o inferiores jerárquicos, sobre los que se ejerce cierta autoridad). Como función comunicativa se integra en el nivel B2, a fin de reforzar la descripción del carácter. También encaja en el nivel intermedio por la dificultad que entraña la estructura pronominal "<alguien $>$ se $<$ le $>$ sube a las barbas $<a$ alguien>", más complicada de asimilar que la UF rumana equivalente, donde funciona el esquema $\mathrm{S}+\mathrm{V}+\mathrm{CCL}$.

Como último apunte, subrayamos el uso activo de la locución adverbial en rumano "în barbă" (lit. en la barba), presente en estructuras verbales como: "a-şi şopti în barbă" (lit. susurrar para sus adentros) y, sobre todo, "a-şi râde în barbă" (lit. reírse para sus adentros). En este último caso señalamos que la locución adverbial equivalente en español contiene también un somatónimo: "entre dientes" ('articulando palabras de un modo apenas perceptible o inteligible'). 


\subsubsection{Somatismos con el lexema "barriga"}

En el caso de "barriga" ("burtă" en rumano, en ambos casos con etimología dudosa o desconocida), hemos seleccionado cuatro somatismos, de los cuales dos tienen una estructura morfosintáctica idéntica y significado equivalente: "rascarse la barriga" y "tocarse la barriga" ('holgazanear'). La UF rumana que les corresponde es también verbal y somática "a sta cu burta la soare" (lit. estar con la barriga al sol), por lo que encaja en el nivel plataforma. Se trata de una equivalencia parcial, cuyo significado se puede inferir sin dificultad por un aprendiz rumano.

Según el PCIC, el verbo "rascarse" y el sustantivo "barriga" se imparten en el nivel A2, dentro del campo léxico del cuerpo humano, integrando contenidos funcionales como expresar síntomas y dolores.

Tanto en rumano como en español las UF expresan inactividad, pereza y falta de ganas. El esquema sintáctico del español $(S+V+O D)$ resulta más sencillo que la UF pluriverbal equivalente en rumano y recuerda contenidos léxicos y gramaticales de nivel inicial (V reflexivo+OD): "lavarse las manos", "cortarse el pelo", "pintarse los labios", etc., por lo que anticipamos que su comprensión y adquisición serán inmediatas.

Otra UF seleccionada es "echar barriga" con la equivalente rumana "a face burtă" (lit. hacer barriga). La estructura actancial y el contorno morfosintáctico son idénticos en rumano, pero el plurisemantismo del verbo "echar", en este caso con rol de soporte, entraña ciertas dificultades. Pueden surgir, por lo tanto, enunciados incorrectos como *hacer barriga, debido a una transferencia negativa hacia la LM. Por todo ello, consideramos adecuada su presentación en el nivel B1, integrado en el tema "cambios físicos y anímicos".

Finalmente, optamos por introducir la UF "dar cien patadas en la barriga" ('desagradar o disgustar mucho a una persona') en un nivel superior. Nuestros argumentos a favor de esta decisión son la equivalencia nula en rumano, la opacidad del significado y la complejidad morfosintáctica y lexemática: "dar <alguien/algo> cien patadas en la barriga <a alguien>". EI DFDEA no concibe el somatónimo como parte integrante imprescindible de la locución (aparece insertado entre paréntesis) y algunos diccionarios bilingües, como el DSREL, la omite en detrimento de "darle <algo/alguien> cien patadas (en el hígado/el en estómago) <a alguien>". Otra dificultad añadida es la forma apocopada del numeral que, al expresar un número redondo "funciona como alternativa sinonímica en expresiones hiperbólicas" (García-Page 1995:160).

En cuanto a locuciones como "tener barriga de músico", "tener la barriga pegada al espinazo", "tirarse de barriga" (recogidas por el DRAE), consideramos que no cumplen los criterios de relevancia y rentabilidad para que formen parte de la base de datos. 


\subsubsection{Somatismos con el lexema "boca"}

Uno de los mayores retos a la hora de seleccionar las UF con el lexema "boca" (en rumano "gură", procedente del latín gula) ha sido llevar a cabo una criba pertinente entre los más de cincuenta SO que recopilamos en una fase más incipiente de este estudio. En una primera etapa descartamos unidades como "oler/heder la boca" (con su complicada explicación proporcionada por el DRAE, 'ser pedigüeño') o "repulgar la boca" (por su uso restringido), al igual que entradas dialectales de tipo "poner bocas" (Ecuador), "saberle a alguien la boca a medalla" (México) o "tener alguien la boca salada" (Cuba).

En una segunda fase prescindimos de otras UF que habíamos tomado en consideración inicialmente, como "haber hecho la boca un fraile", a pesar de ser reconocida y utilizada por un mayor número de hablantes. Debido a la dificultad del lexema "fraile", a su frecuencia reducida (confirmada por el DILEA) y a la correspondencia nula en rumano, la relegamos a niveles superiores al B2.

En cambio, conservamos el SO "echar espumarajos por la boca" ('estar muy irritado o enfadado'), a pesar de la complejidad del lexema "espumarajos". Justificamos nuestra decisión por la existencia de la locución rumana "a face spume la gură", UF transparente a nivel de significado ('montar en cólera, armar gran escándalo'), a nivel fonético y a nivel sintáctico, donde se sigue un esquema idéntico: $\mathrm{S}+\mathrm{V}+\mathrm{OD}+\mathrm{CCL}$. Sin embargo, apuntamos una leve diferencia morfológica: la ausencia del artículo definido en el sustantivo rumano "gură", a diferencia de su homólogo "boca" en español.

Como anticipábamos, debido a la asociación metonímica, el mayor número de SO que encontramos en este apartado está relacionado con dos actividades cotidianas: hablar y comer, lo que genera un número elevado de UF equivalentes en las dos lenguas.

Para reforzar esta idea, comentamos a continuación algunas UF cuya función comunicativa es "dar y transmitir información". La locución "decir con la boca chica, chiquita o pequeña" ('ofrecer algo por mero cumplimiento') tiene como equivalente en rumano "a spune cu jumătate de gură" (lit. decir con la mitad de la boca). Todos los elementos constituyentes son de nivel inicial, por lo que anticipamos que la UF no le planteará ninguna dificultad a un aprendiz rumano de nivel intermedio. Sin embargo, pueden surgir ciertas dudas de selección entre las variantes que ofrece el español ("chica", "chiquita" o "pequeña"), frente al mayor grado de fijación de la UF rumana.

Otros dos somatismos recogidos son semánticamente muy cercanos: "decir lo que se le viene a la boca" ('no tener reparo ni miramiento en lo que dice') y "decir lo primero que le viene a la boca" ('decir algo irreflexivamente, sin previa meditación'). A pesar de que el rumano cuenta con UF equivalentes: "a spune ce-i trece prin cap" (lit. decir lo que se le pasa por la cabeza) y "a vorbi/a zice cum îi vine la gură" (lit. hablar/decir como le viene a la boca), recomendamos su presentación en el nivel B2. Los motivos que alegamos en favor de esta decisión son precisamente esa delgada línea roja de significado, pero, sobre todo, los rasgos gramaticales complejos. La 
presencia del "se" como intensificador del verbo en combinación con el pronombre indirecto aumenta considerablemente el grado de dificultad, especialmente en las destrezas productivas.

Menos complicados nos parecen los somatismos "andar de boca en boca" y "andar en boca de todos" ('saberse de público, estar divulgado'). EI DRAE recoge la locución adverbial "de boca en boca" ('propagarse una noticia, una alabanza, un rumor') y los somatismos anteriores, pero no considera "correr de boca en boca" como locución verbal. Nos encontramos ante un caso típico de frontera entre una locución adverbial y una locución verbal (cuando va acompañada por verbos como "andar", "ir", "correr"). No obstante, optamos por descartarla del corpus, a pesar de resultar rentable para la clase de E/LE.

En rumano contamos con una serie de UF parcialmente equivalentes. "A fi pe buzele tuturor" (lit. estar en los labios de todos) contiene un somatónimo contiguo, pero no refleja la idea de acción (correr/andar), mientras que "a merge / a (i) se duce vestea" ("andar/irse[le] la noticia") se acerca más al contenido funcional reflejado en español, el de transmitir información. Varios diccionarios bilingües proporcionan traducciones alternativas, aprovechando la existencia en rumano de la locución adverbial "din gură în gură" (lit. de boca en boca): "a duce vorba din gură în gură" (lit. llevar el habla de boca en boca), "a răspândi din gură în gură" (lit. difundir de boca a boca), pero ninguna de estas es una locución verbal.

En el mismo apartado funcional (dar o transmitir información) insertamos la UF "no decir esta boca es mía" ('no decir nada'), una de las pocas entradas con equivalencia nula en rumano. Consideramos que se trata de una locución muy transparente en su componente verbal ("no decir" = callar), pero extremadamente opaca en el componente nominal ("esta boca es mía"). El rumano cuenta con dos locuciones no somáticas, "a tăcea mâlc" y "a tăcea chitic", con referentes tomados del campo léxico de los animales: "callar (como una) caracola" y "callar (como un) pez". Hay que destacar que en ambas situaciones los componentes nominales ("mâlc" y "chitic") han dejado de tener existencia propia, para convertirse en palabras diacríticas, cuya presencia en el rumano actual está confinada a los elementos prefabricados anteriormente mencionados.

En cambio, "no abrir la boca" ('callar cuando se debería hablar') encuentra en rumano un equivalente total en cuanto a significado, a estructura argumental y contorno sintáctico $(\mathrm{S}+\mathrm{V}+\mathrm{OD}$ ), "a nu deschide gura" (lit. no abrir la boca). Una situación idéntica comprobamos en el caso de "mantener la boca cerrada" - "a ţine gura închisă" (lit. tener la boca cerrada), por lo que recomendamos su introducción más temprana, en el nivel inicial y plataforma, respectivamente.

No obstante, un somatismo aparentemente fácil ("abrir boca") ha sido relegado a niveles superiores debido a la nula equivalencia en rumano ("despertar el apetito con alguna bebida o comida") y a la posible confusión con otra locución verbal anteriormente analizada, "abrir la boca". Destacamos aquí, una vez más, uno de los 
rasgos más importantes de las UF, la fijación, y remarcamos como la presencia o la ausencia de un artículo cambia por completo el significado /la función comunicativa.

Incluimos en este apartado del análisis una UF que no contiene el lexema "boca", sino uno de sus derivados. La locución verbal "ser un/una bocazas" ('hablar más de lo que aconseja la discreción") encuentra en rumano un equivalente parcial, "a fi gură-spartă" (lit. ser boca partida). Tenemos la convicción de que la dificultad de muchas UF de este tipo se debe al incumplimiento de algunos esquemas gramaticales interiorizados por los estudiantes (i.e. bocazas - sustantivo masculino acabado en as), a pesar de que el DRAE proporciona como variante la forma en singular ("ser un/una bocaza"). En estos casos, es imprescindible hacer hincapié en el contorno sintáctico al que se refieren Mendizábal y Sastre (2017) - <alguien (masculino singular)> es un bocazas - y diseñar materiales significativos para la correcta asimilación de esta estructura en el nivel intermedio alto.

El contorno sintáctico resulta fundamental en el análisis de las locuciones verbales "írsele la boca" e "irse de boca" ('hablar mucho y sin consideración o con imprudencia'), cuyos equivalentes en rumano contienen el mismo somatónimo: "a lua gura pe dinainte" (lit. tomar la boca por delante) y "a nu-şi ţine gura" (lit. no contenterse la boca). Varios repertorios fraseológicos (como el DILEA) recogen la variante "irse de la boca" (con el artículo definido), lo que da una idea de la falta de uniformidad y de la complejidad de los criterios adoptados.

En el primer caso, el sujeto léxico forma parte de la locución, <la boca>se le va $<$ a alguien $>$, mientras que en la segunda hay un actante (alguien) que se va de (la) boca. Mendizábal y Sastre (2017) analizan detenidamente el segundo somatismo:

en irse de la boca el contorno quedaría así: <alguien> <se> va de la boca. Esto indica que en el uso el hablante no nativo tendrá que decir: yo me voy de la boca, tú te vas de la boca, él/ella/usted se va de la boca, nosotros/-as nos vamos de la boca, vosotros/-as os vais de la boca, ellos/ellas/ustedes se van de la boca (Mendizábal y Sastre 2017:53).

Suscribimos plenamente las conclusiones de las autoras. Si para un hablante nativo estas estructuras no plantean ninguna dificultad, para un aprendiz de E/LE "puede ser un escollo a la hora de poner en funcionamiento la locución, bien porque no conozca el significado o porque falle su competencia gramatical y fraseológica" (Mendizábal y Sastre 2017:53). Por nuestra experiencia docente con alumnos rumanos, consideramos que en el caso de estas locuciones el mayor reto es de índole sintáctica, por lo que recomendamos su presentación en el nivel B2.

En cambio, la UF "calentarse la boca" aporta una dificultad añadida, al no contar con equivalente en rumano. Las explicaciones que proporciona el DRAE son también muy complejas: 'hablar con extensión, explayarse en el discurso'; 'enardecerse, prorrumpir en verdades', por lo que comprendemos que el DSREL haya decidido prescindir de esta entrada plurisemántica. Debido al complejo contorno sintáctico (<a 
alguien > se <le> calienta la boca") y a la falta de transparencia, la relegamos a niveles superiores al B2.

En una situación similar se encuentra la UF "Ilenársele la boca a alguien" ('hablar mucho, con gran orgullo o interés', <a alguien > se <le > llena la boca, donde el reflexivo se mantiene invariable, mientras que el verbo pronominal flexiona con el complemento indirecto. La locución española conlleva matices muy finos, inexistentes en rumano, como expresar hipocresía o falta de coherencia.

Por razones de índole semántico - pragmática hemos dejado fuera del corpus la locución "lavarse la boca con jabón", al considerar que los aprendientes tendrán pocas oportunidades de expresar amenaza en estos niveles y con este tipo de estructuras.

Además de la función comunicativa "dar y transmitir información", recurrimos al somatónimo "boca" para expresar otras funciones, aunque se genera un menor número de UF.

Expresamos enfado o fastidio a través de la locución verbal "dejar mal sabor de boca" ('dejar un mal recuerdo' o 'producir un disgusto por haber sido triste o desagradable'). El rumano cuenta con una UF parcialmente equivalente, "a lăsa un gust amar" (lit. dejar un sabor amargo) que recupera prácticamente los elementos constitutivos ( $\mathrm{V}+\mathrm{OD}$ acompañado de adjetivo), pero prescinde del somátonimo. Por lo tanto, la locución es muy transparente, a pesar de una leve diferencia morfológica ("gust" aparece articulado con artículo indefinido en rumano, frente a la forma no articulada del sustantivo "sabor").

A pesar de que el DRAE no recoge la locución antónima, la encontramos en varios repertorios fraseológicos, como el DSREL: "dejar algo (muy) buen sabor de boca" ('dejar un recuerdo agradable'). Su equivalente en rumano, "a lăsa un gust plăcut" (lit. dejar un sabor agradable) no aparece en fuentes fraseológicas monolingües como el DELS y tiene una presencia muy escasa en la red.

Mendizábal y Sastre (2017) analizan una variante de la locución que incluye una preposición, "dejar con mal sabor de boca".

Hay locuciones compuestas por un verbo seguido de un complemento argumental no lexicalizado. Obviamente, si el complemento argumental no está lexicalizado, no aparece en la locución verbal, pero tiene que aparecer obligatoriamente (se trata del complemento argumental) en el contorno sintáctico. Esto no es un obstáculo para que la locución tenga otros formantes. Por ejemplo, en las locuciones verbales de tipo dejar con mal sabor de boca (...) el contorno sintáctico sería <alguien o algo> deja con mal sabor de boca <a alguien> (...) (Mendizábal y Sastre (2017:53-54).

Las autoras ejemplifican sus argumentos con somatismos encontrados en el buscador Google, en junio de 2015. Asimismo, en un subcapítulo que dedican a los problemas de delimitación entre unidades, analizan otra UF que hemos barajado para 
nuestro corpus: "salir a pedir de boca", con su equivalencia en rumano "după pofta /placul/ voia inimii” (por el gusto/deseo del corazón).

Somos conscientes de que a veces resulta complicado establecer límites entre las unidades fraseológicas equivalentes a un verbo (por ejemplo, entre locuciones verbales, colocaciones verbales, predicados complejos o sintagmas libres); incluso tampoco se distinguen siempre con nitidez las locuciones verbales (por ejemplo, no está del todo claro si a pedir de boca es una locución adverbial o es un formante de la locución verbal salir a pedir de boca). (...) tampoco ayudan a discernirlo los diccionarios y repertorios lexicográficos, con lo que tanto los hablantes nativos como los no nativos se sienten desamparados en este sentido (Mendizábal y Sastre 2017:54).

Personalmente coincidimos con el DRAE, que recoge la locución "a pedir de boca" ('tal como se deseaba') como adverbial, por lo que no la incluimos en el corpus, a pesar de su fuerza expresiva.

Tampoco seleccionamos la locución adverbial "con la boca abierta" para expresar sorpresa, generalmente encontrada en construcciones con los verbos "estar", "dejar" o "quedarse", a pesar de que todas las locuciones tienen equivalencias en rumano: "a fi/ a lăsa/ a rămâne cu gura deschisă" (lit. idem.). El somatismo "con tanta boca abierta", que el DRAE sugiere como alternativa, tampoco forma parte de la base de datos (por ser locución adverbial, menos frecuente que las anteriores, y por su extraña combinación de elementos léxicos). 


\subsubsection{Somatismos con el lexema "brazo"}

En el caso del lexema "brazo" (en rumano "braţ", pero por extensión también "mână" - "mano"), observamos que las locuciones más rentables no son verbales, a pesar de que generalmente van acompañadas de un elemento verbal.

Es el caso de "con los brazos abiertos" ('cordialmente, con agrado'), locución adverbial que suele aparecer en combinación con verbos como "recibir", "esperar", "admitir", "acoger "u otros equivalentes, normalmente con complemento directo que designa persona.

Nosotros proponemos dos entradas: "esperar con los brazos abiertos", con un equivalente total en rumano, "a aştepta cu braţele deschise"; y "recibir con los brazos abiertos", que cuenta a su vez con un equivalente total en rumano: "a primi cu braţele deschise". Las dos UF tienen la misma estructura argumental (agente-paciente): <alguien> espera con los brazos abiertos <a alguien> y comparten el contorno sintáctico $(\mathrm{S}+\mathrm{V}+\mathrm{OD}+\mathrm{CCM})$. Un aprendiz rumano no encontrará ninguna dificultad léxica, morfosintáctica, semántica o pragmática, por lo que consideramos conveniente integrar estas locuciones en el contenido funcional de las relaciones sociales y laborales, en el nivel A2.

Una situación casi idéntica notamos en el caso de la locución adverbial "con los brazos cruzados" (con su variante "de brazos cruzados"), definida por el DFDEA en los siguientes términos: "sin hacer nada. Frecuentemente referido a la actitud de indiferencia o pasividad en situaciones que requerían acción”. Decidimos introducir en nuestro corpus tanto la UF "estar de brazos cruzados" como la locución verbal "cruzarse de brazos" por su relevancia, frecuencia y transparencia. El rumano recurre a la misma imagen estática en la locución somática "a sta cu mâinile în sân" (lit. estar con manos en seno). Se trata, por lo tanto, de una equivalencia parcial, puesto que difieren varios parámetros, entre los que destacamos los elementos léxicos que conforman el fraseologismo. Asimismo, recogemos otra UF transparente, aunque de uso menos frecuente, "a sta cu mâinile încrucişate" (lit. estar con manos cruzadas).

Además de estos equivalentes, el DSREL ofrece otra serie sinonímica en rumano, "a sta cu mâinile în buzunar" (lit. estar con las manos en bolsillo), "a arde gazul de pomană" (lit. arder el gas en vano), "a nu mişca un deget" (lit. no mover un dedo"), "a (nu) pune (deloc) mâna", lit. (no) poner la mano (en absoluto), "a freca menta" (lit. fregar la hierbabuena). Sin embargo, consideramos que estas alternativas carecen de explicaciones adicionales de uso y registro, imprescindibles en casos como "a arde gazul de pomană" o "a freca menta" (que presentan restricciones diastráticas) o "a sta cu mâinile în buzunar" (de uso restringido; no aparece en la versión impresa del DEX, aunque sí en la edición en línea). En este punto del análisis, coincidimos con Mellado (2015:155) cuando afirma que "(...) en los diccionarios sería aconsejable que junto a las equivalencias en la L2 se explicaran las posibles restricciones de uso, cuestiones combinatorias o divergencias en la estructura del significado de los respectivos fraseologismos en la L2." 
Observamos que el rumano no cuenta con una locución verbal propiamente dicha que refleje la idea de acción ("cruzarse"), por muy paradójica que la acción sea en este caso, donde el significado idiomático es el de actitud pasiva. Prevalece en cambio el uso extenso del verbo "a sta" (quedarse, estar, permanecer) junto con la UF analizada previamente, "cu mâinile în sân". En resumen: por el contorno sintáctico, la estructura actancial y el tipo de equivalencia, sugerimos introducir estas UF en el nivel B1, aprovechando la presentación de contenidos funcionales como el mundo laboral o las relaciones laborales.

En cuanto a las demás locuciones verbales, apuntamos "abrir los brazos" ('recibir con cordialidad'), recogida por el DFDEA, pero no reflejada con tal en el DRAE. Es un caso con el que nos hemos encontrado frecuentemente a lo largo de nuestro estudio y que muestra, una vez más, la complejidad de delimitar estos elementos léxicos y la multitud de los criterios manejados. EI DEX recoge un somatismo equivalente en rumano, "a deschide braţele" (lit. abrir los brazos) y proporciona la siguiente definición: "recibir a alguien con alegría". Ambas UF tienen la misma estructura argumental (<alguien> abre los brazos <a alguien>0 < a algo $>$ ) y la misma función comunicativa: relación social. A pesar del alto grado de transparencia, la recomendamos para el nivel $\mathrm{B} 2$, debido a su uso más restringido.

Un somatismo complejo lo representa "dar el brazo a torcer" ('ceder en una opinión, actitud o propósito en que se ha mantenido firme') por su uso preponderante en negativo, por la posibilidad de usar el posesivo en detrimento del artículo definido ("dar su brazo a torcer"), pero principalmente por la ausencia de una clara equivalencia en rumano. Varias fuentes lexicográficas consultadas insisten en proporcionar una alternativa, pero se trata más bien de intentos explicativos, parafraseando la locución española: "a (nu) da un pas înapoi" (lit. [no] dar un paso atrás, [no] retroceder), "a (nu) se lăsa convins" (lit. [no] dejarse convencer), "a (nu) se da bătut" (lit. [no] darse por vencido), etc. Entendemos y respetamos el anhelo de escudriñar en la lengua meta a fin de encontrar equivalencias funcionales, pero nuestro enfoque es distinto, ya que consideramos más honesto no forzar traducciones artificiosas y admitir los casos con equivalencias nulas. Consideramos que el somatismo que estamos analizando se inserta en este apartado, a pesar de que la locución verbal "torcer el brazo" sí que tiene en rumano un equivalente perfecto "a forţa mâna" (lit. forzar la mano). Además, detectamos el mismo contorno sintáctico, verbo transitivo + grupo nominal que ejerce de OD: <alguien> <le> fuerza la mano <a alguien> = <cineva > <îi forţează mâna $<$ cuivas. A pesar de las similitudes señaladas, consideramos más rentable la presentación de estas UF en el nivel B2, sobre todo desde la perspectiva del contenido funcional: expresar resignación. García-Page (1995) menciona el caso de esta UF en el contexto más amplio de las locuciones en las que es opcional la presencia de la negación y que pueden constituir una fuente de errores que comenten los hablantes no nativos en relación con el funcionamiento de la negación. 
Hay locuciones en las que es opcional la presencia de la negación (...) Hay otras cuya modalidad general es negativa, pero en determinados contextos es posible la estructura afirmativa; comp. "Luis era tan engreído y orgulloso que no daba su brazo a torcer nunca, pero, cuando le salió novia, ya lo creo que dio su brazo a torcer. Enseguidita" (GarcíaPage 1995:160).

Desde el inicio de este estudio decidimos acotar el análisis a SO que contienen un sintagma verbal. Por lo tanto, las colocaciones nominales no tienen cabida en nuestro corpus. Coherentes con esta premisa inicial, decidimos prescindir de la UF "brazo derecho" ('colaborador prácticamente imprescindible y de la máxima confianza de alguien), a pesar de que se presencia recurrente en la UF verbal "ser el brazo derecho". Su equivalente en rumano "a fi mâna dreaptă (a cuiva)" (lit. ser la mano derecha de alguien) tiene el mismo contorno sintáctico, por lo que un estudiante rumano reconocerá, comprenderá y utilizará sin dificultad tal somatismo. Se integra perfectamente en el nivel B1, dentro del contenido funcional de las relaciones personales o laborales, sugerido incluso por el propio DRAE, que define el sintagma como "persona subordinada (...) con la que se colabora eficazmente".

Por la complejidad del esquema argumental, relegamos "echar <a una persona> en brazos < de otra>" a niveles superiores, a pesar de que el rumano aplica el mismo esquema: "a arunca <pe cineva $>$ în braţele <altcuiva>". EI DRAE proporciona la locución en su estructura más frecuente, con el pronombre reflexivo ("echarse en brazos de alguien) y, en lugar de una definición explicativa, remite a otro equivalente somático, "ponerse en manos de alguien".

Finalmente, justificamos la ausencia de la UF "estar en brazos de Morfeo" por la presencia de la referencia cultural (Morfeo - dios del sueño), desconocida para la mayoría de los rumanohablantes. La locución verbal aparece registrada en el DRAE bajo la entrada "Morfeo", en el DFDEA encontramos la locución "en brazos", pero nos remite también a "Morfeo" donde se baraja una UF no somática, ya que "en lugar de brazos puede aparecer otro nombre equivalente". Además, se sugiere como alternativa más frecuente "caer en brazos de Morfeo" y se añade la marca humorística. Nosotros propondríamos como variante posible para la traducción al rumano el culturema "vine Ene pe la gene" (lit. llega el Arenero a las pestañas), que recupera el matiz humorístico debido al factor prosódico de rima y una referencia a un personaje mitológico.

Mientras tanto, el DLVES (cuyos destinatarios principales son los estudiantes de E/LE) la omite por completo. Comprobamos, una vez más, la falta de criterios homogéneos, sobre todo a la hora de clasificar UF que plantean más problemas estructurales $y$, como docentes, echamos en falta más uniformidad. 


\subsubsection{Somatismos con el lexema "cabeza"}

El somatónimo "cabeza" (en rumano "cap") genera una multitud de UF en las dos lenguas. En nuestro análisis interlingüístico observamos muchas similitudes entre las locuciones analizadas, tanto en las estructuras morfosintácticas como en cuanto a los componentes léxicos. Asimismo, hemos comprobado que el foco recae generalmente en el actante, otro elemento común entre las dos lenguas.

El esquema argumental de la locución verbal "bajar/agachar la cabeza" ('conformarse o someterse') es <alguien> baja/agacha la cabeza. El rumano maneja una estructura similar $(S+V+O D)$ en "a-şi pleca capul" (lit. agachar la cabeza - 1. darse por vencido; 2. sentirse avergonzado, humillado), pero no del todo idéntica, ya que notamos la presencia de un elemento morfológico pronominal: "eu <îmi> plec capul, tu <îţi> pleci capul, el <îşi> pleacă capul”, etc., que no altera la imagen ni representa una fuente de interferencias. Consideramos que la locución "bajar la cabeza" se puede impartir en el nivel B1, pero relegamos al nivel intermedio alto "agachar la cabeza", debido a que el verbo tiene un uso menos frecuente y que los alumnos ya cuentan con una UF para expresar resignación. Destacamos también el somatismo rumano "a lăsa capul în jos" (lit. dejar la cabeza en abajo) como alternativa a la hora de encontrar una equivalencia, utilizada principalmente para expresar vergüenza.

El antónimo de "bajar" genera también somatismos: tenemos por un lado "levantar cabeza" ('salir de una larga situación de pobreza, enfermedad o desgracia'), usada más frecuentemente en negativo, y, por otro lado, "levantar la cabeza" ('resucitar'), utilizada frecuentemente en la construcción condicional "si <alguien> levantara la cabeza"). Subrayamos la presencia o la ausencia del artículo definido, que desempeña no solamente un papel sintáctico, sino que provoca un importante cambio de significado. Debido a esta sutil diferencia de contorno sintáctico y a fin de evitar posibles confusiones, en el corpus seleccionamos únicamente "levantar cabeza" y su UF equivalente en rumano "a se pune pe picioare" (lit. ponerse sobre piernas). Como se puede observar, se trata de una equivalencia parcial que contiene un somatónimo diferente. Aunque no del todo transparente, consideramos que el significado no presenta mayores escollos para un aprendiz de nivel B1.

Otros somatismos que funcionan en relación antónima son "meter en la cabeza" vs. "quitar (o sacar) de la cabeza", ambas transparentes en rumano, donde contamos con "a băga în cap" y "a scoate din cap". Añadimos las distintas entradas pronominales "meterse en la cabeza" vs. "quitarse de la cabeza" y "metérsele en la cabeza" vs. "quitársele de la cabeza". Al cruzar varios registros fraseológicos nos llama la atención, una vez más, la complejidad del contorno sintáctico presente en las entradas y nos refuerza la convicción de introducir en el corpus locuciones "desnudas", dejando para otra casilla separada la información que configura su estructura argumental: meter [algo a alguien] en la cabeza" - hacér[selo] aprender; meterse [alguien algo] en la cabeza - convencerse [de ello]; 
metérsele [algo a alguien] en la cabeza - convertírse[le] en una idea fija o en una aspiración obsesiva;

quitar (o sacar) [algo] de la cabeza [a una persona] - hacer que [esa persona] deje de pensar[lo];

quitarse (o sacarse) [algo o a alguien] de la cabeza - dejar de pensar [en ello]; quitársele [ a alguien algo] de la cabeza - dejar [esa persona] de tener [lo] en el pensamiento

Tras analizar detalladamente los somatismos anteriores, nos planteamos cuáles serían los más rentables para una presentación coherente con el nivel y los intereses de nuestros destinatarios. Intuimos que en este caso no corren el riesgo de cometer errores de tipo pragmático, pero la complejidad de la estructura argumental podría suponer una traba considerable: <alguien> $0<$ algo > <le > quita de la cabeza <algo> $<a$ alguien $>$. Por nuestra experiencia docente, opinamos que es mejor seleccionar fórmulas más rutinarias de tipo "iquítatelo de la cabeza!" en actividades contextualizadas y relevantes.

Otra serie interesante está constituida por "meter pájaros en la cabeza", "Ilenar la cabeza de pájaros" y "tener la cabeza llena de pájaros". En todos estos casos se trata de UF complejas, con estructuras formadas por tres elementos fijos, por lo que resulta aún más importante idear un contexto adecuado para la emisión de locuciones con semejantes constituyentes. Tanto desde el punto del significado como desde la perspectiva morfosintáctica, para un hablante rumano las UF como "Ilenar la cabeza de pájaros", "meter pájaros en la cabeza" o "tener la cabeza llena de pájaros" no plantean mayores dificultades. El rumano asocia también las ideas extravagantes o extrañas con lexemas que proceden del mismo campo conceptual (pájaros e insectos que vuelan): "a avea fluturi în cap" (lit. tener mariposas en la cabeza), "a fi cu /a avea sticleti (in cap)", lit. estar con /tener jilgueros (en la cabeza), "a avea (o) păsărică /păsărici la cap", lit. tener (un) pajarito / pajaritos en la cabeza expresan con leves matices la falta de cordura.

Una locución verbal equivalente de uso más frecuente nos parece "a avea gărgăuni în/la cap" (lit. tener avispas en la cabeza), donde "gărgăuni" ha sufrido el fenómeno de deslexicalización, ya que el primer significado "avispa grande que vive en los bosques" es prácticamente desconocido por la mayoría de hablantes. Hoy en día, cualquier rumanohablante relaciona esta palabra diacrítica con ideas raras y descabelladas.

En el DSR encontramos una larguísima serie aparentemente sinonímica, con múltiples variantes de traducción: "tener la cabeza a las once/a tres/a pájaros/ llena de pájaros/ de aire/ en Belén con los pastores" = "a umbla cu capul în nori, a trăi în nori, a fi cu gândul aiurea, a nu-i fi mintea acasă, a avea mintea dusă/ plecată cu sorcova, a-i lipsi o doagă". Consideramos contraproducente enlazar tantas locuciones sin proporcionar un contexto adecuado de uso, ningún condicionante de tipo pragmático o discursivo y ninguna información que configure la estructura argumental. 
Por estos argumentos, en nuestro corpus decidimos operar una selección más coherente con los objetivos declarados. Por lo tanto, descartamos la locución "tener (la) cabeza de chorlito" por la dificultad del lema y la inestabilidad del artículo definido y relegamos el SO "tener la cabeza a pájaros" a niveles superiores, debido a la complejidad de la preposición, que provocaría dudas acerca del significado global. Asimismo, prescindimos de las locuciones "tener la cabeza llena de serrín" y "no tener más que serrín en la cabeza", usadas para ponderar la falta de seso o de inteligencia de una persona, debido a la estructura compleja y los difíciles componentes léxicos, pero sobre todo porque los aprendices ya cuentan con recursos fraseológicos para expresar la función comunicativa (describir a una persona que no tiene juicio).

Otras UF complejas que en un primer acercamiento a los somatismos tomamos en cuenta para la creación del corpus fueron "poner la cabeza como un sonajero" y "poner la cabeza como una olla de grillos", a pesar de que las fuentes lexicográficas consultadas las registran como locuciones adverbiales y proporcionan definiciones prácticamente idénticas: "como una jaula (u olla) de grillos" - en estado de gran atontamiento o aturdimiento; referido a la cabeza y generalmente con verbos como "tener" o "poner"; "como un sonajero" - en estado de gran aturdimiento o confusión; referido a la cabeza y generalmente con verbos como "tener" y "poner". No obstante, consideramos prematura su presentación en el nivel B2, principalmente por la complejidad de la estructura, por la dificultad de lemas como "grillo" o "sonajero", pero también, considerando el parámetro semántico, por la falta de una imagen equivalente en rumano. La UF somática equivalente que maneja el rumano es más sintética, "a face capul calendar" (lit. hacer la cabeza calendario), 'aturdir a una persona por decirle demasiadas cosas", y tiene una estructura argumental: "<alguien $><l e>$ hace la cabeza calendario <a alguien>".

No obstante, decidimos conservar en el corpus la compleja locución verbal "esconder la cabeza debajo del ala" y su versión menos frecuente "meter la cabeza debajo del ala" ('no querer ver la realidad o no hacerle frente'), debido a que el rumano cuenta con una metáfora motivada similar, en el SO "a băga capul în nisip" (lit. meter la cabeza en arena). En ambas lenguas encontramos una estructura formal idéntica, $\mathrm{V}+$ nombre (somatónimo) +CCL, y la misma referencia semántica casi inmediatamente reconocible: el rumano alude a un avestruz, mientras que el español remite directamente a un pájaro. Consideramos que se trata de una UF rentable e idónea para el nivel intermedio, integrada en actividades de aula para presentar 0 reforzar contenidos funcionales como las relaciones personales o la gestión de conflictos.

Donde podrían surgir varios problemas de comprensión y, sobre todo, de producción, es en el caso de UF complejas como "escarmentar en cabeza ajena" ('tener presente la experiencia adversa para evitar la misma suerte') o "no dejar títere con cabeza" ('atacar o criticar a todos'). En ambos casos la dificultad radica principalmente en la complejidad de lemas como "escarmentar" (verbo irregular, de 
uso poco frecuente - traducible en rumano por una estructura perifrástica "a se învăţa minte") o "títere" (en rumano "marionetă"). En el caso de "escarmentar en cabeza ajena" cabe señalar también la nula equivalencia en rumano, donde habría que parafrasear el significado convencionalizado: "a învăţa din greşelile altuia" (lit. aprender de los errores de otro). En el caso de "no dejar títere con cabeza", el DSREL ofrece alternativas, algunas poco convincentes, como "a rade tot" (lit. arrasar todo), "a spulbera tot" (lit. idem), pero también una acertada locución verbal no somática, "a face praf totul" (lit. hacer polvo todo). Por todos estos argumentos, recomendamos su presentación en los niveles "maestría" o "dominio operativo eficaz".

En honor a la verdad hemos de afirmar que a medida que vamos analizando más a fondo el corpus de UF recogido, vamos descartando muchas locuciones o las relegamos a niveles superiores al $\mathrm{B} 2$ por motivos expuestos previamente: la complejidad del contorno sintáctico (sobre todo cuando hay implicados rasgos gramaticales pronominales), la dificultad del lema, la opacidad, la equivalencia nula en rumano o la falta de rentabilidad del somatismo.

Sin embargo, no prescindimos directamente de las locuciones complejas si observamos su eficacia, su adecuación a los contenidos funcionales impartidos en el curriculum y una transparencia que facilita su comprensión y producción. Como hemos venido señalando, la selección que operamos es válida únicamente para aprendices rumanos; por consiguiente, el criterio de la transparencia no sería extrapolable a otras lenguas, para las que habría que elaborar otra selección de UF, acorde con sus propias características.

Por lo tanto, decidimos incluir la UF transparente "darse con la cabeza en la pared o en las paredes", ambas versiones contempladas por el DRAE ('desesperarse por haber obrado torpemente'). Nos ha sorprendido su ausencia en otros registros fraseológicos, como el DFDEA (fuente reconocida y apreciada por la comunidad científica) o el DILEA, aunque en este segundo caso su autora afirma que "está concebido como una obra en continua revisión por las clases de locuciones que se irán incluyendo en el futuro y por el examen permanente al que será sometido, el cual puede conducir a modificar los datos existentes, si es necesario" (Penadés 2019). Tampoco encontramos el SO en el DSREL, a pesar de haber buscado la UF en distintas (posibles) entradas: "dar(se)", "cabeza" o "pared". Convendría, quizás, reflexionar una vez más sobre la heterogeneidad de los criterios manejados por los diccionarios generales, por los repertorios fraseológicos e incluso por los trabajos de investigación. Por este motivo, en nuestro análisis hemos "zigzagueado" por todos estos territorios, cruzando numerosas fuentes para que la decisión final tenga un respaldo léxico fidedigno. Siguiendo el análisis contrastivo de la locución "darse con la cabeza en la pared (...)", el rumano cuenta con una UF equivalente en el significado literal, en el fraseológico, en la estructura sintáctica (actancial) y en el componente pragmático. EI DEX incluye "a se da cu capul de toţi pereţii (sau de pereţi)", lit. darse con la cabeza de todas las paredes (o de paredes), con el significado estar preso por 
la desesperación o los problemas, arrepentirse por un error cometido. Las diferencias que señalamos es que el rumano no oscila entre las formas de singular y plural, ya que cualquier variante contempla el lema "paredes", pero sí entre variantes que incluyen o no el adjetivo indefinido. Además, la variante que incluye un elemento prepositivo requiere el sustantivo sin artículo definido: "de pereţi".

En el contenido funcional de la descripción del carácter podemos integrar varios somatismos. Para expresar un rasgo positivo contamos con "tener la cabeza sobre los hombros" ('razonar con sensatez o cordura'), que el DRAE omite en detrimento de su variante "tener la cabeza en su sitio" ('ser muy juicioso'). Al existir en rumano una estructura casi isomorfa ("a fi cu capul pe umeri", lit. estar con la cabeza sobre los hombros), la UF española no plantea ninguna dificultad. Encontramos somatónimos idénticos y una equivalencia pragmática total (ser una persona realista, sensata, en su sano juicio), por lo que podemos integrar el $\mathrm{SO}$ en el nivel inicial.

En el polo opuesto, expresamos un rasgo negativo con la UF "estar mal de la cabeza" ('estar loco'), con su versión antifrástica "no estar bien de la cabeza". El rumano tiene un equivalente en "a fi dus (cu capul)", lit. estar ido (con la cabeza). Ambas locuciones comparten el significado y el somatónimo, aunque en rumano podríamos prescindir del segmento "cu capul" (con la cabeza) sin perder la carga semántica. Sin embargo, apuntamos una diferencia en cuanto al contorno sintáctico. En español la UF es invariable, mientras que en rumano el participio con función adjetival flexiona, concordando con el sujeto en número y género. 


\subsubsection{Somatismos con el lexema "callo"}

El somátonimo "callo" (en rumano bătătură") genera un número reducido de locuciones en las dos lenguas. Para conformar el corpus, hemos descartado UF dialectales como "no doler ni los callos a alguien" ('gozar de buena salud') o de uso más restringido como "criar callos" ('habituarse a los trabajos, al maltrato o a los vicios'). Comprobamos que todos los repertorios fraseológicos consultados hacen la misma criba y se conforman con un par de somatismos frecuentes y rentables.

En primer lugar, señalamos "dar el callo" (interpretado por algunos lexicógrafos como 'trabajar' por otros como 'trabajar mucho'). En rumano encontramos una locución verbal más compleja, "a pune osul la treabă" (lit. poner el hueso al trabajo), que contiene a su vez un somatónimo. Notamos una leve diferencia de significado semántico en rumano: "trabajar seriamente/con sentido de responsabilidad", por lo que nos encontramos ante un tipo de equivalencia parcial. Por esta razón y debido a la opacidad del lema y de la UF española en su conjunto, recomendamos su presentación en el nivel intermedio.

Más transparente resulta la locución verbal "pisar el callo", con su equivalente parcial en rumano "a călca pe bătături" (lit. 'pisar en los callos'). A pesar de esta equivalencia muy útil, que favorece la decodificación, señalamos algunas variantes de la UF que podrían causar confusión en el plano morfosintáctico: encontramos tanto "pisar el callo" como "pisar los callos", mientras que el rumano opera exclusivamente con la forma de plural (no articulado). Destacamos también una flexibilidad inexistente en rumano: "pisar el callo <a alguien>" y "pisar el callo <de alguien>", molestar[le] o fastidiar[le] vs. "a călca pe cineva pe bătături" (lit. pisar a alguien en los callos), estructura con mayor grado de fijación. 


\subsubsection{Somatismos con el lexema "cana"}

Como en el caso anterior, el lema "cana" (traducido al rumano por sintagmas como "păr alb" o "fir de păr alb" - pelo blanco/hilo de pelo blanco) genera pocas UF. Descartamos sin vacilar entradas en desuso como "quitar mil canas a alguien" ('causarle gran gusto y satisfacción') o dialectales, como "sacar canas verdes a alguien" ('causarle preocupación y disgusto').

Tras haber sopesado su inserción en el corpus, finalmente decidimos relegar a niveles superiores la locución "echar una cana al aire", con su variante "echar una canita al aire", indexada también con el verbo "tirar" (mucho menos frecuente). Su significado ('divertirse ocasionalmente - generalmente referido al sexo' -, según el DFDEA o 'tener una relación sexual esporádica', según el DILEA) no tiene una equivalencia clara en rumano. Los diccionarios fraseológicos bilingües recurren a estrategias como parafrasear el significado: "permitirse excepcionalmente un exceso", remitir a otras UF afines semánticamente como "soltarse alguien el pelo" o "darse alguien el gustazo" o proporcionar explicaciones como "hacer una escapada". Por lo tanto, opinamos que para un aprendiente rumano de E/LE las posibilidades de inferir el significado de esta UF son nulas y precisa de un contexto esclarecedor.

Aunque tampoco tiene una equivalencia en rumano, la locución "peinar canas" ('ser vieja una persona') es más transparente, tiene un contorno sintáctico sencillo $(\mathrm{S}+\mathrm{V}+\mathrm{OD})$ y la función comunicativa (descripción física) se adscribe al nivel intermedio. 


\subsubsection{Somatismos con el lexema "cara"}

A pesar del número elevado de somatismos con el lexema "cara" (en rumano "faţă") que contabilizamos en una primera fase de recogida de datos, son relativamente escasas las UF que seleccionamos finalmente. Las dudas no giraron en torno a locuciones dialectales, en desuso, que pertenecen a lenguajes especializados (como el taurino) o que cubren contenidos funcionales superiores a los niveles para los que aplicamos el análisis: "ser la cara cortada de alguien", "volver la cara al enemigo", "escupir en la cara", "terciar la cara", etc. Nos detuvimos más a la hora de decidir acerca de locuciones de uso muy frecuente, como "cara de pocos amigos", "cara de póquer", "a cara o cruz", "por la cara", "por mi/tu/su cara bonita", etc. A pesar de que estas colocaciones y locuciones van acompañadas generalmente por un verbo ("tener cara de pocos amigos", "echar a cara o cruz", etc.), prescindimos de ellas, al no tratarse de locuciones verbales, el objeto de este trabajo.

En el corpus (la herramienta virtual que hemos elaborado y que recoge la información esquematizada) incluimos una serie de somatismos que comparten rasgos semánticos comunes: "cruzar la cara", "romper la cara" y "poner la cara del revés", ya que todos expresan amenaza, violencia o enfrentamiento.

cruzar la cara [a alguien] - dar[le] en la cara dos bofetadas o un latigazo

poner la cara (o volver) [a alguien] la cara del revés - dar[le] un bofetón o puñetazo muy fuerte

romper la cara - remite a "partir la cara" (con otra posible variante "quitar la cara") [a alguien]: dar[le] un puñetazo y otro golpe

El rumano cuenta a su vez con una serie de locuciones verbales equivalentes: "a sparge faţa" ('romper la cara'), golpear fuertemente en el semblante, idéntica a la UF española desde el punto de vista léxico, sintáctico y semántico y "a arde una (peste faţă)", lit. arder una por la cara - pegar una bofetada. Este somatismo posee un grado menos reducido de fijación, al coexistir "a arde peste bot" (lit. arder por el hocico) y "îţi ard una de nu te vezi", lit. te ardo una que no te ves, más cercana en cuanto a equivalencia funcional a "poner la cara del revés". Aunque figuran en nuestro corpus, pensamos que resultaría redundante llevar al aula todas las UF que cubren este contenido funcional sumamente complicado, facilitando contextos de uso adecuados.

En cambio, la locución verbal "echar en cara" ('reprochar') es más idónea y rentable para el nivel $\mathrm{B} 2$, a pesar de su falta de transparencia en rumano, donde existe "a scoate ochii" (lit. sacar los ojos). Sin embargo, comparten el mismo contorno sintáctico: <alguien> <le> echa en cara <a alguien> - <cineva> <îi> scoate ochii <cuiva $>$ y, como hemos podido comprobar, un somatónimo contiguo. Otras fuentes lexicográficas proporcionan una equivalencia más cercana, "a-i arunca în obraz" (lit. echar en la mejilla). Cabe señalar que en rumano la mejilla (obraz) está metafóricamente vinculada con el respeto y la vergüenza, como podemos comprobar en otra UF: "caerse la cara de vergüenza" - "a-i crăpa obrazul de ruşine" (lit. partírsele la mejilla de vergüenza). 
En este punto de nuestro análisis destacamos la teoría de Wotjak (1985) acerca del significado de algunas expresiones idiomáticas que sirven para caracterizar ciertas cualidades de los seres humanos, sus interacciones sociales y sus estados anímicos, hipótesis con la que coincidimos plenamente.

Las expresiones idiomáticas verbales suelen expresar con preferencia una valoración negativa, peyorativa, señalando que, en el caso del comportamiento, de la conducta o cualidad moral descrita se trata de algo reprimible, incorrecto o por lo menos indeseable. Sirven para caracterizar engaño, holgazanería, vanagloria, embriaguez, pero también cansancio, enfermedad, desesperación, rechazo" (Wotjak, 1985).

En esta línea se inscriben locuciones como "cara dura", "cara larga", "cara de viernes", "cara de vinagre", "cara de pan sin sal", "cara de perro" o locuciones verbales como "restregar por la cara", "poner la cara colorada", "no (poder) mirar a la cara".

A su vez, Duţă (2014) analiza semánticamente varios somatismos con el lema "cara" en español y en rumano y concluye que las UF sugieren parámetros contradictorios:

mientras en dar/sacar la cara y echarle algo a alguien en cara, el somatismo implica honor y responsabilidad, en echarle cara a algo y tener más cara que espalda, la parte del cuerpo alude a la valentía, a la resistencia, incluso a la falta de respeto. Por el contrario, en rumano la "cara" (...) sugiere el respeto, posiblemente en relación al cambio de la expresión facial (Duţă 2014:164). 


\subsubsection{Somatismos con el lexema "carne"}

El lexema "carne" es totalmente idéntico en rumano, lo que debería allanar el camino para una mejor comprensión de las UF que lo contienen. Efectivamente, contamos con un número elevado de somatismos con un alto grado de transparencia, aunque, curiosamente, las expresiones rumanas no incluyen el mismo lexema.

Es el caso de "no ser carne ni pescado" (reflejada con esta entrada en el DRAE) y con la versión "no ser ni carne ni pescado" en otros repertorios fraseológicos (DFDEA, DILEA). Para expresar la idea del carácter indefinido, el rumano apela a una UF del mundo animal, "a nu fi nici cal nici măgar" (lit. no ser ni caballo ni burro) - no tener una situación precisa, no pertenecer a una categoría determinada. Consideramos pertinente la inserción de esta locución verbal en el nivel B1 porque, a pesar de la referencia a diferentes campos semánticos, el contorno sintáctico se mantiene igual: siempre aparecen en forma negativa y ambas UF incluyen las conjunciones copulativas "ni...ni".

En el caso de "poner toda la carne en el asador" hay que destacar la falta de equivalencia, aunque algunos diccionarios se empeñan en ofrecer alternativas viables: "a risca maximum într-o singură încercare" (lit. arriesgar al máximo en un único intento) en el DSREL o "a juca totul pe o (singură) carte", lit. jugarlo todo en una (sola) carta, en el DSR. En nuestra opinión, se trata más bien de intentos de traducciones parciales, ya que ninguna refleja plenamente el significado de la UF española, 'utilizar todos los recursos disponibles para conseguir una cosa'.

Además, en el mismo diccionario al que acabamos de hacer referencia (DSR) señalamos la presencia de la locución en la entrada del lema "asador", donde aparece con su variante "echar toda la carne en el asador", no recogida por todas las fuentes fraseológicas consultadas. En este caso, la traducción que proporciona no es idiomática: "a risca totul" (lit. arriesgarlo todo). A pesar de la nula equivalencia con el rumano y de la complejidad del lema "asador", consideramos que la UF podría incluirse en el corpus para el nivel B2, por el contorno sintáctico de fácil asimilación y, sobre todo, por la rentabilidad de la expresión, enmarcada dentro de la función comunicativa "expresar esfuerzo".

Otra UF sin equivalente real en rumano, pero recurrente y rentable, es "ser de carne y hueso", locución verbal coloquial definida por el DRAE como 'ser sensible como los demás a las experiencias y vicisitudes de la vida humana'. Todos los diccionarios bilingües consultados se empeñan en ofrecer traducciones que no son más que calcos del español que nos resultan muy forzadas: "a fi (făcut) din carne şi oase" (DSR), lit. estar hecho de carne y huesos; "a fi de carne şi oase" (DSREL) - (lit. ser de carne y huesos), "a fi din carne şi oase" (DFSR). EI DSREL proporciona una locución equivalente en español ("no ser alguien de piedra") y siente la necesidad de aportar explicaciones adicionales: "expresiones por las que se recuerdan las debilidades de la naturaleza humana". En todas las propuestas notamos el cambio que se opera en el lema "hueso", que pasa a ser "huesos. ("oase") en rumano. Por lo 
demás, se mantiene el contorno sintáctico del español, lo que favorecería su comprensión y rápida producción, a pesar de la nula equivalencia. Cabe señalar también la existencia en rumano de una expresión que reúne los mismos somatónimos, pero tiene un significado distinto: "în carne și oase" (lit. en carne si huesos), locución nominal cuyo significado es "en persona", "en realidad". Será la tarea del docente diseñar actividades significativas para fomentar la conciencia lingüística de los alumnos, con especial hincapié en las diferencias formales y semánticas, a fin de evitar interferencias $u$ otros errores interlinguales.

Aunque en una etapa inicial del corpus habíamos seleccionado la UF "temblar las carnes" ('estremecerse de miedo o tener horror de algo'), optamos finalmente por relegarla al nivel $\mathrm{C} 1$. Contamos con una equivalencia parcial en rumano: "a trece toţi fiorii" o "a trece fiori reci", donde "fior" (usado en plural) significa leve sensación de frío acompañada por temblores y, por extensión, estremecimiento causado por una gran emoción (en general de miedo). Sin embargo, existe una restricción diafásica por la presencia del lema polisémico "fior" que aporta un matiz un tanto poético, carga estilística inexistente en español. Una vez más, el DSR opta por un calco del español, "a tremura carnea pe" (lit. temblar la carne en), pero añade una preposición a modo de guía de uso, mientras que el DSREL evita la traducción y nos remite a otra UF, "tener alguien el alma en un puño".

Asimismo, descartamos la UF "abrir las carnes" (estremecerse de horror), en cuyo caso, además de la opacidad, se añade la dificultad del contorno sintáctico: <a alguien> se $<$ le $>$ abren las carnes.

En todas las locuciones analizadas notamos, curiosamente, la ausencia del somatónimo "carne" en las UF rumanas. Como apuntábamos al inicio de este apartado, se trata de un lexema idéntico en rumano, por lo que anticipábamos encontrar locuciones transparentes. Sin embargo, en todos estos casos el somatónimo falta por completo y hemos tenido que recurrir a listados completos de repertorios fraseológicos para encontrarlo: carne de cañón (esp.) - carne de tun (rum.), en carne viva (esp.) - în carne vie (rum.). En otros casos, el rumano recurre al somatónimo "piel": "carne de gallina" (piel de gallina) o "sufrir en (propia) carne", a suferi (pe propria) piele, pero como tónica general podríamos concluir que las UF verbales seleccionadas en español no tienen como equivalentes locuciones somáticas en rumano. 


\subsubsection{Somatismos con el lexema "ceja"}

El lexema "ceja" (en rumano "sprânceană", ambas procedentes del latín supercilia) genera un número relativamente escaso de UF en las dos lenguas, aspecto reflejado también en este análisis contrastivo. Son cinco los SO que finalmente conforman el corpus, tras descartar la locución adverbial "hasta las cejas" (a pesar de que suele ir acompañada por el verbo "estar") y la locución verbal "dar <a alguien> entre ceja y ceja", debido a su uso restringido, poco documentado en repertorios fraseológicos.

Consideramos menester analizar detalladamente el interesantísimo caso de somatismos como "meterse entre ceja y ceja", "ponerse entre ceja y ceja" y "tener entre ceja y ceja", locuciones adverbiales recogidas tanto por el DRAE como por el DILEA. Como se puede observar, los tres comparten varios elementos léxicos, lo que podría causarle mucha confusión a un aprendiente de E/LE e inducirle la impresión equivocada de que todas son UF sinónimas. Sorprende la entrada en el DRAE "Ilevar alguien, o metérsele, o ponérsele, a alguien, entre ceja y ceja algo" que remite a "tener entre ceja y ceja". Sin embargo, más abajo se desglosan las dos locuciones con el verbo "tener" en entradas distintas, según el OD [+humano] [-humano], que en este caso desempeña un papel fundamental en el significado de la locución.

tener a alguien entre cejas, o entre ceja y ceja

(locs. verbs. coloqs.): mirarlo con prevención desfavorable.

tener algo entre ceja y ceja

(loc. verb. coloq.): tenerlo como pensamiento o propósito fijos.

EI DILEA opta por una única entrada, proporciona el contorno sintáctico y los dos significados diferentes, pero aporta también una información adicional relacionada con la frecuencia de uso: 1. tener a una persona o una cosa una idea fija o una obsesión (más frecuente) y 2 . sentir antipatía hacia una persona (menos frecuente). Sin embargo, hace caso omiso de la variante "tener entre cejas", recogida por el DRAE.

Ante esta delgada línea roja de formas y de significados, la duda que se nos plantea es si estas UF tienen cabida en el corpus, teniendo en cuenta que en ninguno de los casos el rumano cuenta con equivalentes y que la estructura argumental de algunos SO es compleja (<a alguien> se <le> mete entre ceja y ceja <algo>", <a alguien $>$ se $<$ le $>$ pone entre ceja y ceja <algo $>$ ). A pesar de estos inconvenientes, decidimos incluir estas UF en el nivel B2 debido a su rentabilidad, a la repetición del 
lexema que favorece la memorización y al alto índice de recurrencia (frecuencia alta, según DILEA).

En el caso de "quemarse las cejas" ('estudiar mucho') hay una equivalencia parcial en rumano, también somática: "a-şi toci coatele" (lit. degastarse los codos). Mientras la metáfora que evoca la UF española es trabajar intensamente en tareas que requieren esfuerzo visual ("quemarse las pestañas" remite a la misma imagen), el rumano sugiere la postura que tienen los aprendices en las bibliotecas o en los pupitres. Algunos registros fraseológicos rumanos recogen incluso esta UF en su versión más amplia: "a-şi toci coatele pe băncile şcolii" (lit. desgastarse los codos en los pupitres de la escuela). En cuanto al contorno sintáctico y a la estructura actancial, nos encontramos en situaciones totalmente similares: <alguien> se quema las cejas / <cineva $>$ îşi toceşte coatele.

Por estas razones, conservamos el somatismo y lo incluimos en el nivel B2, a fin de elaborar posteriormente materiales cuya función comunicativa será el estudio / el esfuerzo intelectual. Sin embargo, descartamos un SO que no recoge el DRAE, pero sí otros repertorios fraseológicos: "dejarse las cejas" ('esforzarse mucho en una cosa o para conseguir una cosa'), porque ya contamos con suficientes exponentes fraseológicos para esta función.

Finalmente, incluimos en este apartado la UF "arquear las cejas" ('levantarlas, poniéndolas en forma de arco, como sucede cuando alguien se admira') por contar en rumano con una UF totalmente transparente, nada sorprendente al tratarse de un gesto universal. Sin embargo, apuntamos dos variantes en rumano: "a ridica din sprâncene" y "a ridica sprâncenele" (lit. levantar de cejas y levantar las cejas), como también un contexto de uso más amplio, según indica DEX: 'mirar extrañado, mostrar extrañeza, sorpresa o descontento, ira'. Esta definición nos indica, por lo tanto, que el SO rumano abarca el territorio de otras UF españolas, "fruncir el ceño" o "arrugar el ceño" ('hacer demostración o enfado con el rostro') a pesar de contar con dos locuciones más cercanas: "a-şi încrunta sprîncenele" y "a-şi încreţi sprîncenele". Estas "arenas movedizas" a nivel léxico se producen debido a que el rumano carece de lexema como "cejo", "entrecejo" y, extrapolando, "cecijunto,a ". 


\subsubsection{Somatismos con el lexema "cerebro"}

En el caso del somatónimo "cerebro" (en rumano "creier"), recopilamos un número muy reducido de UF, tanto en español como en rumano. Del cruce de los dos listados elaborados, conservamos únicamente tres entradas, que consideramos apropiadas para el nivel intermedio. Siguiendo el orden alfabético, estas serían "estrujarse el cerebro" ('cavilar o pensar mucho'), "lavar el cerebro" ('cambiar las ideas y creencias de una persona') y "machacarse el cerebro" ('cavilar').

Una vez más, echamos en falta más coherencia y unidad de criterios entre las fuentes consultadas. EI DRAE, en su afán por abarcar el espacio hispano en su conjunto, integra la locución verbal cubana "hacerse el cerebro agua" ('pensar insistentemente en la manera de resolver un problema'), pero omite otras de uso peninsular más frecuente, como "estrujarse el cerebro". Mientras tanto, el DILEA recoge "masturbarse el cerebro" ('reflexionar'), locución verbal equivalente a "exprimirse el cerebro", tampoco recopilada por el DRAE. Suscribimos la opinión de Mendizábal y Sastre (2019:52), que se lamentan de "la heterogeneidad de los criterios manejados, que no siempre se siguen en la práctica, lo que hace que el usuario de este tipo de repertorios lexicográficos se despiste y no sepa a veces dónde buscar una locución concreta."

No obstante, un punto de encuentro lo constituye "lavar el cerebro", presente en la mayoría de los repertorios fraseológicos consultados, aunque falta en la propuesta de corpus de Leal Riol (2011). Si bien los diccionarios rumanos no recogen la UF como tal, nuestra competencia como hablantes nativos, una rápida consulta a través de un motor de búsqueda y las enciclopedias de libre acceso en línea (mucho más permeables a los cambios léxicos que van surgiendo en la lengua) nos confirman la existencia de una locución verbal equivalente y transparente: "a spăla pe creier" (lit. lavar en cerebro). Hemos de reconocer, sin embargo, que el rumano maneja con más soltura las formas sustantivas "spălare pe creier", "spălare de creier" y, sobre todo, la estructura con el participio pasado, "spălat pe creier", lo que demuestra quizás que la UF no se ha asentado del todo en el territorio lingüístico rumano, procedente de la voz inglesa brainwashing. En nuestro corpus la insertamos en el nivel B1, donde encajaría perfectamente en temas como la preocupación por el futuro, la vida en el siglo XXI, los medios de comunicación y los mecanismos de control.

En cuanto a "estrujarse el cerebro", el rumano cuenta con una UF equivalente y transparente y con un contorno sintáctico idéntico: "a-şi stoarce creierii" (lit. exprimir los cerebros). El significado es idéntico, 'valor o pensar profundamente, luchar para encontrar una solución', según el DEX, pero notamos una leve diferencia respecto al género: "creierii" aparece en plural, frente al singular "cerebro".

Esto nos remite a analizar el caso del lexema español "seso", descartado del corpus debido a su complejidad. Sorprendentemente, el DSREL opta justamente por 
eliminar por completo la entrada "cerebro" y mantener "seso" (traducido igualmente por "creier") y proporciona UF como "devanarse alguien los sesos", "perder alguien el seso", "sorberle alguien el seso" y "tener alguien sorbido el seso". En ninguno de estos casos proporciona equivalencias viables y se limita a remitir a otras UF españolas, en un alambicado sistema de idas y venidas.

Eso demuestra la complejidad de confeccionar un repertorio lexicográfico en general y uno fraseológico en particular, sobre todo si se trata de obras dedicadas a un público extranjero, que en numerosos casos enfrenta serios escollos para poner en práctica las locuciones, sea por la dificultad a la hora de descodificar su significado, sea por la falta de competencia gramatical. Por estos motivos decidimos relegar a niveles superiores todas las entradas con el lema "seso" (opaco en rumano y fácilmente confundible con "sexo") en detrimento del más transparente "cerebro" (con la misma etimología en rumano). Aún así, prescindimos de UF como "secar el cerebro" y "secársele el cerebro", demasiado complejas y con equivalencia nula en rumano o de "masturbarse el cerebro" (despectiva según el DFDEA, no recogida por el DRAE, poco rentable y extremadamente difícil de contextualizar). 


\subsubsection{Somatismos con el lexema "codo"}

A pesar de que, tras consultar varias fuentes léxicas, recopilamos un número más elevado de UF con el somatónimo "codo" (en rumano "cot", precedente de la misma fuente latina cubitus), los filtros que aplicamos mermaron las entradas finales, hasta llegar a un total de tres locuciones.

Mantuvimos el somatismo "empinar el codo" que cuenta con un equivalente parcial en rumano, "a trage la măsea" (lit. tirar en muela). Destacamos que ambas estructuras recurren a un somatónimo, aunque diferente (codo - muela) y tienen la misma función comunicativa (beber demasiado). No obstante, los contornos sintácticos son ligeramente distintos: $\mathrm{V}+\mathrm{OD}$ en español vs. $\mathrm{V}+\mathrm{CCL}$ prep en rumano. Si bien el DRAE proporciona otras UF equivalentes ("levantar de codo", "levantar el codo" o "empinar de codo"), consideramos que en el nivel B1 resultaría redundante presentar entera la serie sinonímica, así que nos decantamos por introducir únicamente la de uso más frecuente. En la misma tónica, prescindimos de una UF que recogen el DILEA y el DFDEA, ("darle al codo", 'ingerir muchas bebidas alcohólicas'), precisamente por el rasgo que los mismos diccionarios subrayan: menos frecuente/raro.

Otra serie que analizamos a fin de dar con aquellas UF más rentables para nuestros intereses es "clavar (o hincar o apretar o romperse) los codos", tal como aparece en el DFDEA, donde encontramos una definición común, 'estudiar con mucha aplicación' y un apunte diafásico (registro coloquial). En cambio, sorprendentemente, el DRAE prescinde de las UF "apretarse los codos" y de "clavar los codos" y solo conserva los demás somatismos. En el DILEA se recoge la serie en su totalidad, pero se aporta una información adicional referente a la frecuencia de uso. Las dos UF descartadas por el DRAE son, según Penadés (2019), menos frecuentes, pero, en nuestra opinión, no es una explicación suficiente para que no se reflejen en el registro léxico de la Academia de la Lengua, donde sí que encontramos entradas como "agarrarse alguien del codo" ('tomarse demasiadas libertades'), "caminar con los codos" ('ser mezquino') o "ser del codo" ('ser tacaño'). Además, notamos la presencia de somatismos sorprendentes, que no pasan el corte en ningún otro diccionario especializado consultado: "apretar el codo" e "hincar el codo" (subrayamos la presencia del somatónimo en singular) - loc. verb. coloq. 'asistir a un moribundo a expirar'.

Finalmente, incluimos en el corpus la UF "hablar por los codos" ('hablar demasiado'), a pesar de que en algunos diccionarios aparece como locución adverbial. Según DFDEA, "por los codos" es locución adverbial coloquial, con el significado 'de manera exagerada', que acompaña generalmente verbos como "hablar" o "charlar". En otras fuentes consultadas, como el DILEA, no se recoge en absoluto.

DSREL proporciona una larga serie sinonímica encabezada por el SO analizado: "hablar alguien por los codos / como un loro / como un sacamuelas / más que un sacamuelas; enrollarse alguien (como una persiana); darle alguien a la lengua / a la 
sin hueso" y se proporciona un único significado, común para todas las UF, 'hablar sin parar'. Al mismo tiempo, ofrece una serie de equivalencias en rumano: "a da mereu din gură; a-i merge gura ca o meliţă /moară stricată /hodorogită". Las que más nos convencen son "a-i merge gura ca o moară stricată" (lit. andarle la boca como un molino estropeado), según el DEX 'hablar mucho e inútilmente', y la UF "a-i turui gura", 'hablar rápido y mucho, tener un gran caudal verbal, sin decir cosas importantes'. Observamos, por lo tanto, que ambas lenguas cuentan con UF para describir este rasgo de carácter (la incontinencia verbal), función comunicativa que se refuerza en el nivel B2. Conservamos el somatismo "hablar por los codos" por su recurrencia, utilidad y facilidad de los elementos constituyentes y del contorno sintáctico, a pesar de que, como ya hemos comprobado, la expresión es descrita algunas veces como locución verbal y otras como una colocación compleja formada por un verbo + una locución adverbial. Suscribimos la opinión de Mendizábal y Sastre (2017), que afirman que

\begin{abstract}
(...) sería deseable que las fronteras entre colocaciones y locuciones fueran mucho más claras y que los casos que podrían situarse "en tierra de nadie" cada vez sean más escasos. Pero desde el punto de vista lexicográfico no resulta tan fundamental esta distinción; tampoco desde el punto de vista de la enseñanza-aprendizaje de ELE, porque lo que le importa al alumno es conocer el significado de la expresión pluriverbal (llámese locución o colocación) y, lo más importante, poder usarla de manera correcta y apropiada (Mendizábal y Sastre 2017:55).
\end{abstract}

Finalmente, desechamos locuciones como "comerse los codos" o "comerse los codos de hambre" (no recogidas por el DRAE, pero presentes en otros registros lexicográficos) precisamente por la escasa frecuencia de uso, tal como subraya Penadés en el DILEA. 


\subsubsection{Somatismos con el lexema "colmillo"}

De las pocas locuciones que genera el somatónimo "colmillo" (en rumano "colţ", de etimología eslava) conservamos una única entrada, común en todos los registros consultados: "enseñar los colmillos", locución verbal cuyo significado es 'mostrar las propias fuerzas con la intención de hacerse respetar o temer' (DFDEA). El rumano cuenta con un somatismo equivalente y totalmente transparente, "a-şi arăta colţii" (lit. idem.), cuya definición es 'manifestar una actitud agresiva, un carácter arduo' (DEX). Como viene siendo habitual, el DSREL proporciona una serie sinonímica, donde además de "enseñar los colmillos" encontramos "enseñar los dientes" y "enseñar las uñas", locuciones que a su vez cuentan con equivalentes totales en rumano: "a-şi arăta dinţ̧ii" y "a-şi arăta ghearele" (en este último caso el somatónimo rumano procede del mundo animal, y su traducción literal es "enseñar las garras"). Tomando en consideración los aspectos relacionados con la equivalencia y la transparencia, situamos esta UF en el nivel B2 y la usaremos para elaborar materiales que traten la función comunicativa "expresar amenaza".

Los demás somatismos encontrados con el lexema "colmillo" han sido descarcados del corpus por su alto grado de dificultad y por la escasa frecuencia de uso: "escupir por el colmillo", "tener el colmillo retorcido", "tener colmillos o colmillos retorcidos". 


\subsubsection{Somatismos con el lexema "corazón}

Durante la fase inicial de recogida del corpus, augurábamos una mayor presencia de somatismos con el lema "corazón" (en rumano "inimă", heredado del término latín "anima"). Sin embargo, tras descartar las locuciones adjetivales y sobre todo adverbiales ("de corazón", "a corazón abierto", "con el corazón en la mano", "con la mano en el corazón") y un importante número de locuciones verbales en desuso, el resultado es más bien escaso. Además, si contabilizáramos los somatismos encontrados en los registros fraseológicos, descubriríamos que en muchas ocasiones se trata de variaciones de índole formal más que de entradas diferentes a nivel semántico. Veamos, por ejemplo, algunos casos del DFDEA: "encoger el corazón [a alguien]" y "encogérsele el corazón [a alguien]", "endurecer el corazón [a alguien]" y "endurecérsele el corazón [a alguien]", "helar el corazón [a alguien]" y "helársele el corazón [a alguien]", "secar el corazón [a alguien]" y "secársele el corazón [a alguien]", etc. o la artificiosa distinción que hace el DILEA entre "abrir el corazón" ('descubrir o decir una persona los pensamientos o sentimientos íntimos') y "abrir su corazón" ('descubrir o decir una persona los pensamientos o sentimientos íntimos') o entre "romper el corazón" y "romper su corazón" (en ambos casos 'causar una decepción amorosa a una persona'). En estos casos, en otros apartados se proporciona información adicional sobre el contorno sintáctico, elementos imprescindibles para que la UF funcione en el discurso.

Lo que podemos afirmar sin miedo a equivocarnos es que en rumano contamos con un número significativamente superior de somatismos con el lexema "inimă".

En este contexto, en nuestra selección delimitamos un grupo de UF para el nivel inicial que se caracteriza por cubrir funciones comunicativas acordes con el nivel, un alto grado de transparencia y equivalencia total. Es el caso de "tener un corazón de oro" ('ser muy generoso, bien dispuesto o benevolente') al que le corresponden "a avea inimă bună (lit. tener buen corazón), "a avea inimă de aur" (lit. tener corazón de oro) o "a fi bun la inimă" (lit. ser bueno en corazón) y otras variantes que comparten el mismo significado - ser bueno, comprensivo, generoso.

En este mismo apartado (describir el carácter) introducimos la locución "ser todo corazón" ('tener gran bondad y generosidad'), a pesar de que desde el punto de vista del contorno sintáctico el rumano no cuenta con un equivalente. Sin embargo, descartamos de nuestro corpus entradas como "tener <alguien> un corazón que no $<l e>$ cabe en el pecho" por la complejidad de los elementos constitutivos y por tener cubiertas las necesidades funcionales con las UF seleccionadas anteriormente.

Otras UF transparentes son "partir el corazón" (para cuya explicación el DRAE remite a la locución "partir el alma" ('golpear violentamente' y 'herir profundamente los sentimientos') y "romper el corazón" (no recogida por el diccionario de la academia). 
Sin embargo, Penadés señala sutiles matices entre los dos somatismos: "partir el corazón" ('causar mucho dolor a una persona') vs "romper el corazón" ('causar una decepción amorosa a una persona'). EI DFDEA también distingue entre las dos UF que, aunque considera equivalentes, aparecen en entradas separadas y cuentan con definiciones levemente diferentes. Los diccionarios bilingües consultados no ahondan en estas diferencias semánticas y se dedican a ofrecer dos somatismos equivalentes, "a rupe inima" y "a frânge inima" (esta última locución conlleva en rumano un matiz poético y su uso se restringe al ámbito literario). Cabe señalar en ambos casos la importancia de la estructura argumental, ya que el rumano maneja tanto el esquema $\mathrm{S}+\mathrm{V}+\mathrm{OD}$ (<cineva $>$ rupe inima <cuiva $>0$ <cineva $>$ frânge inima <cuiva $>$, como el esquema $\mathrm{Ol}+\mathrm{V}+\mathrm{S}+$ objeto circunstancial: <cuiva $>$ i se rupe inima $<$ de cineva $>0$ <cuiva> i se frânge inima <de cineva> (a alguien se le parte el corazón por alguien), con el significado 'sentir lástima o pena por una persona'.

Matices distintos aporta la UF recogida por el DSREL, "romper/partir alguien corazones" ('seducir') que, a pesar de la equivalencia nula en rumano, no plantea problemas de comprensión en un contexto esclarecedor. De hecho, en el caso de este somatónimo, las dificultades aparecerán en dirección contraria (para un aprendiente hispanohablante de rumano), que encontrará obstáculos a la hora de descodificar adecuadamente el significado de UF como "a rupe inima târgului" (lit. romper el corazón de la feria) cuyo significado irónico es 'comprar lo que es peor, cerrar un mal negocio'.

Otra UF seleccionada para el nivel B1 es "tener el corazón en un puño" ('sentir mucha angustia, inquietud o temor'), que podemos integrar en contenidos funcionales como contar anécdotas, historias y experiencias y en contenidos gramaticales como los contrastes de tiempos pasados. En rumano hay una UF equivalente, "a sta cu sufletul la gură" (lit. estar con el alma en boca), con idéntico significado ('encontrarse en un estado de tensión psíquica; estar inquieto, impaciente'). De hecho, el DSREL remite a la locución "tener alguien el alma en un puño", quizás por el hecho de que comparte uno de los elementos constitutivos.

Finalmente, mencionamos la UF "hacer de tripas corazón", pero llevaremos a cabo su análisis contrastivo en el bloque correspondiente al lexema "tripa". 


\subsubsection{Somatismos con el lexema "coronilla"}

Al igual que el lexema español "coronilla", el somatónimo rumano "creştet" (o "creştetul capului") genera un número muy limitado de UF, de las que muy pocas son locuciones verbales. De hecho, la única entrada seleccionada no está exenta de polémica, ya que para muchos expertos "hasta la coronilla" es una locución adverbial expresando hartura o cansancio total.

Siguiendo la misma línea trazada por el DRAE, recopilamos la UF "estar hasta la coronilla" como locución verbal ('estar cansado y harto de sufrir alguna pretensión o exigencia') y la incluimos en el corpus para el nivel B1. EI DSREL ofrece la serie sinonímica casi al completo, incluyendo las voces malsonantes: "(estar) hasta el cogote /el gorro/ el moño/ las narices", etc. y proporciona los dos equivalentes que se manejan en rumano: "a fi (sătul) pânâ-n gât", lit. estar (harto) hasta en cuello y "a fi (sătul) pânâ peste cap”, lit. estar (harto) hasta encima de la cabeza. Destacamos la presencia de somatónimos en ambas UF rumanas, si bien diferentes si comparamos con la locución española. En cuanto al contorno sintáctico, este es similar en ambas lenguas e incluye un complemento circunstancial de lugar.

Puesto que en rumano existe el lexema "coroană" (corona), la locución no plantea demasiadas dificultades, tiene un grado de equivalencia parcial, pero resulta bastante transparente, por lo que decidimos incluirla en el corpus de nivel B1. 


\subsubsection{Somatismos con el lexema "cuello"}

A diferencia de idiomas como el inglés, el francés o el español, el rumano cuenta con un único lexema ("gât)" para designar tanto el cuello como la garganta, de ahí que los SO recogidos en la base de datos creada para el rumano superan los del español.

El número total de UF seleccionadas para nuestro análisis es relativamente escaso. Descartamos locuciones como "hablar <alguien> para el cuello de su camisa", "no oír ni el cuello de su camisa", "escaparse /salirse por el cuello de su camisa", ya que en estos contextos el lexema no remite al somatónimo, sino a la parte de una prenda de vestir.

Asimismo, prescindimos tanto de la locución adjetival "con la soga a la garganta o al cuello" como de la UF verbal "echar o poner <a alguien> la soga al cuello", a pesar de ser totalmente transparente en rumano ("a pune <cuiva s ştreangul de gât") y de compartir el mismo contorno sintáctico: $V+O D+C C L$. El hecho de no incluirla no se debe tanto a la dificultad del lexema "soga", fácilmente deducible por el contexto y la metáfora motivada del $\mathrm{SO}$, sino más bien al contenido funcional poco rentable: poner a una persona o una cosa en situación difícil o apurada.

En esta misma línea, descartamos "estar con el agua al cuello" y sus múltiples variantes ("estar con el agua a la garganta", "estar con el agua hasta la boca", etc.).

Del resto de la cosecha, apuntamos las locuciones verbales "saltar al cuello" y "tirarse al cuello" ('mostrar a una persona que no se está de acuerdo con ella'), eliminadas en beneficio de "saltar a la yugular", de uso más frecuente.

En cambio, conservamos "jugarse el cuello" a pesar de su complejidad semántica (1. jugarse la vida; 2. apostar cualquier cosa, hasta la vida). Tal como apunta el DFDEA, se usa para asegurar enfáticamente un hecho, es frecuente en la construcción "me juego el cuello" y gramaticalmente antepuesta a una proposición introducida por a que". No encontramos en rumano ninguna UF que cubra totalmente los matices de significado, pero consideramos que la locución es suficientemente transparente para que se imparta en el nivel B2. La compleja expresión rumana "a-şi pune pielea în saramură" (lit. ponerse la piel en salmuera) comparte algunos rasgos semánticos, como correr un riesgo y exponerse ante un peligro, pero no comparte la idea de convicción. 


\subsubsection{Somatismos con el lexema "dedo"}

Las expresiones idiomáticas con el somatónimo "dedo" (en rumano "deget", procedente del mismo lexema latín digitus), recogidas en las primeras etapas de creación de la base de datos, destacan por cubrir campos semánticos muy amplios.

De la treintena de UF que compilamos, descartamos sin vacilar las más complejas, con equivalencia nula, totalmente opacas y poco rentables. Es el caso de "antojarse los dedos huéspedes" ('ser o estar muy receloso o suspicaz'), "dar gusto al dedo" ('disparar sin impedimento alguno un arma de fuego') o "hacer dedos" ('practicar ejercicios con los dedos').

Conservamos en cambio "hacer dedo" ('hacer autostop') a pesar de no tener una equivalencia en rumano. El DFSR recoge el somatismo español y también su variante "ir a dedo", variante que mantenemos también en el corpus, a pesar de que los registros fraseológicos monolingües consultados consideran "a dedo" como locución adverbial. Su otro significado ('mediante designación personal no motivada o arbitraria') tampoco tiene equivalente en rumano y los diccionarios fraseológicos bilingües se limitan a describir el significado de esta UF: "elegir/ nombrar a dedo".

Afortunadamente, las expresiones que generan las locuciones que contienen "a dedo" se pueden acompañar de elementos quinésicos que facilitan significativamente su comprensión por parte de un aprendiz extranjero. A fin de evitar confusiones, optamos por eliminar el somatismo opaco en rumano "ir al dedo malo" (que sirve para expresar que no hay desdicha de la que se libre la persona desgraciada), UF descartada incluso por diccionarios como DILEA o DFDEA.

Asimismo, consideramos contraproducente presentar "chupar el dedo" y "chuparse los dedos" por la distancia semántica que hay entre los SO y las confusiones que pudieran generar. Además, para "chupar el dedo/mamarse el dedo" ('parecer ingenuo') el rumano no tiene un equivalente exacto. DFSR opta por no incluirlo, estrategia frecuente a la que recurren algunos diccionarios ante casos complicados que plantean numerosas dudas. EI DSREL incluye la entrada en una larga serie, como las que nos tienen acostumbrados: "(no) chuparse <alguien> el dedo; (no) haber nacido <alguien> ayer; (no) caerse/ haberse caído <alguien> del nido" y proporciona una bizarra y, en parte, equivocada enumeración de alternativas para su traducción: "a crede că tot ce străluceşte e aur" (lit. pensar que todo lo que reluce es oro); "a crede că tot ce zboară se manâncă (lit. pensar que todo lo que vuela se come) y "a avea un suflet de înger" (lit. tener un alma de ángel), para la que remite a "ser alguien alma de Dios".

En cambio, "chuparse los dedos" ('sentir gran placer con una comida') es totalmente transparente y cuenta en rumano con dos locuciones que incluyen el mismo lexema, "deget". La primera tiene un contorno morfosintáctico idéntico "a-şi linge 
degetele" (lit. lamerse los dedos) y la otra una estructura argumental levemente modificada, ya que en rumano notamos la presencia de un elemento prepositivo: "pe degete" (en los dedos). Nos sorprende la traducción proporcionada por el DFSR, "a-i lăsa gura apă după ceva", somatónimo equivalente en español a "hacerse la boca agua", caso que Duţă (2014:103) señala como un "fenómeno de incongruencia".

Donde, una vez más, no hay unanimidad de criterios es en la entrada de la UF española: el DRAE solo presenta las locuciones adjetivales "de chuparse los dedos" y "para chuparse los dedos" ('muy bueno'), mientras que el DFDEA proporciona versiones más numerosas y explicaciones más exhaustivas: "se usa para ponderar lo mucho que gusta alguien o algo. Frec. en las constrs. de chuparse los dedos, o para chuparse los dedos o como para chuparse los dedos o que te chupas los dedos".

En distintos apartados encontramos también la UF pluriverbal "no tener dos dedos de frente" ('ser de poco entendimiento o juicio'), recogida como tal por el DRAE, donde aparece como locución verbal. En cambio, el DFDEA considera "dos dedos de frente" sintagma nominal, más frecuentemente en la construcción anteriormente mencionada. El rumano sugiere la falta de inteligencia con el somatismo "a fi bătut în cap" (lit. ser golpeado en cabeza) o por una UF más explícita y no somática, "a fi prost făcut grămadă" (lit. ser tonto hecho montón), en traducción más libre en español: "ser tonto de remate".

A pesar de la falta de una equivalencia formal, "no tener dos dedos de frente" forma parte de nuestro corpus por su rentabilidad, por la facilidad de sus elementos componentes (todos impartidos en el nivel inicial) y por el recurso quinésico que suele acompañar esta UF. Además, en rumano se asocia la frente ancha con la inteligencia y la frente estrecha con la estupidez y, en el caso de la mente "estrecha" - "îngust la minte" - con la falta de horizonte. El DFSR proporciona una traducción forzada más cercana al español, "a avea fruntea de un deget" (lit. tener la frente de un dedo), pero nos cuesta registrarla como UF institucionalizada teniendo en cuenta que no aparece reflejada en los repertorios fraseológicos monolingües y que solo hemos contabilizado un único ejemplo en la red, usando los motores de búsqueda.

El elemento quinésico es todavía más patente en la UF "cruzar los dedos", somatismo que sugiere el acto físico de cruzar el dedo corazón sobre el dedo índice para conjurar una desgracia o peligro o para desear que salga bien lo que va a suceder. En rumano se desea suerte usando un somatónimo contiguo "a ţine pumnii" (lit. mantener los puños), con la variante "a ţine pumnii strânşi" (lit. mantener los puños cerrados), lo que conlleva gestos diferentes. En cuanto al contorno sintáctico, cabe destacar que la estructura en rumano es pronominal indirecta: îţi ţin pumnii, îi ţin pumnii, vă ţin pumnii, etc. (te tengo los puños, le tengo los puños, os tengo los puños). Habría que hacer hincapié en esta diferencia para anticipar las transferencias negativas y para evitar errores de tipo *te cruzo los dedos. 
Otro caso de UF pluriverbal seleccionada es "poner el dedo en la llaga" ('acertar con el punto más delicado o difícil de una cuestión o referirse a él'), totalmente transparente en rumano, donde existe "a pune degetul pe rană". Destacamos la presencia del mismo lexema "dedo" y de un sinónimo en el caso de "llaga" (el rumano recurre a la lexía "herida" frente a "plagă" - llaga - cuyo uso se restringe al campo médico especializado). EI DFSR proporciona la variante "poner el dedo en la herida", aunque muchas otras fuentes la ignoran. A pesar de estas similitudes, consideramos que el nivel más adecuado para impartir esta UF es el B2, debido a la función comunicativa que expresa.

En un nivel más bajo colocamos "señalar con el dedo", locución verbal con equivalencia total en rumano: "a arăta cu degetul" (lit. mostrar con el dedo), Ilamar la atención sobre una persona, normalmente con intención descalificadora. Se trata de UF con idéntica estructura argumental y carga semántica y que, además, comparte todos los lexemas.

En un caso similar se encuentra la UF "no mover un dedo", cuyos dos significados (no tomarse ningún trabajo o molestia por algo o por alguien; no obrar en favor de alguien cuando él u otra persona lo ha pedido por él) son absolutamente idénticos con la UF rumana "a nu mişca un deget".

En cuanto a la locución verbal "poderse contar con los dedos de una mano" ('ser muy escaso') recogida como tal por el DILEA o "contarse algo con los dedos, o con los dedos de la mano, o de una mano" (DRAE), encontramos en rumano una serie que presenta una equivalencia y una transparencia totales, como refleja el DSEL: "a (putea) număra pe degete" (sau pe degetele mâinilor ori de la o mână). El único elemento de dificultad que pudiera generar un error interlingual es la presencia de una preposición diferente en las dos lenguas: "con" en español, frente a "pe" (en) del rumano. 


\subsubsection{Somatismos con el lexema "diente"}

Tras sucesivas cribas, tres son los somatismos finales que configuran el corpus con el lexema "diente" (en rumano "dinte"), a pesar del larguísimo listado recogido en una primera fase de este estudio.

Destacamos desde el principio que el número de locuciones (adjetivales, verbales y adverbiales) del español es significativamente mayor en español, aunque muchas representan muestras de Hispanoamérica o son UF de uso restringido: "estar diente, como haca de atabalero, de bulero, o de cominero" ('tener mucha hambre'), "pelar el diente" ('sonreír mucho por coquetería'), "pelar los dientes" ('encoger el labio superior enseñando los dientes ostensiblemente'), etc.

A su vez, los diccionarios bilingües consultados operan con su propia selección y únicamente reflejan las expresiones más recurrentes. Coincidimos con Zafiu (2010:8) en que "un dicţionar e valoros nu doar prin acumularea de informaţie, ci şi prin selecţia ei: lexicograful trebuie să ştie şi la ce să renunţe, ambiţia exhaustivităţii creând de obicei opere de neconsultat sau baze de date destinate strict specialiştilor ${ }^{5}$."

Tanto el DSREL como el DFSR recogen "darse con un canto en los dientes" ('darse por contento cuando lo que ocurre es más favorable o menos adverso de lo que se podría esperar'). A pesar de su opacidad y de falta de equivalencia en rumano, consideramos rentable enseñar la locución en el nivel B2. No obstante, será imprescindible diseñar actividades que aporten un contexto idóneo para la producción y aportar explicaciones que aclaren el plurisemantismo del lexema "canto" (trozo de piedra, en esta locución).

Otro somastismo que plantea retos a la hora de su comprensión exacta es "hincar el diente", debido en gran medida al amplio abanico de su significado, tal como se refleja en el DRAE:

hincar, o meter, alguien el diente

1. acometer las dificultades de un asunto.

2. comer algo difícil de mascar.

3. apropiarse de parte de la hacienda ajena que maneja.

4. murmurar de alguien, desacreditarlo.

Ninguno de estos usos tiene un equivalente fraseológico en rumano. EI DSREL solo se limita a presentar el segundo significado (morder), mientras que el DFSR (cuya

\footnotetext{
${ }^{5}$ un diccionario es valioso no solo por acumulación de información, sino por la selección operada: el lexicógrafo debe saber también a qué renunciar, puesto que la ambición de la exhaustividad suele generar obras imposibles de consultar o bases de datos destinadas exclusivamente a los especialistas.
} 
principal fuente declarada es el diccionario de la RAE) pasa revista a todos los significados y ofrece traducciones acertadas. Sin duda, la falta de una equivalencia clara dificulta la comprensión en rumano, pero aun así mantenemos la locución en el nivel B2, donde consideramos útil insistir en el uso de 'enfrentarse a una cosa difícil o desagradable'.

El caso de "ponerse los dientes largos" es sintomático para las locuciones opacas, sin equivalentes en rumano: los diccionarios bilingües remiten a otras entradas (el DSREL a "baba" - "caérsele a alguien la baba" y el DFSR a otra UF con el mismo somatónimo - "alargársele a alguien los dientes"). Tras una profunda reflexión, optamos por relegarla al nivel $\mathrm{C} 1$, debido también al contorno sintáctico (pronominal indirecto) que entraña dificultad: <a alguien $>$ se $<l e>$ ponen los dientes largos.

Donde encontramos una estructura argumental más asequible es en el SO "enseñar los dientes" ('mostrar una actitud de oposición o resistencia contra una persona') que cuenta en rumano con la UF "a-şi arăta dinţii" (lit. idem.) que convive con su variante "a-şi arăta colţii" (enseñar los colmillos). Estamos ante un caso de equivalencia interlingüística total, ya que se cumplen los parámetros semántico, morfosintáctico y pragmático, por lo que incluimos el somatismo en el nivel B1. Nos encontramos ante una situación en la que es obvia la relación entre los constituyentes de la locución y su significado: el hecho de enseñar los colmillos, característico para el reino animal, es trasladado al comportamiento humano. 


\subsubsection{Somatismos con el lexema "espalda"}

En el caso de "espalda" (en rumano "spate") hemos seleccionado un número de siete somatismos.

En el nivel A2 hemos incluido "dar la espalda" ('ignorar o abandonar a una persona'), con la UF equivalente en rumano "a întoarce spatele" (lit. idem). La única diferencia que podríamos reseñar es que el DFDEA presenta como equivalente "volver la espalda" y que la DRAE recoge la forma del sustantivo en plural como posible variante ("dar las espaldas"), mientras que en rumano la locución es más fjja y solo admite el somatónimo en singular. Anticipando posibles errores de interferencias, convendría presentar la locución rumana "a da pe spate" (lit. dar por espalda), con la que comparte desde el punto de vista formal dos de los elementos constituyentes, el verbo (dar) y el sustantivo (espalda). Sin embargo, la UF equivalente en español es "caer de espalda"/ "caer de espaldas" ('impresionar, sorprender').

En el caso de "cubrir las espaldas" ('proteger a una persona contra un riesgo o una eventualidad') el DRAE no ofrece alternativas, mientras que el DILEA considera la entrada en plural más frecuente y en singular ("cubrir la espalda") menos frecuente. EI DFDEA no aporta información sobre la recurrencia, sino se limita a presentarlas juntas, de manera sintética: "cubrir la(s) espalda(s)" y remite a "guardar las espaldas" ('proteger de riesgo'). Desde la perspectiva didáctica, esto da fe de la dificultad que entraña la selección adecuada de las UF que el docente debe llevar al aula, siendo imposible presentar la totalidad de estas opciones en una clase de E/LE. Además, en rumano solo contamos con "a avea spatele acoperit" (lit. tener la espalda cubierta), diferencia importante de estructura argumental: <eu > am spatele acoperit, <tu > ai spatele acoperit, <el> are spatele acoperit (yo tengo la espalda cubierta, tú tienes la espalda cubierta, él tiene la espalda cubierta, etc.), pero en su variante transitiva la UF deja de ser somática: a acoperi <pe cineva $>-$ cubrir <a alguien>.

A pesar de no figurar en todos los registros fraseológicos consultados, recogemos la locución verbal "clavar un puñal en la espalda/ por la espalda" ('traicionar'), totalmente transparente y equivalente en rumano: "a înfige cuţitul în spate/ pe la spate" (lit. clavar el cuchillo en la espalda/ por la espalda). A pesar de no encontrar el somatismo como tal en los diccionarios monolingües rumanos, una rápida búsqueda en la red nos confirma su institucionalización y su uso extenso en artículos de la prensa política, nada sorprendente al tratarse de una metáfora cultural /internacionalismo fraseológico. Consideramos adecuada su presentación en el nivel B2, integrada en materiales sobre regímenes y partidos. 


\subsubsection{Somatismos con el lexema "estómago"}

Tras comparar las dos bases de datos que incluyen SO con los lexemas "estómago" y "stomac" en español y en rumano respectivamente, nos llamó la atención la diferencia abismal en términos numéricos. Solo hay dos locuciones dignas de reseñar en rumano: "a nu avea pe cineva la stomac" (lit. no tener a alguien en el estómago) - no aguantar a alguien, caerle mal/fatal alguien - y "a avea stomacul deranjat" (lit. tener el estómago desarreglado) - tener diarrea.

En el primer caso, encontramos una unidad somática en español, "tener <a alguien> sentado en la boca del estómago" ('no tragarlo, no soportarlo') y en el segundo una inaudita locución que recoge el DRAE, "escarbar el estómago" ('producir desazón en el estómago'). Consideramos que ninguna de estas entradas cumple los criterios de relevancia y de rentabilidad para su inclusión en el corpus. De hecho, a pesar de la amplia oferta fraseológica en español, descartamos la práctica totalidad de entradas con este somatónimo, o bien por un uso muy restringido ("relajarse el estómago", "ladrar el estómago", "hacer buen/mal estómago", etc.) o bien porque ya contamos con exponentes más frecuentes que cubren las funciones comunicativas ("dar cien patadas en el estómago", eliminado en favor de "dar cien patadas en la barriga", UF analizada anteriormente). 


\subsubsection{Somatismos con el lexema "garganta"}

Como ya hemos señalado, el rumano solo opera con un lexema "gât" para expresar tanto "cuello" como "garganta". Tras analizar las locuciones en las dos bases de datos, son escasas las posibilidades que tenemos para conformar el corpus en los niveles A1B2, ya que "hacerse de garganta" ('preciarse de cantar bien'), "tener los congojos en la garganta" ('estar muy asustado') o "ponerse el corazón en la garganta" ('sentir gran ansiedad') no cumplen los requisitos establecidos al inicio de este trabajo.

Sorprendentemente, el DFDEA tampoco recoge ninguna de estas locuciones verbales y se limita a proporcionar un único sintagma, "garganta profunda" ('informador secreto'). Más rentable nos parece la locución nominal "nudo en la garganta", transparente y con equivalencia total en rumano: "nod în gât", frecuentemente en combinaciones con verbos como "sentir", "tener" o "hacerse". De hecho, el rumano maneja la UF de uso activo "a înghiți cu noduri" (lit. tragar con nudos) - aguantar con pena, amargura o humillación sin decir nada. 


\subsubsection{Somatismos con el lexema "hombro"}

Procedentes de la misma raíz latina humerus, "hombro" (en español) y "umăr" (en rumano) generan un número equiparable de unidades fraseológicas somáticas. Destacamos en primer lugar las que tienen total trasparencia y equivalencia en las dos lenguas.

La locución "arrimar el hombro" ('ayudar o colaborar, contribuir al logro de un fin') cuenta, según el DRAE, con variantes fraseológicas como "poner el hombro" o "meter el hombro" (esta última con uso dialectal). El rumano echa mano del mismo somatismo, "a pune umărul", locución verbal transitiva con idéntica estructura argumental: $V+O D$ articulado con artículo definido. Encontramos la misma estructura en otra UF rumana que el DFSR ofrece como equivalencia, "a pune osul" (lit. poner el hueso), más frecuente en las expresiones pluriverbales "a pune osul la treabă" o "a pune osul la muncă" (lit. poner el hueso al trabajo). Sin embargo, si atendemos a la explicación proporcionada por el DEX, en el plano semántico se pierde el rasgo de ayuda o colaboración: "trabajar seriamente /con sentido de responsabilidad".

Igual de transparentes resultan ser "levantar los hombros"/“alzar los hombros" ('mostrarse indiferente'), locuciones que remiten al mismo gesto, común en la cultura occidental. Sin embargo, en cuanto al contorno sintáctico, hay leves diferencias respecto a la UF rumana: "a ridica din umeri", donde observamos la presencia de un elemento prepositivo (lit. levantar de hombros). La misma preposición es un elemento constitutivo en "a da din umeri" (lit. dar de hombros). Su equivalente español difiere desde el punto de vista estructural sea por la presencia del verbo reflexivo "encogerse de hombros" sea por la ausencia de la preposición "encoger los hombros". Si a nivel de idiomaticidad ninguna UF plantea dificultad alguna, a nivel de fijación hay que anticipar potenciales errores causados por el cruce de todos estos somatismos.

Otra UF con equivalencia total y absoluta transparencia es "llorar sobre el hombro" ('desahogándose contando problemas o preocupaciones') a la que corresponde en rumano "a plânge pe umărul", locución con la que comparte la misma estructura formal: V + preposición + sustantivo somático (con artículo definido).

En el caso de "mirar por encima del hombro" ('desdeñar'), volvemos a encontrarnos en la situación frecuente de los fraseologismos "de frontera" (Zafiu 2010:7), disputables entre varias categorías. En efecto, el DFDEA considera "por encima del hombro" locución adverbial, mientras que el DRAE la recoge como locución verbal. En rumano existe un paralelismo morfosintáctico y léxico total en "a se uita la cineva/ a privi pe cineva peste umăr", con significado de mirar de manera desdeñosa.

Finalmente, hemos decidido prescindir de locuciones como "escurrir/hurtar el hombro" ('excusar el trabajo o la cooperación para el logro de un fin') al considerar mucho más relevante la UF no somática "escurrir el bulto". En el caso de "tener la cabeza sobre 
los hombros" ya la analizamos en el apartado dedicado al somatónimo "cabeza", que constituye el lema de entrada en los registros lexicográficos. En cuanto a "sacar a hombros", otra expresión a caballo entre verbal y adverbial, la relegamos al nivel C1, donde encaja mejor en actividades relacionadas con el mundo de la lidia. 


\subsubsection{Somatismos con el lexema "labio"}

El somatónimo "labio" (en rumano "buză") está presente en el corpus con tres locuciones.

La más compleja es, sin duda, la UF pluriverbal "dejar con la miel en los labios" ('privar de lo que empezaba a gustar y disfrutar'). En rumano encontramos una equivalencia parcial en "a lăsa cu buza umflată" (lit. dejar con el labio hinchado). Observamos el contorno sintáctico diferente, a pesar de compartir ambas UF dos unidades: el verbo "dejar" y el somatónimo "labio". No obstante, el lexema aparece siempre en plural en español, pero es variable en cuanto al número en rumano (en el DSREL recopilamos también la variante "a lăsa cu buzele umflate").

Si en ambas estructuras argumentales el foco recae en el agente, observamos en cambio que en las locuciones "quedarse con la miel en los labios" y "a rămâne cu buza umflată" se destaca el paciente. Consideramos que estos somatismos son adecuados para el nivel B2, integrados en materiales que refuerzan la expresión de la decepción o de los deseos insatisfechos.

Otra fluctuación de número la hallamos en "sellar el labio/ sellar los labios" ('hacer que una persona no hable o deje de hablar', según el DILEA, 'callar, enmudecer o suspender las palabras', según el DRAE). Si atendemos a la estructura argumental, tales definiciones son muy desconcertantes, puesto que cuesta diferenciar entre el actante y el paciente. Todas las traducciones al rumano (según DFSR) recurren a una forma verbal reflexiva, en contradicción con la entrada transitiva del DILEA: "a-şi pecetlui buzele, a-şi pune lacăt la gură, a-şi înghiţi limba, a-şi coase gura" (lit. sellarse los labios, ponerse candado a la boca, tragarse la lengua, coserse la lengua). Asimismo, cabe destacar que aunque diferentes, todas las propuestas anteriores incluyen elementos somáticos. En este contexto, quizás resulte más rentable presentar la locución "tener los labios sellados", cuyo contorno sintáctico más asequible elimina posibles ambigüedades. El somatismo más transparente ("a avea buzele pecetluite") es el que menos nos convence como alternativa, puesto que notamos un cambio en el parámetro del registro (el lema "pecete" pertenece en rumano al registro poético, frente a "sellado" en español, de registro más neutro). 


\subsubsection{Somatismos con el lexema "lengua"}

El somatónimo "lengua" (en rumano "limbă") produce un número importante de locuciones verbales en los dos idiomas, destacando una gran congruencia léxica entre las dos bases de datos. Cabe subrayar también que la mayoría de las UF corresponde a la función comunicativa "transmitir información", ya que el lema aparece con su sentido metafórico de "habla". De estas hemos eliminado las que consideramos dialectales: "tener la lengua sucia" ('decir palabras groseras'), "darse la lengua dos o más personas" ('congeniar') o las UF con simbolismo fonético "trastrabarse la lengua" y "trabarse la lengua".

Asimismo, prescindimos de la locución verbal malsonante "meterse la lengua por el culo" ('tener que dejar de hablar') o de la UF "parecer que alguien ha comido lengua" ('hablar demasiado'), puesto que la misma idea expresamos a través de somatismos de uso menos restringido como "tener la lengua muy suelta" o "tener la lengua muy larga".

Conservamos en cambio somatismos más transparentes en rumano, como "tirar de la lengua" ('hacer hablar, especialmente para decir algo que debería callar o querría callar') al que le corresponde "a trage de limbă", con un leve cambio en el parámetro morfológico del sustantivo (no articulado en rumano). Otra UF seleccionada es "morderse la lengua" ('contenerse para no decir lo que se quisiera'), transparente y equivalente en "a-şi muşca limba". Los diccionarios bilingües consultados proporcionan la misma serie que encontramos en el caso de "sellar los labios", decisión no del todo acertada, puesto que "a-şi pune lacăt la gură" (lit. ponerse candado a la boca) refleja el matiz de autocensura, pero no de frustración.

Destacamos las múltiples opciones que proporciona el español para expresar la idea de "decir lo que no se debía o se quería callar". Encontramos UF como

irse alguien de (la) lengua

(loc. verb. coloq.): decir lo que debiera callar.

írsele a alguien la lengua

(loc. verb. coloq.): escapársele la lengua.

echar alguien la lengua al aire

(loc. verb. coloq.): irse alguien de (la) lengua.

escapársele a alguien la lengua

(loc. verb.): escapársele palabras que no quería decir.

Presentar todas estas entradas en la clase de E/LE nos parece contraproducente, por lo que debemos establecer una atenta selección. Hemos comprobado que las entradas comunes en los repertorios fraseológicos son las UF que incluyen el verbo "ir" y que muchas fuentes consultadas omiten las demás alternativas. Por lo tanto, conservamos únicamente "irse la lengua" ('escapársele a una persona lo que no quería decir'). Además del criterio de recurrencia, optamos por esta entrada 
porque en rumano los somatismos equivalentes son "a fi gură spartă" (lit. ser boca rota) y, sobre todo, "a lua gura pe dinainte" (lit. tomar/coger la boca por delante). Como comprobamos, el rumano recurre también a un somatónimo, el lexema contiguo "boca", con equivalencia parcial. En cuanto al contorno sintáctico, notamos que en el caso de "a lua gura pe dinainte" el sujeto es "gura" (boca), al igual que en español ("lengua"), que existe un elemento prepositivo y que predomina el uso de un tiempo pretérito: "ma luat gura pe dinainte, te-a luat gura pe dinainte, l-a luat gura pe dinainte, etc.

Destacamos también la presencia del pronombre objeto directo en rumano, frente a la combinación objeto indirecto + "se" impersonal en español: "(a mí) se me fue la lengua", "(a ti) se te fue la lengua", "(a él) se le fue la lengua", etc. Finalmente, señalamos una variante que incluye la preposición "de", lo que complica aun más la estructura y provoca un cambio en el contorno sintáctico: "se me fue de la lengua", variación inexistente en rumano, donde hay un mayor grado de fijación. Estas observaciones nos llevan a introducir la UF en el corpus destinado a las locuciones de nivel B2, dentro de la función comunicativa "dar/transmitir información".

Habría que hacer hincapié también en el contorno sintáctico de otra locución seleccionada para el B2, "darle a la lengua". A pesar de que el DILEA la define como "hablar", nos decantamos por las explicaciones proporcionadas por el DRAE ('hablar mucho') o por el DFDEA ('hablar, generalmente con idea de exceso o falta de control'). En rumano, la locución equivalente sería "a da din gură" (lit. dar de boca) y una serie de variantes pluriverbales más complejas como "a avea gura ca o moară stricată" (lit. tener la boca como un molino roto) y la UF "a da din meliţă" (no somática y con una resticción diatópica, al pertener a un registro más regional). Nuestra elección, más transparente, es "a da din gură", ya que conserva el mismo verbo, el elemento prepositivo y un somatónimo contiguo. Sin embargo, aunque desde el punto de vista de la estructura argumental hay más similitudes, difiere el contorno sintáctico. En español la UF contiene un objeto indirecto (yo <le> doy a la lengua, tú <le $>$ das a lengua, él $<l e>$ da a lengua, etc.), mientras que en rumano notamos la presencia de un circunstancial: eu dau din gură, tu dai din gură, el dă din gură, etc. y un leve cambio en el parámetro morfológico del sustantivo (no articulado en rumano).

Finalmente, seleccionamos en el nivel B1 la UF transparente "tener en la punta de la lengua" ('estar a punto de decir algo; estar a punto de recordar y no conseguirlo'). El rumano recupera el significado exacto en "a sta pe limbă" (lit. estar en la lengua), pero con contorno sintáctico ligeramente modificado: "<mie> <îmi> stă pe limbă" (a mí me está en la lengua), donde el sujeto es la información que cuesta expresar, mientras que el actante (también sujeto lógico) es, desde el punto de vista gramatical, un objeto indirecto. Volvemos a notar el parámetro morfológico modificado en el somatónimo, no articulado en rumano a diferencia del español, siempre acompañado por el definido (la lengua). 
Descartamos la locución "no tener alguien pepita en la lengua" ('hablar con libertad y desahogo') frente a su variante mucho más frecuente, "no tener pelos en la lengua", que analizaremos en el apartado dedicado al somatónimo "pelo". 


\subsubsection{Somatismos con el lexema "mano"}

La mayor dificultad en el caso del inventario más productivo de todos los somatónimos analizados ("mano"-"mână") es dar con aquellas locuciones relevantes, rentables y adecuadas al nivel, en otras palabras, encontrar un equilibrio para no abrumar a los aprendientes con demasiadas UF, pero al mismo tiempo sin perder de vista somatismos de uso activo, compartidos por amplias comunidades de hablantes.

En este sentido, hemos descartado cualquier elemento prefabricado no verbal, como "mano izquierda" ('habilidad para manejarse o resolver situaciones difíciles'), "mano derecha" ('persona muy útil'), "con las manos en la masa" ('en el momento preciso de actuar'), "como la palma de la mano" ('a fondo, con detalle y precisión'), a pesar de encontrar todas las entradas anteriores en frecuentes construcciones verbales: tener mano izquierda, ser la mano derecha, pillar con las manos en la masa, conocer como la palma de la mano.

Iniciamos el análisis contrastivo en este amplio apartado por las locuciones más transparentes, que conformarán el corpus. Se trata, en primer lugar, de "lavarse las manos" ('desatenderse de la responsabilidad de un asunto'), con el equivalente rumano "a se spăla pe mâini" (lit. idem.), rechazar la responsabilidad de asumir un problema difícil o un hecho reprobable. En este caso, nos encontramos ante un caso de UF fácilmente asequible por un aprendiente rumano de nivel inicial debido a la facilidad de los elementos constituyentes, a pesar de algunas leves diferencias en cuanto al contorno sintáctico. En rumano, a diferencia del español, notamos la presencia de la preposición "pe" y la forma no articulada del sustantivo. Más cercana resulta ser "frotarse las manos" ('sentir gran satisfacción y alegría'). En este caso, el rumano mantiene intacta la UF del español, pero añade un complemento circunstancial de causa, inexistente en castellano: "a-şi freca mâinile de bucurie" (lit. frotarse las manos de alegría).

La forma pronominal reflexiva se mantiene en "Ilevarse las manos a la cabeza" y en su variante "echarse las manos a la cabeza" ('asombrarse de algo o indignarse a causa de ello'), con una única equivalencia somática en rumano: "a-şi pune mâinile-n cap". La locución rumana comparte la misma estructura argumental, conserva ambos somatónimos, pero difiere en la selección del verbo ("a pune" significa poner) y en la la preposición, puesto que "-n" (en su variante no apocopada "en") expresa localización espacial, frente a la dirección que refleja el elemento prepositivo "a" en español.

Asimismo, seleccionamos "echar una mano", locución verbal más sintética que su equivalente rumano "a da o mână de ajutor" (lit. dar una mano de ayuda), pero también más opaca. Aunque un contexto adecuado facilitaría su comprensión, la dificultad es mayor en las destrezas productivas por el plurisemantismo del verbo "echar", que en ciertas construcciones pierde su significado léxico y cuyo comportamiento semántico y sintáctico se acerca al de los verbos de soporte, 
conocidos como heavier light verbs. Sin embargo, a pesar de su relevancia, descartamos la UF "echar mano" ('valerse de algo para un fin') por la opacidad del somatismo en rumano, por la equivalencia nula y por los problemas de interferencia con la locución anteriormente analizada, "echar una mano". Al consultar los diccionarios fraseológicos bilingües, reiteramos el error de proporcionar UF equivalentes a toda costa, aunque en el fondo son meros calcos del español. En este sentido, el DFSR se empeña en ofrecer una alternativa somática, "a pune mâna pe cineva/ceva" (lit. poner la mano en alguien/algo), a diferencia de otras fuentes que se limitan a dar como alternativa el verbo "a apela" (recurrir).

En el nivel B1 introducimos "tener las manos atadas" ('no tener libertad para actuar'), con su UF somática "a avea mâinile legate" (lit. idem), en una clara trasparencia de significado y de equivalencia morfosintáctica.

EI DRAE recoge la locución verbal "morderse las manos" ('manifestar gran sentimiento de haber perdido, por omisión o descuido, algo que deseaba'), pero la omiten otras fuentes (DILEA, DFDEA). En rumano encontramos documentada la UF somática "a-şi muşca mâinile" (lit. morderse las manos), presente en el DEX y en el DSREL (con la definición 'arrepentirse profundamente"), considerada equivalente por los diccionarios bilingües. A pesar del contorno sintáctico idéntico y de su evidente transparencia, no la consideramos suficientemente relevante para incluirla en el corpus (en rumano apenas encontramos ejemplos en la red).

En cambio, es más frecuente y transparente la locución "morder la mano que da de comer" ('criticar a la persona o empresa que te proporciona ayuda o dinero y, por extensión, ser ingrato'). En esta situación nos encontramos ante un caso de un préstamo semántico, ya que en ambas lenguas (el rumano opera con "a muşca mâna care te hrăneşte") la expresión procede de un proverbio chino. "Cuando hablamos de préstamos semánticos, hablamos de préstamos en el sentido extralingüístico, ya que estas unidades reflejan la realidad extralingüística surgiendo en las lenguas de muchos pueblos a base de ideas, imágenes, mitos, acontecimientos, etc. de otros pueblos." (Zholobova 2005: 1192).

El refranero multilingüe del CVC opta por la entrada en imperativo ("no muerdas la mano que te da de comer") y ofrece paremias equivalentes en varios idiomas. La estructura actancial es inmediatamente reconocible en rumano, ya que en ambas lenguas se respeta la misma arquitectura fraseológica.

En el mismo territorio, el de la paremia comparada, nos encontramos en el caso de la locución proverbial "tirar la piedra y esconder la mano" ('causar daño de manera disimulada') que, a pesar de su equivalencia nula en rumano, podría descodificarse fácilmente si se analizara detenidamente su estructura bimembre. Sin embargo, haría falta hacer hincapié en la diferencia semántica respecto a "tirar la primera piedra", que 
tiene una equivalencia total, puesto que este caso nos encontramos ante un europeísmo cultural.

Una referencia bíblica señalamos en la locución verbal compleja "estar alguien dejado de la mano de Dios" ('cometer enormes delitos o notables desaciertos', aunque en otras fuentes consultadas se hace también referencia al abandono, descuido 0 incluso a la lejanía). Consideramos que esta UF no tiene cabida en nuestro corpus por la equivalencia nula, por la combinación morfosintáctica de sus componentes y, sobre todo, por la función comunicativa. Aun así, nos sorprende que los diccionarios bilingües consultados hayan optado por prescindir de estas entradas pluriverbales, teniendo en cuenta que su fuente primordial son los registros fraseológicos explicativos, donde sí que aparecen reflejadas.

Encontramos, en cambio, la locución muy similar en cuanto a sus componentes básicos, pero con una notable divergencia semántica: "dejar de la mano" ('abandonar, cesar en la ejecución'). EI DFSR aporta una información referente al rasgo gramatical del verbo ("frecuentemente en conjugación negativa"), una equivalencia calcada poco convincente "a lăsa din mână" (lit. dejar de mano) y una paráfrasis más esclarecedora: "a se opri din realizarea unui lucru" (lit. detenerse de realizar una cosa).

Por su alto grado de frecuencia, más rentable nos parece "poner la mano en el fuego" ('confiar en la honradez de una persona o en la veracidad de una cosa'), con una equivalencia funcional en rumano, "a băga mâna în foc" (lit. meter mano en fuego). La ligera variación morfológica (la ausencia del artículo definido en los dos sustantivos) no complica ni la comprensión ni la producción, por lo que consideramos que la UF encajaría perfectamente en el nivel A2.

Asimismo, seleccionamos la locución "poner la mano encima", con su doble significado, 'tocar' y 'golpear a una persona', a pesar de no tener una clara equivalencia en rumano. Los diccionarios bilingües siguen el recorrido trazado por el DRAE $u$ otros repertorios fraseológicos, para acabar en UF alejadas considerablemente como significado. En el DSREL "poner la mano encima" remite a "guante" ("echarle a alguien el guante") o "echarle mano a alguien", con el significado de "atrapar", idea que en rumano expresa la UF "a pune mâna pe cineva" (coger a una persona). EI DFSR se acerca más al significado de la locución original al ofrecer como opción la UF somática rumana que conlleva el matiz de agresión "a ridica mâna asupra cuiva" (lit. levantar la mano contra alguien), tras haber remitido anteriormente a "poner las manos en alguien". Coincidimos con las afirmaciones de Duţă (2014:103) que, en un artículo dedicado al análisis semántico de algunos somatismos en español y en rumano, reseña y examina los mismos diccionarios que representan las fuentes de este estudio. La autora reitera la importancia de consultar fuentes diversas, ya que en algunos casos la equivalencia fraseológica puede resultar engañosa. "Hemos notado que los fenómenos de incongruencia entre los tres diccionarios se pueden clasificar en 
tres categorías: asimetrías, divergencias y casos de homonimia fraseológica, con sus distintas subcategorías (...)".

La misma función comunicativa (expresar agresión) se refleja en "llegar a las manos" ('pegarse dos o varias personas'), sin una correspondencia somática en rumano: "a se lua la bătaie", a se încăiera" ('pegarse'), pero con una congruencia actancial. Sin embargo, consideramos que la facilidad de los componentes (impartidos en el nivel inicial) allana la comprensión y no plantea problemas a la hora de una correcta producción, tanto pragmática como morfosintáctica.

Un caso especial lo constituyen los somatismos que, tanto en español como en rumano, incluyen el verbo "escapar". A pesar de no estar recogidas en el DRAE, seleccionamos las locuciones "escaparse de entre las manos" ('perder a una persona o una cosa que casi se había conseguido') y "escaparse de las manos" ('perder a una persona o una cosa que casi se había conseguido'; 'perder el dominio o el control de una cosa'). En el primer caso, el rumano cuenta con una UF equivalente, "a scăpa printre degete" (lit. escapar entre dedos), lo que remite a la locución española con idéntico somatónimo, "escaparse de los dedos". A pesar de la evidente transparencia de los elementos constituyentes, consideramos que la diferencia de contorno sintáctico podría plantear ciertas dificultades. Mientras en español <a alguien> se <le> escapa de las manos <algo> 0 <a alguien> se <le> escapa de entre las manos <algo>, en rumano coexisten las estructuras pronominal indirecta y transitiva: a-i scăpa <cuiva> $<$ ceva $>$ printre degete y a scăpa <cineva $><$ ceva $>$ din mână. Además, apuntamos leves diferencias en cuanto a los elementos prepositivos y subrayamos la dificultad de la combinación "de entre" para un aprendiz rumano. Por estas razones, consideramos útil la presentación de estas UF en el nivel B2, dentro del contenido funcional "expresar frustración". 


\subsubsection{Somatismos con el lexema "mejilla"}

Lo que más sorprende en el caso del somatónimo "mejilla" (en rumano "obraz", procedente del eslavo antiguo) es la cantidad abrumadora de UF existentes en rumano, si comparamos con la única entrada seleccionada en español. Tras analizar las bases de datos recogidas, explicamos este desajuste por la asimilación de "obraz" en rumano con "cara" en español, lexemas unidos por un nexo conceptual. Encontramos equivalencias funcionales en somatismos como "echar en cara" - "a bate obrazul" (expresar reproche), "dar la cara por alguien" - "a-şi pune obrazul pentru cineva" (expresar solidaridad), "caérsele la cara de vergüenza" - "a-i crăpa obrazul de ruşine" (expresar vergüenza).

El somatismo "poner la otra mejilla" ('perdonar una agresión o una ofensa') no aparece en el DRAE, pero sí en otros registros fraseológicos (DILEA, DFDEA). En rumano existe una locución con equivalencia parcial desde el punto de vista formal, "a întoarce şi celălalt obraz" (lit. volver también otra mejilla), pero con idéntico uso pragmático, al tratarse de un bibleísmo fraseológico (la UF alude a las palabras pronunciadas por Jesucristo, recogidas en el capítulo 5 del Evangelio de Mateo). A pesar de proceder de la misma fuente textual, las leves diferencias en cuanto a sus componentes ("poner" - "a întoarce", la presencia del intensificador "şi" en rumano y la ausencia del artículo definido) nos llevan a situar este somatismo en el nivel B2.

Además, si atendemos a la información adicional proporcionada por el DILEA ("suele utilizarse en infinitivo"), apuntamos otra diferencia frente al rumano, donde predomina el indicativo. 


\subsubsection{Somatismos con el lexema "nariz"}

Aunque el lexema "nariz" (en rumano "nas") genera un número importante de UF, no hemos recopilado muchas locuciones con sintagma verbal (hecho confirmado también por el DILEA, que únicamente incluye cuatro entradas). De estas, "arrugar la nariz" ('mostrar disgusto'; 'mostrar repugnancia') no se refleja en el DRAE y, por consiguiente, falta en los diccionarios bilingües que toman como referencia esta fuente.

En nuestro corpus no prescindimos de esta UF, que consideramos útil y relevante. Además, en rumano hay una equivalencia parcial desde el punto de vista estructural en "a strâmba din nas" (lit. arrugar de nariz), pero con simetría polisémica. El elemento quinésico (el gesto efectivo de arrugar la nariz) facilita la comprensión, pero debido a la dificultad del verbo "arrugar" (opaco para un aprendiz rumano), colocamos la locución en el nivel B2.

En cambio, el somatismo "asomar las narices" ('aparecer en un lugar, especialmente para husmear o fisgar') sí que aparece en todas las fuentes consultadas, algunas de las cuales indican un alto grado de frecuencia. Tras consultar las equivalencias proporcionadas por los diccionarios bilingües, consideramos que la más acertada es la UF que sugiere el DSREL, "a-şi băga nasul unde nu-i fierbe oala" (lit. meterse la nariz donde le hierve la olla). Sin embargo, esta alternativa pluriverbal paremiológica (procedente del refrán "nu-ţi băga nasul unde nu-ţi fierbe oala") subraya la idea de aparición no deseada, no solo el hecho de "aparecer", tal como indica en DILEA en su definición de la locución española. EI DFDEA indica como variante "asomar la nariz" (con el somatónimo en singular), más cercana a la forma del rumano, donde ninguna locución incluye el plural del lexema "nas". Cabe destacar que la mayoría aplastante de las UF recopiladas en español contiene la forma en plural ("narices"), lo que aporta un grado de dificultad adicional. Hay que subrayar también la existencia de una locución más transparente, "meter la nariz", con idéntica carga semántica que en rumano ('entrometerse'), pero considerada por el DILEA menos frecuente. Anticipamos que esta será la producción más frecuente de un alumno rumano de E/LE, cuyo primer impulso será transferir a la LM la locución existente en su lengua materna, utilizando un verbo soporte ("meter") en detrimento del verbo "asomar", de menor recurrencia.

La forma en plural aparece también en la UF "dar con la puerta en las narices", locución verbal somática en todas las variantes proporcionadas por el DRAE (dentro del lema "puerta"): "dar con la puerta en la cara, en las narices, en los hocicos, en los ojos" ('negar bruscamente lo que se pide o se desea'). En rumano encontramos una equivalencia en la UF "a trânti uşa în nas" (lit. cerrar la puerta en nariz), que conserva los mismos sustantivos y el significado metafórico (rechazo). Las leves diferencias estructurales no complican en absoluto la comprensión global, pero representan un escollo a la hora de llevar a cabo una producción correcta: se trata, en primer lugar, 
del verbo polisémico "dar" seguido de la preposición "con" (que los aprendientes rumanos asocian primordialmente con la idea de compañía) y, en segundo lugar, como ya hemos mencionado anteriormente, la presencia del somatónimo "narices" en su forma plural. Por todo ello, recomendamos insertar esta UF en el nivel B2.

Asimismo, incluimos en el nivel B2 "hinchar las narices" ('enfurecer'), locución complicada para un rumanohablante porque carece de una alternativa somática en su lengua. Además, conviven estructuras argumentales diferentes en "hincharle a alguien las narices" e "hinchárse $<l e><a$ alguien $>$ las narices". Para esta última, el DFSR propone como alternativa "a-<i> sări <cuiva muştarul" (lit. saltarle a alguien la mostaza), estructura pronominal indirecta, donde "la mostaza" cumple la función de sujeto: <mie > <îmi $>$ sare muştarul <ţie > <îţi> sare muştarul, <luilei $><\hat{i}>>$ sare muştarul, etc. (a mí me salta la mostaza, a ti te salta la mostaza, a él/ella le salta la mostaza). Sin embargo, a diferencia del español, esta UF no admite otra estructura actancial, por lo que "hinchar $<$ le $><$ a alguien $>$ las narices" tendría como alternativas en rumano "a scoate din sărite/ din răbdări/ din pepeni <pe cineva>" (lit. sacar de saltos/paciencias/sandías a alguien), todas con un elevado grado de idiomaticidad. En cuanto a la variante "inflar las narices", menos utilizada según el DFDEA, la relegamos a niveles superiores, puesto que los aprendientes ya cuentan con suficientes recursos para el contenido funcional "expresar enfado".

Un somatismo cercano desde el punto de vista funcional es "tocar las narices" ('molestar o fastidiar'), con un equivalente parcial en rumano, la UF somática "a bate la cap" (lit. pegar a cabeza). La locución española resulta opaca para un aprendiz rumano, al que le cuesta asociar el verbo plurisemántico "tocar" con la idea de insistencia y malicia, que se desprende de este SO. Por lo tanto, hará falta diseñar actividades de clase para una correcta asimilación de la UF, que no plantea otras dificultades y la estructura argumental es idéntica en ambas lenguas. Sin embargo, habrá que prestar atención para evitar la confusión con una locución sensiblemente parecida desde el punto de vista formal, pero con distinto significado: "tocarse las narices" ('estar sin hacer nada o sin trabajar'). Las equivalencias encontradas en los diccionarios bilingües son idénticas con las que señalamos en el caso de los somatónimos "barriga" y "brazo", analizados anteriormente: "tocarse la barriga" y "estar de brazos cruzados". Si el rumano echa mano de los mismos lexemas para expresar falta de acción o pereza (véase "a sta cu burta la soare", "a sta cu braţele încrucişate" o "a sta cu mâinile în sân"), el somatónimo "nariz" no genera en rumano ninguna UF con este contenido funcional.

Otro somatismo que conforma nuestra base de datos para el nivel B2 es la locución pluriverbal "no ver alguien más allá de sus narices" ('ver muy poco'; 'ser poco avisado, corto de alcances'). Quizás por su complejidad semántica, el diccionario DFSR decide omitirla por completo, mientras que el DSREL recurre a una explicación exhaustiva ("tener una comprensión limitada o una falta de perspectiva") y 
encuentra una equivalencia parcial, que nos parece muy acertada: "a nu vedea mai departe decât lungul nasului” (lit. no ver más lejos que la longitud de la nariz). Identificamos muchos elementos comunes: la forma verbal en negativo, la presencia del adverbio de lugar acompañado por la marca del comparativo y, evidentemente, el somátonimo analizado. Además, destacamos una estructura argumental idéntica en los dos idiomas. Otra posible equivalencia podría ser la locución no somática "a avea ochelari de cal" (lit. tener gafas de caballo), cuyo significado proporcionado por el DEX es "rechazar percibir la realidad en su complejidad global; ser retrógrado."

Finalmente, introducimos en el nivel B2 la locución "importar tres narices" o "importar tres pares de narices" ('no importar en absoluto'), a pesar de no figurar ni el DRAE ni en el DILEA y, sobre todo, de tener una equivalencia nula en rumano.

Sin embargo, hemos descartado algunas entradas más complejas o con ciertas restricciones, como es el caso de "tener narices" o "mandar narices" por su uso con intención enfática, generalmente comentando algo negativo. Asimismo, relegamos al nivel $\mathrm{C} 1$ la entera serie "pasar por las narices (o restregar, refrotar o refregar) por (o en) las narices" por la dificultad de los elementos constitutivos y por las restricciones combinatorias. En cuanto a la UF "hasta las narices" ('en estado de cansancio, harto'), se trata de una locución adverbial y, por lo tanto, no conforma nuestro corpus, pese a admitir un número escaso de verbos en sus combinaciones. Esto no quita que en las propuestas didácticas de este trabajo aparezca junto con un elemento verbal ("estar hasta las narices"), dada su importancia, recurrencia y rentabilidad. 


\subsubsection{Somatismos con el lexema "ojo"}

Huelga decir que las UF que contienen el somatónimo "ojo" (en rumano "ochi", forma común para el singular y el plural) son muy numerosas, por lo que tuvimos que operar una selección cabal, de acuerdo con nuestros intereses.

A través de los ojos percibimos el mundo, por lo que "abrir los ojos" se impone como la primera entrada en nuestra base de datos. El sentido que indica el DRAE, 'conocer las cosas como son, para sacar provecho y evitar las que pueden causar perjuicio o ruina', se refleja en la locución rumana "a deschide ochii" (lit. idem.), con su variante "a căsca (bine) ochii" (lit. abrir bien los ojos). No obstante, a pesar de la aparente transparencia, la locución rumana no cubre la totalidad de significados que encontramos en español: 'nacer'; 'descubrir una cosa'; 'prestar atención'; 'desengañar a una persona'. En rumano, la UF no lexicaliza el acto de nacer, por lo que no se da la situación de polisemia simétrica. Nos encontramos, por lo tanto, ante un caso de laguna fraseológica que podría constituir, en la traducción, un falso amigo fraseológico. Cabe señalar que el rumano cuenta con dos locuciones, "a deschide bine ochii" (lit. abrir bien los ojos) y "a fi cu ochii în patru" (lit. estar con los ojos en cuatro) que además de la idea de 'prestar mucha atención', 'ser vigilante', incluye el rasgo semántico de peligro y de amenaza y tienen la función ilocutiva de advertencia. Estos ejemplos ilustran el fenómeno de cuasi-sinonimia translingüística que se refiere a "unidades léxicas o fraseológicas de dos lenguas que remiten a la misma estructura conceptual, pero cuyos significados no son idénticos, sino que difieren en uno o dos elementos semánticos" (Trivić 2013:76).

En los diccionarios monolingües rumanos, tanto generales como fraseológicos, hemos encontrado una locución parecida desde el punto formal, "a deschide ochii pe cineva" (lit. abrir los ojos sobre alguien), donde el elemento circunstancial provoca un cambio importante de significado: "enamorarse por primera vez". Sin embargo, se trata de una "expresión popular" (DSREL) o "anticuada" (DEX) desconocida por los hablantes jóvenes urbanos.

En el lado opuesto, "cerrar los ojos" también plantea problemas debido a su polisemia. Según DRAE, cerrar alguien los ojos

1. loc. verb. dormir, entrar o estar en sueño. U. m. con neg.

2. loc. verb. morir (ll llegar al término de la vida).

3. loc. verb. sujetar el entendimiento al dictamen de otro.

4. loc. verb. obedecer sin examen ni réplica.

5. loc. verb. arrojarse temerariamente a hacer algo sin reparar en inconvenientes.

EI DILEA se limita a presentar un único uso que considera muy frecuente, "no querer reconocer una cosa o no querer enterarse de ella", mientras que el DFDEA matiza las entradas según el número del somatónimo; "cerrar el ojo (o los ojos)" 
equivale a 'morir', mientras "cerrar (o taparse) los ojos" (ante algo) equivale a 'no querer reconocer', uso que curiosamente falta del listado que propone el DRAE. Nosotros coincidimos con el DILEA y seleccionamos la locución con la definición que nos propone, equivalente a la UF rumana "a închide ochii" (lit. cerrar los ojos). Observamos que tiene la misma estructura argumental y que está formada por los mismos constituyentes léxicos. Además, debido a sus componentes (impartidos en los niveles iniciales) consideramos que encajaría perfectamente en el nivel B1.

Para expresar el significado 'dormir' preferimos incluir en el corpus de nivel B1 la UF somática "no pegar ojo" ('no dormir'), con sus múltiples variantes: "no pegar un ojo", "no pegar el ojo", "no pegar los ojos", todas ellas admitidas exclusivamente en forma negativa. A su vez, el rumano maneja varias locuciones equivalentes, de las cuales dos comparten el mismo lexema ("a nu închide un ochi" y "a nu închide ochii", lit. no cerrar un ojo y no cerrar los ojos) y otra un somatónimo conceptualmente muy cercano - "a nu pune geană pe geană" (lit. no poner pestaña sobre pestaña).

El acto de mirar se refleja también en la UF polisemántica "echar un ojo", pero se añaden otros semas: 1. mirar; 2 . examinar superficialmente a una persona o una cosa; 3. cuidar o vigilar. Tanto el significado nuclear como los significados ampliados se encuentran en rumano en la locución equivalente: "a (a-şi) arunca ochii (un ochi) / o privire" (lit. echar(se) ojos (un ojo) / una mirada". Estamos ante un caso de correspondencia absoluta en polisemia. Asimismo, la estructura argumental (agente paciente) es totalmente idéntica: "<alguien> echa un ojo <a algo/a alguien>/por un lugar". Sin embargo, notamos leves diferencias en el contorno morfosintáctico (el rumano admite la forma verbal reflexiva, conviven el singular y el plural del lexema "ojo" y existe una variación no somática, pero con un término conceptualmente afín, "mirada"). A pesar de estos elementos distintos, consideramos que la UF se puede impartir en el nivel B1, donde no plantea dificultades de comprensión.

En cuanto a la UF española "mirar con buenos ojos" ('mirar con afición o cariño') y su correspondiente antónima "mirar con malos ojos" ('mirar con desafecto'), el DRAE las recoge como locuciones verbales, el DFDEA remite a las locuciones adverbiales "con buenos (o malos ojos)", usadas frecuentemente con los verbos "ver" y "mirar", mientras que el DILEA las omite por completo. Hemos recopilado en rumano las equivalencias "a privi cu ochi buni" y "a privi cu ochi răi" (lit. mirar con ojos buenos y mirar con ojos malos), tal como nos indican los diccionarios bilingües. Sin embargo, a pesar de compartir estructuras sintácticas y léxicas similares, cabe señalar una diferencia en el plano estilístico: "a privi cu ochi răi" ha caído en desuso en favor de la estructura antifrástica "a nu privi cu ochi buni" (lit. no mirar con ojos buenos), por lo que su tono arcaico y anticuado confiere propiedades estilísticas que no posee el somatismo español. De hecho, los motores de búsqueda confirman esta tendencia, como también los registros fraseológicos monolingües que ya atestiguan la entrada "a nu privi cu ochi buni" - desaprobar, no admitir. 
Otro caso fronterizo en cuanto a la delimitación de la categoría verbal se refiere lo encontramos en una locución que no expresa la noción de ver: "(costar) un ojo de la cara" ('ser excesivo el precio o el gasto que se ha tenido'), considerada verbal por el DRAE y adverbial por el DFDEA. EI DSFR, en un intento de proporcionar una equivalencia somática que conserve algunos elementos constituyentes de la UF de origen, ofrece como equivalencia "a costa cât ochii din cap" (lit. costar cuanto ojos de cabeza). Sin embargo, dicha entrada no consta en el DEX, apenas tenemos registros en la red y en su gran mayoría son propios del mundo infantil, a diferencia del español. Consideramos más acertada la equivalencia parcial no somática "a costa o avere" (lit. costar una fortuna). Los componentes de la UF de origen (todos impartidos en el nivel A1) facilitan la comprensión inmediata del significado, a pesar de no contar en rumano con una estructura que incluya el mismo lexema.

El rasgo semántico del peligro y la idea de prevención se reflejan en las UF "andar con ojo" y "andar con cien ojos" ('actuar con cuidado y atención'). En rumano expresamos estos semas a través de dos locuciones somáticas, "a fi cu ochii în patru" (lit. estar con los ojos en cuatro, en una sutil referencia a los puntos cardinales) y "a fi numai ochi si urechi" (lit. estar solo ojos y orejas), ambas equivalencias parciales, proporcionadas por el DFSR. La idea de movimiento, expresada por el verbo "andar", falta en rumano, donde prevalece el estado de alerta (en la primera) y de cautela (en la segunda). Destacamos el contorno sintáctico similar $\mathrm{S}+\mathrm{V}+\mathrm{CCM}$. Todos los elementos constituyentes en español se imparten en el nivel inicial, por lo que desde el punto de vista formal los aprendientes no encontrarán obstáculos para descodificar los componentes léxicos. El significado global será también fácilmente deducible, por lo que incluimos la UF en el nivel B1.

Un caso muy complejo lo representan las locuciones que incluyen el lexema "venda" entre sus constituyentes. En el DILEA hemos recopilado un total de doce entradas diferentes, de las que once son somáticas: "arrancar la venda de los ojos", "caer la venda de los ojos", "caerse la venda", "caerse la venda de los ojos", "poner una venda en los ojos", "poner una venda sobre los ojos", "ponerse una venda en los ojos", "ponerse una venda sobre los ojos", "quitar la venda de los ojos", "tener una venda en los ojos" y "tener una venda sobre los ojos". Ante esta avalancha de opciones, el dilema que se plantea es operar una selección eficaz para dar con aquella(s) entrada(s) más útil(es) para los aprendices rumanos. El DFDEA recopila aun más somatismos, mientras que el DRAE aporta la locución verbal "vendarse alguien los ojos" ('no querer asentir ni sujetarse a la razón por clara que sea'). Los diccionarios bilingües hacen una criba importante, eliminando las que contienen la marca [menos frecuente] y las que resultan redundantes. Tras una profunda reflexión, decidimos conservar en nuestro corpus de nivel B2 la entrada "caerse la venda de los ojos" ('darse cuenta de las cosas o percibirlas como en realidad son'). Un aprendiz rumano se topa con varias dificultades: en primer lugar, la opacidad del lexema "venda" (en 
rumano "bandaj") y, en segundo lugar, la estructura pronominal indirecta: a mí se me cae la venda, a ti se te cae la venda, a él se le cae la venda, etc. Todos los diccionarios consultados encuentran una equivalencia somática presente en los registros fraseológicos monolingües rumanos, equivalencia parcial que no podemos renegar: "a i se lua (sau a-i cădea) cuiva un văl de pe ochi (sau de pe frunte) = a-și pierde (sau a-și recăpăta) seninătatea, vioiciunea; a înceta (sau a începe) să vadă, să înțeleagă, să judece limpede. No obstante, echamos en falta alguna información adicional sobre el registro, puesto que "văl" (velo) remite al burka o al vestido de novia y aporta un efecto estilístico inexistente en español. Proponemos como alternativa traductológica la locución de uso activo "a se trezi la realitate" (lit. despertarse a la realidad), a pesar de la estructura argumental distinta (reflexiva en rumano): eu mă trezesc, tu te trezeşti, el se trezeşte, etc., y de la ausencia del constituyente somático. La variante proporcionada por los diccionarios funcionaría exclusivamente en un registro literario, mientras que en un registro coloquial no tendría cabida. Observamos, sin embargo, que esta "neutralización" de la UF provoca pérdidas estilísticas (desaparición de la metonimia).

Señalamos un caso similar, donde registramos múltiples versiones en las UF somáticas: "no quitar el ojo", "no quitar el ojo de encima", "no quitar los ojos", "no quitar los ojos de encima", "no quitar ojo", "no quitar ojo de encima", junto con entradas que incluyen el lexema conceptualmente afín, "vista". Ortega (2006:77) afirma que

uno de los terrenos resbaladizos - por otra parte, deliciosamente interesantes - de la Paremiología y la Fraseología es la gran cantidad de variantes que un mismo refrán, dicho o sentencia puede tener. Máxime si a esto le unimos el hecho de que para una misma idea existen diferentes aspectos formales.

No obstante, nosotros consideramos que de esta riqueza disfrutan más los investigadores, no tanto los aprendices de una lengua extranjera.

En el corpus seleccionamos también "no quitar el ojo de encima" (1.no dejar de mirar a una persona o una cosa; 2. no dejar de vigilar a una persona o una cosa), presente también en los diccionarios bilingües. Las UF rumanas equivalentes "a nu-şi lua ochii de cineva/ceva", "a nu-şi dezlipi ochii de la cineva/ceva" comparten el somatónimo, lit. no tomarse los ojos de alguien/algo y no despegarse los ojos de alguien/algo. Asimismo, encontramos en rumano una expresión que cubre parcialmente los significados de la polisémica "no quitar el ojo de encima", concretamente la idea de vigilar, guardar, o tomar precauciones: "a sta cu ochii ca pe butelie" (lit. estar con ojos como en bombona). Para este último caso, hace falta aportar una clave interpretativa: las bombonas representaban un símbolo de prosperidad y bienestar durante la dictadura comunista y, por lo tanto, objeto de deseo y de interés por parte de los ladrones. Aunque las generaciones jóvenes ya no descodifican el elemento cultural, la UF ha permanecido intacta y su uso se ha consolidado, dentro del registro coloquial. 
Finalmente, justificamos algunas UF que no hemos seleccionado ni analizado en este apartado. Hemos prescindido de la locución verbal "quemarse los ojos" (considerada menos frecuente por el DILEA) en detrimento de sus variantes "quemarse las cejas" y "quemarse las pestañas". El europeísmo natural - cultural "ojo por ojo, diente por diente" no es una locución verbal, como tampoco lo es (según el DFDEA) "con los ojos a cuadros" (locución adverbial, frecuentemente en combinación con los verbos "dejar" o "quedarse"). 


\subsubsection{Somatismos con el lexema "ombligo"}

El lexema "ombligo" tiene como correspondiente en rumano el término "buric", procedente de la misma fuente latina umbilicus, pero existe también el neologismo "ombilical" (adjetivo encontrado preponderantemente en el sintagma "cordon ombilical"). Esto facilita la comprensión del somatónimo, presente en escasas locuciones en ambas lenguas.

Sin duda, el sintagma "ombligo del mundo", con su valor despectivo ("centro de algo") es el más transparente, debido a raíz mitológica común. Zholobova (2005) aclara que

se llamaba el ombligo del mundo (ónfalos en griego) a la piedra que se veneraba en el santuario de Apolo en Delfos, el mayor centro de espiritualidad para los griegos. Según el mito, Cronos devoró a todos sus hijos menos a Zeus, que fue salvado por su madre. Ella le hizo a Zeus comer piedra, el ónfalos, haciéndole creer que era su hijo menor. Al final Cronos devolvió a sus hijos y también la piedra, que cayó en Delfos (Zholobova 2005:1194).

Sin embargo, consideramos que estos elementos mitológicos son desconocidos por la mayoría de los hablantes, que se basan en su experiencia directa y asocian la idea del centro con la estructura del cuerpo humano.

Aunque los repertorios léxicos españoles no las consideran locuciones verbales propiamente dichas, a diferencia del DEX, hemos seleccionado "ser el ombligo del mundo" y "creerse el ombligo del mundo" debido a su transparencia. Las UF rumanas equivalentes son "a fi buricul pământului" y "a se crede buricul pământului" ('ser /creerse el más importante de todos'). Huelga decir que son estructuras inmediatamente reconocibles y que comparten función comunicativa, rasgos gramaticales y elemento actancial, por lo que las incluimos en el nivel B1.

Otra locución seleccionada, esta vez en el nivel B2, es "mirarse el ombligo ('tener una actitud de autocomplacencia'), que no cuenta con una equivalencia somática en rumano. EI DFSR ofrece dos alternativas, ambas UF muy coloquiales, "a arde gazul de pomană" (lit. quemar el gas en vano) y "a tăia frunze la câini" (lit. cortar hojas a los perros). Sin embargo, ninguna de ellas contiene el sema "actitud egocéntrica", rasgo intralingüístico presente en la locución española. Por lo tanto, nos encontramos una vez más ante un caso de laguna fraseológica. Además, cabe mencionar la opacidad del somatismo en rumano, difícilmente reconocible fuera de un contexto revelador y el rasgo gramatical distinto (verbo reflexivo en español, expresando inactividad vs. verbo transitivo en rumano, expresando una actividad inútil o absurda).

Finalmente, relegamos al nivel $\mathrm{C} 1$ las dos entradas somáticas "arrugarse el ombligo" y "encogerse el ombligo" ('sentirse asustado o desanimado') por la complejidad 
del contorno sintáctico (pronominal indirecto) y por la dificultad de los verbos constituyentes. El rumano cuenta con equivalencias parciales, UF pluriverbales complejas que contienen distintos somatónimos, como es el caso de "a i se face inima cât un purice" (lit. hacérsele el corazón cuanto un piojo).

Una vez más, resaltamos las definiciones de las locuciones ofrecidas por los diccionarios explicativos monolingües, con las que un aprendiente de E/LE no puede operar: encogérsele a alguien el ombligo (loc. verb. coloq.: amedentrarse 0 desalentase). 


\subsubsection{Somatismos con el lexema "oreja"}

El lexema rumano "ureche" tiene dos correspondientes en español, "oreja" y "oído", por lo que el número de locuciones rumanas es superior, abarcando los dos somatónimos del castellano.

Del listado exhaustivo que recopilamos en una primera aproximación al corpus, son pocas las UF que finalmente conforman la base de datos propuesta para análisis y didactización. Por distintas razones, hemos ido descartando paulatinamente entradas como "retiñir las orejas", "tirar de la oreja a Jorge", "amusgar las orejas", "no valer las orejas llenas de agua", unidades que los hablantes de español ya no usan hoy en día o ni siquiera reconocen. Incluso las fuentes fraseológicas admiten en varios casos que nos encontramos ante locuciones dialectales, en desuso o de frecuencia reducida. Es también la situación de expresiones que contienen elemento verbal (véase "no hay orejas para cada martes") que tampoco son objeto de nuestro estudio.

Seleccionamos, en cambio, la expresión pluriverbal "tener la mosca detrás de la oreja", pero prescindimos de la alternativa reflejada en el DRAE "tener la mosca en la oreja" por su uso más restringido. EI DILEA no incluye ninguna de estas UF, acaso por no considerarlas locuciones verbales (según el DFDEA, "la mosca detrás de o tras o en la oreja" también aparece como colocación nominal). El somatismo es totalmente opaco en rumano y no le corresponde una locución clara, que recupere sus matices de significado. En la explicación del DFSR subyace la idea de peligro "a fi cu atenţia mărită" (lit. estar con atención aumentada) y "a fi atent la primejdie" (lit. estar atento al peligro), pero no conceptualiza semas como el recelo y la desconfianza. EI DSREL proporciona una equivalencia en la entrada del lexema "chamusquina", incluyendo la UF en una serie que también contiene la expresión "haber gato encerrado". La opción que ofrece "a fi ceva putred în Danemarca" (lit. haber algo podrido en Dinamarca) es un culturema que solo nos satisface en parte. La disimetría en la estructura actancial hace difícil que un aprendiz rumano de E/LE internalice la locución y proceda a una producción correcta. Sin embargo, a pesar de que el somatismo no comparte ni la base metafórica ni los elementos léxicos con un equivalente rumano, lo incluimos en el nivel B2.

La locución "ver las orejas al lobo" ('darse cuenta de la dificultad de una situación') incluye también el rasgo semántico de peligro. En las fuentes bibliográficas rumanas que analizamos encontramos opciones muy dispares e incongruentes. El DSREL proporciona una UF somática, "a se da cu capul de pragul de sus" (lit. golpearse con la cabeza con la viga de arriba), lo que indica una experiencia previa "advertir la existencia de un peligro tras sufrir una experiencia negativa", según indica el mismo diccionario. Consideramos que esta propuesta se aleja demasiado del significado de la UF de origen, con la que no comparte elementos constitutivos, base metafórica o características pragmáticas. EI DSR propone "a fi în gura lupului" (lit. estar en boca del lobo), también somática, pero también algo alejada de la locución 
española, con la que, eso sí, comparte un componente. Los problemas que surgen son dos: por un lado, ilustra un peligro ya inevitable ("estar" frente a "ver") y, por otro lado, no toma en consideración los rasgos intralingüísticos de la colocación nominal polisémica "gura lupului" - según Duţă (2013:108), "objeto de chismes, de calumnias".

En el nivel B2 introducimos la UF "planchar la oreja" ('dormir'), también opaca en rumano y sin equivalencia somática. Consideramos que la presencia del verbo "planchar" (impartido en los primeros niveles) en esta UF con alto grado de idiomaticidad podría confundir más que aclarar. EI DFSR remite a la locución "aplastar la oreja" y ofrece como alternativa traductológica "a pune cornul în pernă" (lit. poner el cuerno en almohada). Observamos que las autoras se decantan por una ligera variación frente a la entrada del DEX - "a pune cornu-n pernă" - que refleja la locución en su autenticidad, desprovista de artículo definido y con la preposición apocopada, muestra del lenguaje oral. Además, señalamos el matiz de sueño "profundo" que desprende la locución en rumano y que no hemos documentado en el español peninsular.

Varias entradas diferentes en español ("aguzar la oreja", "poner la oreja" y "pegar la oreja") encuentran en el DFSR un elemento común, la UF somática, "a trage cu urechea" (lit. tirar con la oreja). Sin embargo, si atendemos las definiciones exactas, "aguzar la oreja" (con su variante "aguzar las orejas") significa "prestar atención para oír", mientras que "pegar la oreja" es polisémica en español, con el significado nuclear 'escuchar' y el ampliado 'escuchar disimuladamente'. Opinamos que es contraproducente presentar toda la serie en una clase de E/LE; lo más sensato sería prescindir de la entrada "aguzar la oreja", debido a la complejidad del verbo y optar por "poner", de uso más activo.

Finalmente, seleccionamos en la base de datos (nivel B1) la locución "tirar de las orejas" ('criticar o reprender') a pesar de su sorprendente ausencia en algunos de los repertorios fraseológicos consultados. El rumano cuenta con una UF somática, "a trage de urechi" (lit. idem.), que presenta similitudes en muchos aspectos con la locución de la lengua base: elementos constituyentes, significado denotativo y connotativo, estructura argumental, rasgos pragmáticos, etc. Sin embargo, notamos una diferencia en el parámetro morfosintáctico, ya que en español es posible la nominalización (tirar de las orejas $\rightarrow$ tirón de orejas), mientras que el rumano no admite cambio de categoría gramatical. 


\subsubsection{Somatismos con el lexema "pelo"}

A diferencia del español, donde conviven los somatónimos "pelo" y "cabello", el rumano solo cuenta con un lexema: "păr", procedente del latín pilus.

A la hora de elaborar el corpus nos planteamos si conservar las dos entradas en la base de datos. Sin embargo, tras analizar detenidamente las UF existentes, tomamos una medida eficaz y optamos por incluir exclusivamente las que contengan la palabra "pelo", puesto que muchas locuciones se solapan: "cortar un pelo en el aire /cortar un cabello en el aire", "poner los pelos de punta/ poner los cabellos de punta", "traer por los pelos/ traer por los cabellos", etc. Finalmente, nuestro corpus está conformado por siete somatismos, que abarcan desde el nivel A2 hasta el nivel B2.

La locución "tomar el pelo" ('burlarse de una persona') tiene como correspondencia parcial en rumano la UF somática "a lua peste picior" (lit. tomar encima pierna), con la que comparte muchos rasgos; significado, estructura argumental, registro. Sin embargo, son distintos el contorno morfosintáctico y la base metafórica, por la presencia de la preposición "peste" y la imposibilidad de la nominalización en rumano, frente al español, donde sí hay transformación morfosintáctica (tomar el pelo $\rightarrow$ tomadura de pelo).

A pesar de la complejidad estructural de la locución "ponerse los pelos de punta" (<a alguien > se <le> ponen los pelos de punta"), consideramos rentable presentarla en el nivel B1, debido principalmente a su función comunicativa (expresar angustia y/o miedo). Además, contamos con una equivalencia parcial en rumano, "a i se face părul măciucă" (lit. hacerse el pelo mazo), que remite a la misma lectura metafórica. Consideramos que las dificultades surgen en el plano morfosintáctico (el ya mencionado rasgo gramatical pronominal indirecto), la variación en cuanto al número ("pelos" vs. "părul”) y la presencia de la locución adjetival "de punta".

Al nivel B2 hemos relegado el somatismo "no tener pelos en la lengua" ('decir sin reparos lo que se piensa') por su opacidad y por la falta de una equivalencia clara en rumano. Los diccionarios fraseológicos bilingües optan por algunas variantes somáticas: "a spune verde în faţă" (lit. decir verde en cara) o "a spune de la obraz" (lit. decir de la mejilla), pero también recurren a combinaciones libres de palabras, en un claro intento de parafrasear la UF española, ya que no hay una equivalencia en rumano que abarque ni comparta todos sus semas: [+habla], [+claridad], [+honestidad], [+libertad], [-reparo]. Una propuesta traductológica más personal es recurrir a la expresión de índole paremiológica "ce-i în guşă, şi-n căpuşă" (lit. lo que hay en el bocio, también en la mollera). La rima en rumano, la estructura bimembre, la impersonalidad y cierto uso popular la alejan de la UF base en la LO, pero a nivel semántico consideramos que es la que mejor consigue trasvasar su sentido. 
En cuanto a la forma verbal, subrayamos también una restricción importante, dado que la UF solo admite la forma en negativo, a diferencia de todas las opciones encontradas o propuestas en rumano.

Nos topamos con la misma situación en la locución "no tener un pelo de tonto" que pierde fuerza evocadora en traducciones como "a avea mintea ageră" (lit. tener la mente ágil), "a fi deştept foc" (lit. ser listo fuego) o "a-i merge mintea" (lit. andarle la mente), todas resaltando (en forma afirmativa) la inteligencia y la perspicacia. Para expresar la misma idea, el rumano recurre también a una palabra procedente del campo semántico de los objetos: se trata de "brici" (navaja), pero delexicalizada en su significado adverbial "estupendo", "formidable", recogido por DEX. Hemos documentado en rumano UF como "a fi brici" o "a avea mintea brici" o "a merge mintea brici", todas opciones locucionales válidas para la traducción de la unidad "no tener un pelo de tonto", aunque propondríamos una combinación libre de palabras, más cerca del significado original, incluso sacrificando el somatónimo.

Gracias a la lectura metafórica motivada, encontramos más posibilidades de recuperar todos los elementos constituyentes en la UF "tirarse de los pelos" ('arrepentirse') que cuenta con varias correspondencias parciales en rumano: "a-şi smulge părul din cap" (lit. arrancarse el pelo de cabeza) y "a se lua cu mâinile de cap" (lit. tomarse con las manos de cabeza) y "a se lua cu mâinile de păr" (lit. tomarse con las manos de pelo). Todas las locuciones se apoyan en la misma metáfora motivada y transmiten una identidad sémica equivalente: frustración, ira, desesperación, arrepentimiento. En cuanto a los rasgos gramaticales, señalamos la presencia del verbo reflexivo en español (yo <me> tiro, tú <te $>$ tiras, él $<$ se $>$ tira, etc. de los pelos), mientras que el rumano opta por un dativo (eu <îmi> smulg, tu <iții smulgi, el <îşi> smulge... părul), lo que hace que el somatónimo cumpla la función sintáctica de objeto directo, a diferencia del español, donde funciona como circunstancial. Un elemento común es, en todos los casos presentados, la presencia imprescindible de la preposición ("de - din/de").

Otra UF que integra el corpus de nivel B2 es "tocar un pelo" ('hacer el más mínimo daño'). Sin embargo, no incluimos sus variantes menos frecuentes "tocar un pelo de la cabeza" y "tocar un pelo de la ropa" (ambas incluidas en el DILEA). Ninguno de estos exponentes se ve reflejado en los repertorios bilingües. El DFSR opta por una entrada no somática, "no tocar a alguien a la ropa", ya que, como comprobamos en casos anteriores, toma como referencia el DRAE ("no tocar a alguien en un hilo de la ropa" - 'no decir ni ejecutar algo que de algún modo pueda ser en su ofensa'). Como equivalencias fraseológicas, el diccionario proporciona dos locuciones, una somática "a nu atinge nici cu un deget" (lit. no tocar ni con un dedo") y otra no somática, "a nu atinge nici cu o floare" (lit. no tocar ni con una flor). A pesar de que en rumano existe un paralelismo en la estructura sintáctica y léxica entre las dos UF, consideramos que habría que profundizar en las restricciones de uso, puesto que en rumano este SO se ciñe al contexto de la violencia doméstica, las agresiones o la igualdad de género. En la mayoría aplastante de 
casos, los rumanohablantes interpretan que el agente es un hombre y el paciente una mujer (a la que nunca hay que tocar, ni siquiera con una flor). Por lo tanto, no son equivalentes traductológicos absolutos. Lo que sí aporta el DFSR es la función comunicativa: "expresión utilizada frecuentemente como amenaza". Desde el punto de vista formal, hacemos hincapié en la primacía de la estructura negativa, a pesar de que las entradas en los diccionarios españoles optan por la forma afirmativa y no aportan información adicional sobre el uso.

Encontramos la misma situación en la UF "ver el pelo" ('ver a una persona'), mucho más frecuente en forma negativa o con significativo negativo (el DILEA documenta el ejemplo "apenas se le ve el pelo"). La equivalencia parcial que encontramos en rumano es también somática, "a vedea la faţă" (lit. ver a cara) aunque, para aportar cierto matiz irónico, proponemos la locución pluriverbal "a fi scump la vedere" = a se arăta rar în societate, printre ceilalți oameni; a fi greu de găsit (tener escasas apariciones en sociedad).

Desde el punto de vista formal, la UF española es más sintética, debido a la ausencia del elemento prepositivo. Destacamos también una diferencia en el orden sintáctico: en español "ver<le> el pelo <a alguien>" es una estructura de tipo $\mathrm{V}+\mathrm{OD}+\mathrm{OI}$, mientras que en la locución rumana "pe cineva ("a alguien") se convierte en objeto directo y el somatónimo cumple una función circunstancial.

Finalmente, comentamos el caso de la UF española "caerse el pelo" (definida por el DILEA como 'recibir un castigo o una reprimenda por una cosa mal hecha'). Se trata de una locución opaca en rumano, que no tiene una equivalencia somática. El DFSR proporciona dos alternativas "a fi muştruluit" y "a primi o săpuneală" que no nos acaban de convencer. Ambas respetan el significado nuclear del español, pero aportan un halo arcaico inexistente en la UF de origen. Sospechamos que la segunda (lit. recibir una enjabonadura) es desconocida por los rumanohablantes más jóvenes o la perciben como muy literal y no la usan en sus conversaciones diarias. Quizás por evitar esta solución menos acertada, el DSREL opta por explicar la UF española ("sufrir un castigo severo") y proporcionar una información de índole pragmática: "habitual como amenaza". A nivel morfosintáctico, notamos también importantes diferencias. Si en español "<a alguien $>$ se <le> cae el pelo" (locución doblemente pronominal), la alternativa "a fi muştruluit" (también considerada anticuada por el DEX) aparece en la voz pasiva. En cuanto a la construcción "a primi o săpuneală", únicamente hemos podido documentar en los diccionarios monolingües rumanos la locución "a trage <cuiva > o săpuneală = a dojeni, a critica aspru <pe cineva>", lo que supone una desviación, una alteración de la UF original (en cuanto a selección del lema, pero sobre todo en cuanto a estructura actancial). No apoyamos estas libertades que se toman los lexicógrafos, que deciden construir sus propios sintagmas y expresiones a fin de cubrir necesidades traductológicas porque consideramos que el campo de la fraseología no deja margen de maniobra para invenciones propias. 
A pesar de todas estas dificultades que un aprendiente de E/LE rumano pudiera encontrar, conservamos la UF en el nivel B2, debido a la importancia de la locución en español.

Al tratarse de locuciones adverbiales, hemos descartado de la base de datos "por los pelos", "a pelo" o "con pelos y señales", pero aprovecharemos los materiales didácticos diseñados para introducirlas en actividades que fomenten las destrezas reflexivas y productivas, ya que (como en el caso anteriormente presentado) se trata de exponentes lingüísticos de gran recurrencia. 


\subsubsection{Somatismos con el lexema "pestaña"}

El lexema "pestaña" (en rumano "geană") produce un reducido número de locuciones verbales en ambas lenguas. Tras un atento análisis, en el corpus encuentran lugar las UF "quemarse las pestañas" ('esforzarse mucho en una cosa o para conseguir una cosa') y "dejarse las pestañas", con el mismo significado. Incluimos las dos, a pesar de que el DRAE no recoge la segunda. En cambio, prescindimos de la variante "dejarse hasta las pestañas", al ser (como indica el DILEA) menos frecuente.

El rumano no cuenta con ninguna UF que conserve el somátonimo del español. De hecho, el DSFR no proporciona ninguna locución somática equivalente y se decanta por "a învăţa pe rupte" (lit. estudiar a romper) y "a mânca cartea" (lit. comer el libro) que reflejan la misma idea: estudiar con ahínco. En cambio, el DSREL remite a un somatónimo contiguo, "ceja", en la UF "quemarse las cejas" y ofrece una amplia serie de equivalencias intra e interlinguales que también incluye el lexema "codo": dejarse/romperse/hincar alguien los codos - estudiar intensamente. Estos ejemplos podrían formar parte del corpus para el nivel B1 (debido a su transparencia), pero las UF que incluyen el lexema "pestaña" podrían relegarse al nivel B2, debido a su alto grado de opacidad.

Del resto de las locuciones, mencionamos que en algunos casos optamos por otra variante somática que consideramos más rentable: "no pegar pestaña" descartada en favor de "no pegar ojo" o "jugarse las pestañas", eliminada en detrimento de "jugarse el cuello". 


\subsubsection{Somatismos con el lexema "pie"}

Los lexemas "pie" y "pierna" tienen en rumano un equivalente común ("picior"), aunque también existe el sintagma "laba piciorului" ("pie") utilizado en contextos concretos para eliminar la ambigüedad.

De las numerosas locuciones somáticas registradas, hemos seleccionado algunas que consideramos importantes para su didactizacion y presentación en clase. La mayoría, debido a su complejidad, conforman el corpus para el nivel B2.

Es el caso de "poner pies en polvorosa" ('huir', según el DILEA; 'huir, escapar', según el DRAE). EI DSREL, a su vez, proporciona una acertada definición ("huir para ponerse a salvo de una situación adversa") después de ofrecer una larga serie sinonímica: "poner tierra de por medio", "tomar las de Villadiego", "levantar el vuelo", "salir pitando", etc. A su vez, el rumano maneja una serie de UF equivalentes. Aunque en el DSFR ninguna de ellas es somática ("a o lua la sănătoasa", a o rupe la fugă", "aşi lua tălpăşiţa"), consideramos que sí hay alternativas somáticas, tal como lo refleja el DSREL: "a-şi lua picioarele la spinare" (lit. tomarse los pies a espalda) y "a fugi cât îl ţin picioarele" (lit. correr cuanto le aguantan los pies). En estos casos, destacamos que el somátonimo aparece con su sentido básico y literal. La mayor dificultad para un aprendiente de E/LE rumanohablante reside en descodificar el lexema "polvorosa" (adjetivo que el DRAE define como algo que 'tiene mucho polvo') e internalizar la estructura $\mathrm{V}+\mathrm{OD}+\mathrm{PREP}+\mathrm{ADJ}$. Aunque no hay un acuerdo entre los especialistas para explicar el origen de la UF, al menos consideramos útil evocar la metáfora motivada (el polvo que se levanta revoloteando tras una huida precipitada). Asimismo, si bien no forma parte de nuestro corpus, se podría aprovechar esta UF para introducir la expresión fija "pies, ¿para qué os quiero"?", con la que comparte varios semas, como [+peligro], [+huida] o [+precipitación].

Otra UF con origen incierto es "no dar pie con bola" ('no hacer nada con acierto'). Algunas fuentes fraseológicas registran también la variante "no dar pie con bolo", pero optamos por no incluirla, debida a su frecuencia reducida. Además, resultaría redundante, puesto que los aprendices ya contarán con una muestra para expresar ignorancia, aturdimiento, desacierto, fracaso. Ninguno de los elementos constituyentes representa un escollo, dado que todos se imparten en el nivel inicial. Además, una imagen procedente del campo deportivo ayudaría a comprender el significado de la locución. No obstante, la dificultad reside en la falta de una equivalencia clara en rumano. No nos convencen las UF que proporciona el DSREL, "a da cu băţul în baltă" (lit. dar con el palo en el charco) y menos aun "a da cu oiştean gard" (lit. dar con la viga en la valla). La primera se aleja del significado de la lengua de origen, teniendo más rasgos en común con la UF española "meter la pata", mientras que la segunda es arcaica, en desuso y procede del mundo rural (de hecho, en este contexto los autores citan la UF "dar una en el clavo y ciento en la herradura" - acertar por casualidad, equivocarse a menudo). Hay, por lo tanto, alteraciones de rasgos 
importantes al no mantener las restricciones diacrónicas y diatópicas. En cambio, el DFSR recupera la carga coloquial con "a da chix", locución que mantiene la densidad idomática y recupera el significado de la UF española original: 'fallar, no acertar, no alcanzar el resultado deseado'. Asimismo, es también válida la equivalencia parcial "a o da în bară" (lit. darla en el palo/travesaño), que mantiene la referencia al mundo de los deportes (pie - bola - "bara") y, a nivel estrictamente formal, el verbo soporte "a da" (dar). Sin embargo, como podemos comprobar, ninguna equivalencia es somática ni mantiene la partícula negativa del original. La estructura actancial es la única que permanece intacta.

Otra UF española sin equivalente somático en rumano es "buscar tres pies al gato" ('buscar complicaciones donde no las hay o en situaciones donde no tiene sentido'), con su variante menos frecuente "buscar cinco pies al gato". Como en el caso anterior, destacamos que todos los elementos constituyentes (verbo, sustantivo, numeral) se imparten en el nivel inicial A1, pero la comprensión global de la UF no es inmediata. Los diccionarios bilingües proponen acertadamente como variante traductológica la locución "a căuta nod în papură" (lit. buscar nudo en el junco), definida por el DEX como "tratar de encontrarle a alguien defectos a toda costa". Sin embargo, destacamos algunas diferencias en el plano sintáctico: mientras la UF española suele usarse en infinitivo (según el DILEA), la locución rumana debe conjugarse obligatoriamente. Además, en rumano esta UF coexiste con "a găsi nod în papură" (lit. encontrar nudo en el junco"), que desprende la misma idea: 'observar defectos donde no los hay, acusar injustamente'. Como apunte de didáctica, habría que hacer hincapié en la distinción entre los lexemas "pies" y "pata" (palabra usada en el caso de los animales) para evitar que los aprendientes trasladen el sintagma a otros animales y cometer de esta forma un error de falsa selección. Asimismo, podría ser un momento idóneo para llamar la atención sobre un aspecto muy importante de las UF, el de la fijación (formal) y, si parece oportuno, estimular una reflexión metalingüística.

Otras UF complejas seleccionadas para el nivel B2 son "cojear del mismo pie" ('adolecer del mismo vicio o defecto') y "saber de qué pie cojea" ('conocer bien los defectos o las debilidades de una persona'). Aunque los lexemas constituyentes no deberían suponer ninguna dificultad para un aprendiz de nivel intermedio, el hecho de que no haya una equivalencia clara en rumano complica la comprensión de estas locuciones. Como era de esperar, algunos registros fraseológicos bilingües consultados optan por explicar las UF, proporcionando una combinación libre de palabras. EI DSREL remite a una posible equivalencia en español, "saber dónde le aprieta a alguien el zapato", pero a nuestro parecer es una estrategia menos afortunada, por ser más opaca y por alejarse del significado inicial ('saber bien lo que le conviene'). También nos sorprende una información inexacta que aporta el DILEA: "el elemento cojea se conjuga en relación con el elemento saber" cuando, en realidad, la estructura actancial es <alguien> sabe de qué pie cojea <alguien> (otra persona), 
con una doble interdependencia (alguien + saber y alguien + cojear), pero no interverbal.

EI DFSR encuentra dos locuciones equivalentes que consideramos acertadas, de las cuales una es somática: "a şti ce-i poate pielea cuiva" (lit. saber que le puede la piel a alguien), 'conocer muy bien el perfil moral de una persona' y "a şti în ce ape se scaldă" (lit. saber en qué aguas se baña), con el significado "conocer las intenciones de alguien".

En cambio, la UF "sacar con los pies por delante" ('llevar a enterrar') cuenta con un equivalente claro en rumano, "a scoate cu picioarele înainte" (lit. idem.), debido a la metáfora motivada que comparten. La estructura actancial es también idéntica, como lo es la función comunicativa. Señalamos una leve diferencia a nivel morfológico, la presencia en español de la preposición "por", siempre motivo de dudas y fuente de errores para los aprendices de E/LE. Asimismo, señalamos la mayor flexibilidad combinatoria de la locución adverbial rumana "cu picioarele înainte", presente, según el DEX, en UF como "a vedea (pe cineva) cu pioarele înainte" (lit. ver a alguien con los pies delante - ver muerto a alguien) y "a ieși cu picioarele înainte" (lit. salir con los pies delante - estar muerto).

Hemos seleccionado también la UF "nacer de pie" ("nacer con suerte") que cuenta en rumano con una equivalencia parcial, también somática: "a se naşte cu stea în frunte" (lit. nacer con estrella en frente). Obviamente, la locución nos remite a las UF españolas "nacer con estrella" ('nacer con buena suerte') y "tener estrella" ('tener buena suerte'), con las que comparte lexema y carga semántica. Insertamos en este punto la locución recogida por el DEX "a se naşte sub o stea norocoasă" (lit. nacer bajo una estrella suertuda) y su variante antónima, "a se naşte sub o stea rea" (lit. nacer bajo una estrella mala) para dar fe de los paralelismos estructurales y semánticos encontrados en este caso. Sin embargo, la locución "nacer de pie" es muy opaca, a pesar de los elementos constituyentes asimilados en niveles anteriores, por lo que la incluimos en el nivel B2. Además, señalamos una restricción diafásica, puesto que la UF equivalente en rumano aporta un aire arcaico, inexistente en español.

En este apartado encontramos dos somatismos que se inscriben en el mismo contenido funcional, el de la descripción de carácter: "tener los pies en el suelo" y "poner los pies en el suelo" se refieren, según el DILEA, a "una persona realista", con la marca de "más frecuente" y de "más realista" en el caso de la primera locución. El rumano cuenta con una locución equivalente, "a fi cu picioarele pe pământ" (lit. estar con los pies en tierra), que designa a una persona con un agudo sentido de la realidad, más cercana a nivel formal a la UF recogida por el DILEA (como menos frecuente) "tener los pies en la tierra". Señalamos el contorno sintáctico idéntico y la misma función pragmática, pero una leve diferencia a nivel morfológico, por la presencia en rumano de la preposición "cu" y la ausencia del artículo en el lexema "pământ". 
Reencontramos el mismo lexema ("pământ" - "tierra") en la UF rumana "a (re)aduce cu picioarele pe pământ", lit. (volver a) traer a alguien con los pies en la tierra, considerada por el DSREL la equivalente a la locución española "parar los pies" ('detener o contener la actuación o el comportamiento de una persona'), por lo que el lexema incluye el rasgo semántico de realismo. Sin embargo, el DFSR opta por una correspondencia traductológica no somática, "a pune pe cineva la locul lui" (lit. poner a alguien en su sitio), una evidente pérdida en el nivel semántico y pragmático. Las demás alternativas que nos proporciona presentan mayor aceptabilidad, "a tempera elanul" (lit. aflojar el impulso) y "a tăia avântul" (lit. cortar el ímpetu). Ante estas equivalencias parciales poco convincentes, consideramos más acertado integrar la UF de la lengua meta en actividades significativas de compresión lectora, en contextos esclarecedores, de modo que los aprendientes infieran la totalidad de sus rasgos.

En el caso de "caerse el alma a los pies" ('sufrir una decepción o un desengaño'), la dificultad reside por un lado en el contorno sintáctico doblemente pronominal ("<a alguien> se <le> cae el alma a los pies") y, por otro lado, en por la falta de una correspondencia traductológica sin equívoco. EI DSREL propone una UF somática inaudita para un rumanohablante, "a cădea inima în călcâi" (lit. caer el corazón en talón), documentada únicamente en antologías de proverbios y refranes, por lo que se viola la restricción diafásica al conseguir un efecto estilístico indeseado. En cambio, el DFSR recurre a una forma oracional con valor explicativo - "a simţi o mare dezamăgire" (lit. sentir un gran desengaño, pero también ofrece dos alternativas fraseológicas que recuperan uno de los elementos constitutivos de la locución española: "a cădea parcă cerul pe cineva" (lit. caer como si el cielo en alguien) y "a simţi cum îi fuge pământul de sub picioare" (lit. sentir cómo le corre la tierra de bajo pies).

Finalmente, a pesar de contar en rumano con una locución equivalente, relegamos a niveles superiores la UF "echarse a los pies" ('mostrar a una persona acatamiento y sumisión') principalmente por su función comunicativa que requiere de un contexto bien específico (no es de extrañar que todos los ejemplos que proporciona el DILEA pertenecen al campo semántico de la religión).

Asimismo, a pesar de su alto grado de recurrencia, decidimos prescindir de la UF "a pies juntillas" en primer lugar por tratarse de una locución adverbial, pero sobre todo por la dificultad de explicar un elemento prefabricado que rompe esquemas gramaticales.

La imposibilidad de explicar los hechos de la fraseología de acuerdo con las reglas de la gramática estándar actual representa un verdadero problema tanto para el enseñante como para el extranjero que aprende español, ya que, entre otros inconvenientes, no se puede poner en práctica un sistema de corrección de errores basado en paradigmas regulares, de modo especial cuando la frase ofrece una estructura construida contra o al margen de las reglas de la lengua común, que son justo las que se enseñan (García-Page 1995:155). 
A pesar de su uso activo, otras locuciones adverbiales que no forman parte de este estudio son "con buen pie", "con mal pie", "con los pies", "con el pie derecho", "con el pie izquierdo" o "con pies de plomo". En el caso de la UF "sin pies ni cabeza" ('sin sentido'), descartamos la locución adverbial, pero recuperamos la locución verbal homónima "no tener ni pie ni cabeza" ('no tener sentido, ser incoherente o absurdo'). Su equivalente (parcial) en rumano sigue el mismo patrón, con elementos copulativos negativos: "a nu avea nici cap nici coadă" (lit. no tener ni cabeza ni cola). Comparten, por lo tanto, imagen base, estructura actancial y rasgos pragmáticos, por lo que presagiamos su inmediata comprensión y producción, a pesar de las leves diferencias en el plano léxico. 


\subsubsection{Somatismos con el lexema "pierna"}

Como ya hemos señalado en el apartado anterior, el sustantivo rumano "picior" cubre dos lexemas en español: "pie" y "pierna".

Si el en caso de "pie" las UF son múltiples y el reto consiste en operar una selección adecuada, sorprende la escasez de entradas en el caso del somatónimo "pierna". En el DFE se contempla una sola locución verbal, "hacer piernas" ('andar'), mientras que el DFDEA y el DRAE recopilan algunas más. Sin embargo, descartamos "abrirse de piernas" por el registro vulgar y sexista al que pertenece o "pasarse por entre las piernas" que, a su vez, remite a una locución vulgar: "pasarse algo por la entrepierna" ('para expresar menosprecio hacia ello').

Algunas UF proceden del campo de la equitación, como "meter o poner piernas al caballo" ('apretarle para que corra'), "ponerse sobre las piernas el caballo" ('supenderse con garbo entre ellas'), otras son dialectales - "hacer pierna" ('contribuir') o en desuso, "echar piernas" ('preciarse o jactarse de galán o valiente'). EI DILEA recoge la locución "irse por la pierna abajo" ('perder el control de las necesidades fisiológicas'), variante menos frecuente de la UF "irse por la pata abajo".

En este contexto, la única locución somática que seleccionamos para el corpus es "estirar las piernas" ('dar un paseo después de haber permanecido inmóvil durante largo tiempo'), que encuentra su equivalente en la locución rumana "a-şi dezmorţi picioarele" (lit. desentumecerse las piernas). Ambas UF comparten imagen base, contorno sintáctico, estructura actancial y función comunicativa, por lo que consideramos oportuna su presentación en el nivel B1. La única dificultad reside en la complejidad del verbo "estirar", ya que las oportunidades de usarlo en conversaciones cotidianas son más bien escasas. Además, existe una posible contaminación con una locución muy semejante en cuanto a los términos constituyentes ("estirar la pata"), pero muy alejada como significado. 


\subsubsection{Somatismos con el lexema "piel"}

El sustantivo "piel" y su correspondiente rumano "piele" comparten etimología (el latín pellis) y, como comprobaremos a continuación, algunas locuciones verbales de uso activo. El número de UF que registramos en rumano es significativamente mayor comparado con los somatismos encontrados en español. Consideramos que una posible explicación podría ser la coexistencia del lexema "pellejo", que a su vez genera locuciones verbales en español.

Sorprendentemente, la UF "meterse en la piel" ('ponerse en las circunstancias o la situación de una persona') no es recogida por el DRAE, pero está presente en otros registros fraseológicos como el DILEA, el DFDEA o el DFE (en estos dos últimos registrada junto a su variante menos frecuente "meterse dentro de la piel"). A su vez, el rumano maneja una locución somática equivalente, "a se pune în pielea cuiva" (lit. ponerse en la piel de alguien). Sin embargo, la UF española es polisémica ('transformarse en una persona para interpretar un papel') y es allí donde se bifurcan los caminos, ya que el rumano recurre a otra locución para expresar este nuevo significado: "a intra în pielea cuiva" (lit. entrar en la piel de alguien).

En el caso de "salvar la piel" ('librar la vida en un peligro') encontramos menos diferencias debido a que en rumano existe "a-şi salva pielea" (lit. salvarse la piel). Ambas UF comparten elementos constituyentes, base metafórica y estructura argumental, pero notamos una diferencia en cuanto al contorno sintáctico, ya que el rasgo gramatical en rumano es pronominal reflexivo (eu îmi salvez pielea, tu îţi salvezi pielea, el îşi salvează pielea, etc.), a diferencia de la estructura transitiva en español $(\mathrm{V}+\mathrm{OD})$.

Por su alto grado de transparencia y gracias a las equivalencias existentes en rumano, consideramos que las UF anteriormente analizadas encajarían en el nivel B1. No obstante, situamos en el B2 la locución "dejarse la piel" ('esforzarse mucho en algo o para conseguir una cosa') por no contar en rumano con una UF que incluya el mismo somatónimo. De hecho, el DSREL remite a "írsele a alguien el alma en algo" y proporciona como alternativa en rumano las locuciones "a se dedica trup şi suflet" (lit. dedicarse en cuepo y alma) y "a pune (mult) suflet", lit. "poner (mucha) alma". En cuanto a los rasgos gramaticales, consideramos importante hacer hincapié en el régimen preposicional diferente en este caso en las dos lenguas: "dejarse la piel" <alguien>, $<$ en/para algo $>$ frente "a se dedica trup şi suflet $<\mathrm{a}+\mathrm{Ol}$.

Finalmente, incluimos en el nivel B2 una estructura oracional que procede del campo paremiológico, "vender la piel del oso antes de cazarlo" ('celebrar un éxito antes de conseguirlo'). De hecho, el CVC, en su apartado dedicado al refranero multilingüe, señala que la unidad lingüística "no hay que vender la piel del oso antes de cazarlo" se halla "en la frontera de las paremias y las locuciones. Por la forma lexicalizada negativa y el mensaje sentencioso, estaría en el mundo de las paremias". Siguiendo la 
taxonomía que propone el DILEA, nosotros consideramos que se trata de una locución verbal y la incluimos en la base de datos. En rumano existe una UF transparente, con equivalencia parcial a nivel léxico, pero con idéntica función pragmática y estructura actancial, "a vinde pielea ursului din pădure" (lit. vender la piel del oso del bosque), por lo que auguramos una comprensión inmediata y una producción sin mayores escollos. 


\subsubsection{Somatismos con el lexema "puño"}

Los lexemas "puño" y "pumn" (procedentes del mismo término latín pugnus) generan un número muy reducido de locuciones verbales tanto en español como en rumano.

EI DILEA recoge tres UF ("meter/poner/tener el corazón en un puño") que tratamos en un apartado anterior, dedicado al somatónimo "corazón", mientras que el DFDEA únicamente documenta la locución adverbial "en un puño" ('en un estado de sometimiento o intimidación total'), acompañada de verbos como "estar", "tener" o "meter". En cambio, el DRAE, en su afán de abarcar el español en un amplio abanico de registros, jergas y usos dialectales, proporciona un mayor número de UF. Sin embargo, no representan interés para este estudio entradas como "partir al puño un buque", procedente del lenguaje marinero ('inclinar la proa hacia la parte de donde viene el viento') o locuciones desconocidas por la mayoría de los hablantes, como "ser como un puño" ('ser miserable') o "pegarla de puño" ('engañar').

Tras estas breves consideraciones, consideramos que la única UF válida para la base de datos que estamos elaborando es "apretar los puños" ('esforzarse; poner todo su empeño'). Si la comparamos con la locución rumana "a strânge (a încleşta) pumnii", lit. apretar (agarrar) los puños, observamos una situación de simetría formal y una base metafórica común. No obstante, nos encontramos ante un caso de falso amigo fraseológico, ya que la UF rumana denota una actitud amenazante. La equivalencia rumana (reflejada también en el DFSR) es a su vez somática, "a strânge din dinţi" (lit. apretar los dientes). Esta importante diferencia, que puede causar una transferencia negativa de significado, nos lleva a incluir la locución en el nivel B2. 


\subsubsection{Somatismos con el lexema "riñón"}

Otro sustantivo con escasa presencia en los repertorios fraseológicos es "riñón", mientras que su equivalente rumano ("rinichi") no genera ninguna UF. La única entrada que presenta interés para nuestro estudio es "costar un riñón" ('tener un precio muy alto'), con su variante (también recogida por el DRAE), "valer un riñón". Ante la imposibilidad de recurrir a una locución equivalente, los diccionarios bilingües se conforman con explicar el significado: "costar una fortuna", "costar un montón de dinero" o remitir a otras UF ("costar el oro y el moro", en el caso del DSREL). Previamente, hemos analizado la locución "costar un ojo de la cara", que consideramos más frecuente y equivalente en cuanto a función comunicativa y completamente reemplazable en cualquier contexto. Sin embargo, descartamos las demás alternativas que propone el DFE al considerarlas vulgares ("costar un huevo", "costar un carajo") o de uso menos frecuente (los culturemas "costar un Perú" y "costar un Potosí", lagunas fraseológicas debido a su aspecto idiosincrásico). 


\subsubsection{Somatismos con el lexema "sangre"}

Comparado con los precedentes lexemas analizados, el somatónimo "sangre (en rumano "sânge", procedente del mismo sanguis) es muchísimo más proclive a insertarse en UF. Sin embargo, de la lista que elaboramos en una fase inicial de este estudio hemos ido descartando entradas como "arder la sangre" y "alterarse la sangre" ('enfadarse mucho o irritarse'), consideradas por el DILEA como "menos frecuentes", "correr ríos de sangre" ('producirse gran cantidad de muertos y heridos') por cubrir una función comunicativa que supera el nivel B2, "olfatear sangre" ('percibir la posibilidad de un fuerte enfrentamiento') por su uso restringido y el registro demasiado formal del componente verbal o "irse la sangre a los talones/a los zancajos" ('asustarse mucho') por la complejidad de los elementos constituyentes y del contorno sintáctico doblemente pronominal.

Muchas otras locuciones entre cuyos componentes encontramos el lexema "sangre", presentes en los registros bibliográficos, fueron eliminadas desde el inicio de este estudio, por tratarse de elementos de uso dialectal, de registro literario o más afines a las paremias: "tener sangre de chinches", "igualar la sangre", "escupir sangre en bacín de oro", etc. Las consideraciones anteriores vienen a justificar el número muy reducido de locuciones que finalmente conforman nuestro corpus. Las que hemos seleccionado cuentan con UF equivalentes en rumano, con las que suelen compartir numerosos rasgos.

Es el caso de la locución "no tener sangre en las venas" ('no ser capaz de actuar con viveza o con energía'), que tiene como correspondiente en rumano "a nu avea sânge în vine" (lit. no tener sangre en venas). Observamos la presencia de la negación en ambas locuciones, la estructura actancial idéntica, la práctica totalidad de constituyentes que comparten y, sobre todo, el significado similar. El único elemento discordante es la ausencia del artículo definido en rumano, pero sin repercusión en la comprensión y producción inmediatas por parte de un aprendiente rumano de E/LE.

Otra UF en situación similar es "subirse la sangre a la cabeza" ('montar en cólera'), con su correspondiente rumano "a i se urca sângele la cap" (lit. subirle la sangre a cabeza). En este caso, las locuciones comparten elementos constituyentes y metáfora motivada y el contorno sintáctico es idéntico, pronominal indirecto, con el somátonimo actuando como sujeto de la oración: se me sube la sangre a la cabeza, se te sube la sangre a la cabeza, se le sube la sangre a la cabeza, etc. - mi se urcă sângele la cap, ţi se urcă sângele la cap, i se urcă sângele la cap, etc. Sin abandonar la función comunicativa "expresar ira", apuntamos la UF "hinchár(se)<le $><$ a alguien $>$ las narices", recogida por el DSREL como sinónima y analizada por nosotros en las páginas anteriores.

Un número significativo de locuciones lexicaliza el concepto de irritación extrema, enfado, cólera, indignación. Además de la UF analizada anteriormente 
("subirse la sangre a la cabeza"), hemos documentado: "arder la sangre", "hervir la sangre", "encender la sangre", "quemar la sangre", "pudrir la sangre", "revolver la sangre". Si bien todas y cada una por separado presentan interés, consideramos que no sería rentable presentar un listado exhaustivo de UF. Se trata de secuencias fraseológicamente intachables, pero no hay que perder de vista la vertiente práctica: no pretendemos agotar los elementos prefabricados adscritos a una determinada función comunicativa, sino de dotar a los aprendices de herramientas para que se manejen con soltura y eficacia en distintos contextos comunicativos.

Finalmente, analizamos la UF "llevar en la sangre" ('ser innato o hereditario'), incluida en el nivel B1 debido a que los elementos que la componen se imparten en los niveles iniciales y porque en rumano contamos con una locución equivalente, "a avea în sânge" (lit. tener en la sangre). El DFE opta por una entrada pronominal ("Ilevarlo en sangre") y proporciona algunas variantes como "llevarlo en la masa de la sangre" o "llevarlo en las venas". No obstante, siguiendo las indicaciones de García-Page (1995:160-161) prescindimos de la variante menos usada porque "el hablante no nativo aprende mejor y emplea más apropiadamente las frases que no tienen variantes (...) que las que las admiten, ya que los márgenes de error son mayores". 


\subsubsection{Somatismos con el lexema "tripa"}

El lexema español "tripa" y su correspondiente rumano "maţ" tienen en común su uso preponderante en plural. Al elaborar el corpus de UF para el idioma rumano, destacamos la mayoría aplastante de entradas acompañadas por marcas de tipo regional, popular, familiar o anticuado.

De las pocas locuciones verbales españolas recogidas de las fuentes consultadas, descartamos las menos frecuentes ("sacar las tripas de mal año"), las que conllevan una función comunicativa superior al nivel B2 ("sacar las tripas", utilizada como amenaza) o las que no incluyen un elemento verbal de uso activo y/o tienen contornos sintácticos doblemente pronominales ("revolverse las tripas"). Asimismo, prescindimos de la locución "rascarse la tripa" ('no hacer nada de provecho') puesto que ya contamos con una entrada similar, de mayor recurrencia, "rascarse la barriga".

Al aplicar los filtros anteriores, la única UF seleccionada es "hacer de tripas corazón" ('esforzarse para disimular el miedo, dominarse, sobreponerse en las adversidades'), unidad pluriverbal somática también en rumano: "a-şi lua inima-n dinţi" (lit. tomarse el corazón en dientes), que acertadamente propone el DFSR como equivalente. Sin embargo, nos ha llamado la atención la traducción que proporciona el DSREL, mucho más alejada del significado anterior: "a face haz de necaz" (lit. reírse de pena). En realidad, se trata de un elemento prefabricado inquebrantable, que funciona a la semejanza de un refrán, en parte debido a su rima ("haz-necaz") y cuyo equivalente en español es "a mal tiempo, buena cara". En el refranero multilingüe del CVC, al analizar esta paremia, se hace referencia a las ideas claves (desgracia - conformidad) y, efectivamente, se remite a la UF que es objeto de nuestro estudio: "recuérdese la locución hacer de tripas corazón". 


\subsubsection{Somatismos con el lexema "uña"}

Los dos somatónimos "uña" (en español) y "unghia" (en rumano) proceden del mismo término latín ungula $\mathrm{y}$, a grandes rasgos, las UF recogidas presentan metaforizaciones similares.

La locución "ser uña y carne" ('tener una estrecha amistad con una persona') tiene como equivalente en rumano "a fi prieten cu cineva unghie şi carne" (lit. ser amigo de alguien uña y carne), aunque es más frecuente entre los hablantes nativos la UF no somática "a fi prieten la cataramă" (lit. ser amigos a hebilla).

El rasgo de agresividad lo encontramos en una serie de locuciones como "sacar las uñas" ('mostrar disposición agresiva o de pelea'), "afilar las uñas" ('prepararse para la pelea') o "enseñar las uñas" ('mostrar una disposición agresiva'), también existente en rumano en UF como "a-şi arăta unghiile" (lit. enseñar las uñas) o "a pune unghia-n gât" (lit. poner la uña en cuello), con significado de 'forzar a alguien a actuar urgentemente'. EI DSFR agrupa todas las UF españolas en un renglón: "enseñarle/mostrarle/sacarle las uñas <a alguien>" y proporciona una larga serie de equivalencias, todas ellas somáticas: "a-şi arăta unghiile/ colţii/dinţii/ghearele" (lit. enseñar las uñas/los colmillos/los dientes/las garras).

Reiteramos nuestra opinión acerca de los listados completos de locuciones, contraproducente en el aula, por lo que optamos por seleccionar una única muestra de uso activo, cuyos elementos constituyentes son más transparentes para un aprendiz de E/LE de nivel intermedio.

En el caso de la UF polisémica "mirarse las uñas" ('jugar a los naipes'; 'estar enteramente ocioso') el primer significado muy opaco no tiene correspondencia traductológica fraseológica en rumano, mientras que para el segundo contamos con mejores opciones (de hecho, incluso el DFRS recurre a la traducción "a sta cu burta la soare" - "rascarse la barriga").

La UF "dejarse las uñas" ('esforzarse mucho en una cosa o para conseguir una cosa') es considerada menos frecuente por el DILEA. En el DSREL la locución no está documentada, pero el DFSR ofrece una equivalencia no somática, "a munci de-i sar capacele" (lit. trabajar hasta saltarle las tapas), muy recurrente en rumano y que incluye el rasgo semántico de esfuerzo agotador. La locución española podría plantear ciertas dificultades a la hora de la selección apropiada de la preposición que requiere el contexto (en/para algo), aunque también es posible que el complemento no aparezca.

A pesar del interés que presenta, descartamos la UF "con uñas y dientes" ("con la mayor intensidad y energía posibles") por tratarse de una locución adverbial, si bien su existencia no se entendería sin elementos verbales como "defender" o "luchar". 
En cuanto a las demás locuciones verbales que aporta el DRAE y que no documentan los diccionarios fraseológicos, se trata, como viene siendo habitual, de muestras dialectales o en desuso: "no tener uñas para guitarrero", "quedarse soplando las uñas" o "libertar de las uñas". 


\subsubsection{Somatismos con el lexema "vena"}

La mayoría de los somatismos que incluyen el lexema "vena" (en rumano "venă") están estrechamente vinculados con otro somatónimo tratado anteriormente, "sangre": "no tener sangre en las venas", "quedarse sin sangre en las venas", "helarse la sangre en las venas", etc.

Al cruzar los repertorios fraseológicos, sorprende la falta de homogeneidad a la hora de documentar locuciones verbales que incluyen el lexema "vena". EI DRAE cubre jerga minera ("acostarse la vena" - 'cambiarse el buzamiento del filón') y médica ("descabezarse una vena" - 'romperse por sí misma o por haber recibido un golpe, por lo cual resulta gran pérdida de sangre').

Mientras tanto, los diccionarios fraseológicos aportan locuciones que no tienen demasiado interés para nuestro estudio: "coger de vena" ('encontrar en buena disposición a alguien para atender lo que se le dice o se le pide'), "darle la vena/la venada" ('se dice de una persona que de repente experimenta un ataque de ira o rabia') en el DFE, "correr por las venas" y "llevar en las venas" ('tener innato') en el DFDEA, descartadas al contar previamente con exponentes similares.

Nos atrevemos a proponer una UF que no aparece en ningún repertorio léxico consultado, pero es compartida por las comunidades de hablantes en ambos países: "cortarse las venas" y "a-şi tăia venele" (expresar desesperación), con una equivalencia estructural y funcional y con una base metafórica compartida. 


\subsubsection{Somatismos con el lexema "yugular"}

Concluimos el repaso alfabético de las UF somáticas con el lexema "yugular" (en rumano "jugulară"), que genera un par de entradas sinónimas: "saltar a la yugular" y "tirarse a la yugular" ('mostrar a una persona de manera violenta que no se está de acuerdo con ella'). Aunque tanto el DFSR como el DSREL las omiten por completo, fiel reflejo del DRAE (que no documenta ninguna), nuestra competencia de hablantes nativos y los resultados obtenidos con los motores de búsqueda nos confirman la existencia de la UF "a sări la jugulară" (lit. saltar a yugular) como variante de "a sări la gâtul cuiva" (lit. saltar al cuello de alguien).

En la base de datos únicamente hemos seleccionado la locución "saltar a la yugular" debido a su semejanza formal y a los rasgos gramaticales comunes con la locución rumana (el verbo "saltar" es transitivo, frente al reflexivo "tirarse"). EI DILEA aporta una observación concerniente al complemento <a alguien>, que en español "es posible que no aparezca". 


\subsection{Conclusiones del análisis contrastivo}

Para finalizar este capítulo central de análisis contrastivo de las UF somáticas en español y en rumano, aportamos datos de carácter cuantitativo relativos al número de locuciones seleccionadas por cada lexema. En ningún momento pretendemos hacer un análisis estadístico, pues ese no es nuestro objetivo, pero sí corroborar las hipótesis de partida de esta investigación apoyándonos en datos objetivos acerca de la distribución porcentual de los lexemas analizados, con el fin de conocer cuáles son los lexemas más utilizados de cara a la aplicación didáctica, así como la distribución de las UF según la función comunicativa y los niveles en los que se encuadran. Asimismo, ofrecemos datos relativos a la equivalencia de estas locuciones en ambas lenguas en virtud de si es total, parcial o nula, extrayendo, en todo caso, conclusiones que incitan a la reflexión.

El proceso de selección de una base de datos conformada por UF somáticas (niveles A1-B2) cuyos destinatarios son aprendices rumanohablantes de español ha supuesto un complejo proceso de selección y acotación. El elevadísimo número inicial de locuciones recogidas tras consultar distintas fuentes lexicográficas hacía inviable uno de los objetivos de este trabajo: diseñar propuestas de didactización de dichas unidades fraseológicas, para su posterior implementación en el aula de E/LE. En su selección natural de elementos léxicos para transmitir mensajes, los hablantes nativos no utilizan un abundante caudal de somatismos, por lo tanto, resultaría artificioso y hasta contraproducente introducir una cantidad abrumadora de exponentes. A diferencia de otros lingüistas, como Julià Luna u Ortiz Rodríguez (2012), nuestro reto no es de índole cuantitativa (delimitar e impartir una determinada carga fraseológica por nivel). Consideramos que "menos es más" y abogamos por una integración natural de las UF en la clase de E/LE, acorde con otros contenidos fijados por los documentos marco. Comparando con los 803 fraseologismos somáticos que selecciona Sciutto (2006), las 206 UF finales que conforman nuestro corpus podrían parecer escasas a primera vista, pero no hemos tenido ningún reparo en prescindir de aquellas entradas que no cumplían con los criterios establecidos previamente (locución verbal, español peninsular, norma estándar, uso activo, etc.). 


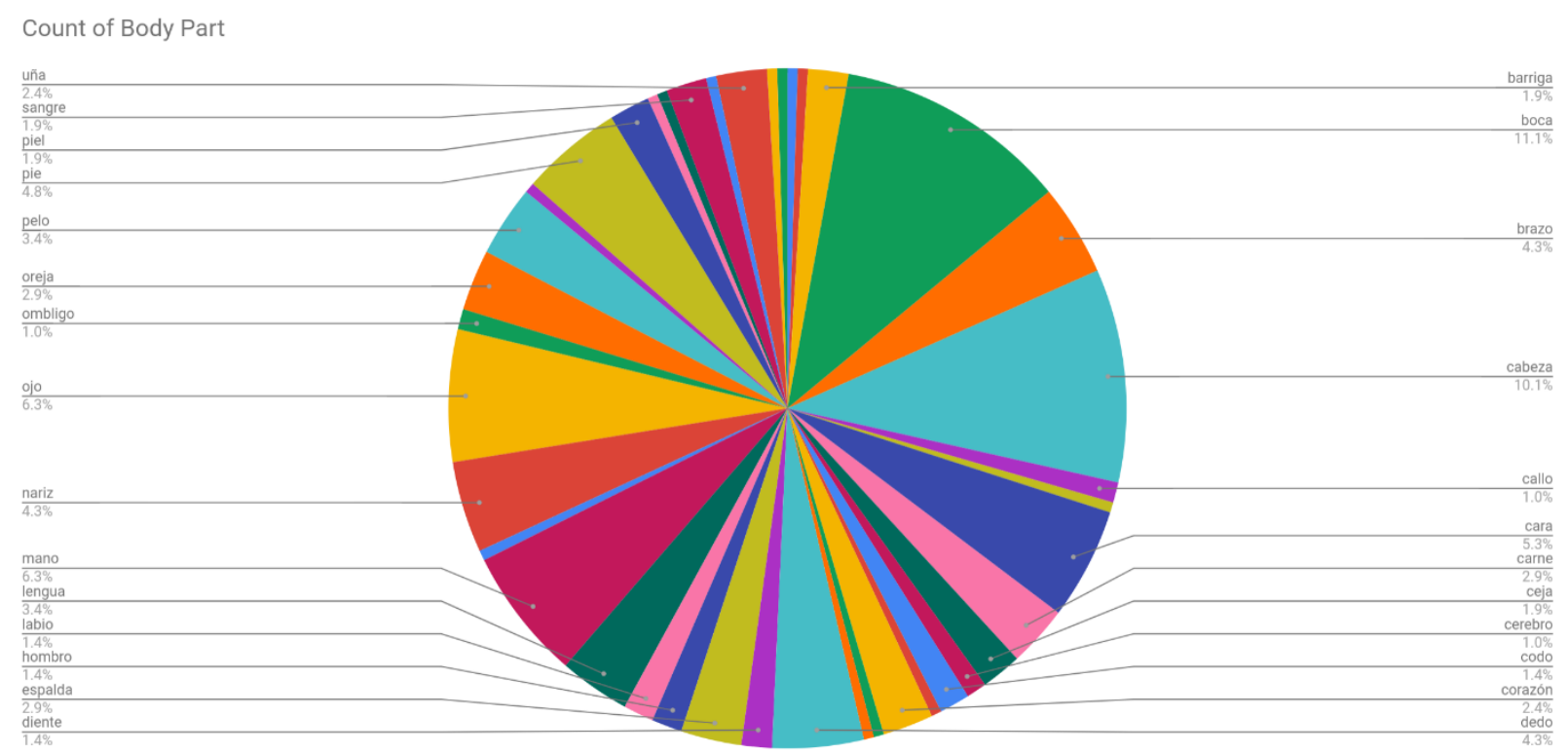

Tabla 14. Distribución porcentual de lexemas analizados. Fuente: elaboración propia

Nénkova (2006), en un estudio contrastivo de somatismos fraseológicos en español y en búlgaro, notaba que "revisando los diccionarios fraseológicos de las dos lenguas, se puede concluir que los componentes más productivos en cada una de ellas son la cabeza, el ojo, la boca, el pie, la pierna, la mano, la lengua, el brazo y el oído" (Nénkova 2006:97). Esta afirmación se puede aplicar también en el caso del rumano y, en el fondo, confirma una intuición basada en la observación atenta de las producciones orales y escritas que conforman nuestra "cotidianeidad lingüística". Los somatónimos que ocupan la mayor parte del análisis que llevamos a cabo son precisamente la boca (23 UF, 11,1\%), la cabeza (21 UF, 10,1\%), el ojo, la mano, presentes en la misma medida (13 UF, 6,3\%) y el pie (10 UF, 4,8\%). Como ya hemos señalado, lexemas como la mano y el brazo corresponden en ocasiones a un mismo somatónimo en rumano (mână), situación idéntica en el caso de oreja y oído (ureche) o pie y pierna, solapadas en las UF rumanas que contienen el lexema picior. Esta ausencia de equivalencia léxica exacta justifica la escasa presencia en la base de datos de somatismos con el lexema brazo y la ausencia de locuciones que incluyen oído o pierna entre sus elementos constituyentes. Asimismo, reiteramos que no tienen cabida en el corpus las UF que incluyen voces malsonantes 0 vulgares, a pesar de su frecuencia de uso elevada. Nuestros destinatarios son aprendices de E/LE sin suficientes recursos pragmáticos y la clase no representa el lugar recomendado para proporcionar contextos idóneos para su empleo. Cabe señalar también el caso de lexemas que, a pesar de pertenecer a un registro estándar, no se reflejan en el corpus porque no generan locuciones verbales o porque las descartamos por no cumplir con los requisitos fijados (nivel de dificultad, recurrencia, rentabilidad, etc.): cadera, hígado, garganta, pulmón, rodilla, seno, tobillo, etc. No hemos fijado un objetivo numérico, ni hemos buscado ajustar el corpus a un número "redondo". Hemos seguido criterios preestablecidos, entre los que destaca la integración de las UF en las funciones 
comunicativas previstas para los niveles con los que operamos. En este sentido, tomando como referencia el PCIC y el modelo que Leal Riol (2011) adapta para su base de date FIDIE (Fijo, Idiomático, Español) operamos con siete grandes bloques: (1) relación social, (2) información y comunicación, (3) acciones comunicativas; (4) sentimientos; (5) opiniones, gustos y preferencias; (6) descripciones; (7) referencia a necesidades físicas y a realidades cotidianas. A continuación, desglosamos cada bloque, indicando el índice de funciones comunicativas: relación social (expresiones referentes a las relaciones sociales y personales: diversión y atracción amorosa; expresar admiración, sorpresa; pedir y ofrecer ayuda), información y comunicación (expresar conocimiento, desconocimiento o descubrir algo; cambiar de tema, idea, opinión; dar, transmitir, rechazar información; expresar acierto, triunfo; concluir un discurso), acciones comunicativas (convencer, aconsejar; expresar enfado, fastidio, irritación, frustración; expresar desaprobación; expresar reproches; expresar quejas; expresar amenaza; expresa rechazo; negarse a hacer o a decir algo; expresar dificultad o facilidad para hacer algo; expresar disimulo; llamar la atención), sentimientos (expresar alegría, gozo, satisfacción; expresar confianza o desconfianza; expresar aburrimiento e indiferencia; expresar miedo, angustia o preocupación; expresar riesgo o dilema; expresar pena, dolor, tristeza; expresar alivio; expresar resignación; expresar decepción), opiniones, gustos y preferencias (expresar intereses, gustos y preferencias; mostrar acuerdo o desacuerdo; expresar duda, reserva, posibilidad e imposibilidad), descripciones (expresar comparativas; describir el carácter de una persona; describir físicamente a una persona; describir lugares y situaciones), referencia a necesidades físicas o a realidades cotidianas (comer, beber y dormir; desplazarse; expresiones referentes al trabajo y al estudio; expresiones referentes a la muerte y a la enfermedad; expresiones referentes al dinero; expresiones referentes a la fortuna). 


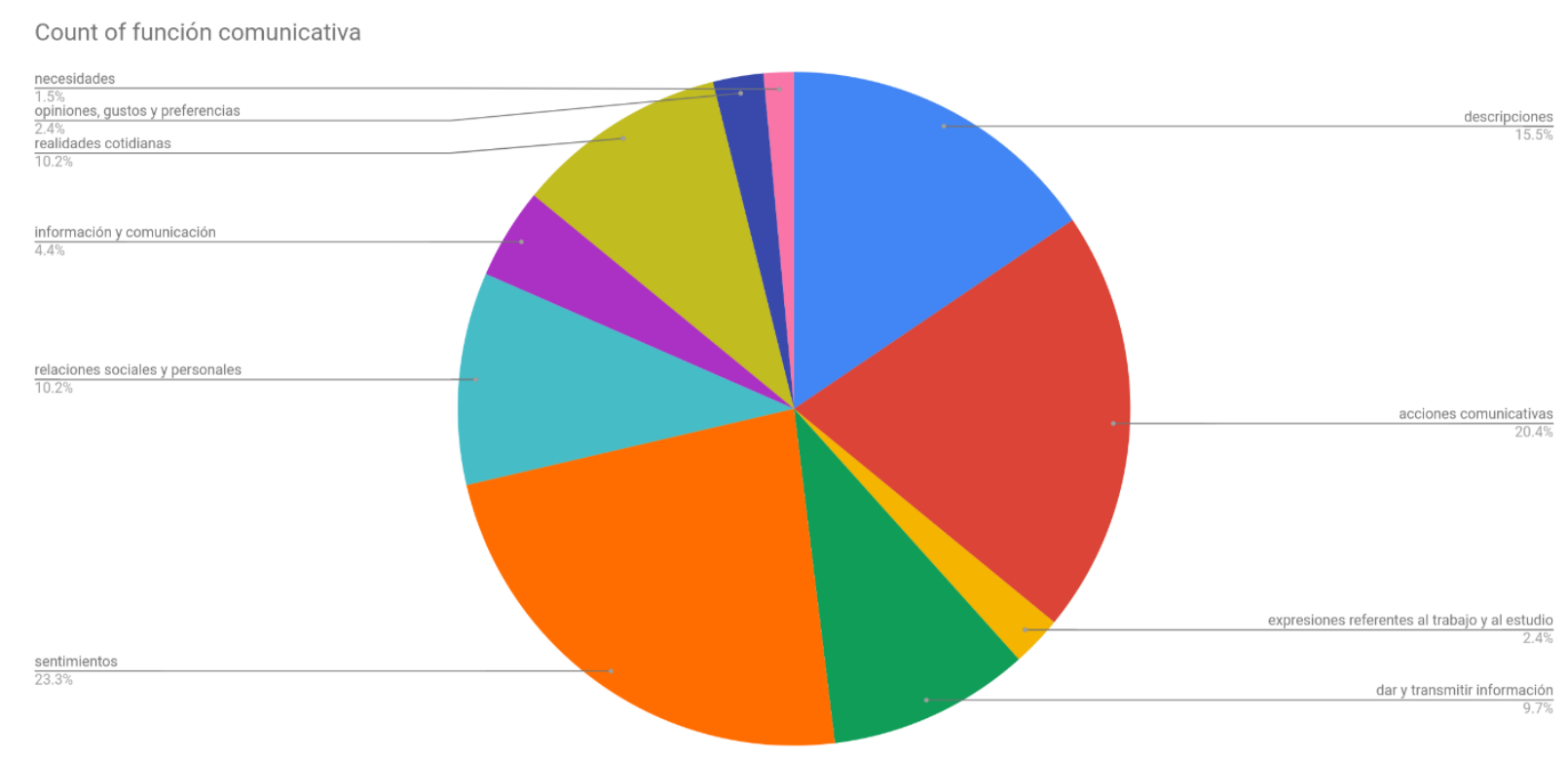

Tabla 15. Distribución de las UF según las funciones comunicativas. Fuente: elaboración propia

Al tener bien delimitadas las funciones comunicativas, hemos tratado de encontrar componentes idiomáticos para la gran mayoría de ellas y, en caso de duda, prescindir de ciertas locuciones si los aprendices ya contaban con suficientes exponentes para expresar una determinada función. Porcentualmente, las que mayor peso ocupan en el cómputo final han sido las UF adscritas a "sentimientos" (23,3\%), "acciones comunicativas" (20,4\%) y descripciones $(15,5 \%)$ por lo que hemos llevado a cabo un análisis cuantitativo más pormenorizado dentro de estas subcategorías.

En este apartado, la mayor dificultad ha sido delimitar una función comunicativa concreta en el caso de las UF plurisemánticas. Por poner un solo ejemplo, el DILEA define la locución "abrir los ojos" como 1) nacer; 2) descubrir o dar a conocer una cosa a una persona; 3) descubrir una cosa; 4) mirar una cosa o prestarle atención; 5) desengañar a una persona; 6) desengañarse. En este caso, hemos optado por ubicarla dentro del apartado "información y comunicación: expresar conocimiento" (al considerar que es la más prototípica y que encaja mejor con los niveles analizados), aunque en las propuestas didácticas (actividad 5.3.1. de esta tesis) buscamos abarcar más funciones y cubrir de esta manera los significados reflejados por las fuentes lexicográficas.

La función comunicativa ha cobrado especial relevancia en la selección del corpus y ha constituido también un criterio que seguimos para insertar correctamente las UF en su correspondiente nivel. Muchas de las locuciones seleccionadas, transparentes y con equivalencia total en rumano, podían haber conformado la base de datos del nivel A1. No obstante, su número se vio reducido considerablemente justamente porque la función comunicativa a la que iban adscritas representa, según el PCIC, un contenido de nivel superior. Aportamos como ejemplo el caso de la UF "saltar a la yugular", totalmente comprensible para un aprendiz hablante nativo de rumano, que cuenta en su lengua con 
la locución "a sări la jugulară". Sin embargo, los contextos de uso en los niveles A1-A2 son prácticamente nulos, puesto que la acción comunicativa "expresar amenaza" se imparte en el nivel intermedio. Este caso refleja la perspectiva multicriterial que nos ha guiado en la elaboración de la base de datos y el complicado proceso de negociación interno llevado a cabo, con tal de encontrar el equilibrio entre equivalencia interlingual, dificultad semántica, motivación de la imagen, estructura actancial, función comunicativa, etc. a la hora de situar una UF en un nivel acertado (A1-B2), siempre teniendo presente el aprendiz rumano de E/LE.

Podrían sorprender también los datos porcentuales respecto a la distribución por niveles de UF que incluyen somatónimos como "barba", "colmillo", "pestaña", "puño", "tripa" ( $100 \%$ en el nivel B2). En realidad, al tratarse de entradas únicas ("subirse a las barbas", "enseñar los colmillos, "quemarse las pestañas", etc.), el sistema de cálculo automático genera cifras absolutas. Es también el caso de "cana" (100\% en el nivel A2, gracias a su única presencia en el corpus, "peinar canas") o "riñón" (100\% en el nivel B1 por el único exponente seleccionado, "costar un riñón"). En el caso de lexemas con mayor peso en la base de datos ("boca", "cabeza", nariz", etc.), estos generan locuciones repartidas en todos los niveles que abarcamos en este análisis.

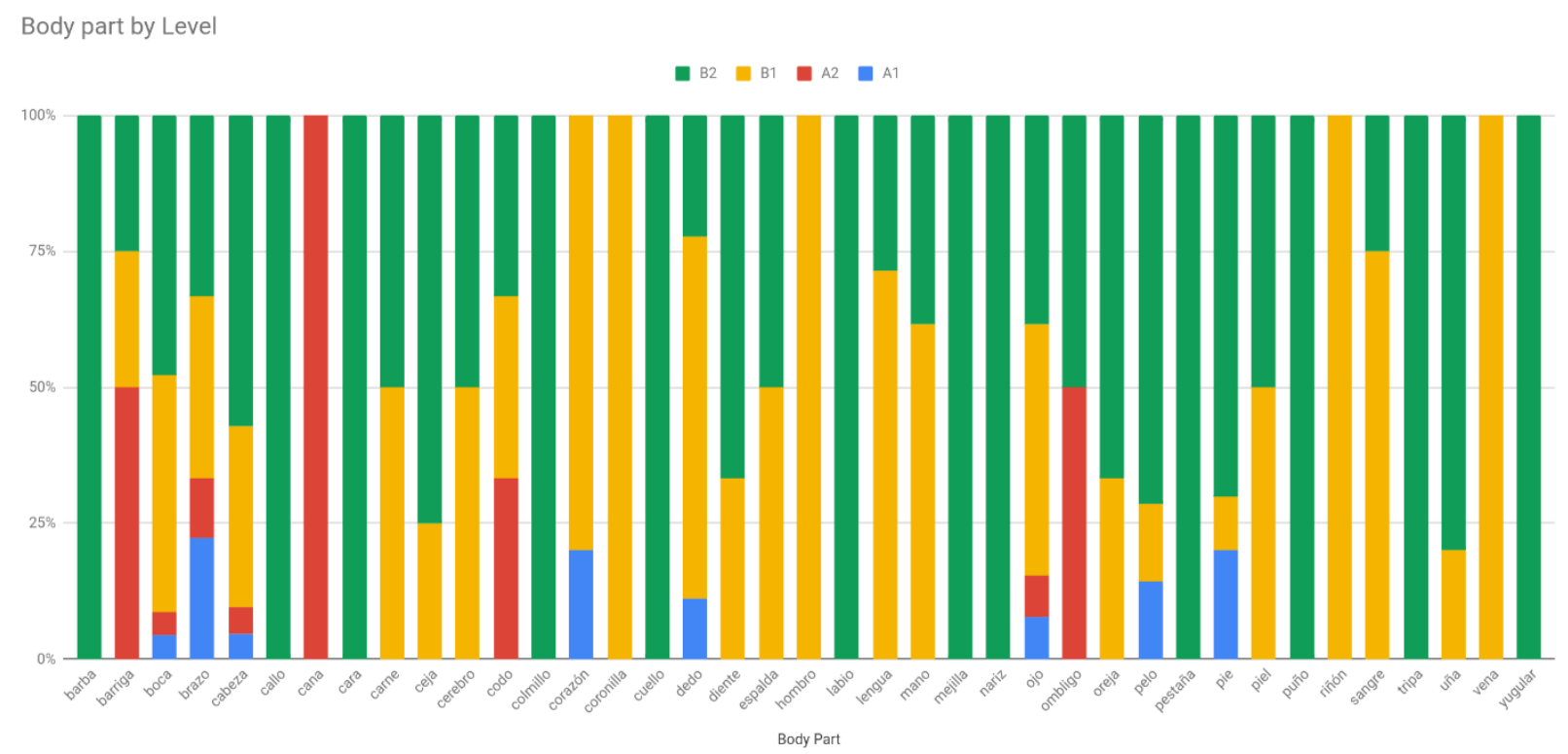

Tabla 16. Distribución de las UF por nivel. Fuente: elaboración propia

En cuanto a los tipos de equivalencia, los resultados globales confirman lo que se iba configurando a lo largo del análisis cualitativo: una UF difícilmente cumple los requisitos para que la equivalencia sea total. Sin embargo, en cierta medida sorprende la selección de un número elevado de UF con equivalencia nula, lo que da fe de la confianza depositada en el alumnado, en su capacidad de adquirir el componente fraseológico en el territorio lingüístico de la lengua meta, sin recurrir a la lengua rumana como instrumento de apoyo en la consolidación de su competencia léxica. 


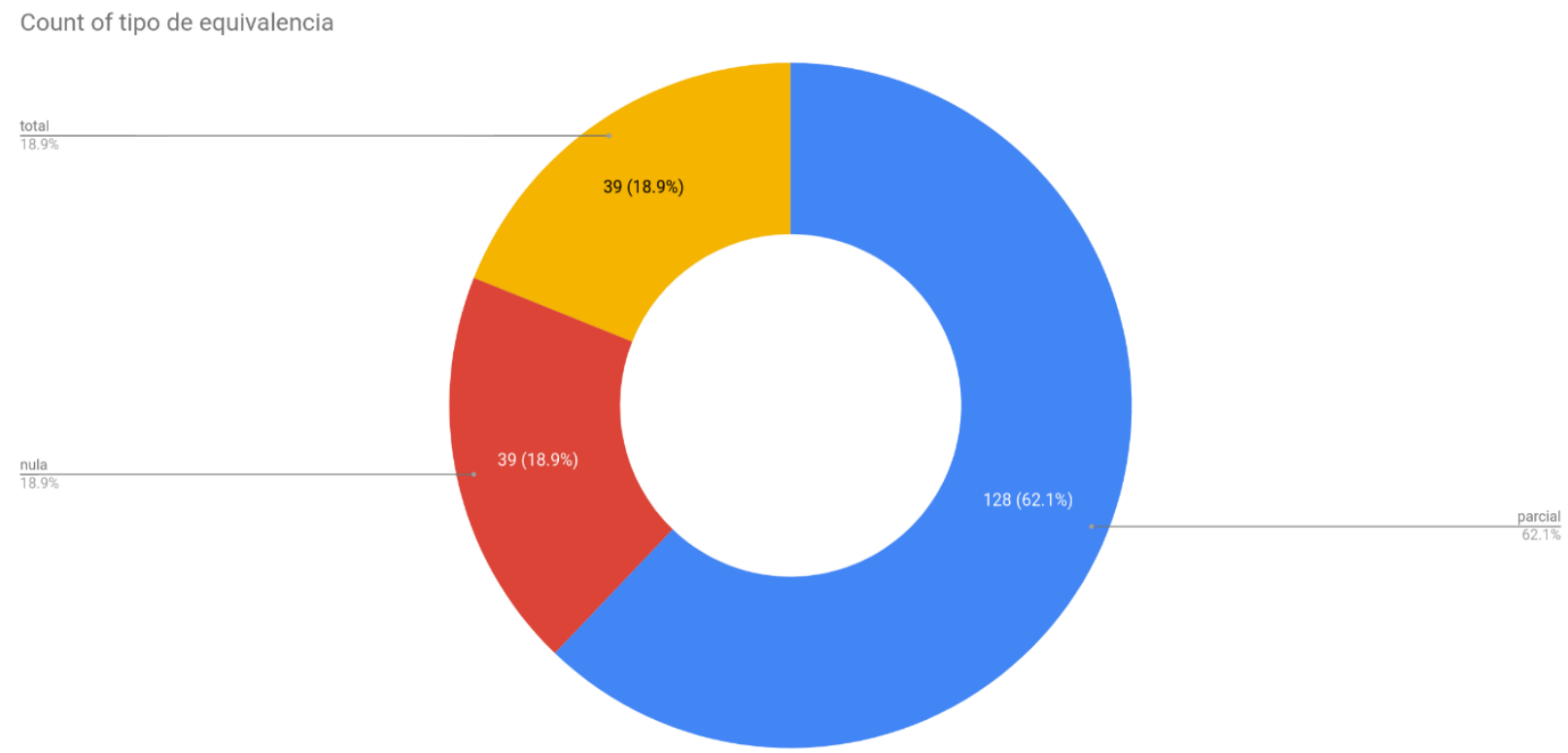

Tabla 17. Tipo de equivalencia de las UF analizadas. Fuente: elaboración propia

En el anejo de esta tesis adjuntaremos desglosada toda la base de datos y los gráficos generados. Consideramos un acierto el hecho de haber recurrido a una herramienta digital, que nos brinda posibilidades de operar cambios instantáneos, de ampliar el corpus a otros niveles, a otros campos semánticos y a otras lenguas, siguiendo el modelo creado. Es, en el fondo, una base de datos viva, como la lengua misma. 


\section{FUNDAMENTOS CURRICULARES DE LA FRASEOLOGÍA: LA FRASEODIDÁCTICA}

En este punto iniciamos la segunda parte de esta investigación, que ocupará los siguientes tres capítulos, que detallamos a continuación. En primer lugar (tercer capítulo), nos centraremos en cuestiones relacionadas con los fundamentos curriculares, el estudio del MCER y del PCIC, con el objetivo de poner de relieve la importancia de aplicar al proceso de enseñanza/aprendizaje unas bases metodológicas recogidas en estos documentos.

Nos centraremos, por lo tanto, en el peso que ocupa la fraseología en los documentos marco, defenderemos nuestra postura respecto a la introducción temprana del componente fraseológico en el aula de E/LE y examinaremos aspectos relacionados con la fraseodidáctica y las competencias comunicativas. El segundo capítulo de esta segunda parte (el cuarto en el cómputo global de la tesis) tratará sobre el análisis crítico de materiales en la plataforma digital AVE GLOBAL, mientras que el último capítulo (el quinto) constituye la aplicación práctica de esta tesis y aporta una propuesta personal de didactización de SO para aprendices rumanohablantes, sustentada en las directrices de los documentos marco y avalada por el estudio empírico llevado a cabo. 


\subsection{Importancia de la fraseología en $\mathrm{E} / \mathrm{LE}$}

Hemos comprobado en las páginas anteriores la preocupación de los lingüistas por crear un marco teórico, por acotar el campo de estudio de la fraseología y dotarla de instrumentos propios de análisis para dejar de ser esa "tierra de nadie a la que acudían investigadores de todas las escuelas, movidos por el interés que despertaba en ellos las combinaciones fijas de palabras" (Ruiz Gurillo 1997:17). Sin embargo, cabe destacar también una vertiente práctica que se ha venido desarrollando paralelamente y que se ha visto plasmada tanto en la creación de diccionarios fraseológicos (intra o interlingüísticos) como en la didáctica de las unidades fraseológicas.

En un mundo cada vez más globalizado, en el que se fomenta el intercambio y la movilidad geográfica, aprender idiomas se ha convertido en una necesidad, una afición y una rutina diaria común a millones de personas. Estos aprendientes descubren a través de la lengua una puerta hacia una manera de enfocar el mundo por una comunidad que comparte saberes y valores. Desde esta perspectiva, las UF son quizás el vínculo más directo y más auténtico para llegar a ese profundo conocimiento,

la sal y la pimienta que condimentan el discurso oral y escrito de cada lengua. (...) joyas del idioma, tesoro que adorna y enriquece una comunicación espontánea, cercana y efectiva entre usuarios que comparten lengua, lupa que da a conocer y entender los presupuestos culturales y sociales y las visiones del mundo de los individuos de una cultura (Martín Salcedo 2017:9).

Aunque resulta impensable alcanzar un nivel equiparable al de un nativo en la lengua meta sin apropiarse de las UF, en la enseñanza-aprendizaje de las segundas lenguas estas fueron marginadas durante mucho tiempo. Las causas son múltiples, desde la creencia de que las UF son producciones que pertenecen a la lengua popular y carecen de relevancia desde el punto de vista de la variedad normativa, hasta la falta de formación de los docentes y de recursos específicos para las clases (repertorios fraseológicos, actividades significativas, etc.).

Afortunadamente, en los últimos años se han dado pasos importantes para cubrir esos huecos con la publicación de diccionarios, estudios contrastivos, artículos de reflexión teórica y propuestas didácticas. En este sentido, queremos destacar las aportaciones lexicográficas monolingües más importantes: Diccionario de locuciones verbales para la enseñanza del español de Penadés (2002), Diccionario combinatorio del español contemporáneo REDES dirigido por Bosque (2004), Diccionario Fraseológico Documentado del Español Actual. Locuciones y modismos españoles de Seco, Andrés y Ramos (2004) reeditado en 2018, Diccionario de locuciones adverbiales para la enseñanza del español de Penadés (2005), Diccionario combinatorio práctico del español contemporáneo - las palabras en su contexto de Bosque (2006), Diccionario de 
locuciones nominales, adjetivas y pronominales para la enseñanza del español de Penadés (2008).

Asimismo, además de los registros lexicográficos, cabe subrayar que numerosos trabajos de investigación incluyen propuestas didácticas: Sagban (2010), Duţă (2014), Saracho (2015), D'Andrea (2019). No obstante, al referirse al lugar que las UF ocupan en el aula, en los libros de texto y, extrapolando, en la percepción que tienen los docentes sobre el valor del contenido fraseológico, Leal Riol afirma tajantemente que "la fraseología española no se enseña en el aula E/LE" (2011:57).

Si los nativos recurren el uso de UF constantemente, si están presentes en conversaciones, canciones, películas, en los medios de comunicación y en la publicidad, es inconcebible que no se incorpore las UF en la enseñanza, incluso desde el nivel inicial. Puede ser que un aprendiz no cuente con recursos suficientes para comprender completamente una unidad fijada e idiomática. No obstante,

si en los primeros niveles otras unidades reciben un tratamiento superficial para su introducción e iniciación y luego se estudian con más profundidad en los siguientes niveles intermedio, avanzado y superior, entonces por qué no plantear eso con las unidades fraseológicas (Leal Riol 2011:58).

Forment Fernández (1998:340) señala también la práctica inexistencia de referencia a las UF en los materiales de nivel inicial e intermedio, justificada probablemente porque "estas locuciones presentan peculiaridades morfológicas y sintácticas que no harían más que dificultar la retención de los aspectos paradigmáticos del sistema lingüístico $\mathrm{y}$, consecuentemente, parece apropiado no introducir su enseñanza hasta que el aprendiz ya domine esas reglas básicas". A pesar de estas dificultades, admite el gran interés que despierta en los aprendices esta parcela del vocabulario y la motivación intrínseca que demuestran por las frases hechas, debido a la espontaneidad que imprimen al discurso. Como propuesta de didactización, aporta listas de locuciones elaboradas en torno a varios somatónimos ("boca, "cabeza", "ojo", "pie") y justifica su elección por "la relación inequívoca entre algunas partes del cuerpo y ciertas actividades o estados que las personas desarrollan con ellas. Además, este es un hecho que se da para toda la humanidad, por lo que habremos encontrado en este punto algunas de las locuciones que se pueden traducir casi literalmente a muchas lenguas (1998:344). Desglosa los semas principales de cada lexema y propone que en los niveles más bajos se enseñen las UF más motivadas, puesto que "la claridad de la imagen que está detrás de la expresión hace que el alumno no tenga ningún problema en llegar al significado idiomático" (1988:345).

A su vez, Navarro (2004) ahonda en la importancia de la introducción posible y necesaria de la fraseología desde niveles muy tempranos y de manera gradual, sobre todo si se trata de lenguas afines, como es el caso del rumano: 
el alumno, que ya desde el nivel perceptivo suele notar la índole de la combinación, está mucho más motivado ante una expresión idiomática que ante fórmulas discursivas, rutinarias y colocaciones, ya que, sobre todo en el caso de las lenguas afines, no tiene demasiadas dificultades de comprensión (Navarro 2004:2).

Rodríguez y Bernardo Vila (2011) reiteran la misma convicción, de que la introducción de los elementos fraseológicos se lleve a cabo desde niveles iniciales:

al igual que un nativo los adquiere desde su primer contacto con la lengua, en principio como competencia pasiva y más adelante como competencia activa, un aprendiente de una lengua debe estar expuesto a la $L 2$ de modo natural. Además, las unidades fraseológicas introducidas de modo gradual incentivan el desarrollo de las competencias metafórica, irónica y referencial (Rodríguez y Bernardo Vila 2011:171).

Leal Riol (2011) sugiere que el docente debería introducir el componente fraseológico en el aula dependiendo de los niveles y teniendo en cuenta las dificultades que pueden encontrar los alumnos en aspectos fonético-fonológicos, morfológicos, sintácticos, semánticos, discursivos, pragmáticos y socioculturales. Tomando como referencia los aprendices de lengua inglesa, considera que en el nivel inicial se pueden enseñar UF comparativas de idiomaticidad baja o media, en el nivel intermedio los binomios que presentan una equivalencia total, de idiomaticidad baja o media, mientras que para el nivel superior recomienda la enseñanza de UF que encuentran una equivalencia parcial en su lengua y de idiomaticidad baja, media y alta. Desde el punto de vista sintáctico el reto es aún mayor, puesto que las UF se caracterizan, entre otros rasgos, por la ruptura de las reglas gramaticales que rigen el sistema.

En esta tesis doctoral defendemos las mismas creencias y en las propuestas didácticas impulsamos la enseñanza de los SO desde el nivel inicial, dado que nos encontramos ante universales lingüísticos fácilmente reconocibles: el español y el rumano son lenguas afines y los alumnos de E/LE se sienten motivados ante este tipo de estructuras que los acercan a los hablantes nativos y mejoran su competencia léxica en general y fraseológica en particular. Nuestra experiencia directa y personal en el aula da fe de la total implicación de los aprendices, que incluso están preparando (incluso nos atreveríamos a decir "premeditando") el contexto comunicativo idóneo para insertar el elemento fraseológico recién aprendido. 


\subsection{MCER: pautas para una mayor unidad curricular}

El Marco Común Europeo de Referencia para las lenguas: aprendizaje, enseñanza, evaluación (2001) forma parte de un amplio proyecto de unificación de las políticas lingüísticas llevado a cabo por el Consejo de Europa y nace con el objetivo declarado de

establecer una base común con un metalenguaje común que al mismo tiempo es flexible y se puede adaptar a los diferentes contextos educativos para la elaboración de programas y manuales, diseños y reformas curriculares, formación de profesores y la evaluación de las competencias en las lenguas en toda Europa (Cáceres 2006:272).

Asimismo, pretende vencer "las barreras producidas por los distintos sistemas educativos europeos que limitan la comunicación entre los profesionales que trabajan en el campo de las lenguas modernas" y proporcionar los medios adecuados para que profesores, formadores, diseñadores de currículos y administradores educativos puedan reflexionar sobre su práctica, a fin de aunar esfuerzos y satisfacer las necesidades de sus alumnos. El MCER fomenta la cooperación en el campo de las lenguas modernas, proporcionando una base común para la elaboración de programaciones, orientaciones curriculares y exámenes y favorecer la validez, la fiabilidad y la transparencia de los criterios que describen las competencias lingüísticas. La unificación de criterios contribuirá a un reconocimiento mutuo de títulos y certificaciones y generará una mayor movilidad geográfica que ayudará a un mejor conocimiento y entendimiento de la diversidad cultural.

De especial interés para nuestro estudio es otro importante objetivo del MCER, la descripción de forma integradora de los contenidos que tienen que adquirir los estudiantes, a fin de utilizar una lengua para comunicarse, así como los conocimientos y destrezas que tienen que desarrollar para poder actuar de manera eficaz y los niveles de dominio.

En este nuevo paradigma se establecen tres niveles amplios ( $A$, B y $C$ ) que podrían corresponder, grosso modo, a los niveles inicial, intermedio y avanzado, siguiendo una terminología tradicional. A su vez, cada uno de estos niveles se dubdivide en dos, configurando lo que se ha denominado "cono invertido", concepto utilizado para incluir el componente de duración temporal que los aprendices tienen que invertir para alcanzar los objetivos establecidos en un determinado nivel. Los seis niveles comunes de referencia así resultados son bautizados Acceso (A1), Plataforma (A2), Umbral (B1), Avanzado (B2), Dominio operativo eficaz (C1) y Maestría (C2).

EI MCER establece niveles de dominio que permiten comprobar el progreso de los alumnos en cada etapa de su aprendizaje y se dedica a inventariar y desglosar las competencias de los alumnos, entendidas como la suma de conocimientos, destrezas y características individuales que permiten a una persona realizar acciones. Las 
competencias generales son las que no se relacionan directamente con la lengua (conocimiento del mundo, competencia existencial o capacidad para aprender), pero a ella se puede recurrir para acciones de todo tipo, incluyendo las actividades de la lengua. Las competencias comunicativas son las que posibilitan a una persona actuar utilizando específicamente medios lingüísticos y están subdivididas en competencias lingüísticas, competencias sociolingüísticas y competencias pragmáticas.

Las competencias lingüísticas incluyen los conocimientos y las destrezas léxicas, fonológicas, sintácticas y otras dimensiones de la lengua como sistema, la competencia ortográfica, semántica y ortoépica. El MCER señala que estas competencias se relacionan no solo con el alcance y calidad de los conocimientos, sino también con la organización cognitiva y la forma en que se almacenan estos conocimientos (por ejemplo, las distintas redes asociativas en que el hablante coloca un elemento léxico) y con su accesibilidad (activación, recuperación y disponibilidad). Por su parte, la competencia sociolingüística se refiere a las condiciones socioculturales del uso de la lengua (las normas de cortesía, las normas que ordenan las relaciones entre generaciones, sexos, clases y grupos sociales, etc.), mientras que las competencias pragmáticas están relacionadas con el uso funcional de los recursos lingüísticos y comprenden, por una parte, una competencia discursiva, referida a la capacidad de organizar las oraciones en secuencias para producir fragmentos textuales, $y$, por otra, una competencia funcional, referida tanto al conocimiento de las formas lingüísticas y sus funciones (microfunciones como saludos, brindis, presentaciones, etc.) como al modo en que se encadenan unas con otras a través de las etapas de su desarrollo (por ejemplo, mediante esquemas de interacción).

El progreso de la capacidad que tiene el alumno a la hora de usar los recursos lingüísticos se presenta de manera estructurada, según los niveles implementados. 


\begin{tabular}{|c|c|}
\hline & COMPETENCIA LINGÜÍSTICA GENERAL \\
\hline $\mathrm{C} 2$ & $\begin{array}{l}\text { Saca provecho de un domino amplio y fiable de un completo repertorio de elementos lingüísticos } \\
\text { para formular pensamientos con precisión, poner énfasis, diferenciar y eliminar la ambigüedad. No } \\
\text { manifiesta ninguna llimitación de lo que quiere decir. }\end{array}$ \\
\hline $\mathrm{C} 1$ & $\begin{array}{l}\text { Elige una formulación apropiada de una amplia serie de elementos lingüísticos para expresarse } \\
\text { con claridad y sin tener que limitar lo que quiere decir. }\end{array}$ \\
\hline B2 & $\begin{array}{l}\text { Se expresa con claridad y sin manifestar ostensiblemente que tenga que limitar lo que quiere decir. } \\
\text { Dispone de suficientes elementos lingüísticos como para hacer descripciones claras, expresar puntos } \\
\text { de vista y desarrollar argumentos, utilizando para ello algunas oraciones complejas y sin que se le note } \\
\text { mucho que está buscando las palabras que necesita. }\end{array}$ \\
\hline \multirow[t]{2}{*}{ B1 } & $\begin{array}{l}\text { Dispone de suficientes elementos lingüísticos como para describir situaciones impredecibles, para } \\
\text { explicar los puntos principales de una idea o un problema con razonable precisión y para expresar } \\
\text { pensamientos sobre temas abstractos o culturales, tales como la música y las películas. }\end{array}$ \\
\hline & $\begin{array}{l}\text { Dispone de suficientes elementos lingüísticos como para desenvolverse y de suficiente vocabulario como para } \\
\text { expresarse con algunas dudas y circunloquios sobre temas como la familia, aficiones e intereses, } \\
\text { trabajo, viajes y hechos de actualidad, pero las limitaciones léxicas provocan repeticiones e incluso, a } \\
\text { veces, dificultades en la formulación. }\end{array}$ \\
\hline \multirow[t]{3}{*}{ A2 } & $\begin{array}{l}\text { Tiene un repertorio de elementos lingüísticos básicos que le permite abordar situaciones cotidianas de } \\
\text { contenido predecible, aunque generalmente tiene que adaptar el mensaje y buscar palabras. }\end{array}$ \\
\hline & $\begin{array}{l}\text { Produce expresiones breves y habituales con el fin de satisfacer necesidades sencillas y concretas: } \\
\text { datos personales, acciones habituales, carencias y necesidades, demandas de información. }\end{array}$ \\
\hline & $\begin{array}{l}\text { Utiliza estructuras sintácticas básicas y se comunica mediante frases, grupos de palabras y } \\
\text { formulas memorizadas al referirse a sí mismo y a otras personas, a lo que hace, a los lugares, a } \\
\text { las posesiones etc. Tiene un repertorio limitado de frases cortas memorizadas que incluye } \\
\text { situaciones predecibles de supervivencia, suelen incurrir en malentendidos si se trata de una } \\
\text { comunicación poco frecuente. }\end{array}$ \\
\hline A1 & $\begin{array}{l}\text { Tiene un repertorio muy básico de expresiones sencillas relativas a datos personales y a } \\
\text { necesidades de tipo concreto. }\end{array}$ \\
\hline
\end{tabular}

Tabla 18. Competencia lingüística general. Fuente MCER (2001)

A continuación, nos centraremos en la competencia léxica, de especial interés para este trabajo. El MCER (2001:107), anclado en el enfoque comunicativo y orientado a la acción, la define como "conocimiento del vocabulario de una lengua y la capacidad para utilizarlo" y la divide en dos apartados: los elementos léxicos y los elementos gramaticales. Los elementos léxicos comprenden expresiones hechas que se componen de varias palabras que se utilizan y se aprenden como un todo y polisemia.

EI MCER (2011:108) desglosa las expresiones hechas en cinco subapartados y es donde encontramos por vez primera una referencia a las UF, denominadas en estos términos:

- fórmulas fijas, que comprenden: a) exponentes directos de funciones comunicativas como, por ejemplo, los saludos ("encantado de conocerle", "buenos días", etc.); refranes, proverbios, dichos y aforismos; arcaísmos residuales como, por ejemplo, "Válgame Dios". 
- modismos, divididos en metáforas lexicalizadas, semánticamente opacas, por ejemplo "estirar la pata", "quedarse de piedra" o "estar en las nubes" e intensificadores, ponderativos o epítetos cuyo uso es a menudo contextual y estilísticamente restringido: "blanco como la nieve" ('puro'), como opuesto a "blanco como la pared" ('pálido').

- estructuras fijas, aprendidas y utilizadas como conjuntos no analizados, en los que se insertan palabras o frases para formar oraciones con sentido; por ejemplo: "Por favor, ¿sería tan amable de + infinitivo...?".

- otras frases hechas, como los verbos con régimen preposicional (por ejemplo "convencerse de", "alinearse con", "atreverse a") y locuciones prepositivas como "delante de", "por medio de", etc.

- régimen semántico o expresiones que se componen de palabras que habitualmente se utilizan juntas, como "cometer un crimen/error", "ser culpable de (algo malo)", "disfrutar de (algo bueno)".

Esta división no está exenta de polémica y, según Saracho (2011:152), "denota una inadecuación conceptual", idea a la que suscribimos. Como se puede observar, están situados en el mismo nivel sintagmas y enunciados, dentro del apartado de las frases hechas están incluidos los verbos regidos por una preposición y, en el caso del "régimen semántico" observamos que se insertan colocaciones.

EI MCER introduce también una escala ilustrativa de descriptores para el conocimiento del vocabulario, de la que se desprende que el dominio de las unidades fraseológicas es privilegio exclusivo de los niveles C1 y C2. 
C2 Tiene un buen dominio de un repertorio léxico muy amplio, que incluye expresiones idiomáticas y coloquiales; muestra que es capaz de apreciar los niveles connotativos del significado

C1 Tiene un buen dominio de un amplio repertorio léxico que le permite superar con soltura sus deficiencias mediante circunloquios; apenas se le nota que busca expresiones o que utiliza estrategias de evitación. Buen dominio de expresiones idiomáticas y coloquiales.

B2

Dispone de un amplio vocabulario sobre asuntos relativos a su especialidad y sobre temas más generales. Varía la formulación para evitar la frecuente repetición, pero las deficiencias léxicas todavía pueden provocar vacilación y circunloquios.

B1

Tiene sufciente vocabulario para expresar con algún circunloquio sobre la mayoría de los temas pertinentes para su vida cotiviana como, por ejemplo, familia, aficiones e intereses, trabajo, viajes y hechos de actualidad.

A2 Tiene suficiente vocabulario para desenvolverse en actividades habituales y en transacciones cotidianas que comprenden situaciones y temas conocidos.

Tiene suficiente vocabulario para expresar necesidades comunicativas básicas. Tiene suficiente vocabularic para satisfacer necesidades sencillas de supervivencia.

A1 Tiene un repertorio básico de palabras y frases aisladas relativas a situaciones concretas.

Tabla 19. Riqueza de vocabulario. Fuente: MCER (2001)

Sin embargo, como ya hemos señalado, abogamos por la inclusión gradual de las UF en el proceso de enseñanza. En los niveles altos se impartirán aquellas unidades fraseológicas que presenten mayores dificultades de comprensión, debido a su opacidad o complejidad del contorno sintáctico.

Como elemento positivo, el MCER (2001:109) deja libertad a los usuarios para que decidan "qué elementos léxicos (expresiones hechas y palabras polisémicas) tendrá que aprender a reconocer y utilizar el alumno, cómo se le capacitará para ello o qué se le exigirá al respecto" y "cómo se eligen y se ordenan tales elementos".

A pesar de este intento de matización, pensamos que estas observaciones no son suficientemente esclarecedoras ni para docentes ni para aprendientes. Además, el MCER carece de precisión terminológica al no hacer una distinción clara entre sintagma y enunciado, si bien desde el punto de vista práctico no parece imprescindible esta distinción. Con esto no pretendemos mermar los méritos del MCER, documento no dogmático que constituye el primer eslabón alrededor del cual confluyen reflexiones, aportaciones teóricas y líneas de actuación. 


\subsection{PCIC: hacia niveles de concreción}

El Plan Curricular del Instituto Cervantes (2007) fija y desarrolla los seis niveles de dominio establecidos en una planificación curricular de enseñanza de E/LE, siguiendo las directrices establecidas por el MCER (2001), con el intento declarado de proporcionar a los equipos docentes de la red de centros y a los profesionales relacionados con la enseñanza de E/LE un amplio repertorio de material que pueda servir para distintos fines y utilidades.

En un posterior nivel de concreción, ofrece un tratamiento sistemático para la preparación de los objetivos y los contenidos de los programas de enseñanza, sin ahondar en las otras dos vertientes de un currículo, la metodología y la evaluación.

El contenido del material de aprendizaje se estructura en cinco grandes campos, que reciben el nombre de componentes que, a su vez, contienen uno o más inventarios en los que se enumeran detalladamente las unidades que formarán parte del programa de diferentes cursos: el componente gramatical (al que le corresponden tres inventarios: de gramática, de pronunciación y prosodia y de ortografía), el componente pragmáticodiscursivo (con inventarios de funciones, de tácticas y estrategias pragmáticas, de géneros discursivos y productos textuales), el componente nocional (con inventarios de nociones generales y nociones específicas), el componente cultural (con inventarios de referentes culturales, de saberes y comportamientos sociales y de habilidades y actitudes interculturales) $y$, finalmente, el componente de aprendizaje que contiene los procedimientos de aprendizaje.

En la introducción del apartado dedicado a las nociones generales (2011) se aclara que "el enfoque nocional se basa en un tipo de análisis de la lengua que identifica una serie de categorías de carácter semántico-gramatical, concebidas como conceptos descriptivos generales, que no se ajustan al concepto tradicional de palabra (...)". La unidad léxica se concibe desde una perspectiva más amplia que incluye la dimensión combinatoria, lo que supone la presencia en los inventarios de

toda una serie de unidades léxicas pluriverbales, como colocaciones y expresiones idiomáticas (sobre todo locuciones). Este enfoque se sitúa en una línea de investigación que parte de la base de que un hablante cuenta (...) con un número amplio de bloques semiconstruidos que puede combinar al hablar. Estas investigaciones están avaladas por estudios psicolingüísticos que demuestran que la lengua también se procesa - y generalmente se adquiere - en bloques o en grupos de palabra y nos solo palabra a palabra (PCIC 2011:305). 
Estas líneas dan fe de los avances realizados por el PCIC. En primer lugar, destacamos la benéfica separación del léxico en nociones generales y nociones específicas, entre las que se establecen nexos semánticos que favorecen una mejor integración y didactización en el aula de E/LE. Las nociones siguen una organización jerárquica (nociones existenciales, cuantitativas, espaciales, temporales, cualitativas, evaluativas, mentales), mientras que las nociones específicas, "sin perder de vista el horizonte didáctico del destinatario de la obra" (PCIC 2011: 321), se desglosan en individuo (dimensión física, dimensión perceptiva y anímica); identidad personal; relaciones personales; alimentación; educación; trabajo; ocio; información y medios de comunicación; vivienda; servicios; compras, tiendas y establecimientos; salud e higiene; viajes, alojamiento y transporte; economía e industria: ciencia y tecnología; gobierno, política y sociedad; actividades artísticas; religión y filosofía; geografía y naturaleza.

Además, nos parece oportuna la visión acerca de la unidad léxica, contemplada desde su faceta pluriverbal y combinatoria, fruto del cotejo de obras lexicográficas como REDES (Bosque 2004), DFDEA (Seco, Andrés y Ramos 2004) o DICE, diccionario en línea de colocaciones en español.

Hay que tener en cuenta que la inclusión de la combinatoria en este inventario es sin duda novedosa y debe ser entendida como una ayuda para la correcta comprensión del significado de una determinada noción, no como la única posibilidad combinatoria de las palabras correspondientes" (PCIC 2007:307).

La inclusión de la combinación de las piezas léxicas se lleva a cabo de manera gradual y de forma ilustrativa, no exhaustiva, a fin de "profundizar más en el tratamiento de palabras conocidas y no solo entender el aprendizaje del léxico como una acumulación de nuevos exponentes" (PCIC 2011:308). Para ejemplificar este enfoque, contamos con las unidades que incluyen el lexema "duda", dentro del apartado dedicado a las nociones existenciales. 


\begin{tabular}{|l|l|l|l|}
\hline B1 & B2 & C1 & C1 \\
\hline tener una duda & $\begin{array}{l}\text { tener } \sim \text { dudas/la } \\
\text { seguridad }\end{array}$ & $\begin{array}{l}\text { plantear/resolver } \sim \\
\text { una duda }\end{array}$ & $\begin{array}{l}\text { albergar/suscitar/alimentar } \\
\sim \text { dudas/ la duda }\end{array}$ \\
\hline & $\begin{array}{l}\text { sembrar } \sim \text { dudas /la } \\
\text { duda }\end{array}$ & $\begin{array}{l}\text { despejar } \sim \text { una incógnita / un } \\
\text { interrogante / una duda }\end{array}$ \\
\hline
\end{tabular}

Tabla 20. Distribución de UF por nivel. Fuente PCIC (2011)

En la tabla anterior se puede observar que el PCIC considera el nivel B1 como punto de partida para la introducción de las colocaciones en el aula, si bien afirma en reiteradas ocasiones el "carácter abierto" del documento. Asimismo, se desprende el trato privilegiado que reciben las colocaciones frente a otras construcciones y la presencia de unas sólidas argumentaciones teóricas en torno a las reglas combinatorias, pero la ausencia de referencia a otros rasgos de las UF, como la fijación o la idiomaticidad.

Tras revisar a fondo los inventarios del PCIC en todos los niveles, podemos concluir que en los niveles A1 y A2 las muestras encontradas son, ante todo, fórmulas rutinarias y discursivas, agrupadas en torno a funciones comunicativas como saludar ("buenos días"), responder a una presentación ("mucho gusto"), preguntar la identidad ("¿De parte de quién?"), formular buenos deseos ("ique aproveche!"), dirigirse a alguien ("por favor”), expresar acuerdo ("de acuerdo"). No obstante, el PCIC admite que el tratamiento que reciben es mínimo y está restringido a su aprendizaje memorístico.

No es infrecuente la presencia en los niveles A1 y A2 de exponentes fijos, que el alumno aprende tal cual, dado que en estos niveles iniciales no dispone todavía de los conocimientos necesarios para analizar esa concreta "pieza de lengua", que se aprende, pues, de forma holística, sintética. Posteriormente, en los niveles subsiguientes, se presenta el exponente generativo correspondiente (PCIC III 2007:173).

Se analiza como ejemplo el deseo "que aproveche" enseñado, como hemos visto anteriormente, en el nivel A2, sin proporcionar ninguna información sintáctica, puesto que el aprendiz todavía carece de herramientas gramaticales suficientes. Posteriormente, en el nivel B1 se retomaría el exponente, integrándolo dentro del contenido gramatical "que + presente de subjuntivo". Esta estrategia nos parece acertada, puesto que la competencia gramatical no tiene que ser un escollo insalvable para que las UF estén presentes desde los niveles más básicos del aprendizaje. Además, de esta forma, los aprendices dispondrían de más tiempo para incorporarlas de forma progresiva a su repertorio fraseológico productivo. 
Es cierto que los aprendientes de los niveles iniciales, A1 (Acceso) y A2 (Plataforma), no disponen de los conocimientos necesarios para analizar muchas expresiones fraseológicas y, a pesar de ello, estas están presentes en el proceso de aprendizaje-enseñanza desde el primer momento, sin que el aprendiente tenga que ser consciente de que una u otra combinación de palabras entra dentro del campo de la fraseología (López Vázquez 2010: 535).

En los niveles B1 y B2 se vuelve a reiterar el afán por incluir en los inventarios del componente nocional "toda una serie de unidades léxicas pluriverbales como colocaciones y expresiones idiomáticas (sobre todo locuciones)", tomando como referencia "criterios relacionados tanto con fines didácticos como fraseológicos y lexicográficos" (PCIC II 2007:389). Efectivamente, señalamos la presencia de las colocaciones y locuciones, pero de manera esporádica y, sobre todo, sin sistematizar. Están dispersadas en los apartados de funciones de cada uno de los niveles y echamos en falta, como afirma Mendizábal (2016:6) al referirse a las locuciones verbales, un "espacio fijo".

Aunque el PCIC (2007:208) declara que "a partir del nivel B2 se inicia la presentación de exponentes que incluyen expresiones idiomáticas y frases hechas", las UF cobran verdadero protagonismo en los niveles $\mathrm{C} 1$ y C2, donde encontramos una clara mención en la descripción global del nivel. Desde su perspectiva como agentes sociales y expresándolo en términos de capacidad, los alumnos podrán llevar a cabo transacciones de todo tipo, aunque sean delicadas y complejas. En el nivel $\mathrm{C} 1$ "son capaces de adaptarse con precisión al contexto, a las intenciones y a los interlocutores. Reconocen registros; son capaces de captar el sentido implícito de lo que oyen o leen, puesto que comprenden la carga connotativa de los modismos, frases hechas y expresiones coloquiales, aunque puede que sea necesario confirmar detalles, sobre todo si el acento es desconocido" (PCIC III 2007:21). Mientras tanto, en el nivel C2 "tienen un buen dominio de expresiones idiomáticas y coloquiales y saben apreciar los niveles connotativos del significado" (PCIC III 2007:21). Las mismas referencias aparecen en otros objetivos generales de nivel, como participar y tomar la iniciativa en interacciones sociales dentro de la comunidad o de las comunidades sociales, académicas o profesionales en las que se integre o desenvolverse con textos orales y escritos de cualquier tipo, sea cual sea la situación y el tema.

No obstante, a pesar del papel destacado que desempeña la fraseología en estos niveles, el PCIC no aporta en ningún momento un apartado específico, un inventario donde "se describan de manera exhaustiva todas las expresiones fraseológicas susceptibles de aprendizaje" y las encontramos "dispersas en la mayoría de los puntos que componen el texto, sin que exista ningún tipo de marca o índice que facilite su búsqueda o recopilación" (López Vázquez 2010:536). 
Efectivamente, aparecen en los inventarios de gramática (las UF se han considerado unidades a medio camino entre gramática y vocabulario) y en los inventarios de las funciones comunicativas. Hemos recopilado elementos fraseológicos en distintos subapartados de gramática: los artículos ("un ir y venir"), los posesivos ("salirse con la suya"), los cuantificadores ("es todo corazón"), sobre todo, dentro del sintagma verbal ("iVaya cara que tiene!", "Tiene una cara que no te imaginas", "para dar y tomar”).

En cuanto a la presencia de UF dentro de las funciones, los ejemplos son numerosos: expresar que no se recuerda ("se me ha ido el santo al cielo"), expresar aversión ("no puedo verlo ni en pintura"), expresar indiferencia ("me importa un pimiento"), expresar tristeza y aflicción ("se me viene el mundo encima", "no levanto cabeza"), expresar miedo, ansiedad y preocupación ("se me hiela la sangre"), expresar vergüenza ("se me cae la cara de vergüenza", "¡Tierra, trágame!"), expresar sensaciones físicas ("estoy sudando como un pollo"), expresar empatía ("por mucho que intento ponerme en tu piel no puedo imaginarme cómo debes de sentirte"), etc. No obstante, no existe cohesión ni coherencia terminológica y

(...) desde el punto de vista didáctico, pensamos que al profesor no se le facilita de una manera clara todo el enorme caudal fraseológico que contiene el documento, pues en los exponentes se han utilizado diferentes denominaciones para un tipo concreto de unidad fraseológica y no siempre, en un mismo inventario, las combinaciones que tienen el estatus de unidad fraseológica han sido marcadas sistemáticamente como tales (Ruiz Martínez 2007:14).

En el inventario de "Tácticas y estrategias pragmáticas" encontramos una mejor estructuración de las UF recogidas, quizás debido a la naturaleza intrínseca del apartado que incluye mayoritariamente elementos de coherencia discursiva.

Finalmente, destacamos el elevado número de unidades fraseológicas recogidas en los inventarios de nociones de los niveles $\mathrm{C} 1$ y $\mathrm{C} 2$, donde el PCIC relega los componentes que pertenecen al registro coloquial.

Tanto las especificaciones como los ejemplos que se dan en los distintos inventarios responden en general a la norma culta, si bien se incluyen también aspectos relacionados con el uso coloquial - en los niveles más altos -, cuyo dominio denota un mayor grado de profundidad en el conocimiento y uso de lengua por parte del alumno (PCIC 2007:15).

En estos inventarios encontramos muchas de las locuciones somáticas que constituyen el objeto de este trabajo. Reconocemos las dificultades de selección y agrupamiento, pero la decisión de incluirlas en el nivel C1 o en el nivel C2 parece en ocasiones arbitraria y desconocemos los criterios que ha seguido el PCIC para operar el 
reparto: "estar en los huesos" (C1) vs. "estar entrado en carnes" (C2), "encogerse de hombros", "arquear las cejas", "fruncir el ceño", "arrugar la nariz/la frente", "guiñar el ojo" (C1) vs. "andar tieso" (C2), "estirar la pata" (C1) vs. "irse al otro barrio", "pasar a mejor vida", "criar malvas" (C2), "perder los nervios"(C1) vs. "hervir la sangre" (C2), "tener mano izquierda" (C1) vs. "tratar con mano dura" (C2), "tener un corte de digestión" (C1) vs. "viajar a dedo" (C2), etc. No obstante, tras haber llevado a cabo el análisis contrastivo españolrumano y haber elaborado una base de datos con somatismos destinada a aprendientes nativos de rumano, consideramos que ya podemos contar con suficientes elementos de juicio para una correcta distribución por niveles, no solamente en $\mathrm{C} 1$ y C2, sino desde las primeras etapas del aprendizaje. Reiteramos nuestra convicción de que muchas de estas locuciones tienen cabida en niveles de estudios más bajos, sobre todo si se trata de lenguas afines (como es el caso de dos lenguas románicas como el español y el rumano) y que la forma de organizar las UF es mejorable.

No obstante, el PCIC representa sin duda un paso adelante en cuanto a niveles de concreción. Además, gracias a la manera de enfocar las unidades léxicas, siguiendo criterios semánticos, lo convierte en una herramienta de gran utilidad para los profesores de E/LE. En nuestro caso, ha resultado extremadamente últil para la descripción detallada de las funciones comunicativas, unos de los componentes clave en la base que datos que hemos elaborado para este estudio. 


\subsection{Fraseodidáctica}

En este primer capítulo de la segunda parte de nuestro trabajo consideramos sumamente útil esbozar unos párrafos necesarios sobre fraseodidáctica, cuyo fin es aclarar conceptos y sentar la base teórica para la aplicación práctica que aportaremos posteriormente (batería de actividades con UF para la enseñanza/aprendizaje de español a aprendientes rumanos).

Fruto del interés por llevar al aula las UF y de construir un andamiaje teórico imprescindible para su enseñanza-aprendizaje surge una nueva área de estudio, denominada fraseodidáctica. El término, acuñado en español por Larreta Zulategui (2001), procede del concepto alemán Phraseodidaktik y se inspira de autores como Kühn (1987), Lüger (1997) o Ettinger (1998).

En un esclarecedor artículo en torno a la nomenclatura de la disciplina, González Rey (2012) aporta leves matices entre la fraseología, entendida como didáctica de la fraseología (cuyo origen se sitúa en la glotodidáctica o didáctica de la lengua) y la fraseodidáctica definida como la didáctica de toda una lengua a través de su fraseologogía. Szyyndler (2015:201) sigue la misma línea de pensamiento y opina que la fraseodidáctica "se ha convertido en campo de estudio independiente, de carácter interdisciplinar que combina elementos de la fraseología, la enseñanza de lenguas, la lingüística contrastiva, así como la psicolingüística y la sociolingüística."

Según Ettinger (2008), la fraseodidáctica no es un fin en sí mismo, sino un medio para alcanzar una meta más amplia, la mejora de la competencia comunicativa del aprendiente, que incluye el conocimiento y el grado de control de las UF como uno de los indicadores de dominio de la LE. "La persona que aprende una lengua extranjera no solo se enfrenta a la corrección lingüística, sino a la adecuación social y a un mundo metafórico construido sobre un imaginario colectivo que probablemente no conoce o que, incluso, no comparte" (Calero Fernández 2020:109). Uno de los objetivos de la fraseodidáctica es precisamente proporcionar situaciones comunicativas para que los aprendientes puedan reutilizar de manera eficaz UF que reconocen, comprenden y aprenden en la clase de idioma. Parafraseando las etapas que el PCIC propone para el desarrollo de la dimensión (inter)cultural del alumno, se trataría de una fase de aproximación, una fase de profundización y una fase de consolidación.

En esta misma línea, Ettinger (2008) considera esencial la adquisición de fórmulas rutinarias desde los niveles básicos (aunque no es partidario de introducir tan temprano otro tipo de UF), mientras que Calero Fernández (2020) se plantea una cuestión metodológica de índole similar, los límites de la selección cualitativa y la necesidad de enfoques cuantitativos en la labor de decidir qué exponentes se incluyen y en qué etapas del proceso. 
Por su parte, Kühn (1992, apud. Ettinger 2008) propone tres pasos necesarios en la didáctica de las UF: identificar las UF en contexto real, llevar a cabo el proceso de descodificación de las UF, guiado por el docente, y reutilizar la UF recién aprendida en un contexto similar y adecuado. Además, Lüger (1997) sugiere una fase intermedia situada entre el descifrado del fraseologismo y su utilización: la fase de fijación (que contribuiría a memorizar la UF) y destaca la importancia de aplicar la competencia fraseológica activa tan solo a una parte del caudal fraseológico y no a su totalidad, ya que el aprendiz puede no ser consciente de todas las restricciones de uso asociadas a cada UF. La importancia del contexto es una constante permanente en todos los estudios. Según Leal Riol (2011:224), "es evidente que conocer una unidad fraseológica implica reconocerla en un contexto, ser consciente de que su significado es compositivo y con gran frecuencia idiomático, y ser capaces de usarla en el contexto y el registro apropiado". Esas UF que tienen la posibilidad de utilizarse en diferentes situaciones son las que consideramos más rentables en el aula, al igual que las UF productivas, que permiten la sustitución o adición de algunos de sus elementos para generar nuevas unidades de significado de fácil comprensión.

Finalmente, desde la reflexión teórica, pero también desde la experiencia directa en el aula, señalamos el recurso al metalenguaje para explicar fraseología. Conceptos como "fijación", "idiomaticidad", "significado denotativo o connotativo" son muy útiles para un alumnado que domina la terminología lingüística. No obstante, si los aprendices no cuentan con una desarrollada conciencia lingüística, ese desconocimiento no debería ser un escollo insalvable porque "se puede prescindir totalmente de estos términos" (Leal Riol 2011:225) por no causar un sentimiento de ignorancia o de culpabilidad. La didáctica de una lengua extranjera y la fraseodidáctica en particular deben de tener en cuenta la dimensión afectiva.

En este capítulo hemos examinado el componente fraseológico desde la compleja perspectiva del aprendizaje y de la enseñanza de UF en el aula de LE, como también las orientaciones, los enfoques y la distribución de contenidos que reflejan los documentos fundamentales, el MCER y el PCIC. Asimismo, hemos presentado los principios teóricos y los objetivos de la fraseodidáctica, los retos de los docentes y nuestra postura acerca de la enseñanza de los SO para un alumnado meta constituido por rumanohablantes. 


\section{EL ENFOQUE LÉXICO Y EL COMPONENTE FRASEOLÓGICO: REVISIÓN CRÍTICA DE RECURSOS EN LÍNEA (NIVELES A1-B2)}

Una vez constituido y analizado pormenorizadamente el corpus y tras haber revisado cómo enfocan la fraseología los documentos fundamentales en el ámbito de la enseñanza de E/LE en Europa (MCER y PCIC), emprenderemos un análisis crítico de materiales para comprobar el tratamiento léxico en los materiales de E/LE.

En estudios similares al nuestro, Haddouch (2013), Saracho (2015) o d'Andrea (2019) apuntan como objetivo práctico en sus trabajos de investigación el tratamiento que reciben las UF en los manuales de E/LE. De la extensa oferta editorial, Saracho selecciona dieciséis manuales que abarcan todo el itinerario de niveles, mientras que Haddouch opta por el método Prisma (niveles B1-C1), "puesto que es a partir de estos cuando la enseñanza de las UF se va a hacer más notoria; es decir, se exige un conocimiento básico tanto lingüístico como cultural por parte del alumno para que pueda comprenderla" (Haddouch 2013:141).

En este trabajo hemos decidido prescindir de cualquier material impreso. La realidad inmediata nos confirma el auge de las plataformas virtuales, el imprescindible uso las herramientas digitales y la necesidad de las tutorías telemáticas. Estamos avanzando a pasos agigantados hacia un modelo de enseñanza en línea y el mundo del E/LE no puede quedarse atrás. En esta línea de pensamiento, hemos optado por analizar desde un enfoque léxico, con especial hincapié en el componente fraseológico, la plataforma AVE GLOBAL. 


\subsection{AVE GLOBAL: español en línea}

Creada por el Instituto Cervantes, el Aula Virtual de Español (AVE) nace a principios del siglo XXI con el fin de fomentar el aprendizaje y la enseñanza del E/LE en línea, aprovechando los avances tecnológicos. La versión adaptada y mejorada (bautizada AVE GLOBAL) surge en 2014, respondiendo a la aparición de nuevos gadgets y al auge de diversas formas de relacionarse en la sociedad (mensajería instantánea, redes sociales y otras aplicaciones). Los usuarios de esta tecnología en continua expansión son alumnos que conciben de otro modo las interacciones y la forma de comunicación: más real y más significativa.

En los cursos que ofrece el AVE (para niños o adultos) el aprendiz avanza por medio de una secuencia guiada, siguiendo una serie de actividades interactivas y multimedia y evaluando su progreso mediante pruebas corregidas automáticamente.

Las propuestas del AVE están especialmente diseñadas para adaptarse a diferentes estilos y ritmos de aprendizaje y a los intereses de diferentes estudiantes en todo el mundo. Asimismo, proporciona al profesor una gran cantidad de recursos didácticos y está diseñado para poder ser utilizado en la enseñanza presencial como material de uso en el aula, en la enseñanza semipresencial con cursos que combinan clases presenciales con aprendizaje a distancia o en el aprendizaje a distancia, bien con un grupo de aprendizaje y un tutor, bien de forma autónoma. Los materiales didácticos incluyen muestras reales de lengua y cultura de los países y regiones del mundo hispano y están diseñados para promover valores como el respeto y la tolerancia hacia la diversidad social.

Los materiales de cada curso están distribuidos por temas, sesiones y actividades y la plataforma proporciona fichas de consulta, técnicas de estudio y talleres de práctica dentro de lo que titula genéricamente "material complementario". Según los autores, en los materiales de los cursos en línea del Instituto Cervantes

se pretende dar una imagen realista de la sociedad contemporánea, en la que se representan las diferencias de forma positiva y se fomenta el conocimiento de las minorías. Esta visión actualizada se plasma en la concepción general de los contenidos culturales de los temas y cursos y, más concretamente, en la creación, selección y revisión de los vídeos, las locuciones, los textos, las ilustraciones y las fotografías.

Señalamos, por lo tanto, el protagonismo que se le dan a las locuciones dentro del tratamiento a la diversidad social y cultural, idea destacada en muchos trabajos sobre fraseología. Luque Nadal (2012) enfoca el estudio de las UF desde un prisma culturológico, mientras que Martín Noguerol (2017) ahonda en el componente sociocultural que se desprende del conocimiento de las fórmulas rutinarias. 
El componente cultural está muy presente en la fraseología ya que esta suele tener su origen o ser reflejo de citas, hechos históricos, sabiduría popular, idiosincrasia, tradiciones, convenciones sociales, etc., que los miembros de una comunidad fijan lingüísticamente y sobre los que comparten un conocimiento sociocultural. Además, la fraseología siempre ha resultado atractiva para los estudiantes de lenguas ya que, por una parte, ven reflejados en estas frases hechas elementos de la cultura de la lengua que estudian y que, a veces, son comunes a su cultura; y, por otra parte, consideran que el conocimiento y uso correcto de estas expresiones les hacen sentir que hablan como un nativo, que, en cierta manera, forman parte de la comunidad de hablantes de la lengua que estudian y esto refuerza su autoestima (Martín Noguerol 2017:132-133).

La decisión de tomar como única fuente de análisis AVE tiene también un propósito práctico, debido a que la plataforma engloba la totalidad de niveles contemplados por el MCER, por lo que, al cubrir el itinerario completo, nos proporcionará un material coherente para el análisis. Es, además, la plataforma que usan a diario miles de aprendices en todo el mundo y el instrumento que mejor conocemos, como personal docente del Instituto Cervantes. Los temas, las actividades y los materiales de calidad acreditada que incluye el AVE GLOBAL forman parte de nuestra realidad laboral y nuestra visión crítica viene avalada por el uso activo de la herramienta.

En cuanto a la distribución de contenidos, el AVE sigue las pautas marcadas por el PCIC (en conformidad con el MCER), aunque desglosa más a fondo los niveles contemplados por los documentos curriculares, como se puede comprobar en el siguiente esquema:

\begin{tabular}{|l|l|}
\hline Curso & Descripción y objetivos \\
\hline Curso Inicial A1.1 & $\begin{array}{l}\text { Aprender a saludar y a despedirse; a dar y } \\
\text { pedir información personal y profesional; a } \\
\text { hablar de profesiones, países y } \\
\text { nacionalidades; a describir físicamente y a } \\
\text { comparar personas; }(. . .)\end{array}$ \\
\hline Curso Inicial A1.2 & $\begin{array}{l}\text { Aprender a preguntar y a dar instrucciones } \\
\text { para ir a algún lugar; a describir ciudades y } \\
\text { viviendas; a pedir y dar información sobre el } \\
\text { transporte urbano; a hablar sobre la rutina } \\
\text { diaria; (...) }\end{array}$ \\
\hline Curso Inicial A2.1 & $\begin{array}{l}\text { Aprender a hablar del pasado y de las } \\
\text { experiencias de la vida; a valorar actividades; } \\
\text { a describir el carácter de una persona; a } \\
\text { comprar en una tienda; a describir objetos; a } \\
\text { expresar necesidades; (...) }\end{array}$ \\
\hline Curso Inicial A2.2 & $\begin{array}{l}\text { Aprender a hablar de planes y proyectos } \\
\text { sobre viajes; a describir un viaje; a hablar del }\end{array}$ \\
\hline
\end{tabular}




\begin{tabular}{|c|c|}
\hline & $\begin{array}{l}\text { clima y a hacer recomendaciones. Conocer } \\
\text { diferentes tipos de turismo. Aprender a dar y a } \\
\text { pedir opinión; (...) }\end{array}$ \\
\hline Curso Intermedio B1.1 & $\begin{array}{l}\text { Aprender a hacer presentaciones y a } \\
\text { reaccionar en ellas; a dar información } \\
\text { personal; a hablar de hábitos y costumbres en } \\
\text { el pasado y en el presente; a contar } \\
\text { experiencias y relacionar acciones del } \\
\text { pasado; (...) }\end{array}$ \\
\hline$\underline{\text { Curso Intermedio B1.2 }}$ & $\begin{array}{l}\text { Aprender a hablar de hábitos para llevar una } \\
\text { vida sana; a expresar sensaciones y estados } \\
\text { físicos; a describir productos gastronómicos, } \\
\text { platos y recetas de cocina; a describir una } \\
\text { vivienda; (...) }\end{array}$ \\
\hline Curso Intermedio B1.3 & $\begin{array}{l}\text { Aprender a concertar una cita; a expresar } \\
\text { opiniones; a expresar sentimientos. Conocer } \\
\text { artistas, escritores y músicos } \\
\text { hispanohablantes y sus obras. Aprender a } \\
\text { justificar y argumentar una opinión; (...) }\end{array}$ \\
\hline Curso Intermedio B1.4 & $\begin{array}{l}\text { Aprender a participar en actos sociales; a } \\
\text { entregar o recibir un regalo; a hacer cumplidos } \\
\text { y reaccionar ante ellos; a proponer un brindis; } \\
\text { a ofrecerse para hacer algo; a expresar la } \\
\text { propia opinión; (...) }\end{array}$ \\
\hline Curso Avanzado B2.1 & $\begin{array}{l}\text { Aprender a describir de forma detallada el } \\
\text { físico y el carácter de las personas; a hablar } \\
\text { de parecidos y hacer comparaciones; a contar } \\
\text { la vida de una persona destacando los hechos } \\
\text { significativos; (...) }\end{array}$ \\
\hline Curso Avanzado B2.2 & $\begin{array}{l}\text { Aprender a describir detalladamente pueblos } \\
\text { y ciudades con sus entornos y paisajes; a } \\
\text { hablar del clima y de los cambios graduales y } \\
\text { de los que suceden paralelamente a ellos; a } \\
\text { participar en un debate; (...) }\end{array}$ \\
\hline Curso Avanzado B2.3 & $\begin{array}{l}\text { Aprender a hablar de reformas en una } \\
\text { vivienda sugiriendo, elogiando y } \\
\text { respondiendo a elogios; a pedir, conceder y } \\
\text { denegar permisos y favores justificando la } \\
\text { decisión; a ofrecerse para hacer un favor; (...) }\end{array}$ \\
\hline Curso Avanzado B2.4 & $\begin{array}{l}\text { Aprender a expresar condiciones en el pasado } \\
\text { y sus posibles consecuencias; a redactar } \\
\text { documentos formales de diversa índole. } \\
\text { Reconocer la importancia de los } \\
\text { descubrimientos científicos; (...) }\end{array}$ \\
\hline Curso Superior C1.1 & $\begin{array}{l}\text { Aprender a redactar una carta de } \\
\text { presentación; a preparar una entrevista } \\
\text { radiofónica; a escribir sobre uno mismo y } \\
\text { valorar experiencias ajenas. Acercarse a los } \\
\text { medios de comunicación; (...) }\end{array}$ \\
\hline Curso Superior C1.2 & $\begin{array}{l}\text { Aprender a expresar nostalgia; a entablar un } \\
\text { diálogo intercultural; a percibir las diferencias }\end{array}$ \\
\hline
\end{tabular}




\begin{tabular}{|l|l|}
\hline Curso Superior C1.3 & $\begin{array}{l}\text { culturales y comunicarse con éxito en el } \\
\text { extranjero; a tomar notas durante una } \\
\text { conferencia; (...) }\end{array}$ \\
\hline Curso Superior C1.4 & $\begin{array}{l}\text { Aprender a describir y valorar prendas de } \\
\text { vestir; a situar lugares y dar indicaciones para } \\
\text { localizarlos; a establecer comparaciones en } \\
\text { torno al consumo familiar; a formular hipótesis } \\
\text { sobre el pasado; (...) }\end{array}$ \\
\hline $\begin{array}{l}\text { Aprender a hablar sobre la ecología y el } \\
\text { cambio climático; a realizar una reseña crítica; } \\
\text { a resumir un texto y analizar su intención; a } \\
\text { participar en un debate cuestionando la } \\
\text { información; (..) }\end{array}$ \\
\hline
\end{tabular}

Tabla 21. Descripción y objetivos de curso. Fuente: PCIC (2011)

De estos cursos únicamente analizaremos los niveles A1-B2 porque, como ya hemos podido comprobar anteriormente en el capítulo dedicado a los fundamentos curriculares, en los niveles C1 y C2 el PCIC contempla la impartición de un sólido contenido fraseológico, que los aprendices sabrán utilizar. No obstante, en esta tesis abogamos por que se amplíe la enseñanza de las UF a los demás niveles. El análisis interlingüístico y la investigación contrastiva demuestran que esto se puede llevar a cabo, sobre todo entre lenguas con una base tipológica común, como son el español y el rumano. Por esta razón, de los niveles analizados miraremos más detenidamente Acceso y Plataforma y nos detendremos menos en el Intermedio Alto porque tenemos la convicción de que a medida que vaya avanzando, el aprendiz se encontrará con un mayor input fraseológico. Martín Noguerol (2017) afirma que

siempre se ha relacionado el dominio de una lengua con el conocimiento fraseológico, pero, para llegar a conocer, usar correctamente y ser consciente de las implicaciones que las unidades fraseológicas comportan, durante su aprendizaje el estudiante ha tenido que ir adquiriendo una serie de conocimientos relacionados con los aspectos lingüístico, pragmático y sociocultural de las mismas (Martín Noguerol 2017:133).

Nos interesa sobre todo cómo la competencia fraseológica se va desarrollando en y desde los niveles bajos. Una vez adquirida esa base lingüística y pragmática a la que se hacía referencia anteriormente, resultará más fácil reconocer la UF, descodificarla a nivel cognitivo y verbal, acotar el contexto de aparición, las posibles combinaciones sintagmáticas e incorportarla al lexicón mental. Por esta razón, centraremos el foco en las actividades disponibles creadas para la adquisición de la competencia léxica, exclusivamente en los niveles inicial e intermedio porque carecemos de estudios empíricos fidedignos y ni siquiera los documentos oficiales lo contemplan de manera convincente.

Para nuestro propósito adaptaremos el modelo que propone Vidiella Andreu (2011) en su trabajo centrado en materiales destinados especialmente para la adquisición de 
léxico y trataremos de dar respuesta a preguntas como: qué tipo de unidades léxicas y fraseológicas se trabajan en el AVE; qué destrezas se activan al introducir UF; en qué momento de la unidad didáctica se presenta la unidad fraseológica; con qué finalidad; en qué contexto; existen actividades para revisar, reforzar y reactivar las UF presentadas anteriormente; qué recursos se utilizan para favorecer el mejor uso de las UF.

Se trata, por lo tanto, de un análisis a caballo entre criterios estrictamente lingüísticos y de índole didáctica.

Aprovechamos el privilegio de tener acceso ilimitado a este material versátil que es el AVE, plataforma que forma parte de nuestra realidad docente cotidiana. Además, como su nombre indica, es una plataforma "global", que llega prácticamente a todos los rincones del planeta. No podíamos pasar de largo esta oportunidad; esperamos que nuestro empeño resulte novedoso y, sobre todo, útil. 


\subsection{AVE GLOBAL - nivel A1}

En el curso A1.1 señalamos el papel destacado que ocupa el léxico, introducido en la práctica totalidad de las sesiones con el fin de lograr su adquisición temprana y contextualizada. Nos atrevemos a afirmar que en esta etapa del aprendizaje el léxico, integrado dentro de las funciones comunicativas, ocupa el papel protagonista.

El léxico presentado se estructura según unos campos semánticos bien definidos y acorde al nivel: presentación personal (origen, nacionalidad, edad, profesión, familia), gastronomía (productos, envases, medidas), rutina diaria y actividades de ocio, etc. Subrayamos el input constante de léxico de Hispanoamérica (Perú, Argentina, Colombia) que se enlaza con el contenido cultural, integrado de forma natural. Siguiendo un concepto acuñado por Sanz y Miquel (1992), se trata tanto de cultura "con mayúscula" (en referencia a escritores, actores, artistas visuales, etc.) como de cultura "con minúscula" (en referencia a costumbres, tradiciones, creencias, etc.).

Asimismo, hay que poner de manifiesto la presencia de muestras reales de habla que se ofrecen a través de breves secuencias de películas españolas, otra inspirada manera de integrar contenido cultural en el AVE, como también hipervínculos y referencias a páginas web reales y actuales: correos.es, casareal.es, deliberry.com, recetascocina10.com, etc. De esta manera, los alumnos entrarán en contacto con un español vivo, no adaptado para el aula de E/LE, elemento que consideramos un factor motivador.

En cuanto al tipo de unidades léxicas que se introducen, además de las unidades léxicas simples, señalamos la preponderancia de las fórmulas rutinarias que carecen de autonomía textual y tienen un significado textual, discursivo o expresivo. En este curso destacamos la presencia de las fórmulas discursivas que cumplen funciones de organización del discurso. Según Alvarado Ortega (2008)

las fórmulas rutinarias discursivas se llaman así porque se utilizan para integrar el enunciado en la enunciación, es decir tienen un papel en la conversación y en la interacción entre hablante y oyente. Estas fórmulas se usan para organizar, estructurar y hacer avanzar la conversación. De ahí que podamos establecer dos grandes grupos, (...) las fórmulas rutinarias discursivas de apertura y cierre de la conversación y las fórmulas rutinarias discursivas de transición (Alvarado Ortega 2008:318).

Como era de esperar, en este primer curso del AVE tienen más peso las fórmulas rutinarias discursivas de apertura y cierre de la conversación, saludos y despedidas como "buenos días", "hola, ¿qué tal?", "hasta luego", etc.

Asimismo, señalamos la presencia de locuciones prepositivas y adverbiales y un importante número de colocaciones ("árbol genealógico", "código postal", "ciencias 
exactas", "cadena hotelera", "diseño gráfico", "parque de atracciones”, "núcleo familiar", "retrato robot", "pareja de hecho", "empleada del hogar", etc.), aunque únicamente hemos detectado una locución verbal, "tener buen tipo".

No obstante, echamos en falta la inserción de algún somatismo, puesto que el contexto favorecía la introducción de locuciones verbales: en el tema 2 se tratan contenidos como la descripción física (sesión 2) y el cuerpo humano (sesión 8), por lo que contamos con un número muy elevado de somatónimos ("boca", "ojos", "labios", "pelos", "dientes", etc.). Consideramos que en este punto el AVE desaprovecha una buena oportunidad para introducir paulatinamente input fraseológico, puesto que una UF motivada como "no tener dos dedos de frente" tendría cabida dentro de una amplia función comunicativa como la descripción personal.

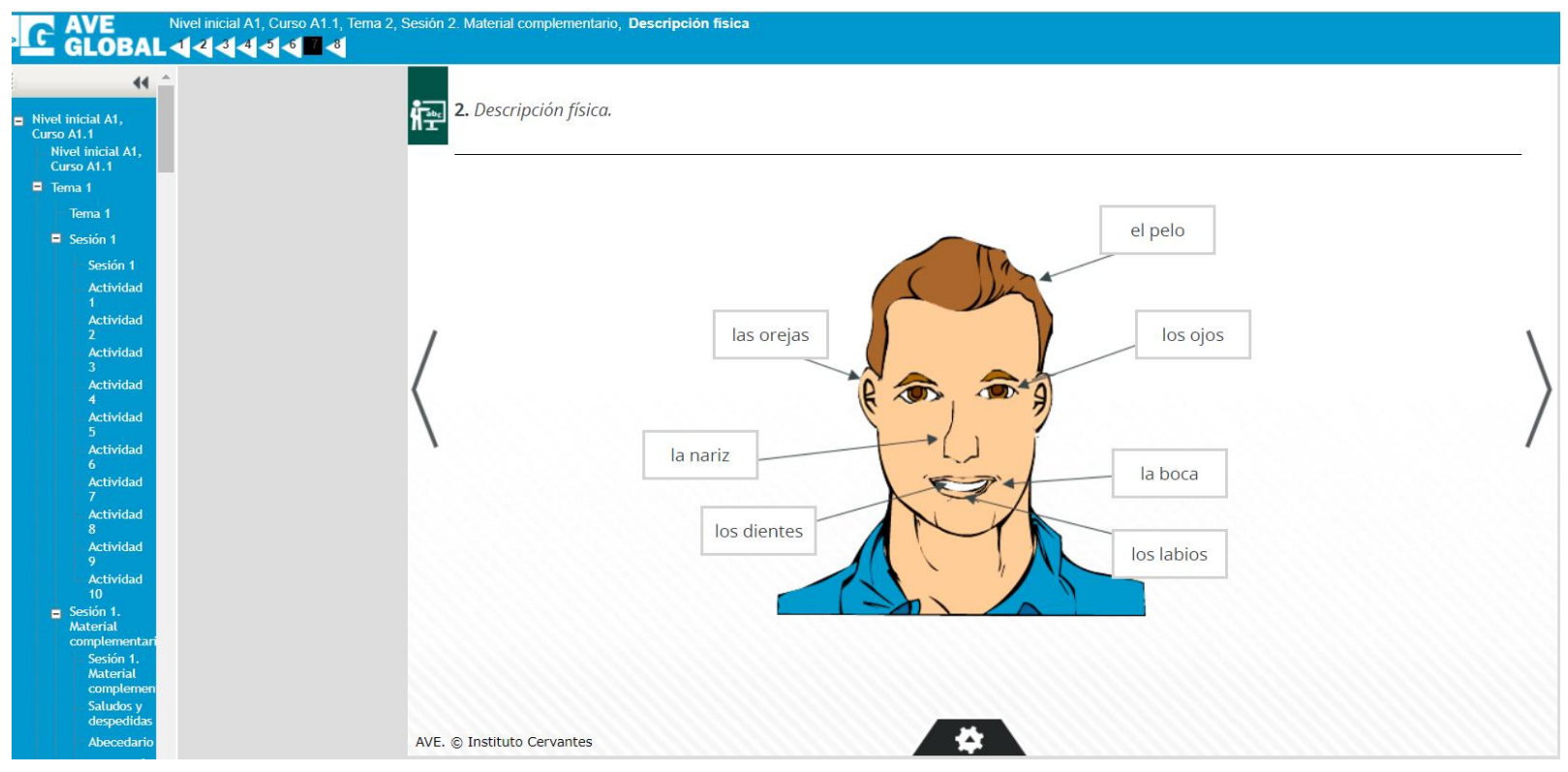

Como elemento positivo, observamos que las actividades que contiene este primer curso del AVE son muy variadas y respetan la taxonomía de Bloom (1956): los aprendices empiezan desarrollando habilidades de nivel inferior (recordar, comprender aplicar) para ir adquiriendo paulatinamente nuevas habilidades y conocimientos con procesamiento de orden superior (analizar, evaluar, crear). Por lo tanto, encontramos principalmente actividades de comprensión auditiva y lectora, de expresión escrita, de repetición, selección e identificación en las que los aprendices tienen que relacionar, ordenar, completar o corregir. Asimismo, mencionamos algunos recursos lúdicos para la adquisición de léxico, como el memory, el dominó, las adivinanzas, las sopas de letras o, como se desprende de esta pantalla, descubrir palabras con letras desordenadas $\left(\mathrm{A} 1.1 \mathrm{~T} 3 \mathrm{~s} 5^{6}\right)$.

${ }^{6}$ Optamos por proporcionar referencias sintéticas que contienen el nivel, el tema, la sesión y la actividad. 


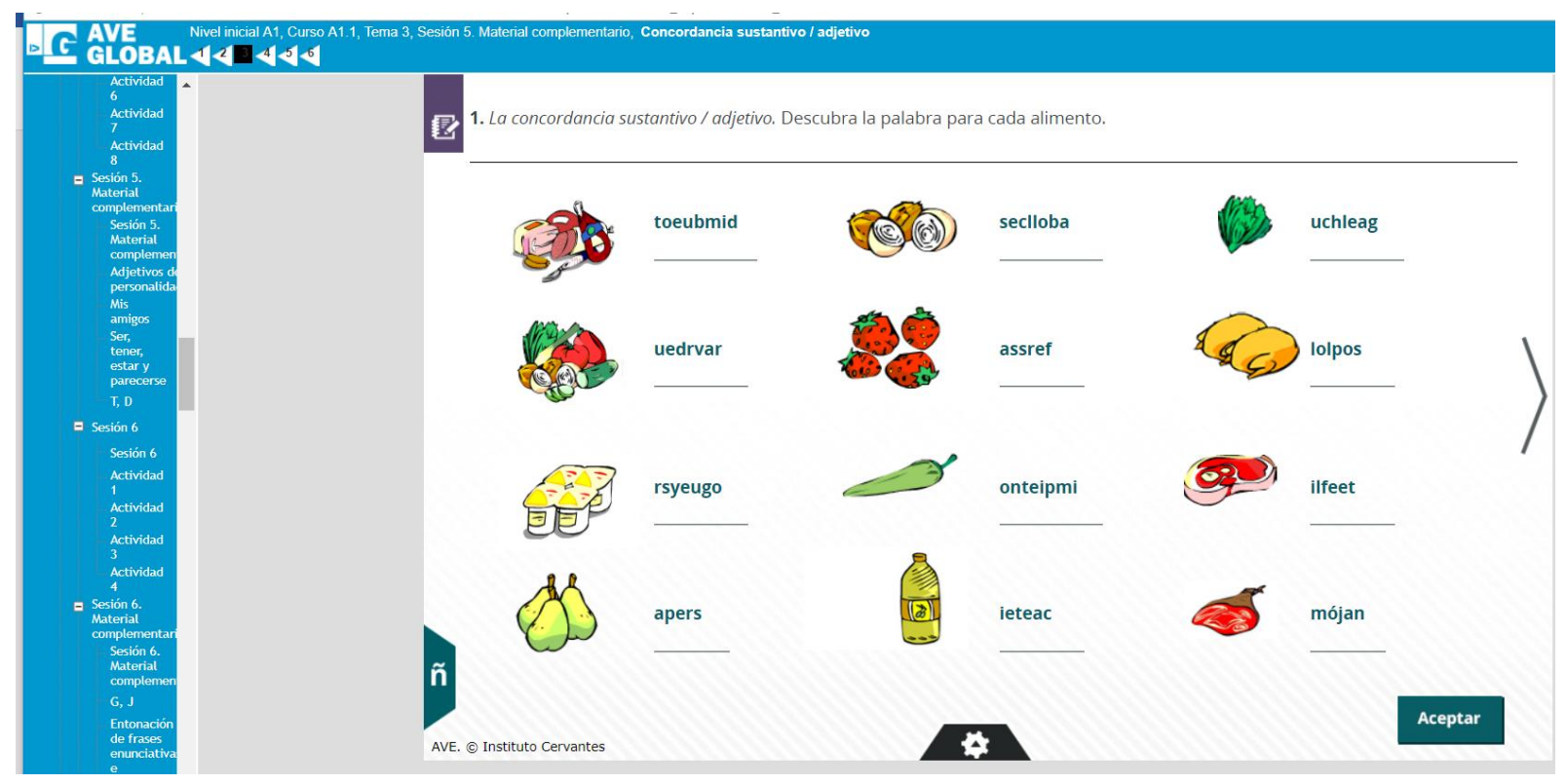

Finalmente, apuntamos algunas estrategias de aprendizaje que sugiere la plataforma, que remite al estudiante a fuentes lexicográficas o le anima a usar su capacidad de deducción con tal de llevar a cabo la tarea planteada. El enunciado de la actividad A1.1T3s3 Material complementario (en un bar) es "Lea los cinco diálogos. No se preocupe si no conoce todas las palabras, use su capacidad de deducción", lo que evoca una de las tres perspectivas que contempla el PCIC, la dimensión del alumno como aprendiente autónomo, capaz de hacerse responsable de su proceso de aprendizaje, de conocer mejor su manera de aprender y de gestionar su progreso.

Siguiendo la línea del curso anterior, el A1.2 pone énfasis en el componente léxico, con una presentación contextualizada y sistematizada. Los campos semánticos presentados giran en torno a las actividades habituales y de ocio, con su lógica extensión: la casa (tipos de vivienda, habitaciones, muebles, electrodomésticos, etc.), la ciudad (lugares públicos, medio de transportes, etc.), el mundo de la cultura (cine, música), los deportes y las fiestas (celebraciones, vida nocturna).

Destacamos el input visual (fotos, símbolos, etc.) como recurso reiterado para introducir componente léxico. Consideramos que es una técnica muy válida debido a que los grafismos y los colores motivan y ayudan a los aprendices, sobre todo si disponen de una desarrollada inteligencia visual, en clara referencia a los tipos de inteligencia múltiples establecidos por Gardner (1983) ${ }^{7}$.

\footnotetext{
7 Howard Gardner y su equipo de la Universidad de Harvard identificaron en 1983 varios tipos de inteligencias, de las que mencionamos algunas más relevantes: la inteligencia lingüístico-verbal, la inteligencia lógico-matemática, la inteligencia visual o espacial, la inteligencia musical, la inteligencia corporal kinestésica, etc.
} 


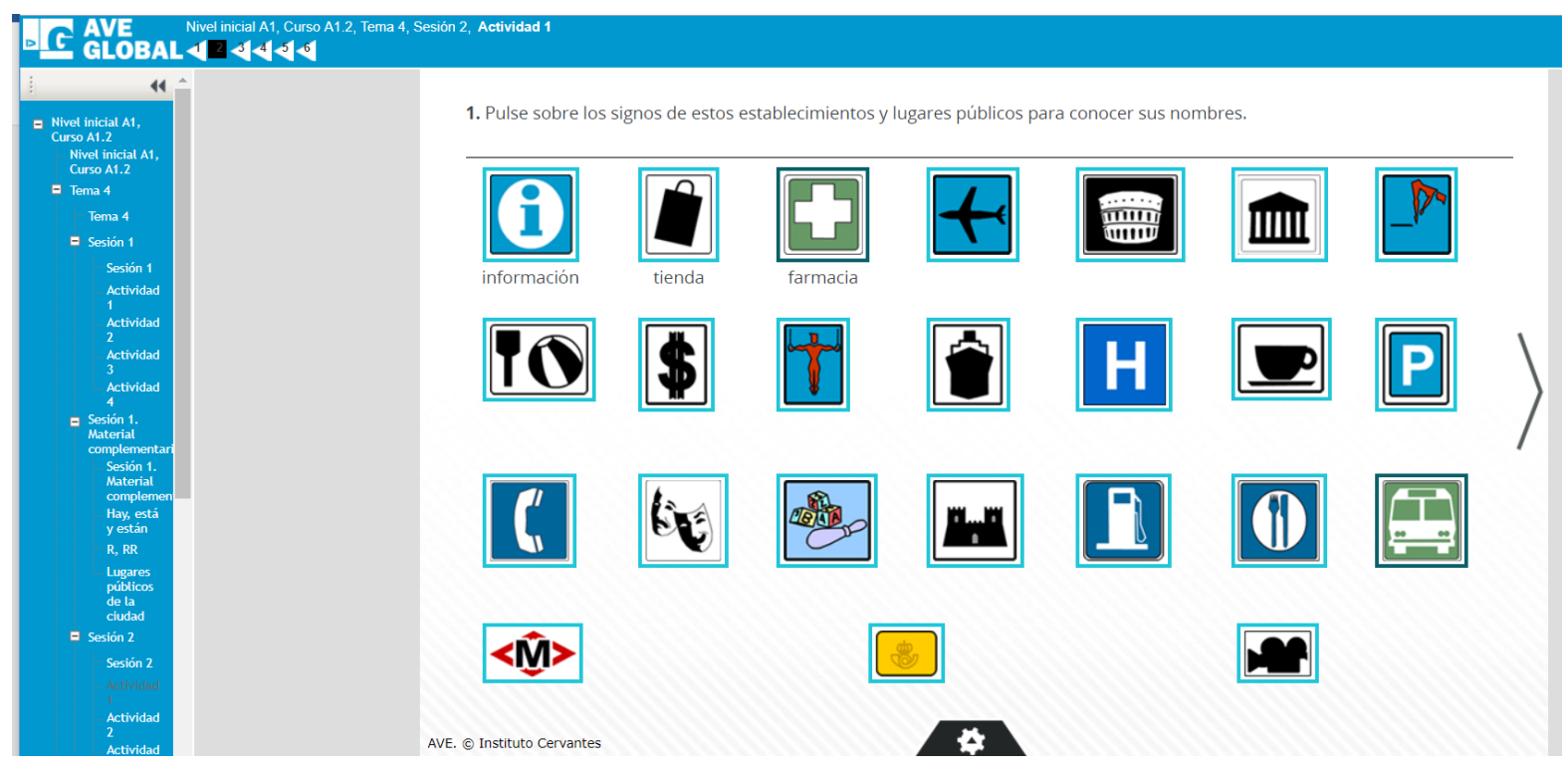

Asimismo, observamos que en los textos provistos de hipervínculos se aprovecha este recurso más sintético en detrimento de la definición explicativa (A1.2T4s7a2).

Analizando el campo visual y comparando con el curso anterior, sorprende la presencia elevada de gráficos y encuestas del Centro de Investigaciones Sociológicas (CIS), pero la consideramos justificada por las numerosas actividades de este tipo que suelen estar presentes en las pruebas de certificación lingüística.

En cuanto al tipo de unidades léxicas que se trabajan, seguimos teniendo un elevado número de unidades léxicas simples y de fórmulas rutinarias, comprensible por los contenidos pragmáticos que se introducen o se refuerzan. Siguiendo el modelo que propone Alvarado Ortega (2008), se trata ante todo de fórmulas que pertenecen a las categorías de la modalidad de enunciación declarativa ("enhorabuena", "feliz cumpleaños") y, sobre todo, de la modalidad del enunciado subjetiva evaluativa ("iqué bonito!", “qué agradable!", “iqué grande!”, “iestá muy bien!”, etc.). Asimismo, encontramos formas lingüísticas llamadas "evidenciales" que expresan modalidad epistémica, es decir, marcan el grado de certeza o conocimiento del hablante respecto a un enunciado anterior ("desde luego", "por supuesto") y numerosas fórmulas rutinarias de enunciación interrogativa (“¿qué le debo?”, “¿cuánto es?”, “¿tiene hora?,” ¿qué van a tomar?”, “¿dónde quedamos?”, “¿de parte de quién?”, etc.).

Asimismo, el número de colocaciones es bastante mayor, pero intuimos que se debe más bien al azar, no a un criterio claro; no aparecen agrupadas o sistematizadas, ni se trabajan actividades especialmente diseñadas para fomentar su adquisición: "calidad de vida", "instalaciones deportivas", "atención médica", "coste de vida", "medio ambiente", "salón comedor", "espacio televisivo", "equipo de música", "chalet adosado", "carril bici", "jornada partida", "energía renovable", "mercado laboral", "protección social", "redes sociales", "ciencia ficción", "Semana Santa", "árbol de Navidad", etc. Coincidimos con 
Kiuchukova-Petrinska (2017) en la importancia de presentar las colocaciones de manera sistematizadas y de fomentar cierta conciencia lingüística respecto a su formación, restricciones combinatorias y uso.

El hecho de que posean fijación, independientemente de cuál sea su estatus, fraseológico o no, indica que se les debe prestar una especial atención en la enseñanza-aprendizaje del español como segunda lengua. El alumno debe ser consciente de esta tendencia de las palabras de aparecer en un número limitado de combinaciones léxicas, debe conocer la restricción combinatoria (impuesta por el uso) de los lexemas de coaparecer con otros lexemas, debe aprender estos «bloques prefabricados» en su conjunto (Kiuchukova Petrinska 2017:13).

Exceptuando la presencia masiva de locuciones prepositivas (justificadas por la presentación de contenidos léxicos como "la casa" o "la ciudad"), señalamos contadas locuciones verbales, como "hacer puente" o "hacer trasbordo".

Observamos que se confía en el alumno cuando en las instrucciones o en los enunciados de las actividades se introducen estructuras perifrásticas, tiempos y modos verbales desconocidos (“¿De qué están hablando estas personas?" "Pulse sobre la opción correcta", "No creo que salgamos de Madrid", "La UE ha crecido en tamaño por sucesivas adhesiones", etc). Sin embargo, lamentamos que se evite su contacto con expresiones que contengan algún grado de idiomaticidad o fijación, por muy transparentes que fuesen.

En cuanto a la tipología de actividades, señalamos que los textos presentados son de mayor extensión y el abanico para la explotación didáctica más amplio. Hay actividades de comprensión lectora y auditiva, de producción escrita y oral (sobre todo en las tareas grupales del apartado "Relaciónate"). El aprendiz tiene que identificar (objetos), completar (con la palabra o letra que falta), seleccionar (cuando dispone de opciones múltiples), formar palabras (a partir de sílabas desordenadas), definir, ordenar y clasificar. Constatamos, por lo tanto, que se le exigen habilidades de orden cognitivo más alto ${ }^{8}$ y que se multiplican las actividades que implican un componente semántico (buscar rasgos comunes y encontrar diferencias, identificar el intruso en una serie de palabras, formar parejas de adjetivos opuestos, clasificar características según su aspecto positivo o negativo). Hay una gran variedad de actividades lúdicas: palabras cruzadas, dominó,

\footnotetext{
${ }^{8}$ Anderson y Krathwohl, discípulos de Bloom, publicaron en 2001 una versión revisada y actualizada de la taxonomía de este. La nueva versión comprende una transición desde las habilidades de pensamiento de orden inferior hacia las habilidades de pensamiento de orden superior, desglosada en dos esquemas: conocimiento - comprensión - aplicación - análisis - síntesis - evaluación y recordar - comprender - aplicar - analizar - evaluar - crear, respectivamente.
} 
memory, adivinanzas, con el fin de favorecer la adquisición léxica y de dinamizar el proceso de enseñanza-aprendizaje.

El input léxico presentado en este curso procede de diferentes fuentes, incluso de lo que llamamos "realia" (todo tipo de objeto que, aunque no fuese diseñado con un propósito didáctico, se lleva al aula y se utiliza con un fin educativo). El aprendiz dispone de anuncios de agencias inmobiliarias, entradas de cine, carátulas de discos, carteles de películas, programaciones de diferentes cadenas de televisión, etc. Además, se remite a páginas web que contienen muestras de habla fuera del ámbito E/LE (metromadrid.es, phe.es, guiadelocio.es). Es una manera sutil y eficaz de introducir contenido cultural español e hispano en el aula virtual (los premios Goya, el festival de cine de San Sebastián y su sección dedicada a los horizontes latinos, la obra de Arturo Ripstein, las composiciones de Manuel de Falla, etc.).

La mayoría de las muestras pertenecen a la lengua estándar, pero también está presente el lenguaje poético, en la canción "Busco un lugar" de Jarabe de Palo o a través del poema "El fantasma del buque de carga" de Pablo Neruda (A1.2T4s2). Huelga decir que nos encontramos ante un texto sumamente complicado a nivel léxico: "Distancia refugiada sobre tubos de espuma, sal en rituales olas y órdenes definidos, y un olor y rumor de buque viejo, de podridas maderas y hierros averiados" y, una vez más, nos planteamos las razones del destierro de las UF, teniendo en cuenta que la fraseología cuenta a su favor con la curiosidad que despierta y la espontaneidad que sus unidades imprimen al discurso. "Si desde el principio utilizamos canciones, películas, artículos, textos literarios y otros materiales no exentos ninguno de ellos de dificultad, ¿por qué no enseñar algunas estructuras fijas e idiomáticas?" (Leal Riol 2011:43).

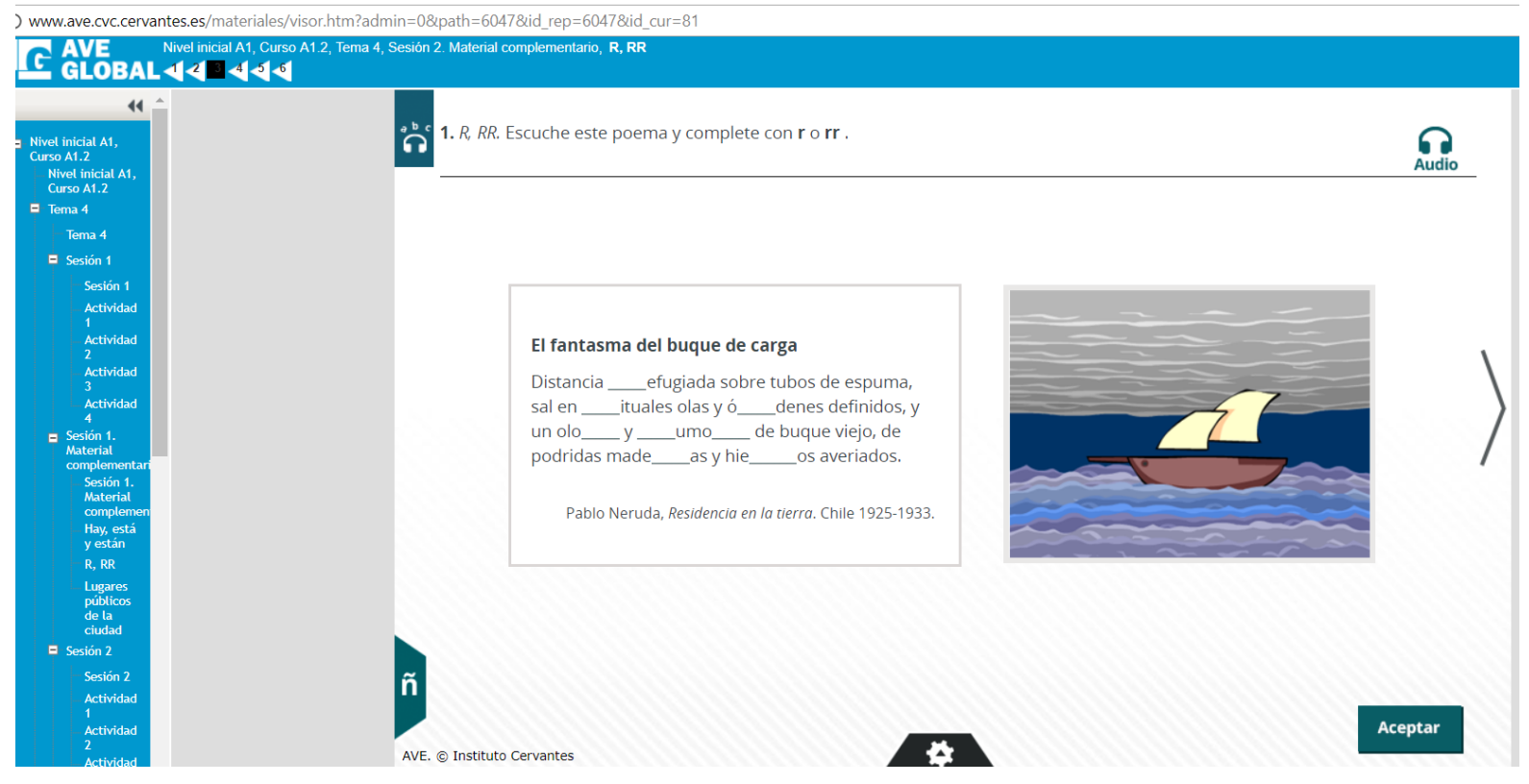

Para concluir con el análisis del curso A1.2, valoramos positivamente los pasos que se dan para fomentar la consciencia léxica. Señalamos varias actividades cuyo 
objetivo es que el aprendiz deduzca significados y reflexione sobre el proceso cognitivo que le ayuda a inferir significados: "usted ha deducido el significado de la palabra alrededor porque...", "el conocimiento del mundo también ayuda a comprender textos en otras lenguas", etc.

Como apunte final en el análisis del nivel $A 1$, señalamos la escasa referencia a expresiones fraseológicas, a pesar del contexto favorable creado, gracias a las actividades significativas que propone el AVE. Las muestras existentes (mayoritariamente fórmulas rutinarias y colocaciones) son más bien arbitrarias y carecen de sistematización. Consideramos que esta ausencia se debe a las dificultades que plantean los rasgos internos de las UF, pero también al hecho de que los autores de los materiales asocian la fraseología con un uso coloquial y popular, obviando la fuerza comunicativa del mensaje y la motivación intrínseca de los alumnos. 


\subsection{AVE GLOBAL - nivel A2}

De los tres temas que conforman el curso A2.1, dos de ellos ("Nuestra experiencia. Hablar de nuestro pasado personal y profesional" y "Nuestras biografías. Relatar y describir el pasado") se centran fundamentalmente en presentar, explicar y practicar contenido gramatical, con especial hincapié en el pretérito indefinido, el pretérito perfecto y el pretérito imperfecto (morfología, usos y contrastes de pasados). Todos los soportes gráficos, los esquemas y los cuadros están al servicio de la comprensión de las reglas y del uso correcto de los nuevos tiempos impartidos.

El léxico, por lo tanto, se ve relegado a un mero vehículo dentro de un enfoque menos comunicativo y más tradicional, dominado por el focus on form. Lo encontramos estructurado en dos grandes apartados: por un lado, los marcadores temporales ("esta semana", "este mes", "este año", "últimamente", "hace un rato", "en 1980", "ayer", "hace mucho tiempo", "todos los veranos", etc.) y, por otro lado, los conectores discursivos ("al principio", "de repente", "hasta que", "y así", "por fin"). El AVE opta por presentar estos exponentes bajo el título evasivo de "elementos" y prescinde de cualquier referencia metalingüística, decisión que consideramos acertada,

ya que no hay un consenso terminológico ni de definición y es posible encontrar términos como marcadores conversacionales, operadores discursivos, marcadores de estructuración de la conversación, apoyos del discurso, enlaces extraoracionales, enlaces supraoracionales, conectores pragmáticos" (Mazzaro y Goettenauer de Marins 2008:487).

Abundan las actividades de corte estructural: rellenar con la forma adecuada, relaciona las formas de estos dos tiempos verbales, escribir el infinitivo, completar el paradigma verbal, etc. Incluso los soportes gráficos y las actividades más lúdicas tienen como principal propósito la explicación de las reglas y la práctica controlada de formas descontextualizadas.

Lo que consigue dar cierto dinamismo a estas unidades es la cantidad apreciable de vídeos y de audios, las referencias al mundo actual y la integración, como viene siendo habitual en la plataforma, de mucho contenido cultural. Asimismo, el tema de las biografías proporciona numerosos ejercicios de comprensión lectora, auditiva o expresión escrita sobre personalidades del mundo del cine, de la música o de las letras hispanas: Isaac Albéniz, Vicente Aleixandre, Gabriel García Márquez, Horacio Quiroga, Jorge Luis Borges. Entendemos el afán por integrar contenido cultural, puesto que el PCIC refleja la dimensión del alumno como hablante intercultural (que supone la adquisición de saberes y comportamientos socioculturales, habilidades y actitudes interculturales y, sobre todo, tal como se desprende de esta batería de actividades, referentes culturales). No obstante, nos llama la atención la explotación didáctica que se da a estos materiales. En este 
sentido, un claro ejemplo es el poema "Límites" de Borges que, desde nuestra experiencia docente, consideramos extremadamente complicado para el nivel A2. A nivel léxico los exponentes superan el nivel Plataforma ("la muerte me desgasta, incesante", "hay una calle [...] vedada"), a nivel gramatical el tiempo verbal que predomina es el futuro imperfecto, no impartido todavía, y, desde una perspectiva didáctica, las tareas planteadas son más propias de una clase de escritura creativa: reconstruye el poema, encuentra el verso intruso, qué sentimientos desprende el poema, etc.

Asimismo, consideramos que hay muchas más unidades léxicas que sobrepasan el nivel, integradas dentro del tema del entorno laboral, en particular del mundo empresarial ("departamento de impacto medioambiental", "gestión empresarial", "cubrir el puesto cuya referencia es", "equilibrio ideológico", etc.). Aún más, encontramos exponentes que no pertenecen al vocabulario activo en temas relacionados con los cuentos de hadas, los relatos y las fábulas ("el maleficio de una bruja").

El peso de las colocaciones recopiladas ("niño prodigio", "hábitat natural", "base de datos", "arco iris", "dentadura postiza", etc.) es mayor que el nivel A1, aunque su falta de sistematización no facilita su adquisición consciente. Asumimos, al igual que Penadés (2004), que

Cuando se trata de abordar la cuestión de la enseñanza de las colocaciones en E/LE las dificultades se acrecientan sobremanera en relación con las otras clases de unidades fraseológicas, entre otras razones porque la investigación teórica sobre ellas es mucho más reciente en el ámbito de la lingüística hispánica, porque carecemos de diccionarios de colocaciones del español y porque no son muchas las reflexiones hechas desde la perspectiva aplicada de su enseñanza. Por lo que se refiere a las actividades enfocadas a su didáctica, se ha señalado la oportunidad de proponer ejercicios sobre adquisición de vocabulario de la lengua meta, con la finalidad de potenciar la información colocacional y sintáctica de una palabra. Lo cual trae aparejada la necesidad de que el alumno conozca el ámbito colocacional de las palabras y se interese por su entorno habitual, así como la necesidad de evitar la transferencia de patrones colocacionales de su lengua materna a la española (Penadés 2004:59).

El alumno que se enfrenta a locuciones verbales como las que recompilamos en el curso A2.1 ("tocar la lotería", "montar un negocio", "ser un flechazo", "irse la luz", "estar de gira") y no cuenta con apoyo por parte del docente - que debe guiar su proceso y proporcionarle contextos de uso - podría sentirse desamparado y frustrado. Resulta fundamental que el profesor busque los mecanismos necesarios para integrar de manera eficaz el componente idiomático en la clase de E/LE. No vale con una mera inserción temprana de UF, sino tiene que presentar "muestras de lenguaje idiomático de manera sistematizada para favorecer el aprendizaje relacional, ya sea desde un punto de visto 
temático o nocional. Por ejemplo, a partir de la presencia de elementos que pertenecen a una misma categoría temática" (Muñoz-Basols 2015:451).

Desde el punto de vista del léxico, el curso A2.2 proporciona una cantidad elevada de unidades: lexemas, colocaciones, locuciones y fórmulas rutinarias que se integran en temas generales como los viajes, las opiniones y los sentimientos. En las actividades propuestas, el alumno afianza principalmente sus facetas de agente social y de hablante intercultural, tal como lo refleja el PCIC.

Las fórmulas rutinarias son extremadamente útiles en estas fases del proceso de aprendizaje para que el alumno pueda asentar las bases de la comunicación y el AVE parece consciente de esta importancia. A diferencia del nivel A1, notamos la presencia de las fórmulas rutinarias afectivas que, dentro de las fórmulas rutinarias subjetivas, son "aquellas que expresan una reacción emocional como el temor, la ira, el deseo, etc., esto es, codifican la modalidad subjetiva, puesto que manifiestan la actitud del hablante frente al dictum, pero no evalúan dicho enunciado" (Alvarado Ortega 2008:280). En este sentido, hemos recopilado fórmulas que expresan alegría ("iqué suerte!", “iqué ilusión!"), fórmulas que expresan solidaridad ("iqué pena", "lo siento"), fórmulas que expresan sorpresa ("ianda", "ino me digas"!", "no me lo puedo creer”), fórmulas que expresan enfado ("iqué lío!"), fórmulas que expresan aburrimiento ("iqué rollo"), etc. Como elemento positivo, destacamos las actividades diseñadas precisamente para reforzar estas "expresiones" (siguiendo la denominación operada por el AVE) y la integración de elemento prosódico, muy útil para aclarar la función pragmática de estas fórmulas: "entonación significativa: escucha y arrastre para relacionar la expresión con el dibujo que le corresponda", "escuche cómo reaccionan estas personas en los diálogos y relaciónelos con cada intención en cada caso: expresar extrañeza / incredulidad o expresar sorpresa / alegría".

El tema 4 (Viajes. Turismo y planes de vacaciones) extiende el campo semántico a ámbitos afines como clima y fenómenos atmosféricos, tipos de alojamiento, actividades de ocio, distintos tipos de turismo, categorías de instalaciones turísticas, calidad de servicios, todos ellos muy productivos a la hora de generar colocaciones y locuciones y de las que hemos recopilado un número significativo: colocaciones ("todo-terreno", "tienda de campaña", "tabla de surf", "ola de calor", "hilo musical", "crema protectora", "temporada alta/baja", "media pensión", "albergue juvenil", "efecto invernadero", etc.); locuciones preposicionales y adverbiales ("con respecto a", "en cuanto a", "en cambio"), locuciones verbales ("hacer senderismo", "tomar el sol", "ponerse una vacuna", "hacer bricolaje", "montar a caballo", etc.) Sin embargo, seguimos sin contar con un trabajo riguroso para estas unidades léxicas. Las únicas que se benefician de actividades de refuerzo son las unidades simples consideradas de mayor dificultad ("empapado", "sellar", "refrescar", etc.) que vienen acompañadas de explicaciones adyacentes o disponen de hipervínculos. 


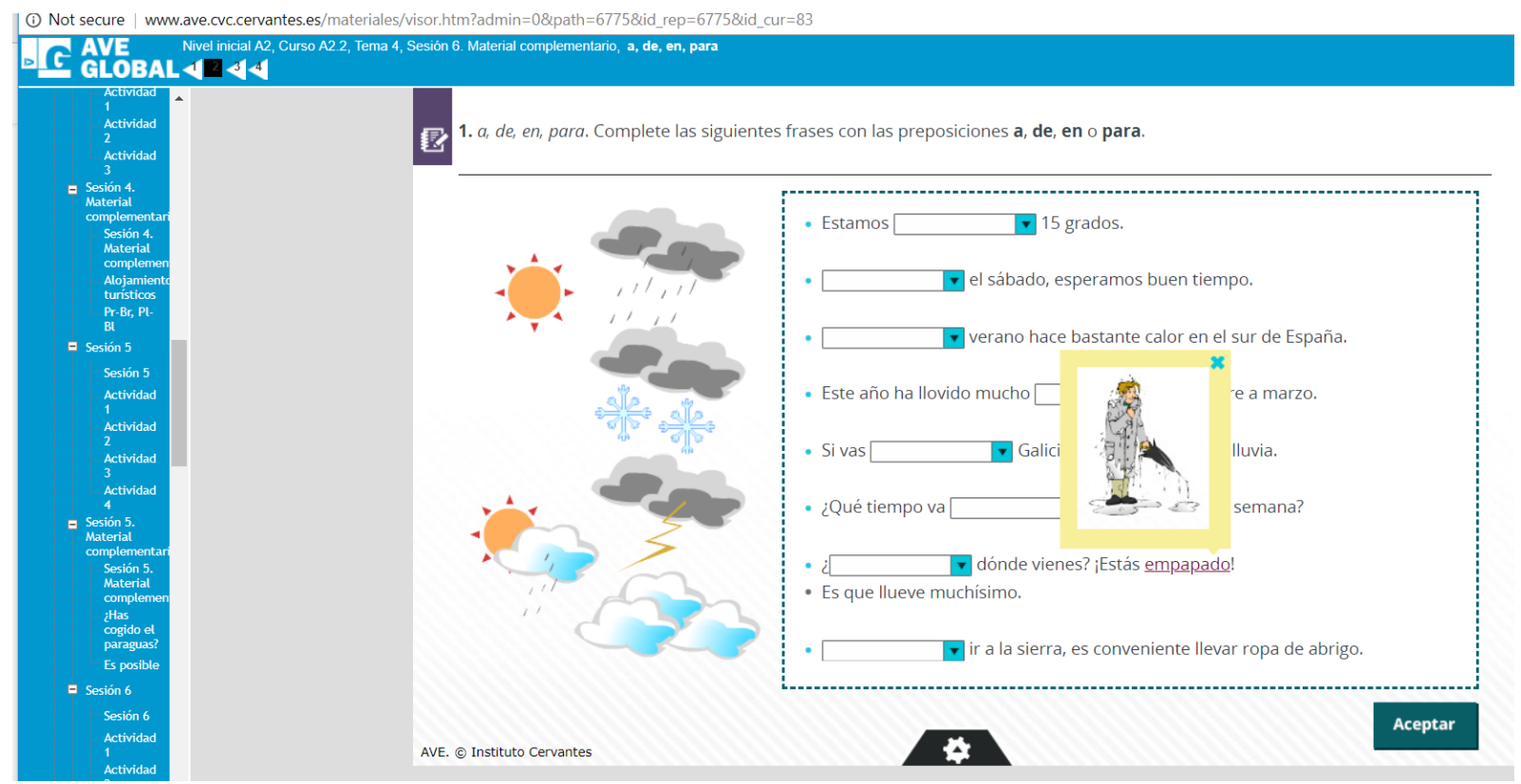

Asimismo, destacamos las actividades diseñadas para la adquisición de las expresiones temporales que acompañan a las estructuras perifrásticas de futuro, obligación y necesidad: "(pasado) mañana", "la próxima semana", "el mes que viene", "dentro de 15 días", "en el mes de junio", etc., como también la variedad de ejercicios propuestos ("arrastre las sílabas para formar palabras", "busque palabras que corresponda a las definiciones", "complete las frases y con la palabra que falta", "observe el esquema y escriba..." o "encuentre la palabra oculta en las frases misteriosas"). Asimismo, señalamos el empeño en dotar a los alumnos de estrategias de aprendizaje, fomentándoles la autonomía: "use el diccionario si lo necesita".

Como crítica, nos parecen menos acertadas las entradas léxicas presentadas dentro del tema "Las opiniones. Expresar el punto de vista" que consideramos demasiado complicadas para el nivel A2: "derrochar", "malgastar", "resaltar", "desecho", "cánones de belleza", "vertido de residuos", "inmigración [...] enriquecedora", etc. A pesar de que algunas palabras o expresiones disponen de explicación o de soporte visual ("sin ánimo de lucro", "viveros", etc.), se trata de exponentes muy difíciles, sobre todo para aprendientes cuyas lenguas están muy alejadas del español y en las que estos términos son muy opacos.

Por desgracia, al tratarse de un material común para aprendientes de todos los rincones del mundo, se descarta automáticamente cualquier referencia a la lengua materna del alumno y, por ende, utilizar un enfoque contrastivo que contribuya a consolidar el aprendizaje del léxico (en general) y del lenguaje idiomático (en particular), así como la comparación de distintas metáforas que expresan un mismo significado. Precisamente, es esta carencia la que queremos cubrir, aplicando el enfoque contrastivo e implementando los resultados obtenidos a raíz del análisis llevado a cabo. El diseño de 
unas actividades pensadas especialmente para alumnos rumanos de español constituiría nuestra aportación más original.

Frente a cursos anteriores, remarcamos un paso adelante hacia el afianzamiento de una conciencia léxica, con la presencia de actividades como la del tema 5, sesión 3 ("Sustantivos derivados de verbos. Seleccione los elementos que se pueden relacionar con los siguientes verbos"), el primer acercamiento a una adquisición de vocabulario basada en criterios combinatorios.

Señalamos también el aprovechamiento de los recursos tecnológicos de la plataforma (haciendo especial hincapié en la calidad de los vídeos). La actividad A2.2T5s7a1 propone una descripción de un cuadro de Sorolla y, de manera muy sutil, el aprendiente adopta el papel del niño presente en la pinacoteca que va descubriendo no solo contenido cultural, sino también léxico (sobre el que pide explicaciones y aclaraciones: “¿Qué significa cromatismo / luminismo / impresionismo?”. Nos encontramos más bien ante un caso de adquisición de vocabulario, puesto que se representa una situación de la vida real. El alumno recibe también constante apoyo para que desarrolle estrategias ("Reflexione sobre cómo lo haría en su propia lengua") y las ya habituales fotos y definiciones.

Por desgracia, el componente visual no se utiliza en la misma medida para maximizar el aprendizaje del lenguaje idiomático. Se desaprovecha de este modo un recurso valioso que serviría para establecer asociaciones lógicas mediante el reconocimiento del carácter metafórico del lenguaje con imágenes o situaciones comunicativas concretas, que llevarían a la automatización de las UF adquiridas.

En estos subapartados hemos analizado las principales características de los materiales que integran el nivel A (usuario básico), convencidos de la importancia de abordar el lenguaje idiomático desde etapas iniciales de aprendizaje, idea compartida por muchos teóricos, pero con escaso reflejo en los materiales analizados. Muñoz-Basols (2015) considera necesario

incidir en la cotidianidad de su uso como parte de idioma y en su valor léxico y nocional, mostrando ejemplos a partir de situaciones comunicativas concretas que, por ejemplo, pueden derivar de exponentes de funciones comunicativas básicas (fórmulas rutinarias y locuciones), hasta otras secuencias más complejas (expresiones idiomáticas, refranes y proverbios, etc.) (Muñoz-Basols 2015:451).

Como era de esperar, las fórmulas rutinarias encuentran su hueco en las actividades planteadas por el AVE, debido a su presencia inevitable en intercambios comunicativos básicos. No obstante, brillan por su ausencia las secuencias de mayor dificultad mencionadas anteriormente. Al tratar de aportar pautas para acercar al 
estudiante de cualquier nivel al componente idiomático, Muñoz-Basols (2015) identifica algunas de las dificultades a las que se enfrentan un aprendiente de LE y que pueden constituir las causas principales por las que el AVE prescinde de UF más complejas: desconocimiento de los parámetros lingüísticos ( $\mathrm{y}$, por lo tanto, de la configuración morfosintáctica de la UF); la incapacidad de interpretar el valor figurado o metafórico de la UF y, por extensión, de sus valores semánticos y pragmáticos reales; desconocimientos de los parámetros culturales; dificultad a la hora de calibrar las tres variables principales que puede poseer una UF: frecuencia de uso, noción de registro y variación diatópica. Estos factores suponen un mayor esfuerzo cognoscitivo por parte de los aprendices para almacenar este tipo de expresiones en la memoria a corto y a largo plazo.

No obstante, auguramos que una vez superados muchos de estos escollos, la presencia de las UF será mucho mayor en los niveles más altos de la plataforma que analizamos. 


\title{
4.4. AVE GLOBAL - nivel B1
}

Siguiendo el planteamiento del "cono invertido"9, el AVE aumenta el número de módulos (e implícitamente el de horas de trabajo individual o grupal), de manera que el nivel B1 cuenta con cuatro cursos, que van desde el B1.1 hasta el B1.4.

El primero de ellos sigue abordando el léxico de manera integrada con la gramática, pero sobre todo con los contenidos funcionales, puesto que uno de los objetivos del AVE es que el alumno lleve a cabo con éxito tareas de comunicación. Encontramos un input abundante, variado, pero sobre todo estructurado. En el tema 1 ("Encuentros. Presentarnos y conversar sobre nosotros mismos") aparece vocabulario del mundo de los negocios, vocabulario relacionado con el aprendizaje de idiomas, vocabulario relacionado con el mundo del cine, la música y las actividades de tiempo libre, vocabulario relacionado con los ordenadores, etc. Hay, por lo tanto, un abanico amplio de contextualizaciones: ámbito personal, social, laboral, con mayor hincapié en las diferencias entre los registros formal e informal.

Se aporta un número elevado de unidades nuevas, pero las únicas que se trabajan de manera explícita son las fórmulas rutinarias discursivas de apertura de la conversación (“icuánto tiempo sin verte!”, “iqué alegría verte!”, “iqué ilusión verte!”, etc.). Una mención aparte merece la fórmula "¿qué hay?", que presenta fijación formal e idiomaticidad, a diferencia de su homófono libre con significado literal, que se encuentra fuera de la fraseología (y que los aprendices conocen y reconocen desde el nivel acceso). Según Alvarado Ortega (2008),

\begin{abstract}
El valor generalizado de saludo que presenta esta fórmula viene determinado por el cumplimiento del Principio I y M de Levinson10 ([2000] 2004) mediante los cuales el hablante reproduce en el discurso la información mínima necesaria para llevar a cabo el acto de comunicación y, además, le saluda de manera no prototípica. Por tanto, el oyente debe enriquecer esa enunciación con la interpretación más adecuada. De este modo, cuando el hablante enuncia ¿qué hay? el oyente debe interferir que le está saludando y mostrando cortesía (Alvarado Ortega 2008:387)
\end{abstract}

Las numerosas colocaciones y, sobre todo, locuciones que hemos encontrado no cuentan con actividades específicas de sistematización, el punto débil que subrayamos desde el inicio de nuestro análisis. Consideramos una omisión sorprendente, puesto que no se trata de locuciones aisladas, fruto del azar, sino de locuciones agrupadas y

\footnotetext{
${ }^{9}$ Ningún nivel superior a otro puede tener asignadas menos horas de clase.

${ }^{10}$ Levinson (2000) identifica un Principio de Informalidad (el hablante reproduce en el discurso la información mínima para llevar a cabo el acto de comunicación y el oyente enriquece esa enunciación con su interpretación adecuada) un Principio de Manera (indica una situación no estereotipada mediante el uso de fórmulas lingüísticas marcadas que constrastan con las que el hablante usaría normalmente).
} 
coherentes con el tema estudiado (el mundo empresarial): "poner en marcha", "alcanzar el éxito", "montar una empresa", etc. Gómez y Ureña (2017) se lamentan del trato no siempre satisfactorio que reciben estas unidades en la enseñanza de E/LE y señalan acertadamente que se trabajan de manera dispersa y aleatoria.

\begin{abstract}
Es sabido que, muchas veces, las unidades fraseológicas, en concreto las locuciones, quedan al margen de las lecciones y únicamente se abordan como elementos anecdóticos. En efecto, no resulta infrecuente encontrarlas dispersas en el manual sin una organización metodológica o al final de una unidad por cuestiones de afinidad temática. También se incluyen a menudo como un dato anecdótico a propósito de un texto o una actividad, o como parte de alguna lección dedicada al español coloquial -si bien no todas las locuciones pertenecen al registro coloquial, pues las hay formales, vulgares y neutras-. En cualquier caso, en ninguna de las circunstancias indicadas, la enseñanza de estas unidades parece quedar integrada en los contenidos del curso ni trabajarse según un planteamiento fundamentado (Gómez y Ureña 2017:315).
\end{abstract}

En cambio, para las unidades léxicas simples se genera un número muy elevado de actividades variadas: "fijese en las palabras señaladas", "pulse sobre los elementos de cada columna para relacionar los contrarios", "ordene los elementos de estas frases", "escuche y marque con el pincel los adjetivos que corresponden a las ocho características", "escriba las palabras que faltan para completar las frases", "arrastre las siguientes frases", etc. Además, el vocabulario nuevo considerado de mayor dificultad para los aprendientes viene acompañado de explicaciones suplementarias, que pueden ser definiciones o dibujos. Sin embargo, la selección de ítems no nos parece siempre acertada: "amable", "duda", "horario" u "obligaciones" se consideran lexemas complicados (y se enseñan a través de hipervínculos), mientras que bloques de mayor extensión y complejidad no se benefician de soporte alguno: "estalla la lucha cruzada...", "facciones religiosas", "biblioteca que atesora [...] sabiduría", etc.

Como elementos positivos, destacamos la preocupación cada vez mayor por la ortografía: pronombres relativos vs pronombres interrogativos (B1.1T1s3), "esta" y "está" (B1.1T1s4) y, lo que representa mayor interés para nosotros, por los marcadores discursivos ("o sea", "es decir", "por ejemplo"), explicados, contextualizados, reforzados. Nogueira de Silva (2011) destaca la utilidad de enseñar y aprender marcadores discursivos porque representan un material auténtico que no sufre adaptaciones operadas por los autores de los manuales de E/LE y recomienda su inserción en actividades que abarquen diversos géneros textuales, entre los que destaca los vehiculados por los medios de comunicación. 
En definitiva, los marcadores del discurso son piezas indispensables para conducir al lector a las inferencias que interesan, puesto que cumplen un papel muy importante en la relación de los enunciados y de las secuencias textuales entre sí. En otras palabras, los MD, indiscutiblemente, se encuentran entre las habilidades y estrategias diversas de las que el interlocutor se vale para relacionar de un modo u otro los diversos enunciados y secuencias textuales. Así, como ejemplo, podemos citar los marcadores que señalan instrucciones pragmáticas de tipo argumentativo (conectores y operadores), cuya aparición y mayor frecuencia son más bien propias del contexto de la argumentación como tipo de secuencia textual (Nogueira da Silva 2011:68).

En el tema que trata la informática y "las palabras relacionadas con ordenadores", nos encontramos por primera vez con préstamos léxicos del inglés, términos que se han afianzado en castellano y que forman parte ya del español activo: "blog", "chat", "podcast", "escáner", etc., mientras que el tema 2 introduce léxico relacionado con la emigración y la inmigración. Empezamos a identificar algunos patrones de explotación didáctica del nuevo vocabulario: relacionar columnas en las que aparecen palabras nuevas (activadas a través del clic o resaltadas), ordenar los elementos de la oración, completar con las palabras adecuadas, recomponer textos, contestar preguntas para comprobar la comprensión lectora, etc. Asimismo, observamos un logrado equilibrio entre campos léxicos presentados en cursos anteriores (que se retoman y amplían ${ }^{11}$ para acompañar contenido gramatical o funcional nuevo) y vocabulario que se introduce por primera vez. En este sentido, mencionamos el tema de los festivales del cine en España, tratado previamente en el módulo A1.2T6s3a4, pero recuperado en el B1.1 con distinto propósito: el uso de algunos marcadores temporales.

En cuanto a las unidades fraseológicas, volvemos a destacar la presencia constante de fórmulas rutinarias afectivas ("janda!", "ino me digas!", “ide verdad?", "vaya", etc.) acompañadas de aclaraciones de orden prosódico. Sin embargo, seguimos sin contar con actividades de presentación para las colocaciones o locuciones, a pesar de que estas ya empiezan a constituir una presencia constante en las muestras de habla del AVE: "prensa rosa", "prensa del corazón", "rueda de prensa", "hacer puente", "tocar la primitiva", "gastar bromas", etc.

El léxico presentado está agrupado temática y conceptualmente: "fantasma", "cementerio", "murciélago", "vampiro", "zombi" (B1.1T3s6a1); "testigo", "secuestrador", "desaparecido", "narcotraficante" (B1.1T3s4a2); "cabo", "bahía", "sierra", "cordillera"

\footnotetext{
${ }^{11}$ Krashen (1983) propone la hipótesis del input comprensible y elabora la fórmula "I+1" para referirse al input comprensible ("I") que contiene elementos lingüísticos ligeramente superiores al nivel actual del aprendiz; es lo que le permite avanzar en su proceso de aprendizaje de la LE gracias a la información proporcionada por el contexto, los factores extralingüísticos o su conocimiento sobre el mundo.
} 
(B1.1T3s21) y, como elemento positivo, destacamos la preocupación por crear un orden y una lógica en el proceso de adquisición del léxico, estructurando la nueva información, ofreciendo oportunidades y contextos para el alumno active conocimientos previos.

En la actividad B1.1T3s1, dedicada al mundo de la medicina y los descubrimientos médicos, encontramos un número muy elevado de colocaciones ("fecundación in vitro", "inseminación artificial", etc.), si bien falta sistematización y, como viene siendo habitual, no contamos con actividades de refuerzo. Es sorprendente el tratamiento privilegiado que se les da a otros exponentes, mientras que las colocaciones se ven relegadas al pintoresquismo. Coincidimos con Molero y Salazar (2012), ya que

\begin{abstract}
consideramos de suma importancia la enseñanza de las colocaciones en el aula de ELE, puesto que son elementos indispensables del discurso natural, y los estudiantes no nativos deben aprenderlas para evitar los errores causados por la transferencia de los patrones colocacionales de su lengua materna al español. Asimismo, el conocimiento de colocaciones ayuda al alumno a predecir las palabras que puede encontrar con otras, facilitándole la comprensión de textos orales y escritos. (Molero y Salazar 2012:80).
\end{abstract}

El AVE sigue las pautas del PCIC, pero consideramos que en muchas ocasiones el componente léxico presentado supera el nivel de dificultad de los inventarios existentes en el Plan. Aportamos como ejemplos las referencias a los deportes extremos, que contienen exponentes muy complejos, de difícil comprensión incluso para hablantes nativos, poco familiarizados con el fenómeno: "barranquismo", "espeleología", "puénting", "neopreno", etc. Asimismo, se proponen actividades que incluyen elementos culturales afines, como la presentación de la pelota vasca, que conlleva ítems como "pelotari", "frontón", "cesta", "pala". En el caso del léxico relacionado con el mundo de la medicina y de los remedios, esta complejidad se hace aún más patente. Hemos recopilado actividades de compresión auditiva y lectora que contienen unidades léxicas como "enfermedades gastrointestinales", "shiatsu", "aguja metálica", "sistema nervioso", "iridólogo", etc. Nos cuesta entender la utilidad de lexemas como "eleuterococo" y consideramos que la presentación demasiado temprana, aunque contextualizada, no es apropiada. Delimitar qué léxico enseñar, cómo y cuándo es quizás uno de los mayores retos del profesorado.

Coincidimos plenamente con Higueras (1997) en que la enseñanza del léxico a alumnos extranjeros no debe descansar solo en los lexemas simples porque

limitarse únicamente a enseñar palabras sería comparable a restringir la enseñanza de la gramática a categorías como el nombre, el adjetivo o el verbo sin tener en cuenta unidades mayores como la oración o el texto o, 
por ejemplo, concluir que la arquitectura es el estudio de los ladrillos con los que se hace una casa (Higueras 1997:36).

Además, como señala Lewis (1993), en la memoria no se almacenan palabras aisladas, sino unidades de significado más amplias, las así llamadas pedagogical chunking, que el aprendiz podrá recuperar y utilizar más fácilmente en otras situaciones comunicativas.

Consideramos que este es el punto débil del AVE, el no explotar las UF, a pesar de crear un contexto favorable para ello. Sin ir más lejos, en un apartado dedicado al cuerpo humano, los somatismos brillan por su ausencia, lo que representa, en nuestra opinión, una oportunidad desaprovechada de haber introducido exponentes mucho más motivadores que los recogidos en las actividades presentadas anteriormente.

En la misma línea se inscriben las numerosas referencias culturales gastronómicas (platos mexicanos, colombianos, salvadoreños), ya que suponemos que los elementos léxicos presentados no permanecerán en la memoria del aprendiz durante mucho tiempo, debido a la falta de un referente inmediato en la vida real: "papas chorreadas", "camarones en apuros", "mole poblano", "enchiladas", etc. Comprendemos y saludamos el afán por variar el input y por aportar contenido cultural enriquecedor. No obstante, las numerosas actividades dedicadas a la artesanía en general y a la alfarería oaxaqueña en particular nos parecen también poco rentables. Unidades léxicas como "alejibre" o "alajero", desconocidas incluso por algunos hablantes nativos, solo quedarán en la memoria a corto plazo y habrá escasas posibilidades de recuperarlas y utilizarlas posteriormente, fuera del aula, a diferencia de las UF, más rentables y motivadoras.

En cuanto a la presencia de la literatura en el AVE, como ya hemos apuntado en el nivel anterior, nos llama la atención la inserción de textos literarios de gran dificultad. En este nivel hemos recogido como muestra el poema "Palabras para Julia" de Juan Goytisolo (B1.1T3s7 - "Complete las palabras con los verbos en futuro para leer el poema"), "Las abarcas desiertas" de Miguel Hernández (B1.1T3s7 - "Escuche el siguiente poema y a continuación léalo en voz alta") y una reseña sobre la lírica de Leopoldo María Panero (B1.1T3s9 - "Lea la siguiente reseña literaria. Fíjese en las palabras que le señalamos. Después, sin recurrir al diccionario, arrastre las palabras para relacionarlas con las del texto de manera que le ayuden a entender su significación"). Asimismo, señalamos una comprensión auditiva cuyo objetivo consiste en detectar las palabras que contienen la "ñ" en un fragmento extraído de la obra "La vida es sueño" de Calderón de la Barca. Somos conscientes de que la dificultad reside en la tarea, no en el texto, pero nuestra experiencia docente nos hace anticipar la frustración de un estudiante de nivel B1 enfrentado a unidades léxicas como "medrar", "afanar", "agraviar", etc.

Reiteramos nuestra opinión sobre los beneficios de la literatura en el aula: es indudable que la literatura ofrece grandes posibilidades didácticas y contribuye al desarrollo intercultural del alumno, pero consideramos que es contraproducente no 
adaptar el grado de dificultad al nivel ni diseñar actividades motivadoras para todos los estudiantes, no solo para aquellos aficionados a la lectura. En otras palabras, si bien el texto literario tiene cabida desde los niveles iniciales del estudio de una LE, resulta imprescindible operar con "criterios de lecturabilidad o grado de facilidad de lectura (léxico, longitud de frases, densidad semántica, etc.), (...) para que los textos sean adecuados para diferentes niveles de dominio" (Sáez 2011:61). Nos preguntamos si en el AVE encontramos literatura para aprender lengua o literatura para aprender literatura. Según Sáez (2011:59), "en el campo de E/LE lo deseable sería tratar de imbricar la lengua y la literatura, defender la conexión lengua - literatura como función formativa y aprendizaje lingüístico-comunicativo. En suma, verlo como algo complementario: aprender lengua y aprender literatura".

Como elemento positivo, volvemos a destacar la presencia de fórmulas rutinarias, bien estructuradas y contextualizadas (B1.2T4s5 expresar buenos deseos a otras personas: "ique te mejores!", "ique tengas suerte!”, "ique cumplas muchos más!", "ique seáis muy felices!"), acompañadas de explicaciones gramaticales y de índole dialectológica ("ique te vaya bonito!"). Asimismo, saludamos el recurso gráfico de los emoticonos para estructurar fórmulas rutinarias ("iqué bien!", "iqué suerte!", "iqué maravilla!" vs "iqué lástima!", "iqué rabia!", "iqué pena!") y el hincapié en las estrategias de aprendizaje ("si tiene problemas para entender lo que dicen en español pregunte, coopere, aclare o verifique e intente recordar palabras asociándolas a una imagen mental").

En el tema 6 encontramos por vez primera una presentación y explotación de UF más complejas, denominadas en los enunciados "expresiones". Las UF recopiladas ("en plan tranquilo", "de aquí para allá", "hacer cuentas", "echarse el tiempo encima", "ir al grano", "irse de veraneo") giran en torno al tiempo libre y a los viajes y su explotación sigue las pautas de "las tres P": presentación, práctica y producción. 


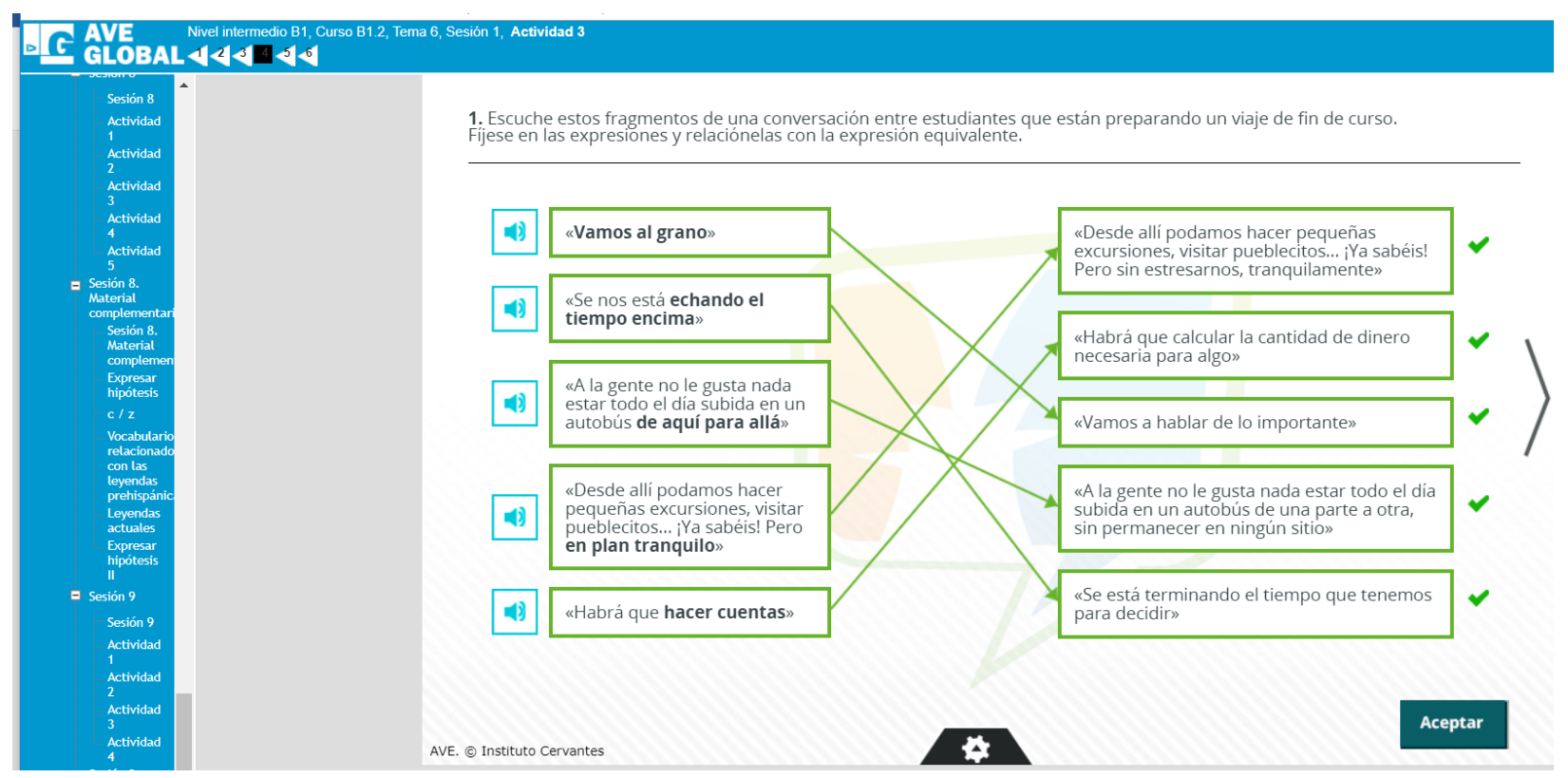

Lo que nos parece menos afortunado es el intento de integrar reglas de pronunciación (acompañadas de explicaciones metalingüísticas) junto con contenido cultural y léxico sumamente complejo: los sonidos interdentales con las leyendas precolombinas o la pronunciación de la /r/ con el vocabulario del reciclaje. Además, las actividades lúdicas propuestas podrían surtir el efecto contrario en los alumnos, debido precisamente a este desfase: "Escuche y relacione la pronunciación que oiga con la imagen del área en que se produce. Luego, lea el trabalenguas en voz alta tal como se pronunciaría en el norte de España y Baleares. Modelo: "si cien sierras asierran cien cipreses, seiscientas sierras asierran seiscientos cipreses" (B1.2T6s8).

En cuanto a las actividades propuestas por la plataforma para la adquisición de léxico, abundan las actividades de comprensión lectora (desglosadas en actividades de prelectura, durante la lectura y post-lectura) con tareas de organización y ordenación textual, búsqueda de información relevante en un texto o resolución de problemas. Como recursos utilizados destacamos el uso de las canciones, por su enorme potencial y valor afectivo y la presencia cada vez más recurrente del vídeo, otro recurso rentable dentro de las unidades. En un mundo cada vez más visual, el docente no puede hacer caso omiso de una realidad tan presente en la vida de los aprendices. Del Valle (2019) enumera algunas ventajas como dinamismo, inmediatez y accesibilidad, ya que el docente cuenta con un sinfín de materiales disponibles en línea. La combinación de sonido e imágenes motiva al estudiante, que dispone al mismo tiempo de información lingüística y paralingüística.

Finalmente, antes de proceder al análisis de lo que será el último nivel en nuestro estudio (B2), nos detenemos para hacer algunas breves observaciones y anticipar lo que podríamos encontrar a continuación. 
En primer lugar, cabe señalar la naturaleza de esta plataforma de e-learning: como personal docente del Instituto Cervantes, gozamos de una situación privilegiada al tener acceso total y gratuito a esta herramienta de aprendizaje. No obstante, no hay que perder de vista que el AVE GLOBAL es, en el fondo, un producto comercial y que la mayoría de los clientes que lo adquieren eligen un determinado segmento (curso o nivel). Si las actividades propuestas resultan de su interés, la presentación de los contenidos es amena, las explicaciones son claras, etc., tomarán la decisión de seguir estudiando en la plataforma. En caso contrario, buscarán otras maneras o soportes de continuar su estudio del español y, simplemente, abandonarán el AVE. Este factor comercial tiene, por lo tanto, un importante reflejo en el planteamiento de la plataforma, en el sentido de que todos los cursos deben tener una distribución equilibrada de contenidos, dinámicas entretenidas, tareas motivadoras, etc. Aunque a nosotros nos puedan resultar monótonas las mismas actividades de "arrastrar", "completar", "seleccionar", "pulsar", "ordenar", "formar", es bastante probable que el público al que van dirigidas no siempre sea el mismo. No es de extrañar que los temas tratados en el nivel B1 se hayan presentado previamente en niveles inferiores: la comida, la ciudad, los viajes, etc. El elemento de novedad lo tendrán que aportar los contenidos gramaticales de mayor dificultad y, lo que nos interesa en este análisis, un léxico apropiado para el nivel, siguiendo las pautas del PCIC.

En este sentido, hemos notado que en muchas ocasiones los exponentes presentados son extremadamente complicados y que el AVE recurre a textos literarios valiosos per se, pero no contemplados desde su función como vehículo de comunicación. En más de una ocasión, nos hemos planteado la eficacia del AVE y su declaración de intenciones de adoptar un enfoque comunicativo.

La presencia de UF en los niveles A1-B1 ha sido escasa, esporádica y azarosa y no ha gozado de sistematización o contextualización. Una notable excepción la representan las fórmulas rutinarias, integradas en distintos actos comunicativos. En el polo opuesto, prácticamente ignorada, se halla la paremia, mientras las colocaciones y las locuciones aparecen dispersas en muchos materiales, y suelen carecer de actividades de refuerzo.

No obstante, anticipamos que en el siguiente nivel habrá más confianza en los estudiantes y que la complejidad gramatical se reflejará en una presencia más sólida de UF. Comprobaremos nuestra hipótesis en las páginas venideras. 


\subsection{AVE GLOBAL - nivel B2}

Los primeros materiales del curso B2.1 parecen confirmar nuestras intuiciones. Nada más arrancar la sesión 1 del tema "¿Nos conocemos? Carácter y personalidad. Formación y experiencia laboral" encontramos la primera actividad estructurada, contextualizada y reforzada que tiene como base UF (bautizadas "expresiones" en el enunciado de la actividad B2.1T1s1).

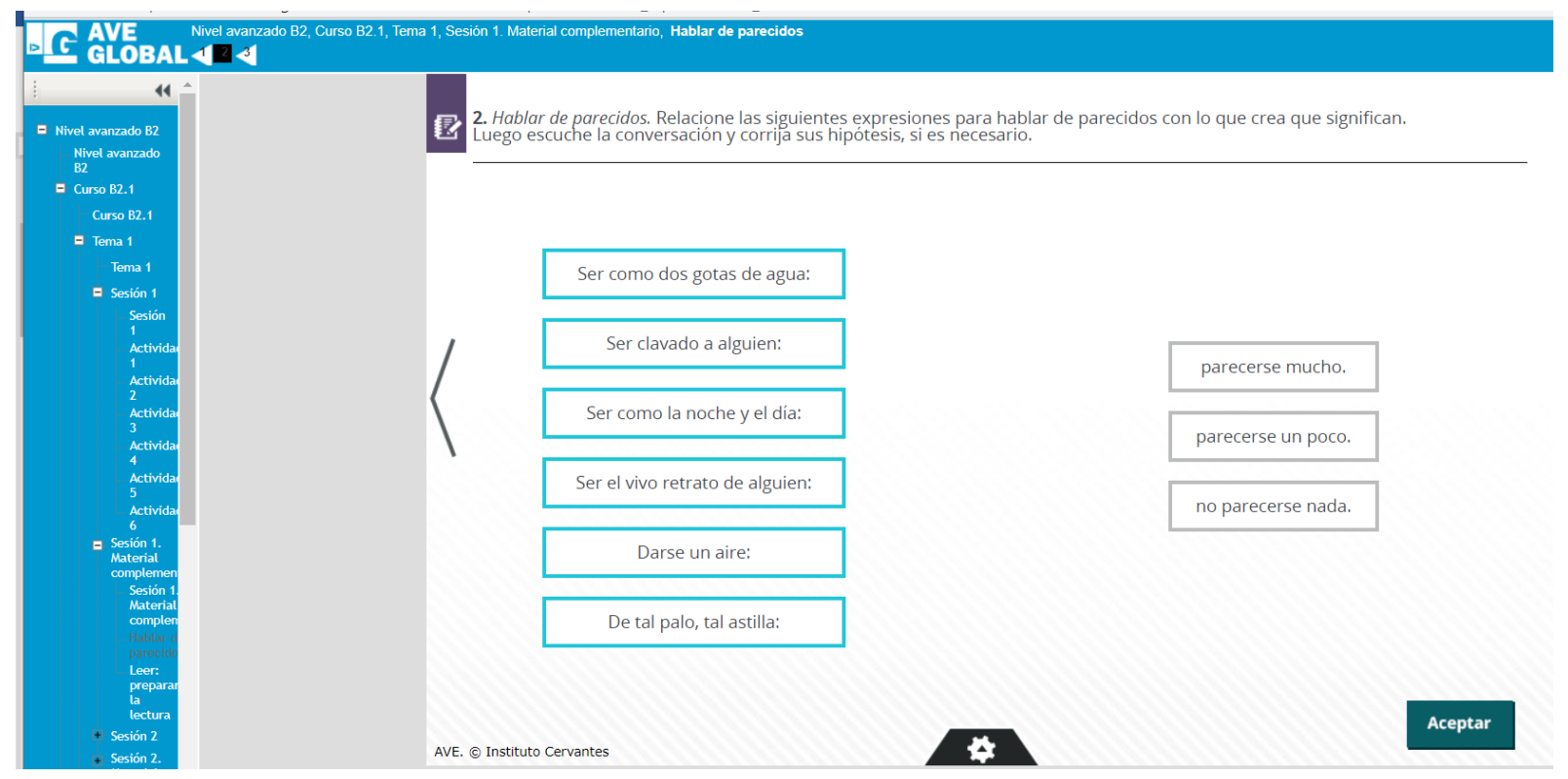

Siguiendo la distinción operada por Higueras (1997), recopilamos locuciones predicativas (que equivalen a un predicado) y, en mayor número, locuciones atributivas (que equivalen a un verbo copulativo o semipredicativo y su atributo): "darse un aire", "ser el vivo retrato de alguien", "ser clavado a alguien" y UF comparativas de idiomaticidad baja o media, idóneas para niveles iniciales de estudio: "ser como dos gotas de agua", "ser como la noche y el día", etc. Asimismo, apuntamos un enunciado parémico ("de tal palo, tal astilla") y una locución adjetiva somática semánticamente transparente que dispone de hipervínculo explicativo ("con los pies en la tierra", expresión utilizada para referirse a personas realistas y prácticas).

La presencia de UF es constante, a medida que las actividades propuestas se abren más hacia el registro informal y predomina el carácter oral. Es el caso de los materiales que giran en torno a los sucesos y anécdotas divertidas relacionadas con los viajes o el mundo laboral. 


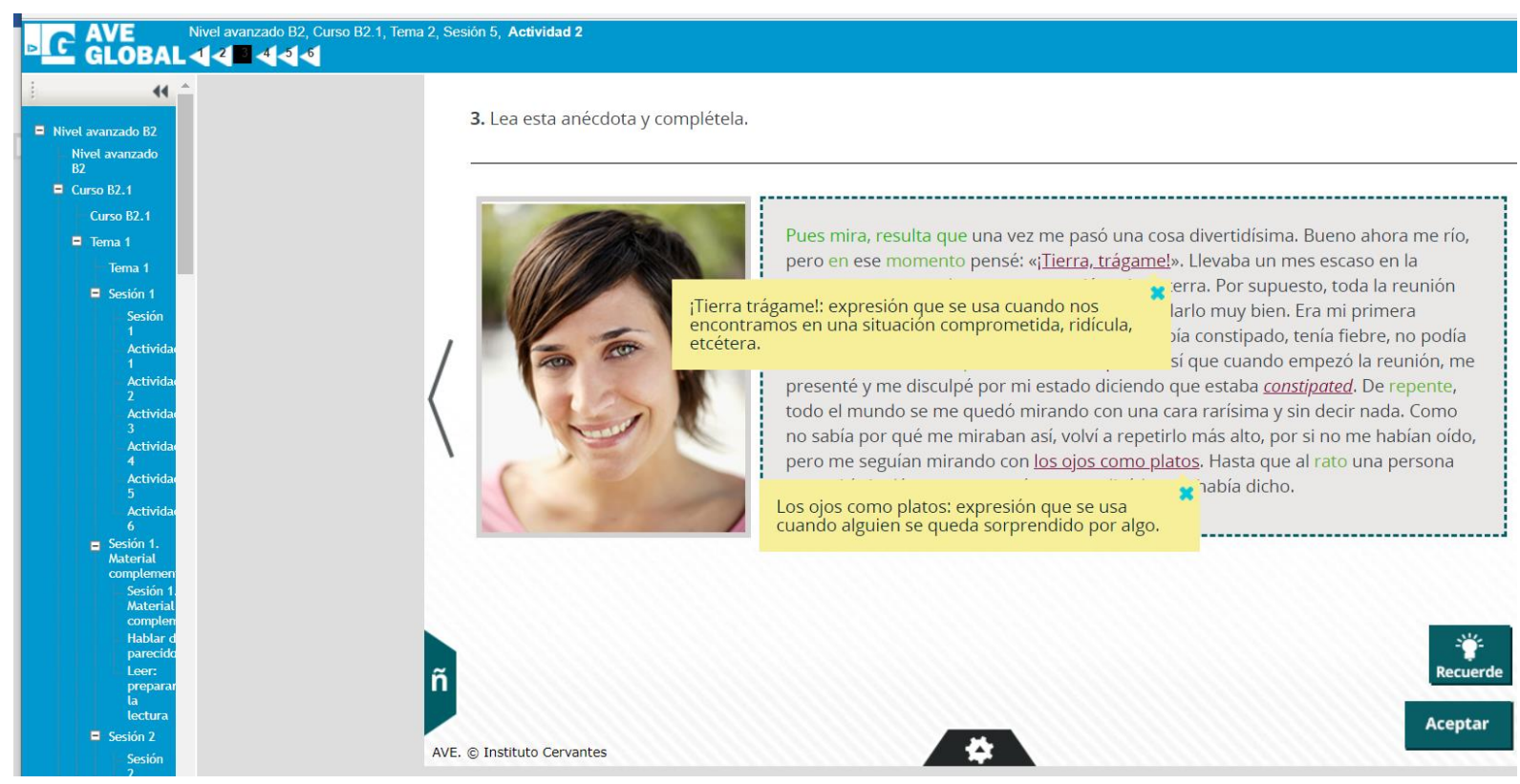

Hemos recopilado locuciones verbales ("estar hecho polvo", "apretarse el bolsillo", "hacer las paces"), locuciones interjectivas ("tierra, trágame") y locuciones adjetivas ("sano y salvo", "con los ojos como platos") integradas en contextos esclarecedores. Se trata de exponentes léxicos capaces de atraer y mantener viva la atención del receptor y motivarlo a participar activamente en el discurso, a diferencia del input que perciben como irrelevante y lejano que provoca su desconexión ("sigilosos trancos de leona").

Los temas deben ser relevantes para el estudiante. Esto depende de los gustos e intereses personales de los alumnos. Les interesa la realidad, la cultura, las fiestas, los viajes, la comida, los sentimientos, la actualidad, las relaciones sociales. Si les damos un texto que no les interesa mucho, su atención es más difícil de mantener (Leal Riol 2011:237).

Abundan también las actividades que tratan las colocaciones, siguiendo las mismas pautas que en niveles anteriores, por lo que no desglosaremos en este apartado su amplia tipología, por no caer en la redundancia. Nos centraremos más en los elementos novedosos, como las comparaciones prototípicas de superioridad, presentes en el curso B2.2 ("es más largo que un día sin pan", "es más listo que el hambre", "es más terco que una mula", "es más lento que una tortuga", "está más claro que el agua", "está más loco que una cabra”, etc.). A pesar de su estructura lingüística de fácil asimilación, constituyen un serio escollo para un aprendiz de E/LE que, con toda probabilidad, contará en su lengua materna con distintos exponentes para situar "el punto de referencia en uno de los extremos de la escala de comparación (...) para expresar el grado sumo o ínfimo de una acción o de una cualidad" (Gutiérrez Ordoñez 1997:64). La comparación prototípica, conocida también como "ponderación elativa" (Narbona 1989) o "comparación intensiva" (Álvarez Menéndez 1989) conlleva una fuerte carga cultural, idiosincrásica (en rumano, 
por ejemplo, se es más tonto que la noche, más malo que la peste, un poco más guapo que el diablo, más católico que el Papa, etc.).

Lo singular de estos ejemplos reside, no en su estructura lingüística, sino en el particular valor cultural de los referentes elegidos como norma de comparación. Son seres o magnitudes que, según el saber generalizado, constituyen los representantes superlativos, el «no va más», el colmo, de la acción o de la cualidad que entra en juego. Tan generalizado que en muchas ocasiones ya constituyen verdaderos clichés (Gutiérrez Ordóñez 1997:46).

No es de extrañar que el AVE proponga una tarea de reflexión interlingual, "¿Existen ese tipo de expresiones en su lengua? Si es así, escriba traducidas al español las que existan para estos adjetivos". Desde la perspectiva didáctica, Rodríguez Ponce (2006) enumera las ventajas de enseñar comparaciones estereotipadas (fuerza ilocutiva o perlocutiva, motivación psicolingüística) y subraya que, además,

constituyen un vehículo perfecto para conseguir una introducción digna, coherente y programada de los contenidos culturales y de civilización en el aula de ELE, porque representan la cultura en la lengua y motivan que los alumnos realicen una reflexión antropológica tras un profundo conocimiento de los materiales lingüísticos. Las comparaciones estereotipadas se convierten en la clase de español en un instrumento multifuncional: por ejemplo, puede resultar mucho más adecuado presentarlas, en lugar de conformando una mera enumeración de frases hechas, como un recurso para introducir los mecanismos morfológicos y sintácticos de la subordinación adverbial comparativa y modal, que a veces se les ofrece a los aprendices de una manera tan árida y esquemática en los manuales (Rodríguez Ponce 2006:533).

En los cuatro cursos que configuran el nivel B2 hemos recopilado un elevado número de UF derivadas de campos semánticos inusitados, como el mundo de los naipes donde, bajo el título de "frases hechas", se introducen, explotan y refuerzan locuciones verbales como "barajar varias posibilidades", "tener un as en la manga", "desmoronarse como un castillo de naipes", "ser un as", etc.).

Finalmente, concluimos este análisis con la actividad B2.3T7s8a3 que incluye "expresiones para mostrar actitudes". Se trata, en el fondo, de una amplia secuencia didáctica cuyo objetivo es introducir locuciones verbales somáticas como "no tener dos dedos de frente", "estar hasta las narices", "no tener pelos en la lengua", "tomar el pelo", "dar la cara", "tener la mosca detrás de la oreja", etc. 


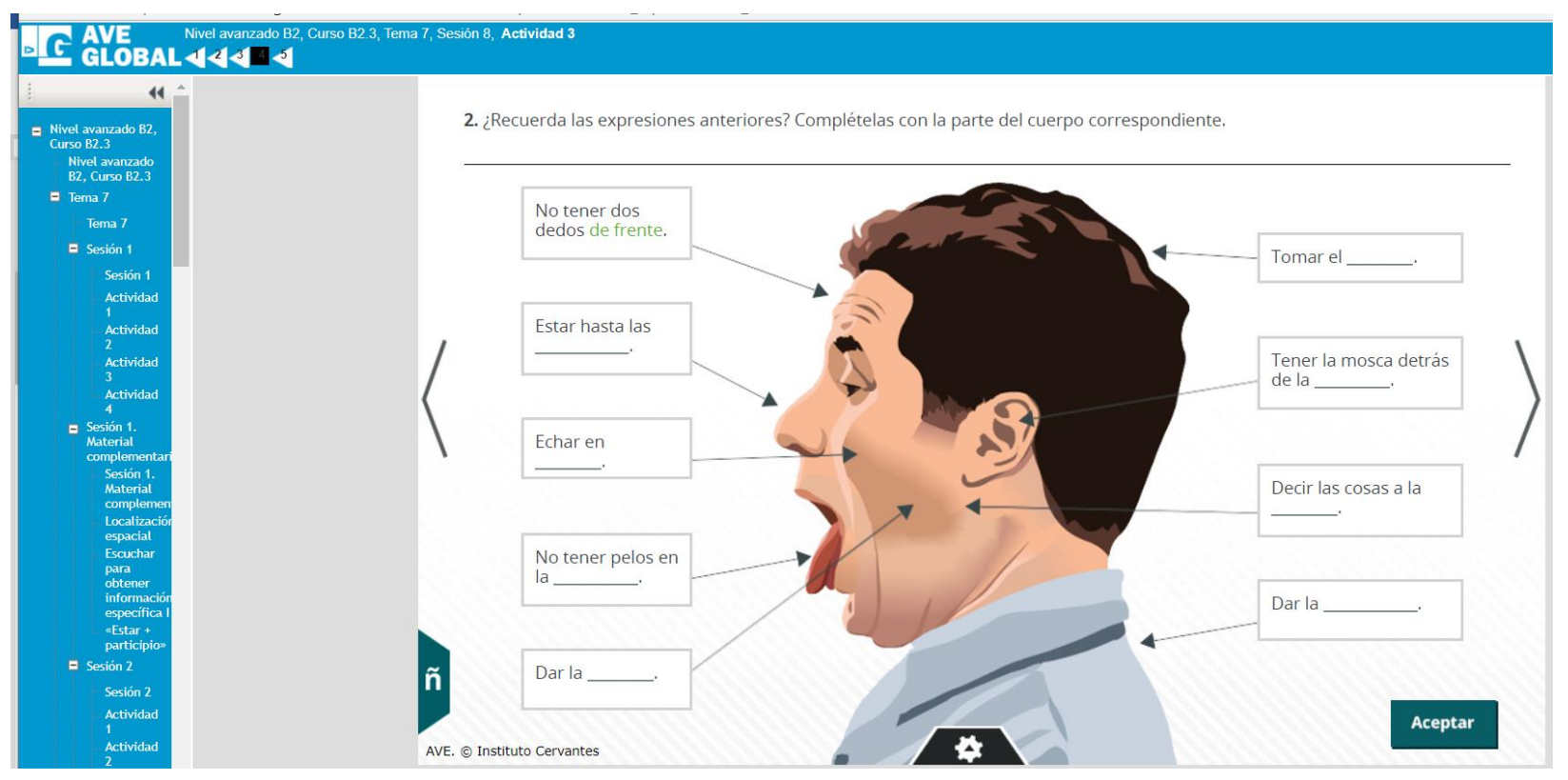

Encontramos, en definitiva, SO de uso activo que se reflejan también en nuestra base de datos, correctamente didactizados, integrados en actividades de compresión lectora, comprensión auditiva y expresión escrita y reforzados en los materiales complementarios.

En este capítulo hemos llevado a cabo un análisis de materiales, desde una perspectiva léxica (en un sentido más amplio), pero con especial hincapié en la presencia de las unidades fraseológicas. En los cuatro niveles recorridos hemos notado una inserción cada vez mayor del componente fraseológico en los materiales propuestos, lo que ha confirmado nuestras hipótesis iniciales. No hay que perder de vista que el AVE GLOBAL representa una plataforma de enseñanza virtual creada por un equipo de profesionales que incluye personal docente del Instituto Cervantes, por lo que el instrumento primordial que toma como referencia es el PCIC. Exceptuando las fórmulas rutinarias, cuya presencia hemos destacado desde el primer momento, el lenguaje idiomático se ve relegado por el PCIC a niveles superiores (C1-C1), como indicador de la competencia de un hablante. Las UF no se consideran, por lo tanto, un elemento imprescindible del idioma y, salvo contadas excepciones, el AVE GLOBAL ha prescindido de este importante componente la lengua. No obstante, en el nivel B2 su presencia se ha hecho más patente, aprovechando un abanico más amplio de registros y la confianza en las mayores posibilidades lingüísticas de los aprendices.

Nuestra propuesta, por tanto, es completar con contenidos fraseológicos estos niveles iniciales e intermedios del PCIC porque consideramos que representa una forma óptima de incrementar el acervo léxico de los aprendientes rumanos, incorporando a la vez elementos culturales desde el inicio de su proceso de aprendizaje. Para ello, en el siguiente capítulo, ofrecemos una aplicación práctica de actividades basadas en el corpus contrastivo creado en esta tesis desde un enfoque léxico, contrastivo e interlingüístico. 


\section{PROPUESTA DE APLICACIÓN DIDÁCTICA DE LAS UNIDADES FRASEOLÓGICAS A ALUMNOS RUMANOS DE E/LE}

Como ya hemos señalado al inicio de esta tesis doctoral, uno de los objetivos específicos es llevar a cabo una aplicación práctica a partir de los resultados obtenidos tras el estudio contrastivo de UF en español y en rumano. En el conjunto de la tesis, este capítulo aporta precisamente esa implementación de los resultados cosechados, avalada por el marco teórico consultado, por la revisión crítica de los materiales en línea de AVE GLOBAL y por la creación de un corpus de UF somáticas diseñado específicamente para aprendices rumanos de E/LE. En las siguientes páginas nos proponemos llevar los postulados teóricos de la investigación a un modelo de enseñanza del componente fraseológico en los niveles inicial e intermedio, basándonos en enfoques léxicos contrastivos.

A fin de dotar de credibilidad las propuestas didácticas, no confinaremos estas actividades a la parcela idiomática en la que hemos centrado nuestro estudio (UF somáticas), ya que los hablantes nativos, en su selección natural de UF, integran componentes léxicos de distintos campos semánticos. Estas propuestas vienen a cubrir las carencias detectadas en los materiales analizados a fondo en el capítulo precedente, que proporcionan una escasa cantidad de UF para los aprendices, sobre todo en los niveles iniciales. Una vez más, incidimos en nuestra premisa de partida, vinculada con la experiencia como alumnos y docentes de E/LE, con la investigación teórica, con el análisis y la creación de materiales: en los cursos más elevados existe una sólida cantidad de input fraseológico, mientras que en las primeras fases del aprendizaje ese contenido se ignora casi por completo. Por esta razón, nos hemos centrado en los niveles iniciales, siendo esta nuestra aportación original y lo novedoso de este estudio centrado en la fraseología como forma de incrementar el componente léxico desde el nivel A1.

Asimismo, no queremos simplemente enlazar una serie de actividades, sino ofrecer ideas y reflexiones, justificando los fundamentos teóricos que subyacen en cada una de las propuestas, el nivel idóneo para su presentación en el aula (reiterando que el alumnado al que van dirigidas está constituido por rumanohablantes), las destrezas que integramos y los objetivos comunicativos perseguidos. 


\subsection{La fraseología en el aula de E/LE para alumnos rumanos: retos didácticos}

Previo paso a la presentación de las actividades didácticas, en los siguientes párrafos haremos una síntesis de lo que hoy en día representa enseñar fraseología.

Reiteramos nuestra convicción de que "el aprendizaje de una LE, así como la integración social y cultural de un extranjero en la comunidad lingüística de acogida, pasa también por la integración fraseológica, es decir, la incorporación de las UF a su discurso" (Timofeeva 2013:323). Por lo tanto, hay que guiar al alumno en su complejo camino hacia la LM, facilitarle la comprensión y la producción de las UF, de manera que su discurso se asemeje en términos comunicativos al de un hablante nativo. Además, detrás de las UF yace un importante trasfondo cultural y "la fuerte conexión entre fraseología y componente cultural supone para el estudiante de ELE una ampliación del conocimiento sociocultural que va unido a la época y circunstancias de uso de la lengua" (Mendizábal 2016:6).

Los docentes han sido los primeros en detectar la necesidad de introducir en el aula de E/LE este componente auténtico, motivador e integrador y, de alguna manera, se adelantaron en su afán a los estudios de corte más teórico. En este sentido, González Rey (2012:67) llega a afirmar que "el origen de la Fraseodidáctica se sitúa en la glotodidáctica o didáctica de las lenguas, en donde emergen las primeras manifestaciones de interés de docentes de lenguas extranjeras por la parte más viva de la lengua que enseñan". Asimismo, al crear y pilotar materiales destinados a alumnos extranjeros, los profesores han podido comprobar que enseñar fraseología en el aula significa mucho más que presentar una serie de expresiones pluriverbales, es un contenido que sirve para enseñar toda una lengua.

En las actividades que planteamos a continuación nos posicionamos en el "postmétodo" (Brown 2002) o "método ecléctico" (Kumaravadivelu 2012), surgido de la voluntad de superar el concepto de "método" que, en el proceso de enseñanzaaprendizaje en el siglo XXI, se ha vuelto obsoleto. Basado en tres principios organizativos fundamentales (particularidad, practicabilidad y posibilidad), el profesorado ha de tener en cuenta aspectos como maximizar las oportunidades de aprendizaje, facilitar la interacción negociada, minimizar los ajustes de la percepción, desarrollar el aprendizaje intuitivo, fomentar la concienciación lingüística, contextualizar el input, asegurar la relevancia social, etc.

En capítulos anteriores de este trabajo hemos criticado técnicas y enfoques que consideramos obsoletos. En nuestra opinión, resulta contraproducente introducir listados memorísticos de UF sin proporcionar contextos $u$ otras restricciones de uso o ninguna información que configure la estructura argumental. Tampoco aporta resultados satisfactorios ni fomenta un correcto uso pragmático la presentación exhaustiva de 
locuciones que generan verbos soportes como "echar", "dar", "poner", "hacer", etc. La fraseología no se adquiere como una tabla de conjugación de verbos (ir)regulares, sino que implica complejos procesos que exceden los aspectos formales, estríctamente lingüísticos. "La información no se almacena en la memoria aleatoria ni aisladamente, tampoco se ordena alfabéticamente, sino estableciendo relaciones con la información ya existente. Nuestra forma de pensar está determinada por dos procesos fundamentales: asociar y clasificar" (Leal Riol 2011:246).

Diamante Colado (2003) y Moreno Pereiro (2006) aplican postulados cognitivistas a la enseñanza de los somatismos, siguiendo las teorías experiencialistas de Lakoff y Johnson (1980): la base de nuestro pensamiento es corporal y los hablantes categorizamos la realidad a través de metáforas básicas, que representan el fundamento explicativo de multitud de expresiones. Las UF son, desde la perspectiva de la semántica cognitiva, el reflejo lingüístico del carácter corpóreo de la mente.

En los materiales propuestos tendremos en cuenta el equilibrio entre las destrezas reflexivas y productivas y la integración de contenido funcional y cultural, fomentando la interacción en el aula. Nuestra experiencia docente coincide con las conclusiones de López Vázquez (2011) que, tras analizar la presencia del componente idiomático en varios manuales de $\mathrm{E} / \mathrm{LE}$, afirma que

También tenemos que llamar la atención sobre el hecho de que estos manuales se centran en la competencia fraseológica receptiva, es decir, en la habilidad de los aprendientes para descifrar y reconocer estas unidades, pero desatienden la habilidad para producirlos, ya que son muy escasos los casos de ejercicios en los cuales los aprendientes deben reutilizar las expresiones (López Vázquez 2011:540).

En este sentido, somos partidarios del concepto didáctico de la enseñanza orientada a la acción, defendemos el protagonismo del alumno en el aula y consideramos el learning by doing un principio fundamental en el proceso de aprendizaje de una LE.

Otro aspecto importante que queremos señalar es la cantidad de input fraseológico insertado en las actividades propuestas. Asumimos que en determinados momentos el número de exponentes es levemente superior a la producción natural de un hablante nativo y coincidimos con Serradilla Castaño (2014) en que

afortunadamente para los aprendientes de ELE, no solemos introducir tantas locuciones seguidas en nuestra lengua habitual pero no es menos 
cierto que recurrimos a ellas con asiduidad en la lengua hablada y escrita por lo que no será difícil encontrar materiales reales con los que enfrentar a nuestros estudiantes a la fraseología del español (Serradilla Castaño 2014:83).

En definitiva, no se trata de abrumar a los aprendices con un sinfín de UF, cuya presencia resultaría forzada en la vida real. No obstante, nuestra experiencia docente nos confirma que una contextualización idónea propicia un número elevado de elementos idiomáticos que los aprendices no perciben como excesivo.

Como hemos venido afirmando a lo largo de este trabajo, abogamos por una introducción temprana de las UF en la clase de E/LE. Julià Luna y Ortiz Rodríguez (2012) diseñan a su vez propuestas metodológicas centradas en el léxico gastronómico, que abarcan el itinerario curricular completo (niveles A1-C2).

Para cada uno de los niveles se ha creado una propuesta docente en la que las UFS se integran como parte del aprendizaje en tareas de distintas destrezas lingüísticas y en relación a factores esenciales en el aprendizaje de fraseologismos de cualquier lengua (el significado, el uso y la motivación de las formaciones). Se trata de un método integrador y transversal (Julià Luna y Ortiz Rodríguez 2012:12).

Asimismo, sugieren una serie de criterios a tener en cuenta a la hora de introducir el componente fraseológico en el aula, entre los que destacamos la relación con el contexto sociolingüístico, la frecuencia de uso, la organización onomasiológica o el vínculo entre el origen, la motivación o el esquema cognitivo y el significado. En un trabajo posterior (2013), se centran en los somatismos y desde la perspectiva de la semántica cognitiva presentan una propuesta transversal y progresiva para el reconocimiento, la comprensión y la reproducción de una serie de UF. Señalan la importancia de que "las expresiones idiomáticas estén presentes desde estadios iniciales de aprendizaje de una lengua (A1) hasta el final de la misma (C2)" (Julià Luna y Ortiz Rodríguez 2013:499).

Los criterios con los que operan son, grosso modo, los mismos que también hemos seguido nosotros a la hora de "confeccionar" los siguientes materiales, que se nutren del acervo teórico presentado en estas páginas, de nuestra experiencia docente y de numerosos recursos auténticos. Con estas propuestas pretendemos que los aprendices adquieran competencia fraseológica, parte fundamental de su competencia comunicativa global. 


\subsection{Propuestas didácticas para los niveles A1 - A2}

Durante el análisis que llevamos a cabo en el segundo capítulo de este trabajo, nos confrontamos en numerosas ocasiones con la difícil tarea de ubicar una UF en un nivel concreto (entre los seis contemplados por el MCER y los cuatro que son objeto de nuestro estudio) y consideramos que muchas entradas se encuentran a caballo entre niveles. Asimismo, varios materiales y métodos de E/LE detectan la dificultad de separar contenidos y exponentes y optan por proponer niveles sui generis como A2+, B1+ o B2+. En nuestro caso, decidimos agrupar las propuestas didácticas en dos grandes bloques que aúnan por un lado el A1 y el A2 y, por otro lado, los niveles intermedios (B1+B2).

En los niveles iniciales queremos fomentar la conciencia lingüística y ayudar a los aprendices a desarrollar el proceso de asociación que se establece entre las unidades, no solo a nivel fonético, morfosintáctico o discursivo, sino también a nivel no lingüístico: estímulo visual, conocimiento cultural, etc. Nos proponemos, por lo tanto, ampliar hacia el universo fraseológico su lexicón mental, entendido como una red asociativa de palabras estructuradas y organizadas en redes intercontectadas, en constante movimiento e incremento (Aitchison 1987).

Los temas de las actividades se enmarcan dentro de los contenidos contemplados por el PCIC y el componente fraseológico se introduce de manera muy sutil, aprovechando muestras auténticas o verosímiles. Huelga decir que son imprescindibles las actividades facilitadoras y que no construimos una unidad didáctica alrededor de una serie de UF, sino que integramos el elemento fraseológico de manera natural.

Asimismo, en los materiales analizados hemos notado que se destierra la lengua materna del aprendiz. Si bien como principio metodológico apoyamos la inmersión total en el aula de E/LE, los alumnos rumanos requieren constantemente la equivalencia de la UF en su lengua materna, lo que les confiere seguridad. Por esta razón, a pesar de la "mala prensa" que tienen las técnicas del método tradicional, hemos optado en ocasiones por respetar la larga tradición educativa de nuestro alumnado meta. Al referirse a la traducción como técnica verbal de transmisión del significado de una UF, Leal Riol (2011) considera que la lengua meta debe usarse si el nivel de competencia comunicativa de los alumnos lo permite, pero "la traducción puede ahorrar mucho tiempo y, además, ganamos precisión y exactitud siempre que la unidad fraseológica se refiera a la misma realidad extralingüística y su significado sea compartido en los dos idiomas" (Leal Riol 2011:242).

Si bien en las actividades perfilamos brevemente los objetivos, las destrezas y los contenidos comunicativos, no queremos elaborar en las siguientes páginas verdaderas guías para los profesores, por lo que prescindimos de otros elementos que conforman las elaboradas pautas pedagógicas, como las transiciones, las dinámicas de grupo o la duración de las actividades. Además, creemos firmemente que una clase es irrepetible y que tanto docente como alumnos disfrutan más aprendiendo con libertad, sin el corsé del 
dogma didáctico. Un buen profesor es capaz de reaccionar ante lo que ocurre en clase y, si resulta imprescindible, modificar su "hoja de ruta" inicial, mientras que un grupo ideal debería involucrarse en la toma de decisiones sobre objetivos, contenidos y materiales, consciente de sus intereses. En este sentido, nos parece una meta inalcanzable establecer un número elevado de UF por nivel y, en parte, discrepamos de la propuesta de Julià Luna y Ortiz Rodríguez (2012), que tratan de cuantificar las entradas por nivel:

cada uno de los niveles no superaría la presentación de 200 UFS y al final del aprendizaje de la lengua el estudiante llegaría a poder reconocer 1.200 UFS. Se trata, evidentemente, de una cifra orientativa puesto que no creemos que el aprendizaje lingüístico sea realmente cuantificable. No obstante, la presentación progresiva de cierto número de UFS permitiría que el aprendiz se familiarizara con este tipo de formaciones, su uso y sus características (Julià Luna y Ortiz Rodríguez 2012:14).

En los siguientes epígrafes aportaremos diferentes materiales didácticos para su puesta en práctica en el aula de E/LE. Todos ellos están diseñados siguiendo la metodología que fundamenta esta tesis, los postulados de la lingüística contrastiva, el análisis de errores y la fraseodidáctica. Con ello queremos demostrar que la contextualización en la que se basa el enfoque léxico que defendemos avala unos resultados óptimos en el aprendizaje desde los niveles iniciales. 


\subsubsection{Actividad 1: No todos somos iguales}

Contenido comunicativo: descripción física y de carácter.

Contenido gramatical: adjetivos que expresan cualidades; verbos más frecuentes (ser, estar, tener, etc.) utilzados para la descripción; el presente indicativo.

Destrezas: comprensión lectora, expresión escrita, expresión oral.

Objetivos: ampliar la competencia léxica a través de UF contextualizadas que integran el lexema "cabeza" y otros somatónimos; fijar los somatismos activando la imagen del lexema somático; fomentar la reflexión cognitiva sobre la naturaleza de las UF que describen cualidades y defectos (locuciones con o sin correlato en rumano); proporcionar contenido cultural (programas televisivos, personajes de comic y cine) como soporte motivador para la práctica de las UF; estimular la cooperación y la creatividad.

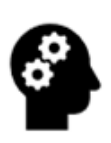

Torbellino de ideas: ¿Cómo crees que son las personas de estas fotos?

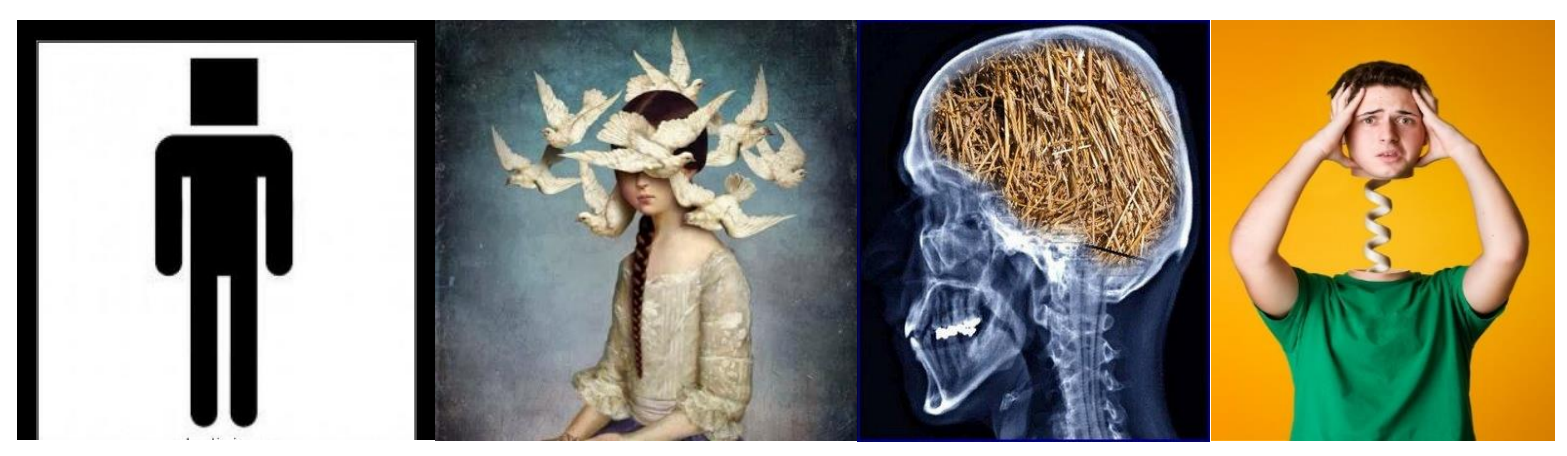

Mercedes tiene la cabeza llena de pájaros: quiere tocar la guitarra y vivir en una comuna hippie.
es inmadura
es responsable
es valiente

Es un cabeza cuadrada: no puedes sacarlo de su rutina y punto.

es inteligente es divertido es testarudo

Es famoso, guapo, millonario y tiene la cabeza sobre los hombros. Y encima soltero.

es realista es egoísta es optimista

Hablo con ella y cada día me dice otra cosa diferente. Tiene la cabeza llena de serrín.

es prudente es insensata es tranquila 


\section{8}

Explícale a un amigo español con qué imágenes asocias "la cabeza" en la lengua rumana. ¿Alguna sirve para describir a una persona? ¿Encuentras alguna relación entre las fotos y los rasgos que describen?
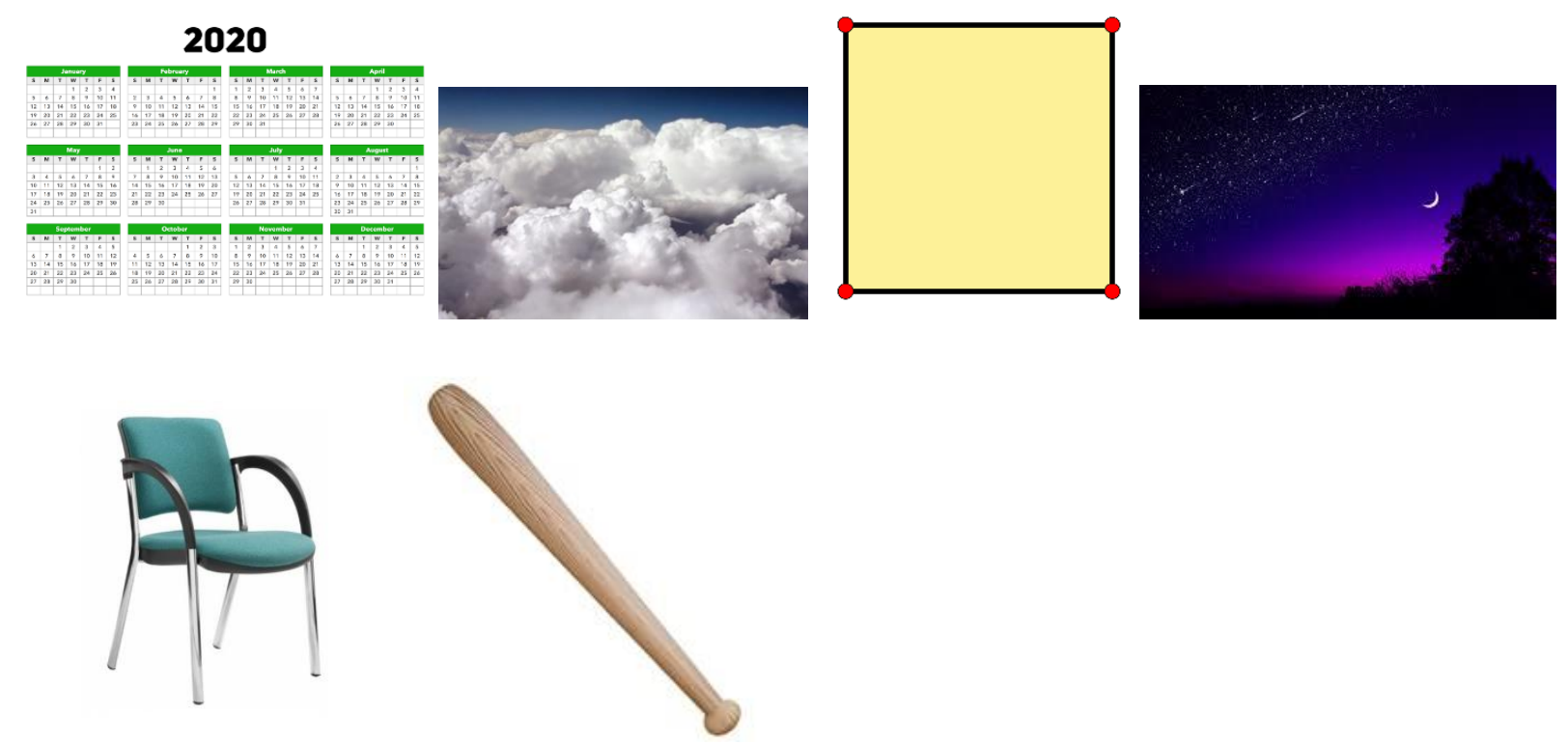

$\infty$

\section{Comprensión lectora}

\section{Lee este texto sobre Anacleto, un detective muy famoso.}

Me llamo Rossy y soy secretaria en una agencia de detectives de Carabanchel. Tengo muchos compañeros de trabajo, pero Anacleto es especial. Ya no tiene veinte años, pero no importa, todavía mantiene un espíritu joven y una gran vida social. Los clientes y los casos más interesantes son siempre para él. Trabaja muchísimo, no tiene tiempo ni para comer. Por eso está muy delgado. Además, es un fumador empedernido. Es muy romántico y tiene un éxito enorme con las mujeres, cada semana tiene una novia diferente, casi siempre extranjera. Es muy buena persona, aunque también muy creído. Piensa que es el mejor agente secreto del universo. 
Sustituye las palabras en negrita con las siguientes expresiones: tiene un corazón de oro, se piensa que es el ombligo del mundo, peina canas, está en los huesos. ¿Alguna tiene correspondencia en rumano?

¿Cuál de estos personajes podría ser Anacleto y por qué?
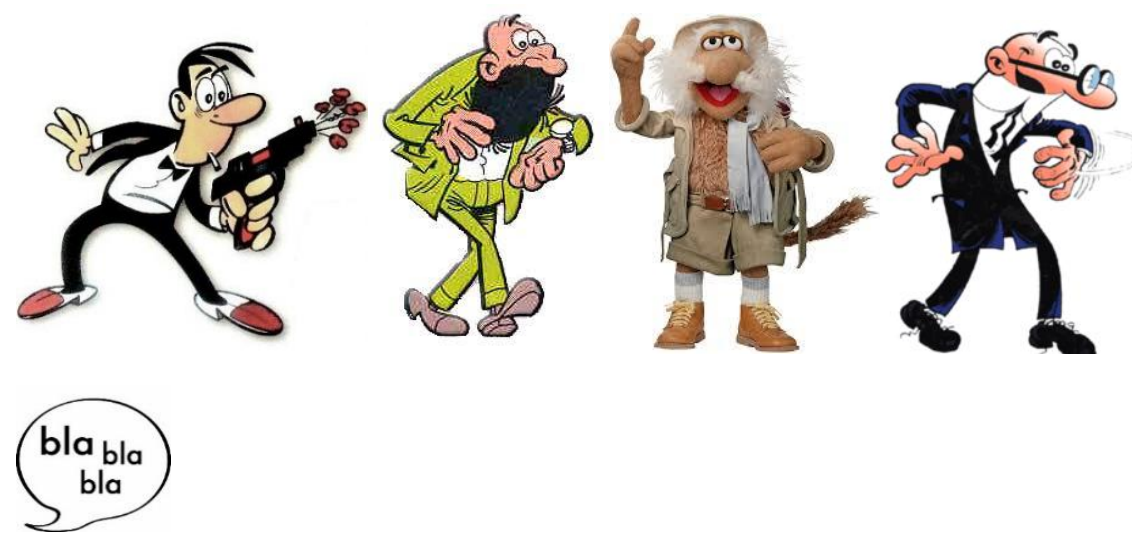

Expresión oral

Vamos a jugar a PASAPALABRA:

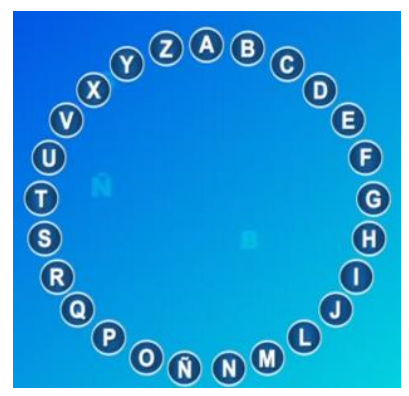

Con la A. Mejor agente secreto: Anacleto

Con la B. No lleva después de afeitarse: barba /bigote

Con la C. Lo que peina Anacleto de vez en cuando: canas

Con la D. Come muy poco, por eso está muy: delgado

Con la E. Siempre va con traje y pajarita, es muy: elegante

Con la F. El mayor vicio de Anacleto: fumar

Con la G. Anacleto está en los huesos, por tanto, no es: gordo 


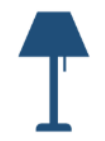

En acción

En parejas, tenéis que seguir redactando preguntas para el rosco de PASAPALABRA, describiendo el carácter, el físico y la vida secreta de Anacleto.

Con la H:

Con la I:

Con la J:

$(\ldots)$ 


\subsubsection{Actividad 2: De ganga, nada}

Contenido comunicativo: hablar de precios; contar experiencias relacionadas con la adquisición de objetos y productos; describir objetos; valorar regalos; elaborar la lista de la compra.

Contenido gramatical: el presente indicativo del verbo costar; el numeral.

Destrezas: expresión escrita, expresión oral.

Objetivo: ampliar la competencia léxica a través de UF contextualizadas que integran el lexema "ojo" y otros somatónimos; integrar UF adscritas a la función comunicativa "realidades cotidianas" (expresiones referentes al dinero); reflexionar sobre la búsqueda de equivalencias idiomáticas; encaminar a los aprendices hacia una estructura somática que se tratará en clase; proporcionar situaciones comunicativas con tal de que los aprendices tengan la oportunidad de reutilizar eficazmente UF que reconocen, comprenden y aprenden (siguiendo el modelo PPP: presentación, práctica y producción); fomentar la competencia plurilingüe y la competencia mediadora (entre alumnos que recurren a explicarse mutuamente significados en varias lenguas).

Pregunta: ¿Qué te sugieren estas fotos?
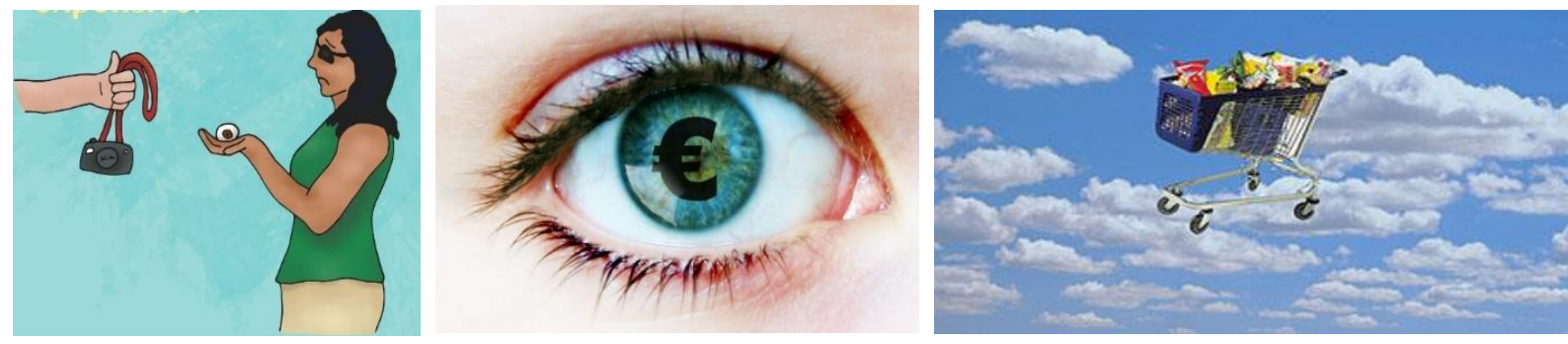

Respuesta: las tres están relacionadas con los precios. ¿Crees que es mucho o poco? ¿Por qué? ¿Qué expresión utilizas en rumano para referirte a algo muy caro / muy barato? ¿Implica una parte del cuerpo? ¿Cómo se dice en inglés?

MUY CARO

MUY BARATO 


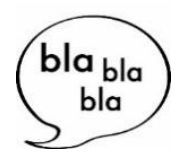

\section{Expresión oral}

Elige una opción y comenta con tus compañeros / tu profesor(a):
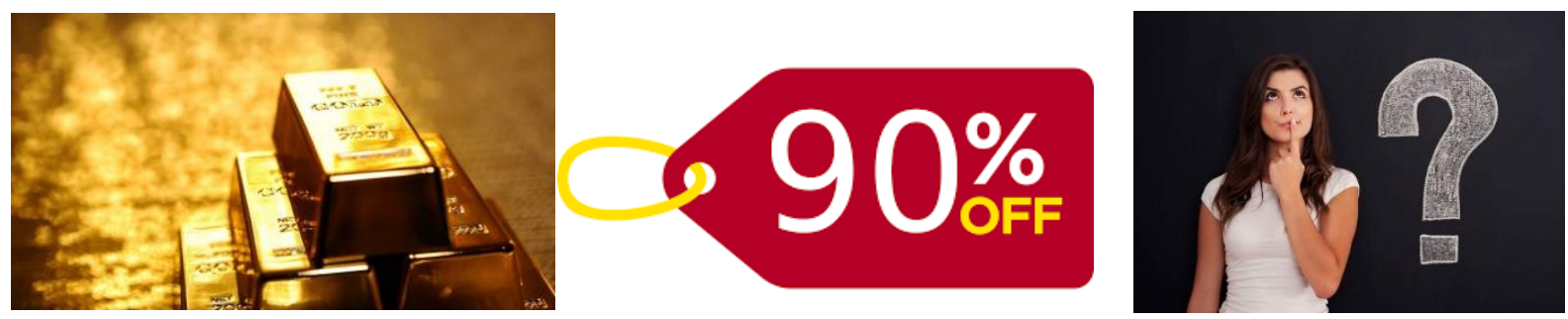

¿Cuánto cuesta un Ferrari?

¿Cuánto cuesta un piso en Ibiza?

¿Cuánto cuesta un cuadro de Matisse?

¿Cuánto cuesta un Huawei Mate X?

¿Cuánto cuesta un abrigo Canada Goose?

¿Cuánto cuesta un billete de autobús en Bucarest?

¿Cuánto cuesta una hora de parking en el centro de Bucarest?

¿Cuánto cuesta una cena en el Sublimotion?

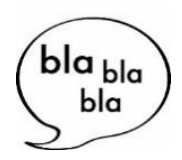

\section{Expresión oral}

¿Qué productos están por las nubes en Navidades?

¿Qué productos están por las nubes en Semana Santa?
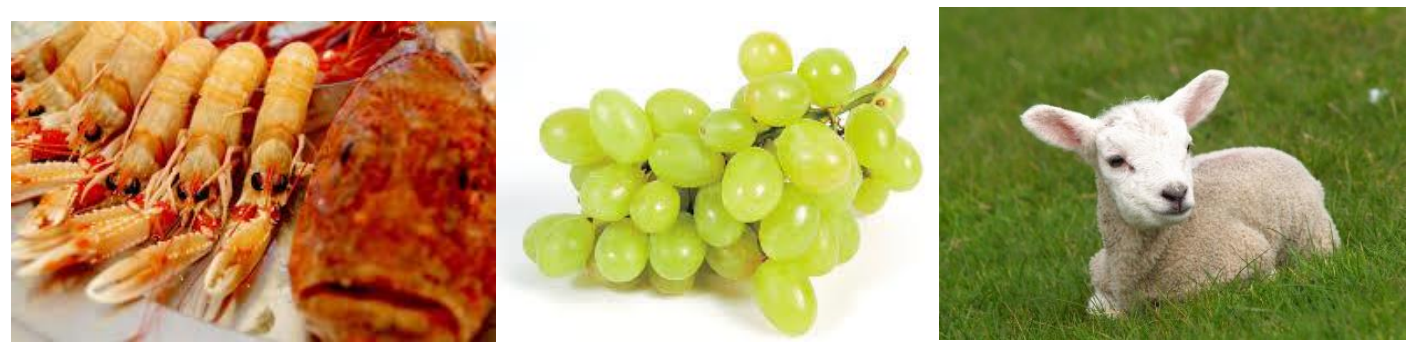


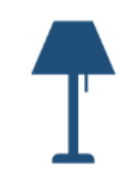

En acción

Prepara una cena de Navidad por todo lo alto. Puedes tirar la casa por la ventana. ¿Qué productos compras?
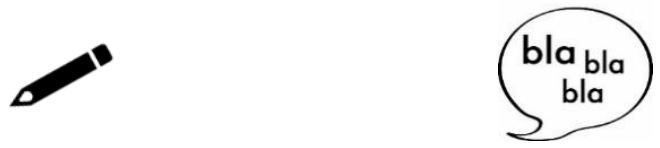

Expresión escrita Expresión oral

¿Qué es lo más caro que has comprado en tu vida? ¿Ha valido la pena?

¿Qué es lo más caro que te han regalado? 


\subsubsection{Actividad 3: Carmelo no mueve un dedo}
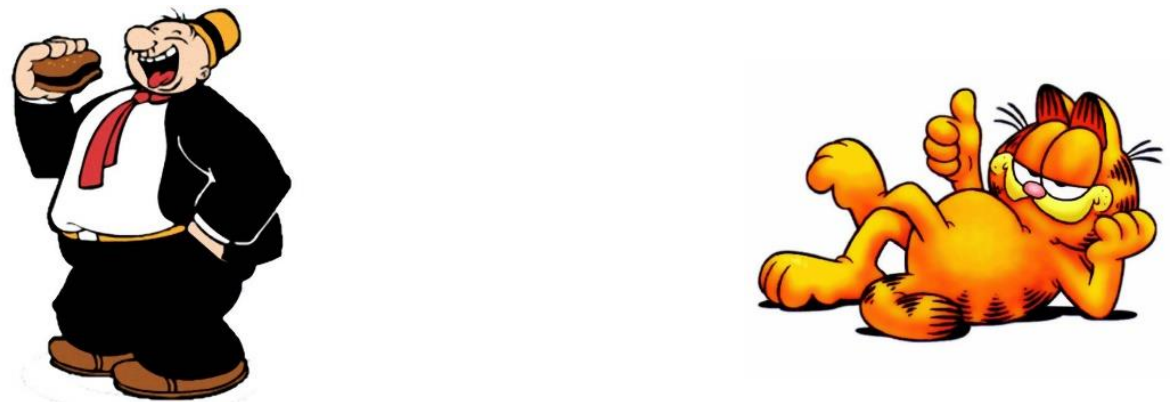

Contenido comunicativo: hablar de rutinas diarias.

Contenido gramatical: el presente indicativo de los verbos regulares e irregulares (transitivos y reflexivos); adjetivos para describir la actitud frente al trabajo.

Destrezas: comprensión lectora, expresión escrita, expresión oral.

Objetivos: ampliar la competencia léxica a través de UF contextualizadas y adscritas a la función comunicativa "realidades cotidianas", relacionadas con el trabajo y el estudio; adquirir conciencia fraseológica (significado literal vs. significado idiomático); fomentar la autonomía de los aprendices y el uso de las fuentes lexicográficas; comprender la importancia de recurrir a los diccionarios, fomentando la competencia pluringüe.

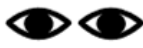

\section{Comprensión lectora}

\section{Lee este texto sobre Carmelo, amante de la buena vida.}

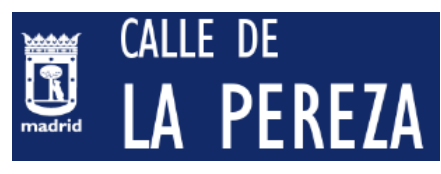

Carmelo es madrileño y vive en la calle La Pereza Galdós. Todo el mundo, tanto amigos como en el trabajo, lo llama "Caramelo" porque siempre tiene uno en el bolsillo: de melón, de chocolate, de miel, de limón, de naranja...Carmelo es guardia de seguridad en un aparcamiento, cerca de su casa. Se levanta todos los días a las diez, se ducha, se viste, come un caramelo y se va a trabajar. Cuando llega al aparcamiento, cruza los brazos, cierra los ojos y espera a que pase el tiempo. No mueve un dedo en todo el día, bueno, sí, para llevarse a la boca un caramelo. Si hay un problema, se lava las manos. ¿Dónde? En el baño, así nadie le ve el pelo en todo el día. Cuando llega a casa, cena y mira un rato la tele. Le gustan los programas sobre animales: tortugas, pandas, kaoalas y osos perezosos. Tiene un gato más vago que él. Se pasa el día ronroneando y rascándose la barriga. Antes de acostarse, Carmelo come un caramelo. 
Ordena estas expresiones que resumen un día normal en la vida de Carmelo.

UN NO DEDO MUEVE

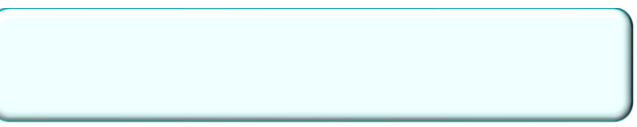

LA TOCA SE BARRIGA

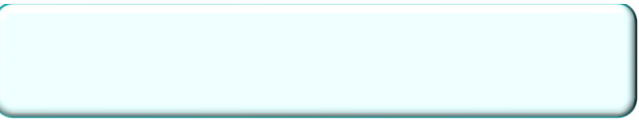

AGUA AL PALO DA UN NO

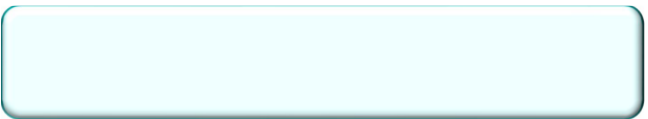

TOCA NARICES LAS SE

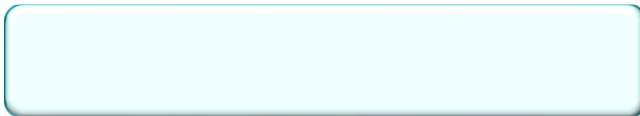

VES LE PELO NO EL

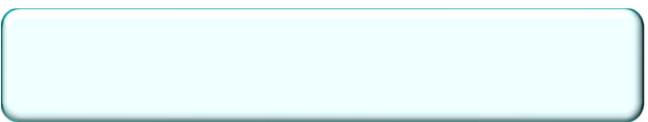

BARRIGA SE LA RASCA

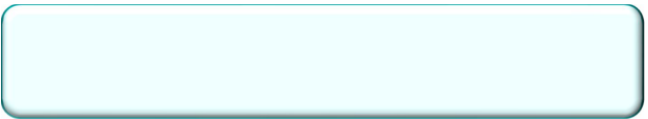




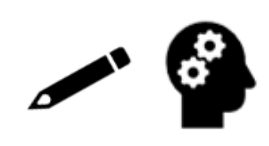

\section{Expresión escrita}

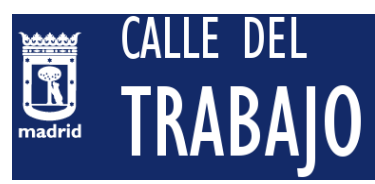

Curro, un vecino de Carmelo, es totalmente diferente. Redacta un texto sobre su día normal y utiliza expresiones como: dejarse la piel, romperse los codos, arrimar el hombro, quemarse las cejas, dar el callo, etc. Previamente, junto con un compañero, busca en los diccionarios los significados desconocidos.

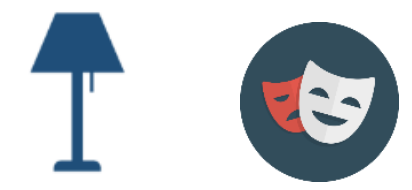

\section{En acción}

Planteada como un concurso por grupos, los alumnos salen por turnos y cogen una ficha que contiene una UF, que escenifican con mímica delante de sus compañeros. Estos cuentan con un minuto para adivinarla.

Se trata de las UF anteriormente estudiadas, en una actividad lúdica, de refuerzo:

no mover un dedo, no dar un palo al agua, tocarse la barriga, rascarse la barriga, estar de brazos cruzados, cruzarse de brazos, lavarse las manos, no ver el pelo, mirarse el ombligo, mirarse las uñas, tocarse las narices, pasar de todo, etc. 


\subsection{Propuestas didácticas para los niveles B1 - B2}

Respecto a las actividades propuestas para los niveles A1-A2, este apartado representa un paso adelante, puesto que los aprendices ya cuentan con más recursos lingüísticos para llevar a cabo tareas complejas. Por lo tanto, perseguimos nuevos objetivos, apoyándonos en el marco teórico (especialmente en el análisis contrastivo) e integrando las UF seleccionadas en la base de datos para el nivel intermedio. Tenemos siempre presente la herramienta que hemos elaborado a la hora de crear materiales que sirvan para que los aprendices rumanos de ELE adquieran competencia fraseológica, pero también locuciones somáticas no verbales, descartadas del corpus, pero que consideramos útiles por su recurrencia y eficacia.

En las unidades didácticas creadas para estos niveles, el componente fraseológico cobra más protagonismo y, en ocasiones, representa la columna vertebral de las propuestas didácticas. Optamos por una batería de actividades integradoras de funciones comunicativas, buscando en todo momento aportar muestras reales, que un hablante nativo produciría libremente. Coincidimos con Aguilar Ruiz (2011) cuando trata de dar respuesta a la espinosa pregunta "qué fraseología enseñar", del elevadísimo número de variantes diatópicas.

hemos de hacer hincapié aquí en que lo verdaderamente importante para el alumno es aprender correctamente las UFS propuestas, prestando especial atención a los aspectos pragmáticos para poder aplicarlas en situaciones adecuadas, y evitando, ante todo, posibles interferencias con su lengua materna (Aguilar Ruiz 2011:3).

Seguiremos aprovechando los recursos visuales, las lluvias de ideas, activaremos conocimentos léxicos previos, fomentaremos la reflexión y las estrategias de autoaprendizaje. Reiteramos nuestra convicción de que la motivación es un factor esencial y que una de las tareas fundamentales del docente es acercarse a los intereses de los alumnos, que son los verdaderos protagonistas de su aprendizaje. En este sentido, coincidimos con la perspectiva de Kaufmann:

In the most effective classrooms it is not the language that is studied, but some other subject of interest to the students. In studying another subject the learners absorb the language, and are less self-conscious about their own language difficulties in their enthusiasm to communicate about something of interest to them. After the learners are exposed to a sufficient amount of interesting content by listening and reading in the language, they gradually become aware of the need for correct structure and word use. Then they are motivated to work on these aspects of the language. It is best if the learners ask for help as they need it, rather than having to respond to the timetable of the teacher. The teacher is able to correct the students privately or on written 
content and to offer relevant grammatical explanations as required. The classroom can be a useful learning environment if it is used in a flexible way which puts the learner and not the teacher in control (Kaufmann 2003:97).

Por esta razón, nuestras propuestas representan en su mayoría actividades lúdicas, dinámicas y divertidas que fomentan la creatividad de los alumnos y están diseñadas para que perduren a largo plazo en su memoria afectiva. Las lecturas seleccionadas son de mayor extensión y ya representan textos auténticos, en ocasiones manipulados por nosotros según los objetivos fraseodidácticos perseguidos. Muchas actividades parten de la premisa fundamental de que podemos comprender lo abstracto utilizando la experiencia y los conocimientos que tenemos de lo concreto. Los significados básicos nos sirven, por lo tanto, para obtener el resto de significados por medio de relaciones metafóricas y metonímicas, concepción sumamente útil para entender muchas UF somáticas integradas en las siguientes actividades. 


\subsubsection{Actividad 1: Flechazo transilvano}

Contenido comunicativo: contar anécdotas; contar experiencias; describir personas y situaciones; hablar de planes y proyectos.

Contenido gramatical: el presente de subjuntivo en las estructuras morfosintácticas con los verbos sugerir, recomendar, aconsejar, esperar, etc.; el presente de subjuntivo en la subordinada temporal.

Destrezas: comprensión lectora, expresión escrita, expresión oral.

Objetivo: ampliar la competencia léxica a través de UF contextualizadas y adscritas a numerosas funciones comunicativas: "sentimientos" (expresar miedo, expresar gozo y alegría) "realidades cotidianas (desplazarse, expresiones referentes al trabajo y al estudio, expresiones referentes al dinero), "descripciones" (describir el carácter de una persona; describir físicamente a una persona), acciones comunicativas (aconsejar, sugerir, aconsejar), "relaciones sociales" (expresar atracción amorosa).

$\infty \odot$

\section{Comprensión lectora}

\section{Lee este correo electrónico que te envía Inmaculada, una amiga que está de vacaciones en Rumanía:}

¡Hola!

Te escribo desde Bucarest. Ya sabes que estoy aquí de vacaciones, pero tengo que darte una gran noticia.

He conocido a un chico estupendo. Es guapo, inteligente y divertido. No te lo vas a creer: estaba sola, haciendo dedo en Transilvania y se me habían puesto los pelos de punta por las historias que me habían contado, vampiros chupasangre y condes con colmillos. Se hacía de noche, los búhos ululaban a lo lejos y se me heló el corazón.

De repente, Marcel paró el coche. Vio mi cara de susto y, con una sonrisa de oreja a oreja, me invitó a subir. Se puso a hablar en rumano, en inglés, en alemán. Yo no me enteraba de nada, pero asentía con la cabeza y me lo comía con los ojos...es que tenía hambre, sabes...

No te lo cuento con pelos y señales, pero fue un flechazo... y hemos decidido casarnos. ¡Y nos vamos a quedar aquí, en Rumanía!! Ya me imagino que dirás que he perdido la cabeza, pero estoy supercontenta. Y enamoradísima de Marcel. Me muero por sus huesos, tía. Es mi media naranja, sabes... Todavía no tenemos la fecha porque tenemos que preparar algunos documentos $\mathrm{y}$, como en todas partes, "las cosas de palacio van despacio".

Claro que primero tenemos que alquilar o comprar una casa. Ahora vivimos con sus padres, en Rahova, un barrio muy auténtico, con mucho ambiente. Pero yo quiero que vivamos solos, porque creo que a mi suegra no le caigo muy bien. Además, habla por los codos y tiene una lengua 
viperina. En cambio, su padre tiene un corazón de oro. Marcel se parece a él, es un sol, no sé si te lo he dicho.

El problema es que la vivienda está por las nubes, aunque todos dicen que hay crisis y que los precios han bajado bastante. En fin, ya veremos. O sea, lo primero es instalarnos y después encontrar curro. Me han dicho que en el Instituto Cervantes necesitan profesores nativos y ahora ese trabajo me viene al pelo.

Tendré que mandar el CV y luego hacer una entrevista. Por lo visto, los alumnos son muy buenos: estos rumanos aprenden idiomas en un abrir y cerrar de ojos y ya sabes que a mí eso de dar clases siempre me ha gustado.

Y luego quiero tener como mínimo tres hijos porque me encantan los niños.

También me gustaría aprender rumano para hablar con la gente. Pensaba que iba a ser pan comido, pero la verdad es que tengo que estrujarme el cerebro para entender algo. Tendré que encontrar una buena escuela porque no quiero perder el tiempo.

Bueno, ya te contaré, como ves, son emociones fuertes.

Y tú, ¿qué tal?

Un beso,

Inma 
Busca en el texto anterior palabras o expresiones que tengan los siguientes significados: hacer auto-stop:

hablar mucho:

ser buena persona:

sentir miedo:

rápidamente:

estar locamente enamorado/a:

pensar mucho:

mirar con muestra de deseo:

actuar sin lucidez:

ocurrir en un buen momento:

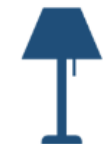

\section{En acción}

Elige la opción que corresponde a los siguientes enunciados del texto anterior:

"las cosas de palacio van despacio"

a) los trámites tardan mucho

b) hay que sobornar a las autoridades

c) las prisas no ayudan

"la vivienda está por las nubes"

a) se construyen rascacielos

b) los pisos son caros

c) se venden áticos

"es pan comido" 

a) cuesta trabajo
b) es complejo
c) es fácil

"con pelos y señales"
a) brevemente
b) por escrito
c) detalladamente

"media naranja"

a) amigo entrañable

b) pareja ideal

c) socio

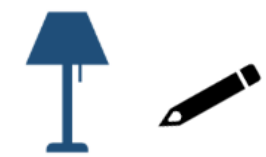

Construye frases con las siguientes palabras: colmillo, búho, curro, flechazo, asentir. 


\section{$-6$}

\section{Expresión escrita}

Ahora intenta hacer una reconstrucción de los planes que tiene Inmaculada para su futuro. Utiliza las expresiones temporales: cuando, en cuanto, hasta que, antes de que, etc.
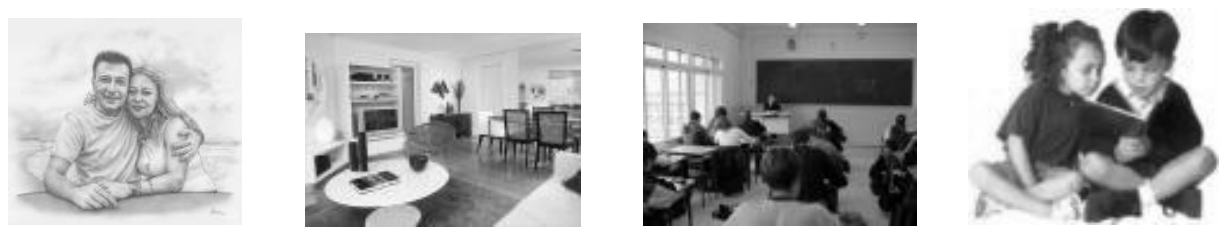

Primero, Inmaculada arreglará los documentos para vivir en Bucarest, y en cuanto

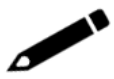

\section{Expresión escrita}

Te has quedado sorprendido/a con todas las novedades de Inmaculada. Escríbele un correo para desearle lo mejor, utilizando las siguientes estructuras: espero que, te deseo que, ojalá.

Podrías usar estas expresiones: "cruzar los dedos", "abrir el corazón", "ser almas gemelas".

Aprovecha también algunas estructuras para advertirle a tu amiga de posibles peligros: te recomiendo que, te sugiero que, te aconsejo y utiliza algunas unidades que aportarán más expresividad a tu escrito: "andarse con cien ojos", "abrir los ojos" "tener pájaros en la cabeza", "meterse en la boca del lobo", "plantar cara", "poner pies en polvorosa", "patinar la neurona", "ir con pies de plomo". 

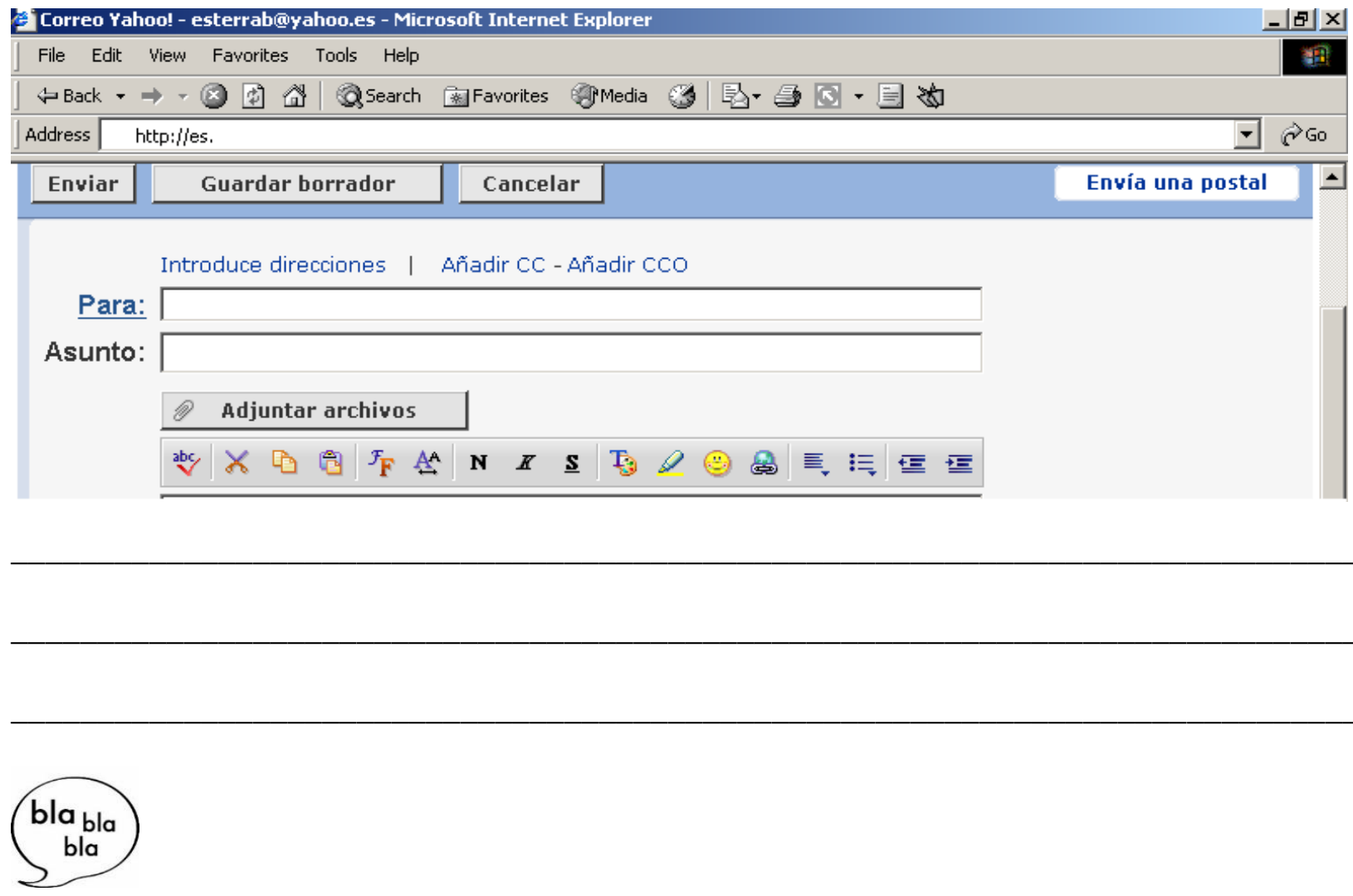

\section{Expresión oral}

Contesta las siguientes preguntas y comenta con tus compañeros:

¿Has hecho auto-stop alguna vez?

¿Has viajado a Transilvania alguna vez?

¿Te has encontrado en una situación de peligro alguna vez?

¿Has vivido en el extranjero alguna vez?

¿Te has enamorado a primera vista alguna vez?

¿Has compartido un piso alguna vez? 


\subsubsection{Actividad 2: El enfado de Brazacos}

Contenido comunicativo: contar un suceso; redactar un informe; contar experiencias; operar cambios de registros (formal - informal).

Contenido gramatical: contraste de tiempos pasados.

Destrezas: comprensión lectora, expresión escrita, expresión oral.

Objetivo: ampliar la competencia léxica a través de UF contextualizadas y adscritas a numerosas funciones comunicativas como "sentimientos" (expresar enfado, fastidio, irritación, frustración), "realidades cotidianas" (dormir, comer, desplazarse, expresiones relacionadas con el trabajo, expresiones referentes al dinero), descripciones (describir el carácter de una persona), acciones comunicativas (expresar amenaza), información y comunicación; reconocer UF y relacionarlas con su lexema principal.

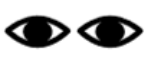

\section{Comprensión lectora}

Lee este fragmento extraído del blog del policía Lorenzo Madrona (más conocido como “Brazacos") y ordena los fragmentos para que su historia tenga sentido.

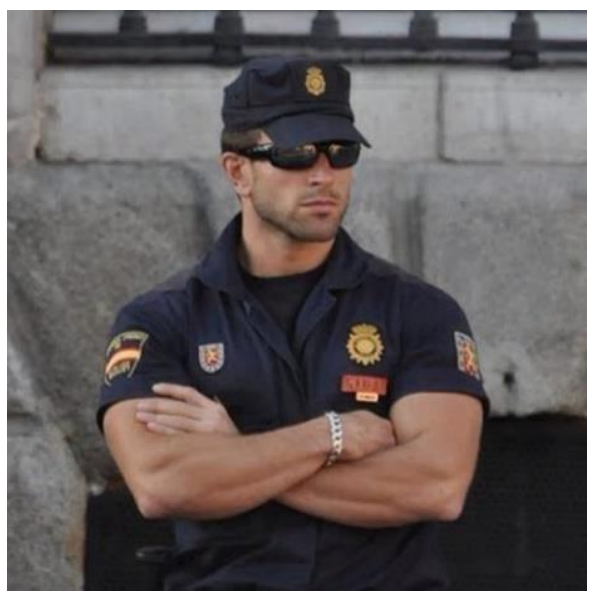




\section{(A)}

Hoy tenía que ser mi día libre, pero anoche me llamó mi jefe para decirme que Nacho se había puesto malo y tenía que sustituirlo yo. Se me subió la sangre a la cabeza cuando me lo dijo, pero me mordí la lengua y le contesté que sí. No quiero discutir con él porque ya lo he hecho en varias ocasiones y siempre se ha salido con la suya. Encima, ahora me tiene entre ceja y ceja.

(B)

Apenas conseguí pegar ojo en toda la noche, por el cabreo, la rabia y porque me tomé unas raciones de albóndigas para hacer boca y acabé comiendo medio kilo. Así que esta mañana a las cinco, en lugar de dormir a pierna suelta, me he despertado para ir a currar. Con lo bien que me habría quedado en mi casa, viendo la tele y rascándome la barriga.

\section{(C)}

Está claro que me he levantado con el pie izquierdo. En la comisaría el teléfono no ha parado de sonar, y eso que era domingo. Eché un ojo a unos informes que no tenían ni pies ni cabeza, los corregí y los archivé. A las once he bajado al bar, tenía el estómago en los pies porque no había desayunado nada. Además, quería estirar un poco las piernas. Me tomé un pincho de tortilla de bacalao para matar el gusanillo y un café en la barra. Estaba tan a gusto que metí la mano en el bolsillo para coger el tabaco. Ostras, pero si lo dejé hace un par de meses, después de la última revisión médica. Que si los pulmones, que si el corazón, que si la garganta. Tonterías. Lo hice por los cinco euros que me dejaba todos los días, que al final te cuesta el vicio un ojo de la cara.

\section{(D)}

Nada más volver a comisaría he tenido que coger la moto y he ido a toda pastilla a la carretera de Colmenar: colisión múltiple en ambos sentidos con cuatro choques en cadena. Hay gente que no tiene dos dedos de frente y se sube al volante con un par de copas de más.

\section{(E)}

Al llegar allí, el tío que había provocado el accidente no quería cerrar la boca y discutía con todo el mundo. Faltó poco para llegar a las manos. Incluso a mí me dijo de todo cuando le obligué a soplar en el aparatito. Me entraron unas ganas locas de romperle la cabeza, pero ya la tenía rota. Además, sabía que si llegaba a tocarle un pelo, me iba a llevar a juicio. ¿Por qué habré dejado de fumar?

Orden correcto: 1. 


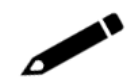

\section{Expresión escrita}

Vuelve a escribir el texto anterior sin utilizar ninguna palabra que exprese una parte del cuerpo.

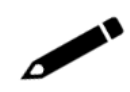

\section{Expresión escrita}

“Nada como la vida narrada por ti”

Inventa otra entrada en el blog de Lorenzo Madrona y cuenta un caso emocionante, utilizando expresiones como atracar a mano armada, armar hasta los dientes, tirar de la lengua, tener la mosca detrás de la oreja, andar con pies de plomo. 


\section{Expresión escrita}

Convierte el diario de Lorenzo Madrona en un informe policial.

bla bla
bla

Expresión oral

Contesta las siguientes preguntas y comenta con tus compañeros:

¿Te ha parado la Policía alguna vez?

¿Te han multado alguna vez?

¿Has llamado a la Policía alguna vez?

¿Has pensado ser policía alguna vez?

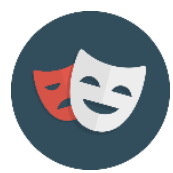

Juego de rol

En parejas, entablad una conversión como si fuerais Lorenzo Madrona y el chófer borracho. 
Durante el confinamiento en Valladolid, Lorenzo Madrona para por la calle a

a) una señora que va a casa de un hombre al que había conocido por Tinder dos horas antes

b) un señor que paseaba una mascota falsa

c) una señora que había sacado a pasear por sexta vez en un día al perro de su vecina

d) un chico piripi que se aburría en casa y se iba a tomar algo con un colega

e) un señor mayor que había salido a cazar pokémons

f) un grupo de personas que estaban organizando una pelea de gallos

En parejas, entablad una conversación como si fuerais los protagonistas del encuentro.

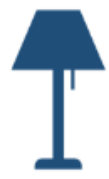

\section{En acción}

Lorenzo Madrona ha tenido un día de perros, así que está cansado, enfadado y frustrado. Fíjate en las siguientes imágenes y piensa qué sentimientos o estados te sugieren. ¿Qué te lleva a sentir eso? ¿Lo relacionas con alguna parte del cuerpo?
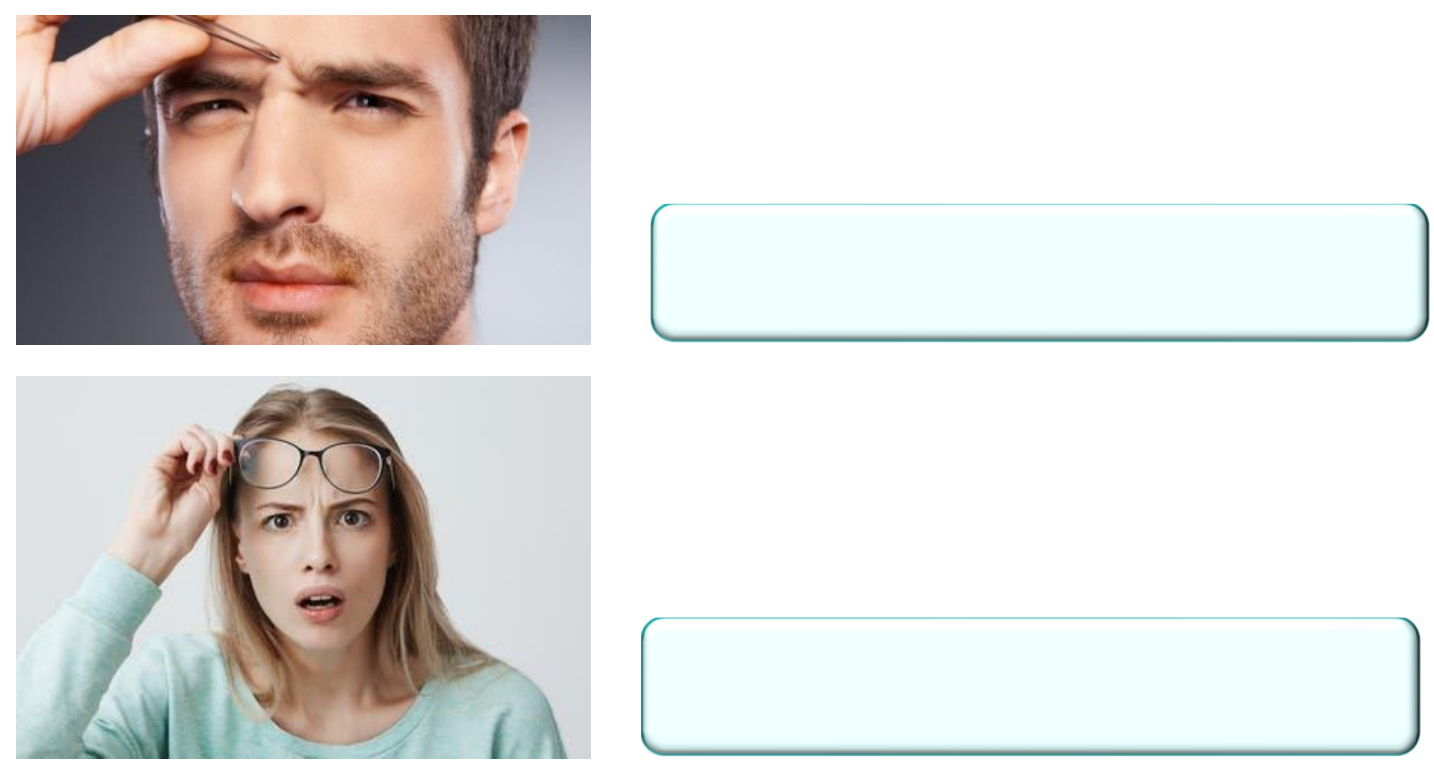

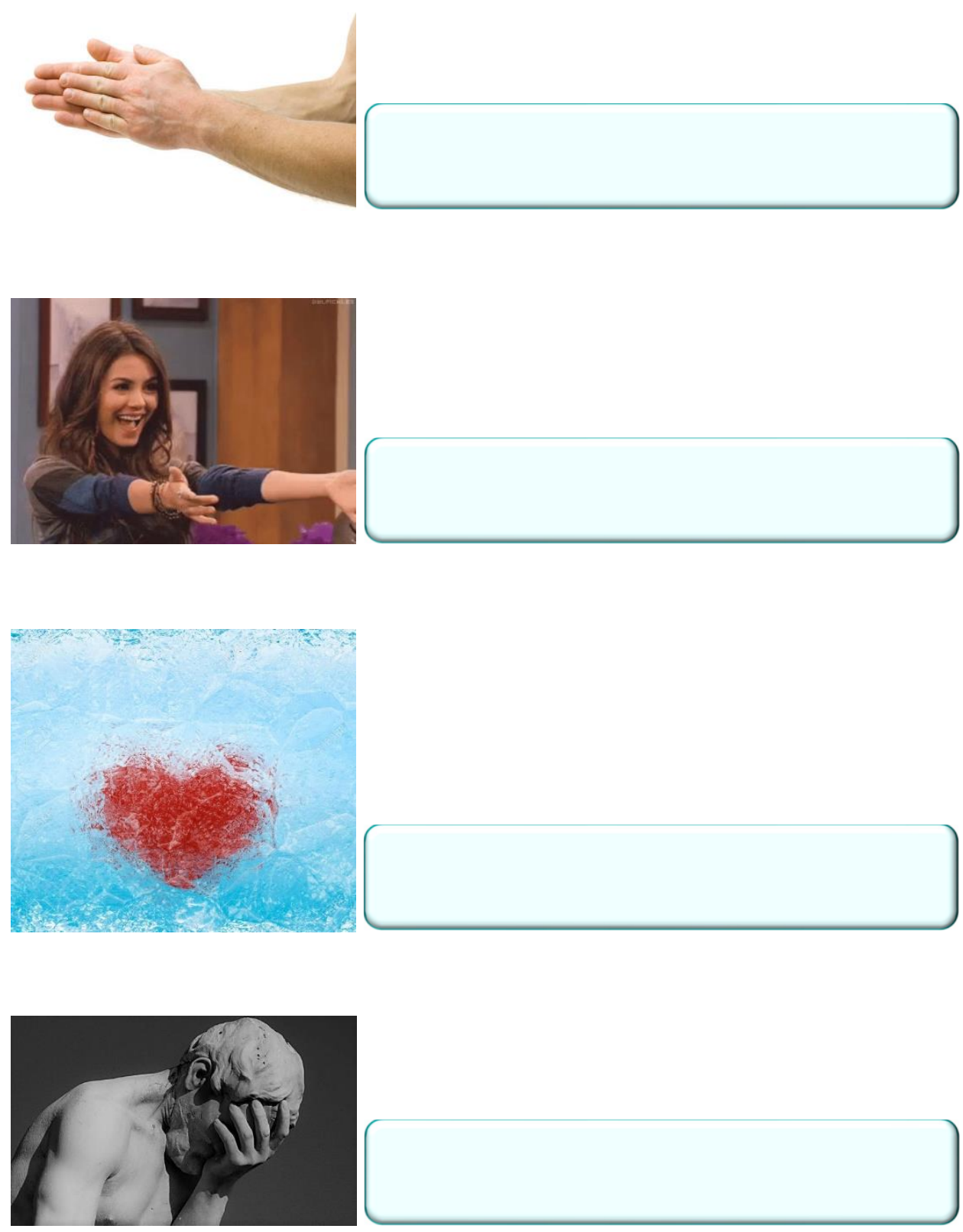

bla bla
bla

\section{Expresión oral}

¿Cuándo sentiste por última vez alegría, vergüenza, miedo, satisfacción, frustración, ira, etc.? Comenta el contexto con tus compañeros. 


\subsubsection{Actividad 3: No hay que andarse con bromas}

Contenido comunicativo: crear campañas publicitarias; debatir sobre costumbres universitarias en España; contar sucesos; contar experiencias.

Contenido gramatical: contraste de tiempos pasados; el imperativo.

Destrezas: comprensión lectora, expresión escrita, expresión oral.

Objetivo: ampliar la competencia léxica a través de UF contextualizadas y adscritas a funciones comunicativas como "sentimientos" (expresar alegría, gozo, satisfacción), "realidades cotidianas" "acciones comunicativas" (expresar amenaza, expresar dificultad para hacer algo), descripciones (describir el carácter de una persona); profundizar en los SO de nivel intermedio con el lexema "cabeza"; crear eslóganes publicitarios a partir de UF; reflexionar sobre significado connotativo y significado denotativo.

\section{$\infty$}

\section{Comprensión lectora}

\section{Lee este artículo y subraya las palabras nuevas.}

(A) Para algunos son un rito de iniciación de cara a la entrada a la universidad y sirven para integrar a los nuevos, mientras que para otros pueden llegar a suponer un trato "vejatorio» para los alumnos recién llegados y no deben consentirse en una institución académica. Hay diferentes opiniones, pero lo cierto es que las universidades -y cada vez en mayor medida los colegios mayores y residencias- se esfuerzan cada año por terminar con las novatadas dentro de los campus y en sus instalaciones.

(B) En el mes de septiembre no es raro ver por algunas ciudades a jóvenes con una «N» en sus rostros acompañados por otros con una « $V$ », son los novatos y los veteranos. Juegos de presentación, disfraces o lanzar harina, huevos podridos y otros productos son algunas de las acciones a las que más se recurre habitualmente para recibir a los nuevos estudiantes, aunque también suele estar presente el alcohol.

(C) «Nos preocupa muchísimo», explica la vicerrectora de estudiantes del centro vallisoletano. $Y$ es que pese a llevar tres años intentando «concienciar» y «sensibilizar» sobre este asunto, las novatadas persisten. "Nos gustaría que la acogida a los nuevos estudiantes fuese más civilizada», explica la representante de la institución académica que, incluso, ha contratado seguridad privada para estos días con la intención de que los estudiantes no hagan botellón. Además, anima a los recién llegados a denunciar todo aquel comportamiento que se pase de la raya y les haga sentirse humillados.

(D) Con el inicio de las clases, la Universidad de Valladolid ha lanzado una campaña en contra de estas prácticas. Entre otras cosas, incluye carteles con emoticonos de WhatsApp, muy utilizados por los jóvenes, que se han colocado en los centros universitarios. 
(E) Tan preocupados están en Burgos por este asunto, que el rectorado ha pedido ayuda a la Policía y ha enviado una carta a toda la comunidad universitaria mostrando su inquietud por el "desarrollo y duración» de las novatadas que se han producido estos días en los recintos universitarios, por su repercusión social y sobre la salud pública, así como por la generación «intolerable de basura». En la Universidad de León, se intentan controlar estas prácticas a través de reuniones con las comisiones de alumnos de cada facultad, detalla la vicerrectora del área. «Nos preocupa, pero por el momento no ha habido quejas de problemas graves», explica.

(F) En la otra cara de la moneda se encuentran los estudiantes. Andrea y Nico son dos de los novatos de este año en la Universidad de Valladolid. Se han enfrentado a "pruebas» como juegos de presentación o mancharse con harina y ketchup, pero no ven ninguna maldad en los veteranos ni les parecen mal las novatadas. Al contrario, creen que les están sirviendo para conocer al resto de sus compañeros de aula y les ayudan a integrarse en su nuevo entorno.

(G) A favor están también los veteranos que hace tan sólo un año estaban en ese mismo papel. «Es una forma de divertirse, de que se conozcan mejor y hagan amigos», asegura convencido Marcos, que también hace hincapié en que nunca se obliga a nadie a pasar las pruebas. "Hay chicos que no han querido participar y no ha pasado nada», relata.

Adaptado de ABC, 25/09/2017

https://www.abc.es/espana/castilla-leon/abci-novatadas-quebradero-cabeza-para-universidad201709250837 noticia.html

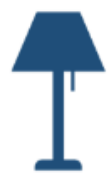

\section{En acción}

Busca en el texto las palabras que tengan los siguientes significados:
a. insistir
b. residencia universitaria que, además de alojamiento, ofrece actividades culturales, deportivas y a veces religiosas............... (colegio mayor)
c. principiante en una facultad (novato)
d. exagerar (pasarse de la raya)
e. natural de Valladolid (vallisoletano)
f. reunión en espacios públicos, normalmente nocturna y ruidosa, para beber alcohol que se compra previamente (botellón) 


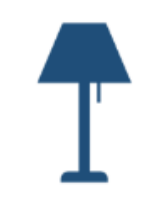

En acción

Relaciona estas ideas con los párrafos del texto:
a) Problemas con la basura
b) La Policía colabora con los centros universitarios
c) Pasan por el aro con alegría
d) Alza tu voz
e) Novatadas clásicas
f) Campaña en las redes
g) Bautismo universitario

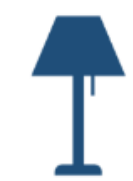

\section{En acción}

Elige un título para el texto entre los que te sugerimos y explica tu elección. ¿Se te ocurre otro mejor? Argumenta tu respuesta.

Novatadas, un quebradero de cabeza para la universidad

Novatadas, una comedura de coco para la universidad

Novatadas, un calentamiento de cabeza para la universidad

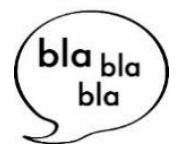

\section{Expresión oral}

\section{Comenta con tus compañeros:}

¿En tu país son habituales las novatadas? ¿Tienen un nombre?

¿Dónde se suelen hacer? (universidad, mili) ¿Cuáles son las más habituales?

¿Has sido alguna vez "novato" o "veterano"?

¿Qué bromas se gastan en los campamentos de verano? 


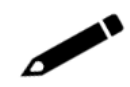

\section{Expresión escrita}

Construye frases con las siguientes palabras, colocaciones y locuciones: broma pesada, no tener gracia, tener sentido del humor, ser un cachondo mental, sosola,

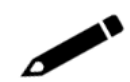

\section{Expresión escrita}

Adopta una de estas posturas y elabora un escrito sobre las novatadas, aportando argumentos.

A. Deberían estar totalmente prohibidas, ya que son humillantes para los nuevos estudiantes y pueden llegar incluso a provocar situaciones perjudiciales para la salud (golpes, comas etílicos, etc.)

B. Es una forma simpática de conocer a tus compañeros, de romper el hielo y de integrarte en un grupo. Aunque se pasa un mal rato, tendrás anécdotas que contar durante toda la vida. 


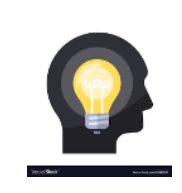

Siguiendo este modelo, crea tu eslogan usando emoticones.
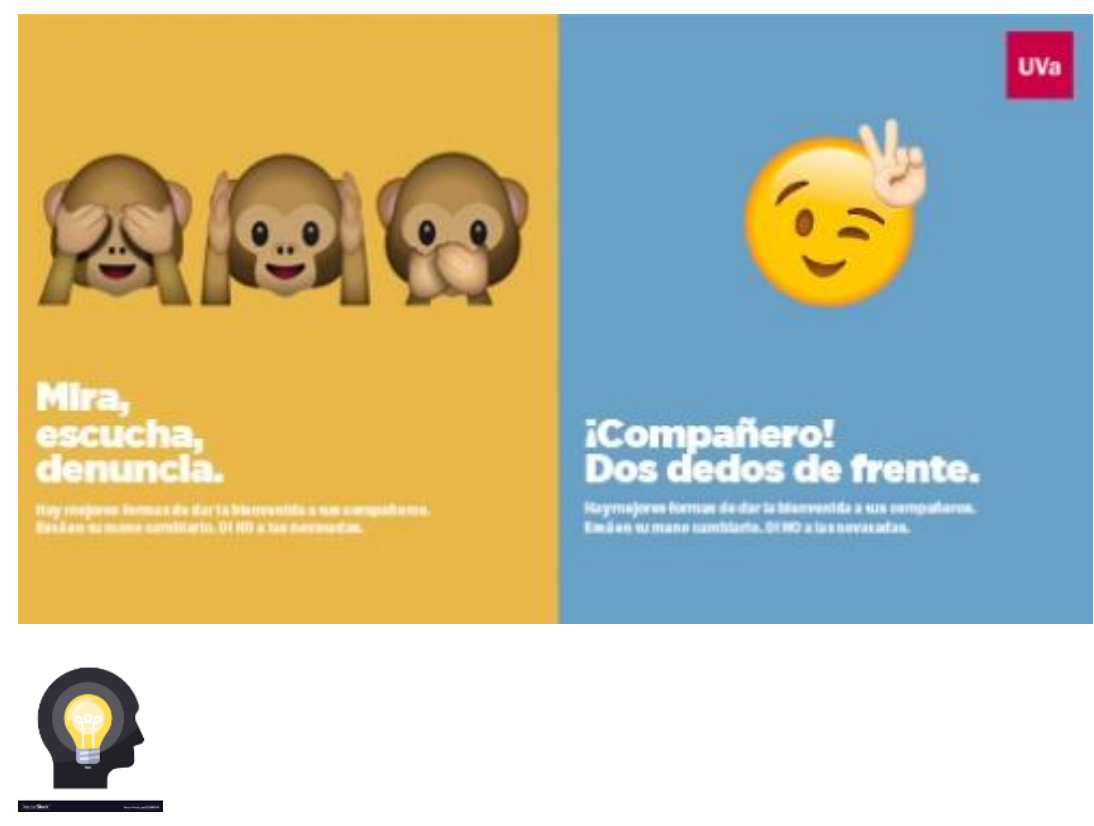

¿Qué te sugiere este cartel?

En parejas, comentad el eslogan: “LEVANTA UNA MANO CONTRA LA VIOLENCIA DE GÉNERO”

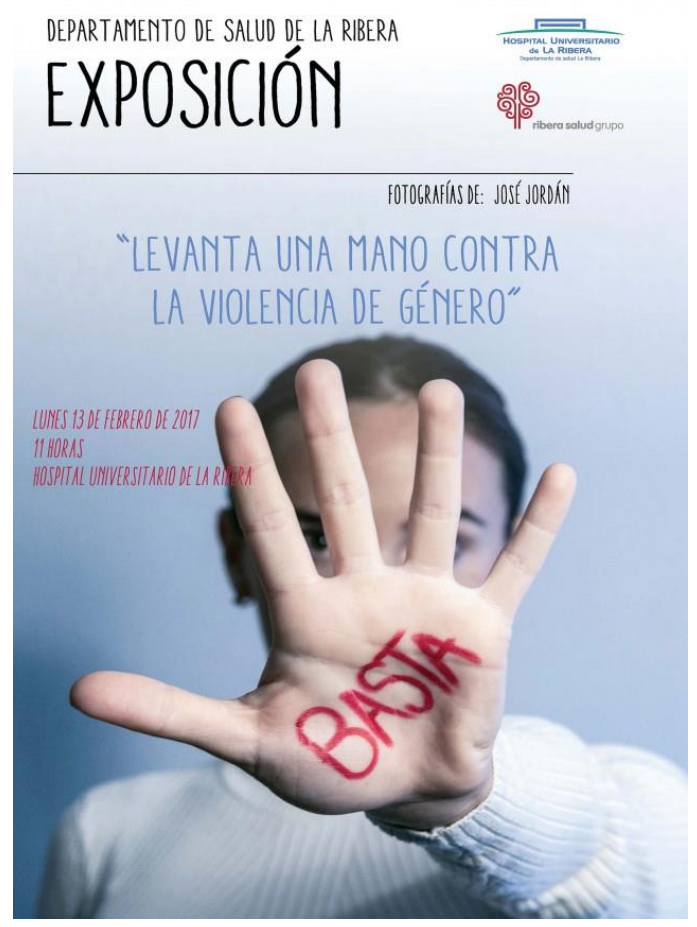


i

\section{En acción}

Siguiendo el ejemplo anterior, elaboraremos campañas publicitarias y eslóganes para llamar la atención sobre aspectos como:

el abandono escolar

la pobreza

la siniestralidad laboral

el consumo de drogas

la ludodependencia

la trata de personas

la explotación laboral

la xenofobia

la homofobia

el maltrato animal

el cambio climático

la censura

el bullying

los trastornos alimenticios (anorexia, bulimia, etc.)

En parejas, elegid tres temas que son de mayor interés para vosotros, buscad fotos e información en la red y presentad vuestra propuesta al resto de la clase. 


\subsubsection{Actividad 4: Jacinto tiene espinas}

Contenido comunicativo: describir personas; describir situaciones; contar sucesos; hablar sobre conflictos laborales; expresar quejas.

Contenido gramatical: contraste de pasados; el subjuntivo presente en estructuras de tipo: estar hasta las narices de que + subjuntivo).

Destrezas: comprensión lectora, expresión escrita, expresión oral.

Objetivo: identificar las UF en un contexto real, llevar a cabo el proceso de descodificación de las mismas y proporcionar contextos idóneos para reutilizarlas con eficacia; ampliar la competencia léxica a través de UF adscrtias a funciones comunicativas como "realidades cotidianas" (expresiones referentes al trabajo y al estudio), actividades comunicativas (expresar reproches, expresar enfado e irritación), "descripciones" (describir el carácter de una persona), información y comunicación; presentar una serie de UF somáticas agrupadas en torno a la función comunicativa "expresar hartazgo"; generar UF a partir del verbo soporte "echar".

\section{Comprensión lectora}

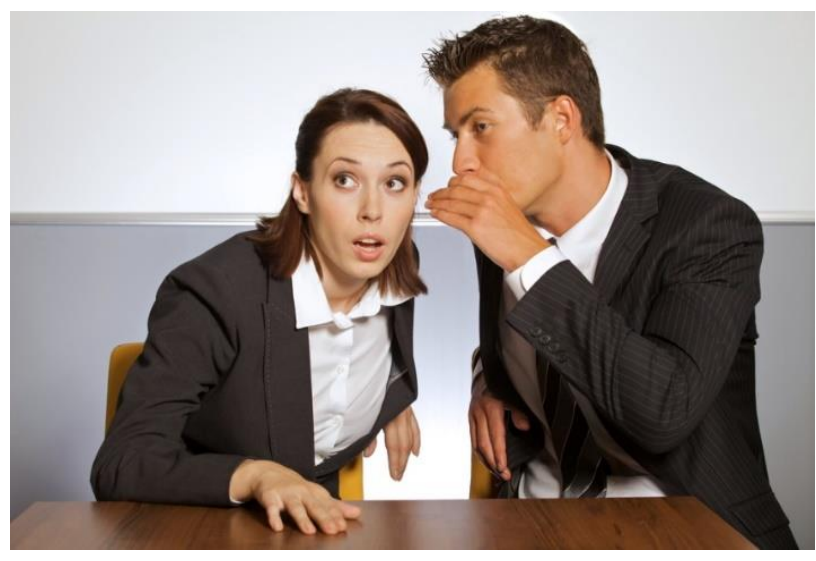

Lee esta conversación entre Narciso y Azucena sobre su nuevo compañero, Jacinto.

- Oye ¿qué te parece el nuevo?

- ¿Quién, Ramos?

- No, Jacinto, de contabilidad.

- Pues no sé, parece majete...un tío normal... ¿por?

- Es que el otro día me quedé a cuadros cuando me echó en cara que las comidas con los clientes eran muy caras. Vaya rata miserable. En la reunión también le dijo al jefe que había que recortar gasto en papel higiénico. Este tío está mal de la cabeza. La cara que puso el jefe...

- Bah, creo que lo decía de broma, le gusta tomar el pelo a la gente. 
- $\quad$ No te creas. Luego siguió con el tóner, el papel, el café soluble. Y nadie le paraba los pies, ¿te lo puedes creer? A mí me hervía la sangre, pero hice un esfuerzo para aguantar el tipo.

- Yo que tú, le diría las cosas a la cara, hablando se entiende la gente.

- Qué va, paso de él. Y he visto que otros también se han dado cuenta de qué pie cojea. Ándate con ojo.

- Bueno, ha empezado el hombre con el pie izquierdo, pero no es para tanto. En el fondo, quiere arrimar el hombro y sacarnos de la crisis.

- Pues, me parece a mí que si sigue así, Jacinto tiene los días contados en la floristería.

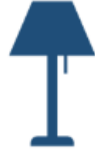

\section{En acción}

Busca en el texto anterior expresiones equivalentes para:
a) ser muy tacaño
b) ayudar
c) enfadarse mucho
d) detener

e) sorprenderse

f) actuar con cuidado

h) reprochar

i) percatarse de los defectos

j) estar loco

k) burlarse

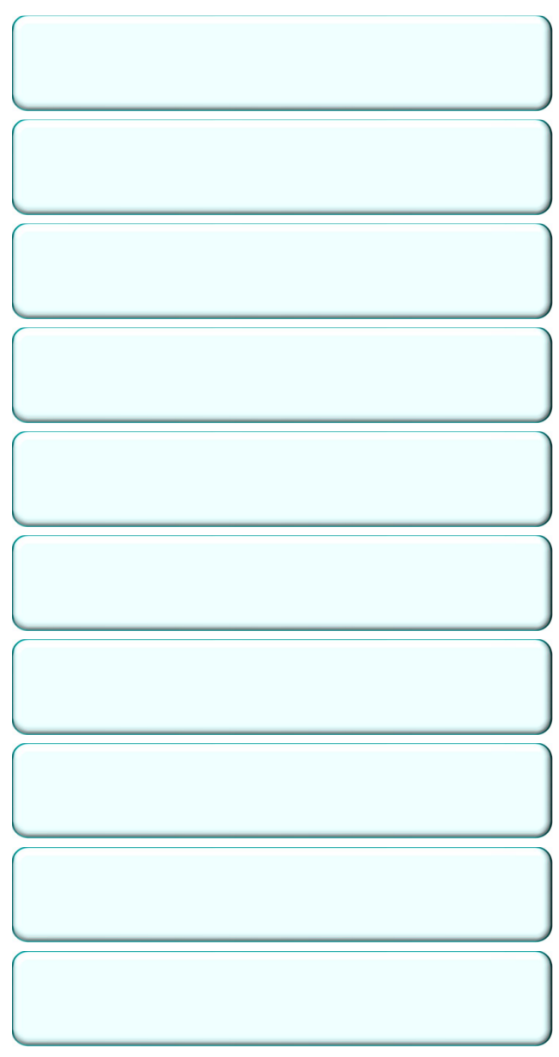




\section{f}

\section{En acción}

Fíjate en las expresiones que se construyen con el verbo "echar" y completa las frases: barriga // un ojo // una mano // espumarajos por la boca// una canita al aire// en cara

¿Cuál de ellas significa "ayudar”, "sentir rabia”, “engordar”, “divertirse”, “reprochar”, "mirar"?

Echa a estos documentos y dime si encuentras algún error. Date prisa que es urgente.

Mi jefa es una histérica, si llegamos tarde al trabajo o no entregamos las planificaciones a tiempo echa

Ha sentado la cabeza, está casado, tiene hijos y un trabajo estable, pero de vez en cuando echa

Dime si quieres que te eche con la traducción, tengo bastante experiencia.

No me eches mis errores, sé exactamente cuáles son.

Después del trabajo, siempre salgo con mis colegas a tomar una caña, no hago nada de deporte y como en el McDonald's de la esquina. No me extraña que haya echado

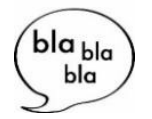

\section{Expresión oral}

\section{Hemos visto que Narciso y Azucena tienen problemas con Jacinto. En el trabajo siempre surgen conflctos que a veces son difícil de gestionar.}

Cuando tienes problemas, ¿quién te echa una mano? ¿Por qué? ¿Cómo se lo agradeces? ¿Sueles ayudar a tus compañeros? Cuéntanos una historia.

¿Tienes jefe / jefa? ¿Cómo es? ¿Se nota cuando se levanta con el pie izquierdo?

¿Quién es su brazo derecho en el trabajo? ¿Y su ojito derecho? Describe a esa persona y cuenta lo que hace.

"Zalameros", "pelotas", "lameculos". Todos conocemos a alguien en el trabajo o en la escuela. ¿Cómo actúa? 


\section{Comprensión lectora}

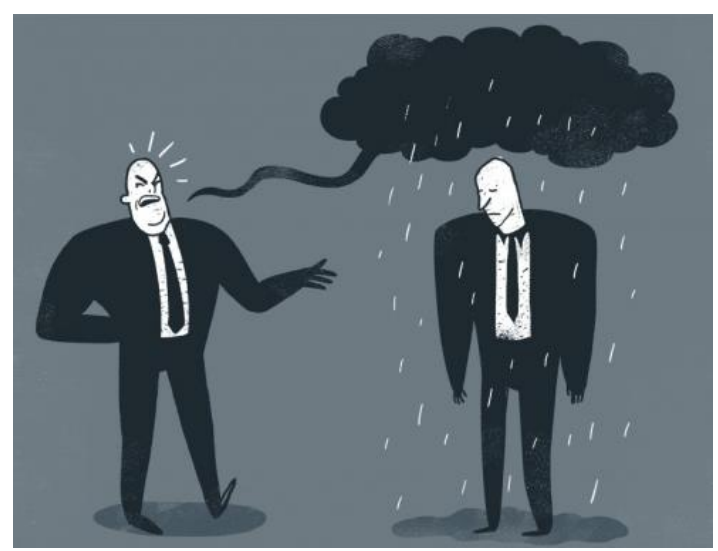

Varios estudios han enfocado el problema de las quejas en nuestra rutina diaria, ¿nos conviene quejarnos o es mejor callar la boca? La evidencia científica afirma que poner verde a la suegra porque otra vez criticó un mínimo detalle nuestro, confesar que te aburriste hasta la muerte en la cena de Navidad con la empresa y que odias con toda tu alma que te llame un amable extranjero para ofrecerte servicios de telefonía móvil que jamás vas a contratar, es algo sano. Sí, la vida no es perfecta ni brillante, así que quéjate, pero con justa razón.<smiles>C1C[C@H]2CC12</smiles>

\section{En acción}

¿Cuál de estas expresiones no significa estar harto?

Estar hasta las narices

Estar hasta la coronilla

Estar hasta los codos

Estar hasta el moño

Estar hasta las cejas 


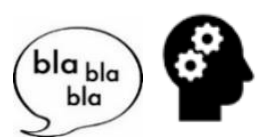

Expresión oral

\section{Quéjate conmigo}

Organiza junto con tus compañeros de clase grupos de terapia y aprovecha para quejarte de todo lo que te molesta en tu trabajo, en tu casa, en tu centro de estudios, en tu ciudad, en tu país o en el mundo que te rodea.

Utiliza las expresiones recién aprendidas y fíjate en la estructura gramatical requerida (estar hasta las narices de que + subjuntivo).

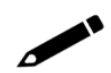

\section{Expresión escrita}

Escríbele una carta a un amigo y cuéntale los problemas en tu trabajo.

Hola:

¿Qué tal estás? Yo, la verdad, cada vez peor... 


\section{En acción}

El tabú del holgazán y del currante. En una empresa, no todo el mundo trabaja igual.

Planteada como un concurso por grupos, en esta actividad los alumnos cogen una ficha que contiene una UF y la explican delante de sus compañeros, sin poder utilizar las tres palabras "tabú" que aparecen en la parte superior de la tarjeta. Guiados por el docente, tienen que descubrir la UF.

\begin{tabular}{|c|c|c|c|}
\hline $\begin{array}{c}\text { NO MOVER UN } \\
\text { DEDO }\end{array}$ & $\begin{array}{l}\text { MIRARSE EL } \\
\text { OMBLIGO }\end{array}$ & $\begin{array}{c}\text { ESTAR DE BRAZOS } \\
\text { CRUZADOS }\end{array}$ & $\begin{array}{c}\text { RASCARSE LA } \\
\text { BARRIGA }\end{array}$ \\
\hline $\begin{array}{c}\text { mano } \\
\text { pie } \\
\text { vago }\end{array}$ & $\begin{array}{l}\text { mundo } \\
\text { cortar } \\
\text { vago }\end{array}$ & $\begin{array}{c}\text { cruz } \\
\text { mano } \\
\text { trabajar }\end{array}$ & $\begin{array}{l}\text { gordo } \\
\text { picar } \\
\text { echar }\end{array}$ \\
\hline $\begin{array}{c}\text { TOCARSE LAS } \\
\text { NARICES }\end{array}$ & $\begin{array}{c}\text { NO DAR UN PALO } \\
\text { AL AGUA }\end{array}$ & DEJARSE LA PIEL & $\begin{array}{c}\text { PONERSE MANO } \\
\text { A LA OBRA }\end{array}$ \\
\hline $\begin{array}{l}\text { cara } \\
\text { respirar } \\
\text { vago }\end{array}$ & $\begin{array}{l}\text { beber } \\
\text { pegar } \\
\text { sed }\end{array}$ & $\begin{array}{l}\text { moreno } \\
\text { esfuerzo } \\
\text { mucho }\end{array}$ & $\begin{array}{c}\text { brazo } \\
\text { comenzar } \\
\text { trabajo }\end{array}$ \\
\hline $\begin{array}{c}\text { SUDAR LA GOTA } \\
\text { GORDA }\end{array}$ & $\begin{array}{l}\text { LAVARSE LAS } \\
\text { MANOS }\end{array}$ & $\begin{array}{c}\text { ARRIMAR EL } \\
\text { HOMBRO }\end{array}$ & DAR EL CALLO \\
\hline $\begin{array}{l}\text { gordo } \\
\text { deporte } \\
\text { líquido }\end{array}$ & $\begin{array}{l}\text { lavabo } \\
\text { sucio } \\
\text { líquido }\end{array}$ & $\begin{array}{c}\text { ayuda } \\
\text { compañero } \\
\text { colaborar }\end{array}$ & $\begin{array}{c}\text { zapato } \\
\text { pie } \\
\text { piel }\end{array}$ \\
\hline
\end{tabular}




\subsubsection{Actividad 5: Próxima estación: amor}

Contenido comunicativo: contar anécdotas; dar consejos; reflexionar, analizar y poner en práctica diferentes registros.

Contenido gramatical: contraste de tiempos pasados; el condicional presente; el imperfecto de subjuntivo en la subordinada condicional.

Destrezas: comprensión lectora, expresión escrita, expresión oral.

Objetivo: ampliar la competencia léxica a través de UF contextualizadas que integran el lexema "ojo" y otros somatónimos; impartir UF adscritas a numerosas funciones comunicativas: "acciones comunicativas" (expresar amenaza, expresar desaprobación), descripciones (describir el carácter de una persona), "realidades cotidianas" (relacionadas con el trabajo).

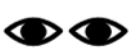

\section{Comprensión lectora}

\section{Ordena los siguientes fragmentos para que el texto tenga sentido}

¿Me está mirando? ¿O simplemente está paseando la vista por la gente del vagón? Voy a espiar todos sus gestos hasta que alguno me dé esperanzas. Ahora está mirando a la rubia. iJodidas rubias! Yo también debería teñirme. Ah, no, es que está embarazada y le está cediendo el asiento. Encima tiene un corazón de oro.

¡Un momento! Le asoma un tatuaje por debajo de la manga. ¿No será expresidiario? Qué tontería, estoy mal de la cabeza, ahora se tatúa mucha gente. Voy a seguir leyendo un rato..."su cuerpo dejará, no su cuidado; serán ceniza, mas tendrán sentido; polvo serán, mas polvo enamorado". Ay...

¿Y mi chico favorito? ¿No se habrá ido? No, ahí está... Mierda. Ha visto que no le quito el ojo de encima y he bajado rápidamente la mirada como una tonta. iQué corte! Oh, no, por favor... no puede ser...lleva calcetines blancos con calzado oscuro. iSerá cutre! Pero bueno, no hay que arrugar la nariz, siempre existe un lado positivo: esto significa que no hay ninguna mujer en su vida, aunque nunca puedes poner la mano en el fuego.

Próxima estación Avenida de América, correspondencia con líneas 9 y circular. iQué jaleo de gente! Se me ha vuelto a escapar... iAnda, pero si se me ha puesto al lado! Barba de dos días... Mi padre siempre dice que un hombre que no se afeita es como una mujer que no se depila, pero a mí... mmmh, casi me gusta. Me quedan tres estaciones, tengo que coger el toro por los cuernos. Pero, ¿cómo? ¿Le pregunto su nombre y le pido el teléfono así, por las buenas? Los hombres 
siempre dicen que están hartos de dar el primer paso, sin embargo, no creo que les guste tampoco tanta iniciativa.

¡Uy, qué morro! Ahora coge y me mantiene la mirada. Tranquila, analicemos la situación. ¿De qué color son sus ojos? Parece que claros, pero no azules. Mejor, nunca me han gustado los ojos azules en un hombre. Me recuerdan a los guiris que se pasan todo el día en la playa.

¿En qué trabajará? Lleva ropa neutra. Un, dos, tres, responda otra vez. Psicólogo, periodista... Está jugando FIFA 2020, será periodista deportivo. Espero que no tenga el fútbol como fuente de lucidez. A mí también me gusta el patinaje artístico, pero no me caliento la boca hablando de él. Pensándolo bien, me da igual.

En fin, llegó mi estación y no he movido un dedo, como de costumbre. iVaya, parece que va a salir detrás de mí! Dios existe, pese a todo. Lo tengo en el cogote, casi no puedo pensar de los nervios. Madre mía, me acaba de tocar el hombro. Me he sonrojado hasta las orejas, como una colegiala.

- La pasta, tía, o te rajo el cuello.

(texto adaptado de Ana Isabel Muñoz Castro, http://www.ariadna-rc.com/numero41/lab51.htm )

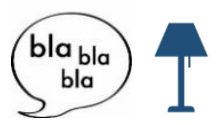

\section{Expresion oral / En acción}

En parejas, tratad de encontrar un final para esta historia.

Una vez descubierto el final original, comenta con tus compañeros: ¿es lo que esperabas?, ¿es un final feliz?, ¿te gusta más vuestra versión?

Este es el título original: AMOR DESDE EL RABILLO DEL OJO. ¿Qué sentido cree que tiene, en relación con el texto?

¿Qué significa "mirar por el rabillo del ojo"?

a) mirar de reojo

b) mirar atentamente

c) mirar fijamente

d) mirar por encima del hombro

e) mantener la mirada

¿Conoces alguna otra forma de "mirar" en español? Completa la lista. 


\section{En acción}

\section{Elije la respuesta adecuada.}

Ella está viajando:
a) en metro
b) en tranvía
c) en autobús

Ella es:
a) rubia
b) teñida
c) no se dice, pero sabemos que no es rubia
Él:
a) Ileva calcetines blancos con calzado oscuro
b) Ileva ropa normal y calcetines blancos
c) va vestido como un expresidiario

En el vagón:
a) hay mucha gente
b) hay poca gente
c) no hay sitio libre para sentarse
Él:
a) es extranjero porque tiene los ojos azules
b) tiene los ojos azules, como muchos extranjeros
c) tiene los ojos claros

\section{A ella:}

a) no le gusta el fútbol

b) le gusta el fútbol

c) le da igual que los hombres se pasen el día hablando de fútbol 


\section{En acción}

¿Cuál de los siguientes resúmenes crees que corresponde mejor con el sentido del texto?

a. Una chica es atracada en el metro por fiarse de las apariencias del atracador.

b. Una chica es atracada en el metro por un hombre con el que creía ligar.

c. Una chica es atracada en el metro por dar a entender al ladrón que le gustaba.

$\begin{array}{ll}\text { En acción } & \\ \text { Encuentra en el texto expresiones equivalentes para los siguientes significados: } \\ \text { ser muy buena persona } & \text { tener un corazón de oro } \\ \text { no actuar } & \text { no mover un dedo } \\ \text { ruborizarse mucho } & \text { sonrojarse hasta las orejas } \\ \text { esforzarse } & \text { estrujarse el cerebro } \\ \text { degollar } & \text { rajar el cuello } \\ \text { disgustarse } & \text { arrugar la nariz } \\ \text { estar loco } & \text { estar mal de la cabeza } \\ \text { vigilar } & \text { no quitarle el ojo de encima } \\ \text { hablar apasionadamente } & \text { calentarse la boca } \\ \text { confiar plenamente } & \text { poner la mano en el fuego }\end{array}$




\section{Expresión escrita}

Construye frases con las siguientes expresiones: dar el primer paso, coger el toro por los cuernos, ser un bicho raro, estar en las nubes.

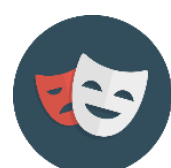

Juego de rol

Cuéntale lo que te ha ocurrido al policía que te toma la denuncia y a tu mejor amigo/a.

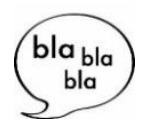

Expresion oral

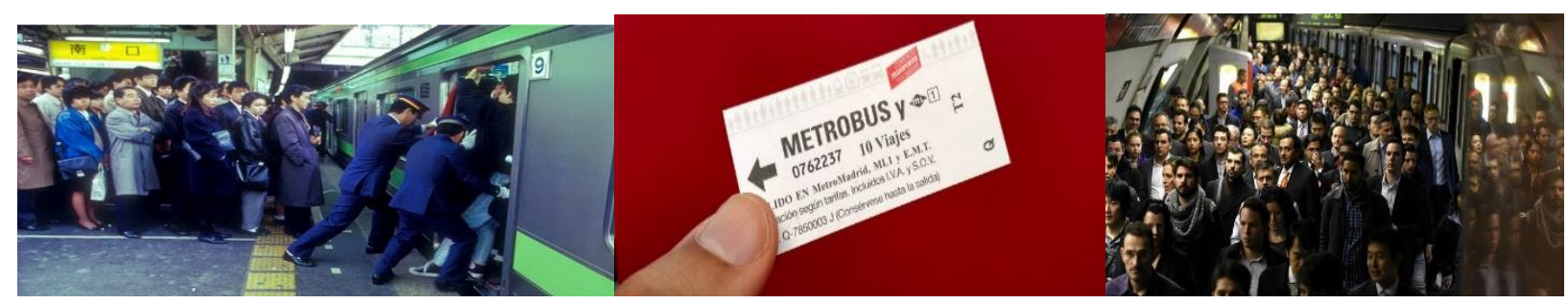

¿Qué medio de transporte usas para venir al centro donde estudias español?

¿Cuál es el medio más usado en tu ciudad?

¿Es eficaz el transporte público en tu ciudad o es mejor tener un coche particular?

¿Pasas mucho tiempo en el transporte público?

¿Aprovechas para algo ese tiempo? (lees, estudias español, juegas con el móvil, trabajas en el portátil, te conectas a las redes sociales o simplemente no haces nada y miras a la gente). 
¿Es caro el metro en tu ciudad? ¿Y en España?

¿Suele ser un punto de encuentro? ¿Es frecuente encontrar gente que espera a alguien dentro del metro?

¿Es normal ceder el asiento? ¿A quién?

¿Has viajado alguna vez en el metro de Nueva York/Moscú/Tokio/Londres/ París/Madrid/Ciudad de México? ¿Qué recuerdos tienes?

¿Hay ladrones/carteristas/gente cantando o tocando/indigentes/ratones/goteras?

¿Hay publicidad en el metro? ¿De qué tipo? ¿Qué productos suele anunciar?

¿Se considera peligroso el metro en tu país?

¿Te han atracado alguna vez estando en algún medio de transporte?

¿Tomas precauciones?

Si entras en un vagón donde solo hay una persona, ¿te sientas lejos o cerca de esa única persona?

Cuando hay mucha gente y es inevitable rozarse, ¿se piden disculpas o no se dice nada?

En el texto los protagonistas se miran fijamente a los ojos durante unos instantes... ¿Es descortés mirar directamente a un desconocido?

¿Es normal que un pasajero desconocido empiece a hablar contigo? ¿De qué temas?
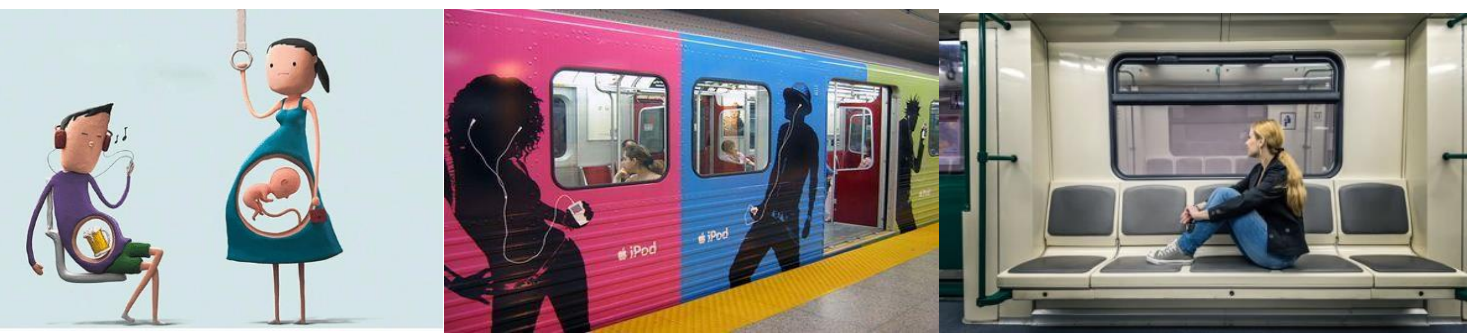


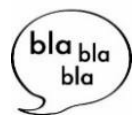

\section{Expresion oral}

¿Qué piensas de un hombre que es como el del texto?

(barba de dos días, tatuaje, ropa neutra, calcetines blancos, ojos claros, jugando en el móvil)

¿En tu país se puede saber por el aspecto físico si un hombre está casado/una mujer está casada?

¿Cuál es el estereotipo de un delincuente en tu país?

¿Qué piensas de una chica que está perfectamente maquillada y va con tacones y falda a las seis de la mañana en el metro?

¿Le darías trabajo a Pedro?
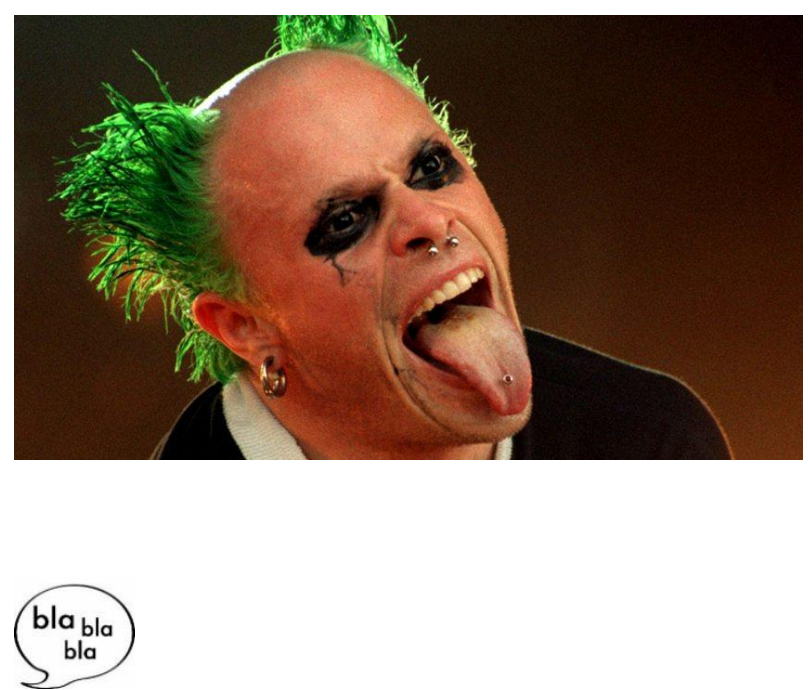

\section{Expresion oral}

¿Las apariencias siempre engañan?

¿Crees en el amor a primera vista? // ¿Crees que tiene futuro una relación que comienza en un vagón de metro?

¿Qué harías si te encontraras en la misma situación que nuestra protagonista? ¿Te ha ocurrido alguna vez algo parecido? ¿Sueles "dar el primer paso" o "no mueves un dedo" como ella?

"Los hombres siempre dicen que están hartos de dar el primer paso". ¿Quién debe empezar? ¿Cómo son las relaciones entre hombres y mujeres en tu país? ¿Sabes cómo son en España? ¿Hay alguna diferencia? 


\section{$\uparrow$}

\section{En acción}

"Jodidas rubias"

¿Las mujeres en tu país suelen decir palabrotas? ¿Qué tipo de personas dicen palabrotas? ¿En qué situaciones?

Clasifica las siguientes palabras y expresiones en tres columnas y busca cómo se podría expresar lo mismo en otro registro.

\begin{tabular}{|l|l|l|}
\hline Registro coloquial & Registro neutro & Registro formal \\
\hline & & \\
& & \\
\hline
\end{tabular}

jodidas rubias; encima; además; cutre; ¡vaya!; iqué tontería!; bicho raro; mierda;

pillar a alguien haciendo algo; iqué corte!; ¡qué vergüenza!; todo el mundo; todas las personas; todo quisqui; toda la peña; todo dios; persona; tipo; tío; chulo; bonito; guay. 


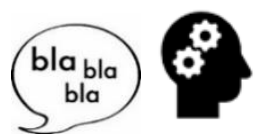

Expresión oral

Da consejos a las siguientes personas para que liguen más, utilizando estructuras como: yo, en tu lugar; yo que tú; yo, si fuera tú. Ejemplo: Yo que tú, me dejaría el pelo largo.
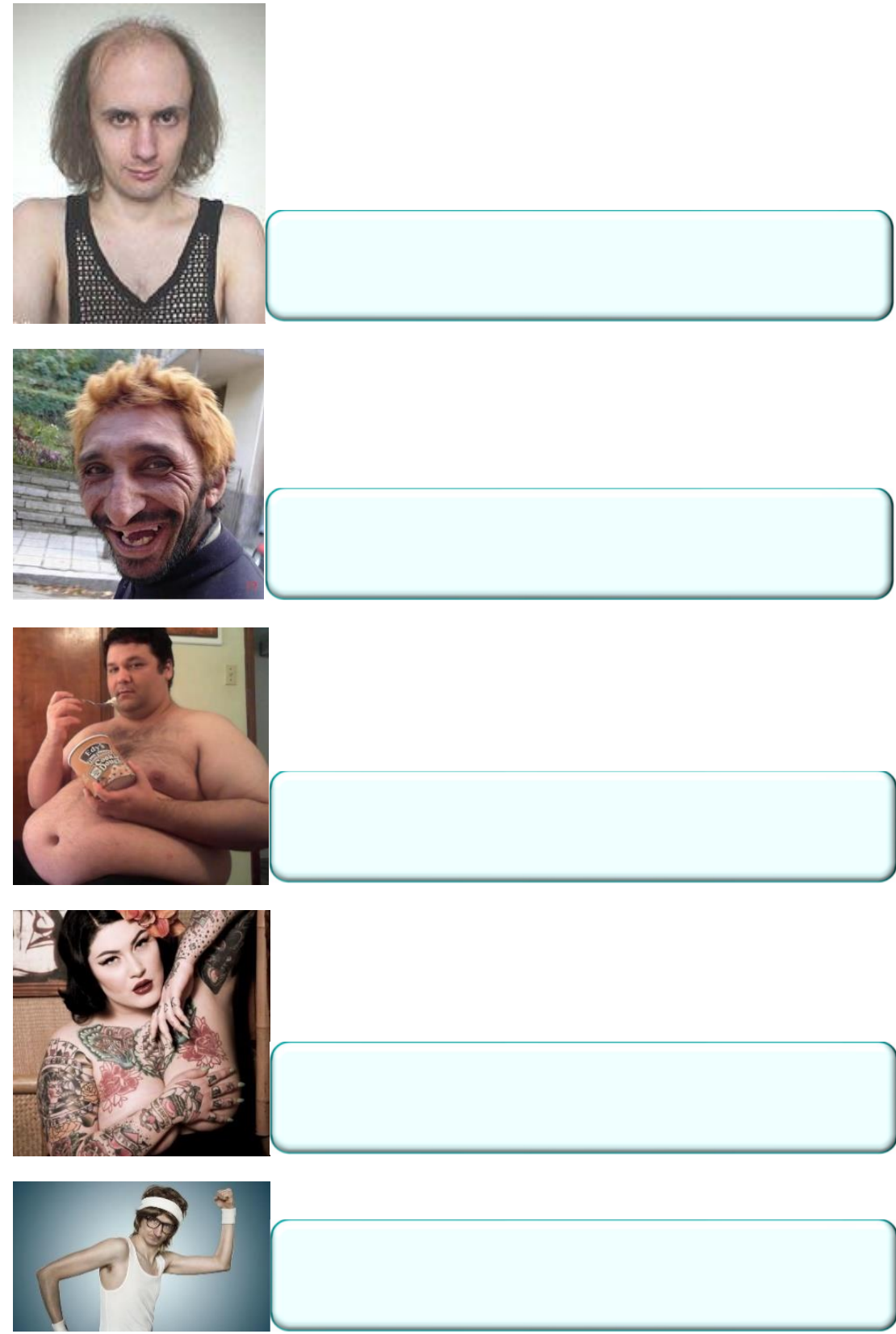


\subsection{Conclusiones de las propuestas didácticas}

En los siguientes párrafos sintetizamos las propuestas didácticas presentadas, surgidas a raíz de los resultados obtenidos tras el estudio contrastivo de UF somáticas que llevamos a cabo en el segundo capítulo de esta tesis y después de haber detectado carencias en los materiales de la plataforma AVE GLOBAL, analizados en el cuarto capítulo de este trabajo.

Hemos aportado un total de ocho propuestas de didactización de las UF, repartidas en dos grandes bloques (tres actividades para los niveles A1-A2 y cinco actividades para los niveles B1-B2). Decidimos limitarnos a estas actividades porque las consideramos relevantes como muestra de nuestra visión sobre lo que entendemos por llevar el componente fraseológico al aula de E/LE. Una vez más, reiteramos dos aspectos fundamentales que sustentan estas aplicaciones prácticas: nuestro alumnado meta está formado por hablantes nativos de rumano y las UF presentadas son un fiel reflejo de la base de datos elaborada, tras el análisis contrastivo y los múltiples filtros aplicados. Este objetivo final de nuestro trabajo se apoya en tres pilares: el marco teórico que aportamos, las experiencias prácticas que otros autores han plasmado en distintos estudios y nuestra experiencia directa en el aula, con alumnos rumanos de E/LE. Varias de estas actividades han sido pilotadas por profesores del Instituto Cervantes de Bucarest con distintos grupos y el feedback ha sido muy positivo, tanto por parte de alumnos como de docentes, si bien de momento carecemos de instrumentos fidedignos de medición (encuestas, estadísticas, etc.). Reiteramos nuestra convicción de que acertamos al introducir el componente idiomático desde las primeras etapas de aprendizaje.

Dado el alto índice de frecuencia de aparición y el carácter coloquial de muchas de estas, un gran número de autores creen indispensable aproximar al alumno, desde niveles iniciales, al conocimiento de ciertas combinaciones fijas de palabras cuya significación no suele ser composicional, esto es, que el alumno no puede descifrar su significado partiendo del vocabulario que conoce (Aguilar Ruiz 2011:1).

Asimismo, estamos cada vez más convencidos de que esta parcela de la lengua es la que mejor se amolda para un enfoque contrastivo, esto es, la morfología o la sintaxis se pueden tratar desde una perspectiva más global, para un alumnado meta "universal", mientras que en el caso del componente fraseológico los creadores de materiales tienen siempre en mente un destinatario final del "producto": los alumnos germanohablantes (Aguilar Ruiz, Larreta Zuluategi), angloparlantes (Leal Riol), lusoparlantes (Saracho), hispanohablantes (Strohschen), italianos (D’Andrea, Minervini), chinos (Wu Fan), árabes (Salem, Haddouch, Sagban), eslovacos (Chrenková), rumanos (Duţă, Dumbrăvescu), etc. 
Para diseñar las actividades hemos tenido en consideración los principios metodológicos y didácticos expuestos en la introducción de nuestro capítulo: partiendo del enfoque comunicativo como postulado fundamental, somos partidarios de una visión más integradora de elementos, materiales, actividades y tareas. Aunque a primera vista pueden parecer más obsoletas, si respetan el estilo de aprendizaje de nuestros alumnos, su larga tradición educativa y aportan resultados concretos, no excluimos ninguna actividad.

Para elaborar la base de datos de UF somáticas hemos recurrido a una herramienta en la nube. No obstante, en este apartado práctico optamos deliberadamente por presentar una batería de tareas que no incorporan tecnologías digitales, al resultar más complejo demostrar su eficacia en un formato impreso, como es nuestro caso. En esta línea se inscriben también las actividades que incluyen el componente audiovisual. Sin embargo, los materiales diseñados son flexibles y se ajustan fácilmente a otros formatos y herramientas, como kahoot.it, thinglink.com, bubbl.us, genial.ly, se pueden integrar en la clase invertida o se les puede aplicar técnicas de gamificación.

Hemos consultado numerosas opiniones acerca de qué, cuándo y cómo hay que enseñar el componente fraseológico antes de diseñar nuestros propios materiales. Seradilla Castaño (2011) señala que el aprendizaje las UF debería llevarse a cabo desde las etapas iniciales, al representar un elemento muy motivador para un aprendiz de LE, se declara partidaria de prescindir de explicaciones metalingüísticas y de sopesar la cantidad de input fraseológico para que no resulte excesivamente forzado en la vida real.

Respecto a cómo enseñarlas, insistiré más en el próximo apartado, pero sí quiero avanzar que, en todo caso, este proceso de enseñanza-aprendizaje debe partir de modelos reales de lengua y, por otro lado, y aunque puede resultar discutible ya que muchos trabajos van en esta línea, quiero señalar que no soy partidaria de enseñar la fraseología a través de un único término base, es decir, por ejemplo, enseñar todas las locuciones que contienen la palabra mano: estar mano sobre mano, echar una mano, dar la mano, ir de mano en mano, abrir la mano, estar en buenas manos, poner la mano, ser la mano derecha... Considero que estas expresiones pertenecen a ámbitos muy diversos y su asimilación puede verse dificultada ya que el alumno puede liarse y mezclar unas con otras si se expone a ellas de forma conjunta en una misma sesión. En la misma línea se posiciona Fernández Prieto (2004) (Seradilla Castaño 2011:81-82).

Aunque en principio estamos de acuerdo con este postulado, optamos por introducir varias actividades que giran en torno a un determinado somatónimo, convencidos de que el abanico de los estilos de aprendizaje es muy amplio, que los 
aprendices interactúan de forma diferente con la información y que cada uno (dependiendo de factores cognitivos, culturales y de otros parámetros motivacionales) la organiza y procesa de modo distinto.

No obstante, el hilo conductor de todas las actividades ha sido la función comunicativa que, en nuestra opinión, aporta una mayor garantía de éxito, pero también la vertiente contrastiva, conscientes de que el hecho de que la UF tenga una equivalencia total, parcial o nula en ambas lenguas repercute a la hora de su comprensión y producción posterior. Hemos elaborado contextos escritos y orales para integrar un amplio abanico de funciones recogidas en el corpus que hemos creado, resultado del análisis contrastivo entre UF somáticas en español y el rumano: relación social, información y comunicación, acciones comunicativas, sentimientos, opiniones, gustos y preferencias, descripciones, referencias a necesidades físicas y realidades cotidianas, solo por mencionar los grandes grupos que contempla el PCIC. A fin de dotar de credibilidad las propuestas didácticas, integramos en una sola actividad varias funciones, como un reflejo fiel del habla de los nativos, que no acotan su discurso a un campo semántico único, no aíslan las funciones comunicativas ni restringen su mensaje a un número limitado de lexemas o UF.

En cuanto a la tipología de las actividades, hemos tratado de encontrar un equilibrio entre las destrezas, sin olvidar en ningún momento la importancia de la "acción", entendida en los términos fijados por el MCER: "el enfoque basado en la acción (...) tiene en cuenta los recursos cognitivos, emocionales y volitivos, así como toda la serie de capacidades específicas que un individuo aplica como agente social" (MCER 2002:9).

En las actividades que fomentan las destrezas interpretativas hemos seleccionado textos en torno a temas familiares y de interés. Para los niveles B1-B2 hemos optado también por textos auténticos, pero manipulados previamente, ya que

Un texto auténtico siempre contiene mucho lenguaje desconocido para el aprendiz. En la enseñanza de la fraseología es necesario que el vocabulario no fraseológico sea bastante conocido para que éste aclare el significado de las unidades fraseológicas y así el estudiante pueda inferir e interpretar (Leal Riol 2011:256).

Las tareas propuestas has sido múltiples: lectura de textos e identificación de UF, completar con una o varias palabras los espacios en blanco de un texto, contestar preguntas sobre un texto, representar con mímica lo que dice un texto, resumir un texto, ordenar un texto y/o UF que aparecen en un texto, traducir un texto, etc.

Las tareas propuestas que corresponden a las destrezas expresivas o productivas han sido tormentas de ideas, conversaciones sobre temas de interés, juegos de rol y 
diálogos que reflejan situaciones reales (para activar la expresión oral) y una amplia batería de tareas para reforzar la expresión escrita: escribir /contestar cartas y mensajes, redactar breves artículos de opinión, crear eslóganes y campañas publicitarias, completar historias, convertir un diario en un informe, etc. En todas las actividades hemos tratado de introducir la mayor cantidad de contenido cultural, de fomentar la cooperación en el aula y de abarcar un amplio abanico de temas. No obstante, por razones de extensión, hemos dejado fuera de estas propuestas interesantes temas como la política o el deporte, que recurren en gran medida al componente idiomático. Nos centramos en cambio en las necesidades inmediatas, las relaciones personales, el trabajo, los estudios $u$ otros aspectos de la realidad cotidiana como la publicidad, que representa un vehículo ideal para aportar soporte visual a las UF (Pindado Roncero 2016).

Las actividades presentadas han perseguido aumentar la competencia comunicativa y fraseológica de los aprendices rumanos de E/LE gracias a la adquisición de UF contextualizadas; fomentar su conciencia lingüística respecto a ciertos fenómenos como la fijación y la idiomaticidad, reflexionando sobre los mismos desde una perspectiva contrastiva y dando valor a la L1; motivar a los alumnos y dotarles de mayor información y control de su proceso de aprendizaje, del cual son los verdaderos protagonistas. 


\section{CONCLUSIONES FINALES}

El principal empeño de este trabajo ha sido llevar a cabo un estudio contrastivo interlingüístico de unidades fraseológicas somáticas a partir de un corpus elaborado para aprendices rumanos de E/LE (nivel A1-B2), analizar desde un enfoque léxico la presencia de las UF en los materiales de AVE GLOBAL y aportar propuestas personales para la integración del componente fraseológico en el aula. En las siguientes páginas presentaremos las conclusiones más relevantes que, en nuestra opinión, se desprenden de esta tesis.

Gracias a esta investigación hemos corroborado, ante todo, que la Fraseología, disciplina lingüística relativamente joven, ocupa un lugar destacado dentro de las ramas filológicas. Tanto en Rumania como en España el interés por las unidades más estables de la lengua se remonta atrás en el tiempo y está vinculado con aquellas UF que reflejan el acervo sociocultural de los hablantes de una determinada comunidad lingüística (proverbios, refranes, dichos, enunciados sentenciosos que conforman el mundo de las paremias). En este trabajo hemos comprobado el desarrollo y la consolidación de la Fraseología moderna, su vigencia y el auge en los últimos años. Las propuestas de definición de los conceptos con los que opera la disciplina y las diferentes taxonomías que hemos reflejado en este trabajo nos han aportado las pautas para perfilar un punto de vista propio. Nos inscribimos en la línea de los estudios que conciben la Fraseología desde una perspectiva ancha y consideramos que las locuciones, las colocaciones y las fórmulas rutinarias cumplen y comparten rasgos y requisitos básicos (idiomaticidad, fijación, pluriverbalidad, etc.). Al analizar las características de los elementos que conforman el lenguaje formulaico hemos llegado a la conclusión de que representan una fuente enriquecedora de conocimiento, con aplicación directa en la clase de E/LE. Como docentes, la Fraseología presenta para nosotros ese punto de intersección ideal donde convergen, se solapan y se complementan la lexicología, la morfología, la sintaxis, la semántica, la sociolingüística y la antropología. No obstante, esta tesis es, ante todo, un trabajo de lingüística aplicada y, como investigadores, el marco teórico aportado en el primer capítulo nos ha permitido recorrer distintas taxonomías, comprobar los puntos de coincidencia y de divergencia de los lingüistas más relevantes en el campo de la fraseología y adquirir sentido crítico y visión propia. En nuestra opinión, la fraseología del siglo XXI debería prestar menos atención al trabajo de "etiquetado" y superar las discrepancias terminológicas para centrarse más a fondo en la esencia de lo que representa un elemento prefabricado de la lengua: fijación, desautomatización, idiomaticidad, pluriverbalidad, composicionalidad, institucionalización, etc., pero, sobre todo, su funcionamiento real, vivo y actual en la lengua.

Una de las principales hipótesis de partida en esta investigación ha sido la necesidad de llevar a cabo un estudio contrastivo español/rumano para anticiparse a los errores de competencia fraseológica que pueden surgir en las producciones de los 
aprendices rumanohablantes de E/LE. Para ello, en el segundo capítulo de esta tesis hemos realizado un análisis contrastivo centrado en las locuciones verbales somáticas en las dos lenguas, desde la visión de un hablante bilingüe. Consideramos que los SO son las UF más productivas y que mejor se podrían adaptar a la realidad de un aprendiz de E/LE porque constituyen universales lingüísticos y su descodificación no requiere amplios conocimientos culturales o enciclopédicos. Asimismo, otra premisa inicial ha sido que, al tratarse de dos lenguas románicas, el español y el rumano comparten numerosas UF, hipótesis de la que deriva un reto de índole más práctica: comprobar si es factible incorporar el componente fraseológico en la enseñanza de E/LE en los niveles iniciales e intermedios porque hemos averiguado que en ningún estudio precedente se ha contemplado la posibilidad de enseñar UF a rumanohablantes desde la primera fase del proceso de enseñanza/aprendizaje de español.

Durante la elaboración de esta tesis hemos comprobado las dificultades y las limitaciones de conformar y analizar una base de datos. En este sentido, tras varios intentos fallidos de englobar un número muy elevado de UF, hemos llegado a la conclusión de que un mayor "caudal fraseológico" no aporta necesariamente datos más fidedignos ni conclusiones más relevantes. Los filtros aplicados nos han permitido operar con un número más reducido de UF para llevar a cabo un análisis contrastivo exhaustivo. Hemos optado por seguir el orden alfabético del lexema (como entrada principal) y añadimos casillas con la locución seleccionada, su definición, su equivalencia en rumano (total, parcial o nula), su estructura actancial, explicaciones de uso y de registro, aclaraciones de orden morfosintáctico, nivel recomendado para su enseñanza y otras observaciones. Durante este proceso, hemos corroborado la importancia de la lengua de origen (en nuestro caso el rumano), un parámetro obviado en las últimas décadas por los enfoques comunicativos que destierran la lengua materna del proceso de enseñanza/aprendizaje de una LE. Por ello, hemos creado una base de datos adicional, con locuciones verbales somáticas en rumano, un corpus convertido en un instrumento interno de trabajo. El "vaciado" al que hemos recurrido arroja luz sobre las UF que genera cada lexema somático en su idioma y en los puntos de intersección interlingual. Hemos podido comprobar en rumano el elevado número de entradas con somatónimos que tienen una doble correspondencia en castellano: ureche (oreja + oído), picior (pie + pierna), mână (mano + brazo). Asimismo, hemos podido extraer varias conclusiones: tal como anticipábamos, los lexemas más productivos serían la cabeza, el ojo, la boca y la mano, que copan el $33,8 \%$ del corpus seleccionado, relacionados con las funciones comunicativas más importantes: actividades y realidades cotidianas, sentimientos, descripciones y acciones comunicativas. No obstante, contábamos con la presencia de otros exponentes (cadera, costilla, nuca, rodilla, seno, etc.) que en rumano generan locuciones verbales de uso activo, pero al ser el español la lengua meta en este estudio, finalmente no se reflejan en la base de datos. 
Pese a tratarse de dos lenguas románicas, comparten menos elementos fraseológicos somáticos de los que esperábamos, especialmente si tenemos en cuenta que nos referimos a un campo semántico que no depende de un contexto cultural nacional. Además, nuestros datos comprueban que el porcentaje de las UF totalmente equivalentes en ambas lenguas es muy escaso (apenas roza el $20 \%$ ) porque no se cumple al menos uno de los parámetros con los operamos en el análisis contrastivo: parámetros semánticos (constituyentes léxicos, imagen, significado, etc.), parámetros morfosintácticos (funciones sintácticas, posibilidades de modificación morfosintácticas, etc.), parámetros pragmáticos (restricciones, frecuencia, carga cultural, etc.). Tras haber aplicado estos filtros, la mayoría de las UF seleccionadas y analizadas han conformado el bloque de la equivalencia parcial $(62,1 \%)$. Otro dato que ha aportado el análisis contrastivo concierne a la distribución de las UF por niveles: hemos llegado a la conclusión de que la comprensión de una UF por parte de un aprendiz rumanohablante, su transparencia debido a la presencia de una metáfora motivada o la existencia de una equivalencia total, no conlleva directamente a su inserción en el nivel A1. Por mucho que nos hubiera gustado equilibrar la distribución de locuciones por niveles, el cómputo final queda reflejado como sigue: A1 (4,88\%), A2 (4,39\%), B1 (37,07\%), B2 (53,66\%) porque no habíamos tomado en cuenta un elemento clave: la función pragmática de las UF seleccionadas y analizadas. La función comunicativa condiciona que una locución se integre en un determinado nivel, ya que por muy transparentes que fuesen UF como "poner la mano en el fuego", "subirse la sangre a la cabeza" o "saltar a la yugular", no se propician contextos de uso en A1-A2 que integren de manera natural las funciones comunicativas que expresan. Mientras que las UF adscritas a funciones como descripciones y realidades cotidianas se pueden impartir en las fases incipientes del proceso de aprendizaje (con garantía de que serán reconocidas, comprendidas y habrá oportunidades para su posterior reproducción), tendremos que situar en los niveles intermedios aquellas que giren en torno a acciones comunicativas como expresar amenaza, fastidio, frustración, reproches, quejas, rechazo, disimulo, etc. (el 20,4\% del total). Asimismo, del análisis efectuado ha resultado que el rasgo gramatical predominante es el intransitivo (59,7\%) seguido por las locuciones pronominales reflexivas (16,5\%) y que todas las estructuras pronominales indirectas se han relegado a los niveles intermedios.

Desde la comprensión y el respeto, nos permitimos una reflexión crítica acerca de las fuentes lexicográficas: muchos diccionarios explicativos monolingües consultados son de difícil manejo, debido a intrincados sistemas de referencia y a la presencia de elementos actanciales que, con el afán de ofrecer datos sobre los rasgos gramaticales, dificultan la comprensión global de la entrada. Por ello, hemos optado por crear una base de datos depurada de actantes no lexicalizados $u$ otros aditamentos de orden morfosintáctico, dejándole al docente la tarea de aportar información estrictamente gramatical. 
Otros diccionarios proporcionan definiciones complejas y a veces parciales 0 reflejan componentes fraseológicos dialectales o arcaicos, omitiendo en cambio UF de uso activo. En cuanto a las fuentes bilingües, entendemos la dificultad de encontrar equivalencias y la frustración que siente el lexicógrafo al no poder proporcionar una variante en la LM. No obstante, consideramos más honesto y, sin lugar a dudas, más correcto desde una perspectiva didáctica, admitir la intraducibilidad como rasgos de ciertas unidades. Al igual que los errores de instrucción que el aprendiz comete debido a explicaciones parciales e incorrectas, pensamos que los diccionarios fallan al no incidir en la intrínseca dependencia de las UF con el contexto o al proporcionar equivalencias inexistentes, meros calcos de la LO.

Para llevar a cabo el análisis contrastivo de las UF hemos recurrido a una herramienta digital (airtable.com), en la que hemos vertido las locuciones somáticas seleccionadas. Hemos comprobado las ventajas de las nuevas tecnologías que nos permiten colaborar en la nube, aportar nuevos datos y modificar las estadísticas en tiempo real, contar con moldes versátiles para ampliar el análisis a otros campos semánticos y a otras lenguas, aprovechar los motores de búsqueda internos, etc. Las nuevas generaciones de aprendices ("generación milénica", "generación Zl posmilénica", "generación muda", etc.), tienen en común la pasión por la tecnología, parte intrínseca de su vida. Como investigadores y docentes, hemos de adaptarnos a esta realidad y acercarnos a su universo, sus intereses y su forma de aprender. Los nativos digitales necesitan aplicaciones, descargas y plataformas virtuales.

En esta línea hemos centrado el análisis de materiales en la plataforma de elearning AVE GLOBAL, ideada por el Instituto Cervantes con el fin de acercarse a un público potencial ubicado en cualquier rincón del planeta. Nuestra realidad inmediata ha confirmado la validez de esta elección, con clases tutorizadas y exámenes monitorizados a través de ZOOM, GOOGLE CLASSROOM, SEESAW, etc., en detrimento del curso presencial, con materiales en formato papel. Tras haber analizado la presencia del componente idiomático en los materiales del AVE GLOBAL, hemos llegado a la conclusión de que su inserción se lleva a cabo de manera paulatina: en los primeros niveles destacamos las fórmulas rutinarias, mientras que en el nivel intermedio alto aparecen tímidamente actividades más sólidas para introducir, trabajar y reforzar locuciones adscritas a un determinado campo onomasiológico a una función comunicativa concreta. Hemos llevado a cabo una minuciosa revisión de cada actividad y material audiovisual presente en la plataforma y podemos concluir que, a nivel "GLOBAL" (valga la redundancia), la presencia del componente idiomático es muy exigua. Esto nos ha llevado a plantearnos tal omisión, puesto que hay un acuerdo unánime acerca de la importancia de la competencia fraseológica como factor clave dentro de la competencia comunicativa general y un elemento imprescindible para comprender y descodificar una realidad extralingüística. Nuestras conclusiones derivan principalmente del hecho de que los factores que explican el tratamiento insuficiente de las UF en el aula de E/LE son su 
complejidad morfosintáctica, la falta de formación teórica del profesorado y de orientación metodológica y, sobre todo, las pautas de los fundamentos curriculares.

En este sentido, hemos dedicado un capítulo a la presencia del componente idiomático en los documentos marco para la elaboración de materiales y manuales de E/LE (el MCER y el PCIC) y hemos comprobado que, exceptuando el caso de las fórmulas rutinarias, su enseñanza /aprendizaje se relega a los niveles más altos ( $C 1$ y $C 2)$. Nuestra visión difiere considerablemente de las pautas marcadas por estos documentos y en este sentido el análisis contrastivo (español-rumano) que hemos llevado a cabo, la observación directa en el aula, el pilotaje de actividades que incluyen lenguaje formulaico, estudios teóricos y reflexiones en numerosos artículos acerca de las UF en el aula de E/LE nos han llevado a concluir que el enfoque adoptado por el MCER y por el PCIC ha quedado obsoleto y requiere una profunda revisión. Nosotros abogamos por revisar los indicadores de las competencias, repensar el currículo y tomar más libertades respecto a la visión de los fundamentos curriculares en materia de fraseología. En nuestra opinión, hay que acercar a los aprendices al componente idiomático de la lengua desde el inicio del proceso de adquisición del español, de manera gradual y coherente. Consideramos que esta progresión garantiza el logro de una competencia fraseológica alta antes de alcanzar los niveles indicados por el MCER y el PCIC.

Otra conclusión que hemos sacado tras estudiar los documentos curriculares es que hacen referencia a alumno "abstracto", en su triple vertiente como agente social, hablante intercultural y aprendiente autónomo. En nuestra opinión, el éxito de la adquisición del componente idiomático depende en gran medida de la capacidad de adaptar el input y de ajustar las propuestas didácticas a un alumnado concreto (en nuestro caso, hablantes nativos de rumano). Gracias al estudio contrastivo llevado a cabo, tenemos la certeza de que reconocerán, comprenderán y almacenarán las UF seleccionadas para su posterior uso en la LM.

Las actividades didácticas diseñadas han tenido en cuenta su nivel y sus intereses. Estamos convencidos de que lengua significa comunicación, de que las unidades léxicas funcionan en redes, de manera dinámica y de que learning by doing asociado a factores afectivos favorece que un determinado segmento se mantenga a largo plazo en la memoria. Algunas de las actividades didácticas siguen postulados cognitivistas porque se apoyan en la conceptualización y categorización cognitiva con las que los seres humanos asignamos significado.

De hecho, entre las posibles líneas de investigación posteriores a este trabajo, la que más fuerza cobra es aplicar al corpus elaborado los instrumentos de análisis con los que opera la semántica cognitiva, según la cual los hablantes categorizamos la realidad a través de ciertas metáforas básicas que son el fundamento explicativo de numerosas UF.

Asimismo, nos interesa comprobar el funcionamiento en el aula de las propuestas didácticas, llevando a cabo un estudio basado en instrumentos fidedignos de medición 
(encuestas, estadísticas) para mejorar y ampliar las actividades hacia otros campos semánticos, otros niveles, otras funciones comunicativas, etc.

No obstante, el proyecto que más nos motiva en este momento es situarnos en el lado opuesto y aportar herramientas, ideas y materiales para el análisis y la enseñanza del componente fraseológico a aprendientes hispanohablantes, aprovechando la base de datos creada para este estudio, nuestra experiencia y formación. Si en el caso del E/LE ya contamos con trabajos previos, tal como se ha visto reflejado en esta tesis, el campo del rumano como lengua extranjera es un territorio virgen en el que queda todo por hacer.

Con esta aportación, hemos pretendido dar un paso más hacia el desarrollo de los estudios contrastivos entre unidades fraseológicas somáticas entre el español y el rumano, aunando las herramientas teóricas, la investigación y la vertiente práctica, de corte didáctico. 


\section{BIBLIOGRAFÍA}

\section{DICCIONARIOS}

Bădescu, I., Guţă, A. y Pănculescu, D. (2011). Corpul omenesc în expresii (domeniul român - francez). Craiova: Aius.

Birtalan, A.M. (Ed.), Dumbrăvescu, D. y Rădoi, M. (2018). Culegere de expresii frazeologice sinonime (română - engleză - spaniolă). Milano: Rediviva Edizioni.

Bosque Muñoz, I. (2004). REDES - Diccionario combinatorio del español contemporáneo. Madrid: SM.

Bosque Muñoz, I. (Ed.). (2006). Diccionario combinatorio práctico del español contemporáneo. Madrid: SM.

Bucă, M. (2012). Marele dicţionar de expresii româneşti. Bucureşti: Meteor.

Buzea, O. y Dumbrăvescu, D. (2018). Culegere de expresii frazeologice antonime. Milano: Rediviva Edizioni.

Calciu, A. y Samharadze, Z. (1992). Dicţionar spaniol - român. Bucureşti: Editura Ştiinţifică.

Cantera Ortiz de Urbina, J. y Gomis Blanco, P. (2007). Diccionario de fraseología española. Madrid: Abada Editores.

Coteanu, I. y Seche, L. Seche y M. Seche (Eds.). (1996). DEX. Dicţionarul explicativ al limbii române. Bucureşti: Univers enciclopedic.

llincan, V. (2015). Dicţionar de expresii româneşti în contexte. Cluj-Napoca: Editura Universitară Clujeană.

Mărănduc, C. (2010). Diç̧ionar de expresii, locuţiuni şi sintagme ale limbii române. Bucureşti: Corint.

Martínez, J. A. y Jørgensen, A. (2009). Diccionario de expresiones y locuciones del español. Madrid: Ediciones de la Torre.

Neagu, V, Necheş, G., Şandru Mehedinţi, T. y Albu, M. (2008). Dicţionar frazeologic spaniol-român. Bucureşti: Univers Enciclopedic.

Papuc, M. (2015). Dicţionar de expresii şi locuţiuni străine. Chişinău: Editura Ştiinţa.

Penadés, I. (2002). Diccionario de locuciones verbales para la enseñanza del español. Madrid: Arco/Libros S.L.

Penadés, I. (2008). Diccionario de locuciones nominales, adjetivas y pronominales para la enseñanza del español. Madrid: Arco/Libros S.L.

Penadés, I. (2019). Diccionario de Locuciones Idiomáticas del Español Actual. (en línea) http://www.diccionariodilea.es/inicio 
Pereş, A. y Pereş, P. (2011). Dicţionar de comunicare, morfologie, corectitudine, expresii generative. Bucureşti: Lucman.

Pisot, R., Mahalu, L. y Teodorovici, C. (2002). Diç̧ionar spaniol-român de expresii şi locuţiuni. laşi: Polirom.

Teodorovici, C. y Pisot, R. (2005). Dicţionar român-spaniol de expresii şi locuţiuni. laşi: Polirom.

Seco, M., Andrés, O. y Ramos, G. (2017). Diccionario fraseológico documentado del español actual. Locuciones y modismos españoles. Madrid: $\mathrm{J}$ de $\mathrm{J}$ Editores.

\section{LIBROS Y ESTUDIOS}

Aguilar Ruiz, M.J. (2011). Enseñanza de E/LE y fraseología: algunas consideraciones teórico-prácticas para la enseñanza de fraseología a aprendices germano-hablantes (I). Foro de Profesores de E/LE (7),1-11. https://doi.org/10.7203/foroele.0.6680

Aitchison, J. (1987). Words in mind. Oxford: Basil Blackwell.

Alvarado Ortega, Ma. B. (2008). Las fórmulas rutinarias en el español actual. (Tesis doctoral). Alicante: Universidad de Alicante.

Álvarez de la Granja, M. (2003). As locucións verbais galegas. Santiago de Compostela: Universidad de Santiago de Compostela.

Álvarez Menéndez, A.I. (1989). Las construcciones consecutivas en español. Estudio funcional sobre la oración compuesta. Oviedo: Universidad de Oviedo.

Anderson, L. W., Krathwohl, D. R. (Eds.). (2001). A taxonomy for learning, teaching, and assessing: A revision of Bloom's taxonomy of educational objectives. New York: Longman.

Aničkov, I.E. (1964). Idiomatika idiom i idiomatika idiomatizmov. En Aničkov 1997: 147165.

Arnaud, P.J.L. (1991). Reflexions sur le proverbe. Cahiers de Lexicologie (95), 5-27.

Baker, M. (1992). In another words. A coursebook on translation. London and New York: Routledge.

Bally, C. (1921). Traité de stylistique française. Heidelberg: Carl Winter.

Benson, E., Benson, M. e Ilson, R. (1986). Lexicographical Description of English. Amsterdam/Philadelphia: John Benjamins. https://doi.org/10.1075/slcs.14 
Birtalan, A.M. y Dumbrăvescu, D. (2019). Las unidades fraseológicas en rumano, inglés y español: clasificación léxico-semántica e identificación de interferencias pragmáticas y discursivas. European Academic Research (VII), 3535-3552.

Bloom, B. (1956). Taxonomy of Educational Objectives Boston: Allyn and Bacon.

Bosque Muñoz, I. (2007). Las categorías gramaticales. Relaciones y diferencias. Madrid: Síntesis.

Brown, H.D. (2002). English Language Teaching in the "Post-Method" Era: Toward Better Diagnosis, Treatment, and Assessment. En J. C., Richardsy W. A. Renandya (Eds.). Methodology on Language Teaching: An Anthology of Current Practice, 9-18. Cambridge: Cambridge University Press. https://doi.org/10.1017/CBO9780511667190.003

Brucart Marraco, J. M. (2009). La gramática en ELE y la teoría lingüística: coincidencias y discrepancias, MarcoELE (9), 27-46.

Cáceres, L. (2006). Una aproximación a MCER: principales contenidos, aportaciones y consecuencias prácticas. Actas XLI (AEPE), 271-282.

Calero Fernández, M. (2020). Criterios de selección de las unidades fraseológicas y de su distribución en niveles en el MCER y el Plan Curricular: adecuación al uso real de la lengua. En F. Gimeno Menéndez (coord.), Lengua, sociedad y cultura. Estudios dedicados a Alberto Carcedo González, Sant Vicent del Raspeig: Universitat d'Alacant - Universidad de Turku, 109-127.

Căpăţână, C. (2007). Elemente de frazeologie, Craiova: Editura Universitaria.

Carneado Moré, Z. (1983). Consideraciones sobre fraseología. En Z. Carneado y A.M. Tristá (Eds.), Estudios de fraseología. La Habana: Instituto de Literatura y Lingüística de la Academia de Ciencias de Cuba, 39-46.

Casares, J. (1950). Introducción a la lexicografía moderna. Madrid: CSIC.

Castillo Carballo, Mạ. A. (1997). Unidades pluriverbales en un corpus del español contemporáneo (tesis doctoral). Málaga: Servicio de Publicaciones de la Universidad de Málaga.

Cecovniuc, I. (2016). ¿Qué prefiere usted, pagar en metálico o con cardo? Los falsos amigos y su concienciación lingüística en las aulas plurilingües de ELE. (Tesis doctoral). Barcelona: Universitat Pompeu Fabra.

Čermák, F. (2000). Revisando los idiomatismos somáticos en Luque Durán, J. D. y Pamies Bertrán, A. (Eds.), Trabajos de lexicografía y fraseología contrastivas, Granada: Método, 55-62.

Chomsky, N. (1957). Syntactic Structures. The Hague: Mouton. 
Colson, J.P. (2008). Cross-linguistics phraseological studies: An Overview. En S. Granger, y F. Meunier (Eds.), Phraseology. An Interdisciplinary perspective. Amsterdam/Philadelphia: John Benjamins, 191-206. https://doi.org/10.1075/z.139

Colţun, G. (2000). Frazeologia limbii române. Chişinău: ARC.

Consejo de Europa. (2001). Marco común europeo de referencia para el aprendizaje, la enseñanza y la evaluación de lenguas. Madrid: Anaya.

Corder, S.P. (1967). The Significance of Learners Errors. IRAL-International Review of Applied Linguistics 5(4), 161-170. https://doi.org/10.1515/iral.1967.5.1-4.161

Corder, S.P. (1971). Idiosyncratic Dialects and Error Analysis. IRAL- International Review of Applied Linguistics 9(2), 147-160. https://doi.org/10.1515/iral.1971.9.2.147

Corpas Pastor, G. (1996). Manual de fraseología española. Madrid: Gredos.

Corpas Pastor, G. (2000). Las lenguas de Europa: Estudios de fraseología, fraseografía y traducción. Granada: Comares.

Corpas Pastor, G. (2004). Diez años de investigación en fraseología: análisis sintácticosemánticos, contrastivos y traductológicos, Madrid: Vervuert.

Coşeriu, E. (1962). Teoría del lenguaje y lingüística general: cinco estudios. Madrid: Gredos.

Coşeriu, E. (1977). Principios de semántica estructural. Madrid: Gredos.

Cristea, D. (2010). Expresiones idiomáticas en español y rumano: puente conceptual entre las dos culturas. Actas del III Congreso internacional de lingüística hispánica (CILHIS). Novos investigadores en linguas e lingüística, Lugo: Editorial Axac, 65-72.

D’Andrea, L. (2019). Las construcciones con verbo soporte en español y en italiano: análisis contrastivo y aplicación didáctica a E/LE. (Tesis doctoral). Salamanca: Universidad de Salamanca.

Del Valle Revuelta, S. (2019). El programa televisivo como recurso para la enseñanza laprendizaje de español lengua extranjera. (Tesis doctoral). Valladolid: Universidad de Valladolid.

Diamante Colado, G. (2003). Fraseología del español en la enseñanza del ELE (caracterización general y principios metodológicos, con especial atención a los somatismos) (trabajo de fin de máster). Madrid: Universidad Complutense de Madrid.

Dimitrescu, F. (1958). Locuţiuni verbale în limba română. Bucureşti: Editura Academiei.

Dinică, C. (2014). Un análisis contrastivo español-rumano: estado de la cuestión. Phylologica Jassyensia, X2 (20), 141-153. 
Dobrovol'skij, D. y Piirainen, E. (2005). Figurative Language: Cross-Cultural And CrossLinguistic Perspectives. Oxford: Elsevier.

Donalies, E. (2009). Basiswissen Deutsche Phraseologie, Tübinegen und Basel: A. Franke Verlag.

Dumbrăvescu, D. (2016). La fraseología como componente identificador de las lenguas culturas: el caso del rumano y del español. AEPE, 206-217.

Dumbrăvescu, D. (2019). Las unidades fraseológicas y la enseñanza/aprendizaje del español como lengua extranjera. Intertext (2), 118-125.

Dumistrăcel, S. (1980). Lexic românesc. Cuvinte. Metafore. Expresii. Bucureşti: Editura Ştiinţifică şi Enciclopedică.

Dumitrescu, D. (1980). Îndreptar pentru traducerea din limba română în limba spaniolă. Bucureşti: Editura Ştiinţifică şi Enciclopedică.

Duţă, O. (2013). Somatismele în frazeologie: congruenţe structurale şi semantice între limbile spaniolă, italiană şi română. En E. Pîrvu (Ed.), Discorso e cultura nella lingua en ella letteratura italiana, Atti del $V$ Convegno internazionale di italianistica dell'Università di Craiova, Firenze: Cesati Editore, 75-86.

Duţă, O. (2013). Sobre los recursos lexicográficos bilingües de fraseología española y rumana. En I. Bădescu y M. Popescu. (Eds.), Studia linguistica et filologica in honorem prof. univ. dr. Michaela Livescu. Craiova: Editura Universitas, 102-115.

Duţă, O. (2014). Paralelismos estructurales y semánticos en la fraseología del español y rumano. (Tesis doctoral). Universitatea din Bucureşti, Bucarest.

Ettinger, S. (1998): Einige Überlegungen zur Phraseodidaktik. En W. Eismann (Ed.) EUROPHRAS 95. Europäische Phraseologie im Vergleich: Gemeinsames Erbe und kulturelle Vielfalt, Studien zur Phraseologie und Parömiologie (15), Bochum: Universitätsverlag Dr. N. Brockmeyer, 201-217.

Ettinger, S. (2008). Alcances e límites da fraseodidáctica: dez preguntas clave sobre o estado actual da investigación. Cadernos de Fraseoloxía galega (10), 95-127.

Fernando, C. y Flavell, R. (1981). On Idioms. Critical views and Perspectives. London: Exter Linguistics Studies.

Fernández Ramírez, S. (1986). Gramática española. El verbo y la oración. Madrid: Arco Libros.

Fleischer, W. (1997). Phraseologie der deutschen Gegenwartsprache. Tübingen: Niemeyer. 
Forment Fernández, M. (1998). La didáctica de la fraseología ayer y hoy: del aprendizaje memorístico al agrupamiento en los repertorios de funciones comunicativas. Actas del ASELE VIII, Alcalá de Henares: Universidad de Alcalá de Henares, 339-347.

Galindo Merino, Ma. M. (2004). Principales modelos de análisis de datos en la investigación sobre adquisición de segundas lenguas (memoria de investigación), Alicante: Universidad de Alicante.

García-Page, M. (1990). Léxico y sintaxis locucionales: algunas consideraciones sobre las palabras "idiomáticas". Estudios humanísticos. Filología http://dx.doi.org/10.18002/ehf.v0i12.4052

García-Page, M. (1995). Problemas en el empleo de la fraseología española por hablantes extranjeros: la violación de las restricciones. Actas del ASELE (VI), León: Universidad de León, 155-162.

García-Page, M. (1995a). Fraseologismos oracionales. Contextos (XIII/25-26), 79-92.

García-Page, M. (2008). Introducción a la fraseología española. Barcelona: Anthropos.

García Rodríguez, J. (2019). Las unidades fraseológicas del español y el catalán con elementos de la naturaleza: estudio cognitivo-contrastivo y propuesta de un diccionario electrónico de fraseología bilingüe (tesis doctoral). Barcelona: Universidad Autónoma de Barcelona.

Gardner, H. (1983). Multiple intelligences. Nueva York: Basic Books.

Gómez González, A y Ureña Tormo, C. (2017). Una propuesta para la enseñanza de las locuciones en la clase de ELE. Foro de Profesores de E/LE (13), 313-323. https://doi.org/10.7203/foroele.v0i13.10813

González Rey, M. (1998). Estudio de idiomaticidad en las unidades fraseológicas. En G. Wotjak (Ed.), Estudio de idiomaticidad en las unidades fraseológicas, Madrid: Iberoamericana, 57-74.

González Rey, M. (2012). De la didáctica de la fraseología a la fraseodidáctica, Paremia (21), 67-84.

González Rey, M. (2018). Competencia fraseológica y modelo pedagógico: el caso del método Phraséotext-le Français Idiomatique. Fraseología, Diatopía y Traducción. En P. Mogorrón Huerta y A. Albaladejo-Martínez (Eds.), Amsterdam/Philadelphia: John Benjamins, 133-154. https://doi.org/10.1075/ivitra.17.07gon

González Royo, C. y Mogorrón Huerta, P. (2011). Fraseología contrastiva: lexicografía, traducción y análisis de corpus. Alicante: Universidad de Alicante. 
Granger, S y Paquot, M. (2008). Disentangling the phraseological web. Amsterdam/Philadelphia: John Benjamins. https://doi.org/10.1075/z.139.07gra

Gross, G. (1996). Les expressions fijées en français - noms composés et autres locutions, Paris: Ophrys.

Groza, L. (2011). Probleme de frazeologie. Studii. Articole. Note. Bucureşti: Editura Universităţii Bucureşti.

Gurrutxaga, A y Alegría, I. (2013). Combining Different Features of Idiomaticity for the Automatic Classification of Noun+Verb Expressions in Basque en NAACL HLT. Workshop on Multiword Expressions (13), 116-125.

Gutiérrez Araus, Mํ. L. (1995). Formas verbales en pasado en indicativo. Madrid: Arco Libros.

Gutiérrez Ordoñez, S. (1997). Estructuras comparativas, Madrid: Arco/Libros.

Haddouch, B. (2013). Las unidades fraseológicas en la enseñanza del español: caso del alumnado marroquí del Instituto Cervantes de Tetuán (Tesis doctoral). Rabat: Universidad Mohamed V Agdal.

Hausman, F. (1979). Un dictionnaire des collocations est-il possible?, Travaux de linguistique et littérature 17 (I), 187-195.

Hebedean, D. (2014). Frazeologia - consideraţii teoretice. Philologica Banatica, VIII (I), 98-113.

Higueras García, M. (1997). Las unidades léxicas en la enseñanza del léxico a extranjeros. REALE: Revista de Estudios de Adquisición de la Lengua Española (8), 35-50.

Hristea, T. (1984). Sinteze de limba română. Bucureşti: Editura Albatros.

Instituto Cervantes (2006). Plan Curricular del Instituto Cervantes. Madrid: Instituto Cervantes - Biblioteca Nueva.

Iordan, I. (1975). Stilistica limbii române (ediţie definitivă). Bucureşti: Editura Ştiinţifică şi Enciclopedică.

Jackson, H. (1981). Contrastive Analysis as a predictor of errors, with reference to Punjabi learners of English. En J. Fisiak (Ed.), Contrastive Linguistics and the Language Teacher, Oxford: Pergamon Press.

Julià Luna, C. y Ortiz Rodríguez, C. (2012). El proceso de enseñanza-aprendizaje de las unidades fraseológicas. VII CIDUI: La universitat, una institució de la societat, Barcelona: Universitat Pompeu Fabra.

Julià Luna, C. y Ortiz Rodríguez, C. (2013). La semántica cognitiva en la enseñanzaaprendizaje de las unidades fraseológicas en ELE: el ejemplo de los somatismos. 
Plurilingüismo y enseñanza de ELE en contextos multiculturales. Congreso de la Asociación de Enseñanza de Español como Lengua Extranjera, Madrid: ASELE, 495-507.

Kaufmann, S. (2003). The linguist. A Personal Guide to Language Learning. Canada: Autor House.

Kiuchukova-Petrinska, B. (2017). Las colocaciones en la enseñanza de ELE. Actas del II Encuentro de Profesores de Español, Sofía: Instituto Cervantes. Departamento de comunicación digital, 11-18.

Krashen, S.D. y Terrell, T.D. (1983). The Natural Approach: language acquisition in the classroom, Oxford: Pergamon. https://doi.org/10.5785/1-2-506.

Kühn, P. (1987). Deutsch als Fremdsprache im phraseodidaktischen Dornröschenschlaf. Vorschläge für eine Neukonzeption phraseodidaktischer Hilfsmittel, Fremdsprachen Lehren und Lernen (16), 62-79.

Kumaravadivelu, B. (2012). La palabra y el mundo. MarcoELE (14), 1-10.

Lado, R. (1957). Linguistics Across Cultures: Applied Linguistics for Language Teachers. Ann Arbor, Michigan: University of Michigan.

Lakoff, G. y Johnson, M. (1980). Metaphors we live by. Chicago: University of Chicago Press.

Larreta Zuluategui, J.P. (2001). Fraseología contrastiva del alemán y el español. Teoría y práctica a partir de un corpus bilingüe de somatismos, Frankfurt am Main: P. Lang.

Leal Riol, Mà. J. (2011). La enseñanza de la fraseología en español como lengua extranjera. Estudio comparativo dirigido a estudiantes anglófonos. Valladolid: Universidad de Valladolid.

Lennenberg, E.G. (1967). Biological Foundations of Language, New York: Wiley.

Leontaridi, E., Peramos Soler, N, y Ruiz Morale, M. (2009). Las unidades fraseológicas del español: su enseñanza y adquisición en la clase de ELE. Jornadas de Formación de Profesorado. Enseñanza de L2/ELE y la Literatura Española Contemporánea, Sofía: Universidad de Sofía "San Clemente de Ojrid", 185-204.

Levinson, S. (2000). Presumptive Meanings: The Theory of Generalized Conversational Implicature. Cambridge: MIT Press.

Lewis, M. (1993). The Lexical Approach. Hove: Language Teaching Publications.

López Roig, C. (2002). Aspectos de fraseología contrastiva (español - alemán) en el sistema y en el texto. Frankfurt am Mein: Peter Lang. 
López Vázquez, L. (2011). La competencia fraseológica en los textos de los manuales de ELE de nivel superior. Del texto a la lengua: la aplicación de los textos a la enseñanzaaprendizaje del español L1/L2. Salamanca: ASELE / Centro Virtual Cervantes, 531-542.

Lüger, H.-H. (1997): Anregungen zur Phraseodidaktik, Beiträge zur Fremdsprachenvermittlung (32), 69-120.

Luque Nadal, L. (2012). Principios de culturología y fraseología españolas. Creatividad y variación en las unidades fraseológicas. Frankfurt am Main: Peter Lang.

Madrona Fernández, A. y Pisot Díaz, R. (2009). Diferencias de usos gramaticales entre el español y el rumano. Madrid: Edinumen.

Martín Noguerol, M. (2017). Aprendiendo cultura a través de las fórmulas rutinarias. Actas de $V^{o}$ Jornadas Internacionales de Didáctica del Español como Lengua Extranjera, Budapest: Instituto Cervantes. Departamento de comunicación digital, 130-14.

Martín Peris, E. (1988). La enseñanza de idiomas modernos: de los contenidos a los procesos, CABLE (1), 16-21.

Martín Salcedo, J. (2017). Fraseología española en uso. ¡Si tú lo dices! ¡Venga! Ya verás como sí. Brasilia DF: Consejería de Educación MECD.

Martinet, A. (1967). Eléments de linguistique générale. Paris: Armand Colin.

Mazzaro, D. y Goettenauer de Marins Costa, E. (2008). Los conectores en el aula de ELE: propuestas de actividades. Actas del V Simposio Internacional José Carlos Lisboa de Didáctica del Español, Río de Janeiro: Instituto Cervantes, 487-496.

Mejri, S. (2003). Introduction: Polysémie et polylexicalité. Syntaxe et Sémantique (5), 1330.

Mel'čuk, I. (1993). La phraséologie et son rôle dans l'enseignement-apprentissage d'une langue étrangère. Études de Linguistique Appliqués (92), 82-113.

Mel'čuk, I. (1998). Collocations and lexical functions. En Cowie, A. P. (Ed.), Phraseology: theory, analysis and applications. Oxford: Claredon Press: 23-53.

Mellado Blanco, C. (2000). Formas estereotipadas de realización no verbal en alemán y español: los cinegramas desde un enfoque contrastivo-histórico. Las lenguas de Europa: estudios de fraseología, fraseografía y traducción. Granada: Comares, 389-410.

Mellado Blanco, C. (2004). Fraseologismos somáticos del alemán. Frankfurt am Mein: Peter Lang.

Mellado Blanco, C. (2015). Parámetros específicos de equivalencia en las unidades fraseológicas (con ejemplos del español y el alemán). Revista de Filología (33), 153-174. 
Mena Martínez, F. (2003). En torno al concepto de desautomatización fraseológica: aspectos básicos, Tonos Digital (5), 1-12.

Mendizábal de la Cruz, N. (2016). Estar en el candelero. La enseñanza de la fraseología española como segunda lengua. MarcoELE (23), 1-12.

Mendizábal de la Cruz, N. y Sastre Ruano, M. (2017). Problemas de las unidades fraseológicas verbales y su aplicación a la enseñanza del español como lengua extranjera. VenPalabras. Estudio de lexicología española. Venezia: Ca' Foscari, 49-62. https://doi.org/10.14277/6969-169-0/VP-1-4

Mendizábal de la Cruz, N. y Muñoz, J. (2019). Estudio contrastivo alemán/español de las locuciones verbales con estructura estar + preposición. Aplicaciones didácticas en el aula. Zeitschrift für Romanische Sprachen und ihre Didaktik, 13(1), 45-64.

Minervini, R. (2019). Las expresiones idiomáticas en la enseñanza/aprendizaje de E/LE: un estudio sobre el nivel intermedio (B1/B2). Rhesis: International Journal of Linguistics, Philology and Literature, 10.1. Cagliari: Università degli Studi di Cagliari.

Miquel, L. y Sanz, N. (1992). El componente cultural, un ingrediente más en la clase de lengua. Cable (9), 15-21.

Molero, C. Mํ. y Salazar, D. (2012). Ejercicios prácticos para trabajar las colocaciones en el aula de ELE. Actas del I Encuentro Nacional de Profesores de Español Bruselas, 7987.

Montoro del Arco, J. (2004). La fraseología en el siglo XX después de Casares. Anuario de Estudios Filológicos (XXVII), 221-236.

Moreno Pereiro, S. (2006). Las unidades fraseológicas en el aula de E/LE: una aproximación cognitiva. Actas del I Congreso Virtual E/LE. La enseñanza del español en el siglo XXI, 1-7.

Muñoz-Basols, J. (2015). Enseñanza del léxico idiomático. Enciclopedia de Lingüística Hispánica (coord. Gutiérrez-Rexach, J.), London: Routledge, 422-453.

Narbona Jiménez, A. (1989). Las subordinas adverbiales impropias del español - bases para su estudio. Málaga: Agora.

Navarro, C. (2004). Didáctica de las unidades fraseológicas. En Mํ.V. Calvi y F. San Vicente (Eds.), Didáctica del léxico y nuevas tecnologías Viarreguio Luca: Mauro Baroni Editore, 99-115.

Navarro, C. (2007). Fraseología contrasiva del español y el italiano (análisis de un corpus bilingüe). Tonos Digital (13,) 1-21.

Nemser, W. (1971). Approximative System of Foreign Language Learners. IRALInternational Review of Applied Linguistics 9(2), 115-123. 
Nénkova, V.A. (2006) Somatismos fraseológicos en búlgaro y español: contraste de unidades fraseológicas desde la praxis traductora. En J. García-Medall (Ed.), Fraseología e ironía: descripción y contraste, Lugo: Axac, 97-110.

Niculescu, A. (1977). El rumano: lengua y cultura románicas. Anuario de letras. Lingüística y filología. Bucarest: Universidad de Bucarest, 283-293.

Nogueira da Siva, A. (2011). La enseñanza de los marcadores del discurso del español en relación con los géneros y secuencias textuales. Revista Nebrija de Lingüística Aplicada, 9(5), 59-85.

Olza Moreno, I. (2009). Aspectos de la semántica de las unidades fraseológicas. La fraseología somática metalingüística del español actual (Tesis doctoral). Pamplona: Universidad de Navarra.

Olza Moreno, I. (2011). Corporalidad y lenguaje. La fraseología somática metalingüística del español. Studien zur romanischen Sprachwissenschaft und interkulturellen Kommunikation. Frankfurt am Main: Peter Lang.

Oprica, D. (2014). Las unidades fraseológicas rumanas relativas al hogar y su correspondencia española. Paremia (23), 187-198.

Oprica, D. (2013). Estudio intercultural de las unidades fraseológicas rumanas relativas a los alimentos. Paremia (22), 135-148.

Ortega Román, J.J. (2006). Paremia y fraseología comparadas españolas y rumanas: buscando equivalencias, acercando idiomas. Paremia (15), 73-81.

Pamies Bertrán, A. (2007). De la idiomaticidad y sus paradojas. En G. Conde (Ed.), Nouveaux apports à l'étude des expressions figées, Fernelmont: EME, 173-204.

Peguret, M. (2009). Pour un cadre canadien commun de référence dans le contexte du français langue seconde post-immersif (Tesis doctoral). Halifax: Dalhousie University.

Penadés Martínez, I. (2004). La enseñanza de la fraseología en el aula de ELE. Carabela (56), 51-67.

Pindado Roncero, A. (2016). La fraseología en el lenguaje publicitario como instrumento de enseñanza de cultura en el aula E/LE. (Trabajo de fin de grado). Valladolid: Universidad de Valladolid.

Pisot Díaz, R. (2005). Propuesta de diccionario fraseológico español - rumano. (Tesis doctoral). Salamanca: Universidad de Salamanca.

Prodromou, L. (2008). English as a Lingua Franca: A Corpus-Based Analysis, London: Continuum.

Rakotojoelimaria, A. (2004). Esbozo de un diccionario de locuciones español - malgache (Tesis doctoral). Alcalá de Henares: Universidad de Alcalá. 
Rădulescu, R. A. (2005). Construcciones idiomáticas con el verbo "salir" en español, inglés y rumano. Verba hispánica (13), 99-112. https://doi.org/10.4312/vh.13.1.99-111

Rădulescu, R. A. (2006). Verbo de habla no convencionales en español y rumano: estudio contrastivo de expresiones idiomáticas con los verbos dar y bate. En M. Villayandre Llamazares (Ed.), Actas del XXXV Simposio Internacional de la Sociedad Española de Lingüística. León: Universidad de León, 1546-1564.

Rădulescu, R. A. (2009). Sobre cuánto puede dar de sí el verbo dar en fraseologismos españoles y rumanos. Fronteras de un diccionario: las palabras en movimiento, 469-500.

Rey, A. (1976). Structure sémantique des locutions françaises. Actas del XIII Congreso Internacional de Lingüística y Filología Románicas, Québec: Presses de I'Université Laval, 831-842.

Richart Marset, M. (2008). Las unidades fraseológicas y su resistencia a la traducción. Foro de profesores de E/LE (4), 1-10. https://doi.org/10.7203/foroele.0.6550

Rodríguez, M. y Bernardo Vila, N. (2011). La importancia del léxico y su didáctica: introducción al aprendizaje de refranes y expresiones, VIII Jornadas de EPELE, Nápoles: Instituto Cervantes,162-176.

Rodríguez Ponce, M. (2006). Las comparaciones estereotipadas y su aprovechamiento en la enseñanza del español como lengua extranjera, La competencia pragmática y la enseñanza del español como lengua extranjera. Oviedo: Universidad de Oviedo, 528-537.

Roesler, P. (2010). Características generales del español hablado por inmigrantes rumanos en Castellón de la Plana (Tesis doctoral). Friburgo: Universidad de Friburgo.

Rojo Sánchez, G. (1986). El lenguaje, las lenguas y la lingüística. Santiago de Compostela: Universidad de Santiago de Compostela.

Ruiz Gurillo, L. (1997). Aspectos de fraseología teórica española. Valencia: Universidad de Valencia.

Ruiz Gurillo, L. (2001). Las locuciones en español actual. Madrid: Arco Libros.

Ruiz Martínez, A.Ma. (2007). La fraseología en el Plan Curricular del Instituto Cervantes. Niveles de referencia para el español. Frecuencia $L$ (34), 7-15.

Sáez Martínez, B. (2011). Texto y literatura en la enseñanza de ELE. Del texto a la lengua: La aplicación de los textos a la enseñanza-aprendizaje del español L2-LE, Actas del XXXI Congreso de ASELE, 57-68.

Sagban, M. (2010). La fraseología comparada del español y del árabe en Irak: su aplicación a la enseñanza de las unidades fraseológicas en el aula de E/LE (Tesis doctoral). Granada: Universidad de Granada. 
Sala, M. (1998). De la latină la română. Bucureşti: Univers Enciclopedic.

Salem, T. (2013). La fraseología en español y en árabe: estudio, comparación, traducción y propuesta de un diccionario (Tesis doctoral). Madrid: Universidad Complutense de Madrid.

Santos Gargallo, I. (1993). Análisis Contrastivo, Análisis de Errores e Interlengua en el marco de la Lingüística Contrastiva. Madrid: Síntesis.

Saracho Arnáiz, M. (2015). La fraseología del español: una propuesta de didactización para la clase de ele basada en los somatismos (Tesis doctoral). Santiago de Compostela: Universidad de Santiago de Compostela.

Sasu, L. (2011). Unităţile frazeologice, marcă a temporalităţii şi a spaţialităţii unei comunităţi, în traducere, Lexic comun/Lexic specializat (2),46-56.

Sava, C. (2009). Errores léxicos en hablantes rumanos: los falsos amigos (Trabajo de fin de máster). Alcalá de Henares: Universidad de Alcalá de Henares.

Šaxmatov, A. (1941). Syntaksis russkogo yazika, Lengingrad: Učpedgiz.

Sciutto, V. (2006). Elementos somáticos en la fraseología del español en Argentina. Roma: Arcane Editrice.

Selinker, L. (1972). Interlanguage. IRAL- International Review of Applied Linguistics (10), 209-241. https://doi.org/10.1515/iral.1972.10.1-4.209

Serradilla Castaño. A. (2014). La fraseología en el aula de ELE: nuevos enfoque y propuestas didácticas. ¿Qué necesitamos en el aula de ELE?: reflexiones en torno a la teoría y la práctica, (Eds. J. González, M. Alonso, J. Pazó y J. García), Madrid: MECD, 7398.

Sevilla Muñoz, J. (2018). Julio Casares, iniciador de la fraseología moderna española. Paremia (27), 11-22.

Skinner, B.F. (1957). Verbal behavior, New York: Appelton-Century-Crofts.

Şodolescu-Silvestru, E. (2002). Expresii frazeologice româneşti din perspectivă comparată. Bucureşti: Editura Fundaţiei România de mâine.

Sosiński, M. (2006). Fraseología comparada del polaco y del español: su tratamiento en los diccionarios bilingües (Tesis doctoral). Granada: Universidad de Granada.

Suárez Cuadros, S.J. (2007). La escuela soviética y sus aportaciones a la fraseología. Interlingüística (17), 999-1003.

Strohschen, C. (2016). El Tratamiento de la Fraseología en los Manuales de DaF de los Niveles B1 y B2: Análisis y Propuesta Didáctica (Tesis doctoral). Murcia: Universidad de Murcia. 
Szyndler, A. (2015). La fraseología en el aula de E/LE: ¿un reto difícil de alcanzar? Una aproximación a la fraseodidáctica. Didáctica. Lengua y literatura (27), 197-216. https://doi.org/10.5209/rev DIDA.2015.v27.50867

Timofeeva, L. (2006). Sobre la traducción de la fraseología: un enfoque pragmático. Interlingüística (17), 1029-1038.

Timofeeva, L. (2009). La desautomatización fraseológica: un recurso para crear y divertir. En J. Jiménez Ruiz y L. Timofeeva (Eds.), Estudios de lingüística: Investigaciones lingüísticas en el siglo XXI. Alicante: Universidad de Alicante, 249-271.

Timofeeva, L. (2012). Sobre la traducción fraseológica. ELUA (26), 405-432.

Timofeeva, L. (2013). La fraseología en la clase de lengua extranjera: ¿misión imposible? Onomazéin (28), 320-336.

Timofeeva, L. (2013a). Fraseodidáctica: a fraseoloxía para a didáctica. Cuadernos de Fraseoloxía Galega (15), 393-410.

Timofeeva, L. (2017). Locuciones. En J. Gutiérrez-Rexach (Ed.), Enciclopedia de lingüística hispánica (1), London and New York: Routledge.

Trivić, A. (2013). Correspondencia recíproca en la fraseología. Análisis contrastivo español-serbio. Colindancias (4), 69-80.

Tudorică, O. (1968). Concordanţe frazeologice romano-spaniole, CL (XI), 1.

Vidiella Andreu, M. (2012). En enfoque léxico en los manuales de E/LE. MarcoELE (14), 1-85.

Villayandre LLamazares, M. (2008). Lingüística con corpus (I). Estudios Humanísticos. Filología (30), 329-349. https://doi.org/10.18002/ehf.v0i30.2847

Vinogradov, V. (1947). Basic concepts of phraseology as a linguistic discipline, Leningrad: University of Leningrad.

Wardhaugh, R. (1970). The Constrastive Analysis Hypothesis, TESOL quarterly (4), 123130.

Weinreich, U. (1966). Languages in Contact: Findings and Problems. The Hague: Mouton.

Weinreich, U. (1969): Problems in the Analysis of Idioms. En: J. Puhvel, (Ed.), Substance and Structure of Language. Berkeley and Los Angeles: University of California Press, 2381.

Wilss, W. (1990). Verbal stereotypes. Meta $35 \quad$ (2), 277-245 https://doi.org/10.7202/004612ar 
Wotjak, B. (1983). Sage und Schreibe. Deutsche Phraseologismen in Theorie und Praxis, Leipzig: Langenscheidt.

Wotjak, G. (1985). No hay que estarse con los brazos cruzados. Algunas observaciones acerca del significado de expresiones idiomáticas verbales del español actual. Linguistische Arbeitsberichte (45), 77-84.

Wotjak, G. (1995). Equivalencia semántica, equivalencia comunicativa y equivalencia translémica. Hieronymus Complutensis (1), 93-111.

Wray, A. (2005). Formulaic Language and the Lexicon, Oxford: Oxford University Press.

Wray, A. y Fitzpatrick, T. (2006). Breaking up is not so Hard to do: Individual Differences in L2 Memorization. The Canadian Modern Language Review/La Revue canadienne de langues vivantes, 63 (1), 35-57. https://doi.org/10.3138/cmlr.63.1.35

Wu, Fan. (2012). La fraseología en chino y en español: caracterización y clasificación de las unidades fraseológicas y simbología de los zoónimos. Un estudio contrastivo. (Tesis doctoral). Madrid: Universidad Autónoma de Madrid.

Zafiu, R. (2010). Cuvânt-înainte, Dicţionar de expresii, locuţiuni şi sintagme ale limbii român, Măranduc, C. (Ed.) Bucureşti: Corint, 7-8.

Zholobova, A. (2005). Acerca de la fraseología internacional: los europeísmos culturales. Interlingüística. 16(2), 1191-1197.

Zuluaga Ospina, A. (1980). Introducción al estudio de las expresiones fijas. Frankfurt am Mein: Peter D. Lang. 


\section{ANEJOS}

Transcripción del corpus (lexema, somatismo, equivalencia, nivel)

\begin{tabular}{|c|c|c|c|c|}
\hline Lexema & UF en español & UF en rumano & Nivel & $\begin{array}{l}\text { Tipo de } \\
\text { equivalencia }\end{array}$ \\
\hline barba & subirse a las barbas & a i se urca în cap; a i se sui în cap & B2 & parcial \\
\hline barriga & dar cien patadas en la barriga & - & B2 & nula \\
\hline barriga & echar barriga & a face burtă & B1 & parcial \\
\hline barriga & rascarse la barriga & a sta cu burta la soare & A2 & parcial \\
\hline barriga & tocarse la barriga & a sta cu burta la soare & A2 & parcial \\
\hline boca & andar de boca en boca & a fi pe buzele tuturor & B1 & parcial \\
\hline boca & andar en boca de todos & a fi pe buzele tuturor & B1 & parcial \\
\hline boca & decir con la boca chica & a spune cu jumătate de gură & B2 & parcial \\
\hline boca & decir lo que se le viene a la boca & a spune ce-i trece prin cap & B2 & parcial \\
\hline boca & $\begin{array}{l}\text { decir lo primero que se le viene a } \\
\text { la boca }\end{array}$ & $\begin{array}{l}\text { a vorbi cum îi vine la gură, a spune ce-i } \\
\text { trece prin cap }\end{array}$ & B2 & parcial \\
\hline boca & dejar buen sabor de boca & a lăsa un gust placut & B1 & parcial \\
\hline boca & dejar con la boca abierta & a lăsa cu gura deschisă & B1 & total \\
\hline boca & dejar mal sabor de boca & a lăsa un gust amar & B1 & parcial \\
\hline boca & echar espumarajos por la boca & a face spume la gură & B2 & parcial \\
\hline boca & hacer la boca agua & a-i lăsa (cuiva) gura apă (după ceva) & B1 & parcial \\
\hline boca & irse de la boca & a lua gura pe dinainte pe cineva & B2 & parcial \\
\hline boca & mantener la boca cerrada & a-și ține gura închisă & A2 & total \\
\hline boca & meterse en la boca del lobo & a se băga în gura lupului & B1 & total \\
\hline boca & no decir esta boca es mía & a tăcea chitic & B2 & nula \\
\hline boca & partir la boca & a sparge fața & B2 & parcial \\
\hline boca & poner en boca & $\begin{array}{l}\text { a-i pune în gură (cuiva); a-i atribui cuiva } \\
\text { ceva }\end{array}$ & B2 & parcial \\
\hline boca & quedarse con la boca abierta & a rămâne cu gura cascată & B1 & total \\
\hline boca & quitar de la boca & a-i lua (cuiva) vorba de la gură & B2 & parcial \\
\hline boca & romper la boca & a sparge fața & B2 & parcial \\
\hline boca & ser un bocazas & a fi gură spartă & B2 & parcial \\
\hline boca & tapar bocas & $\begin{array}{l}\text { a închide gura lumii; a face să tacă gurile } \\
\text { rele }\end{array}$ & B1 & parcial \\
\hline boca & tapar la boca & a închide (a astupa) gura cuiva & B1 & total \\
\hline
\end{tabular}




\begin{tabular}{|c|c|c|c|c|}
\hline boca & no abrir la boca & a nu deschide gura & $\mathrm{A} 1$ & total \\
\hline brazo & cruzarse de brazos & $\begin{array}{l}\text { a sta cu brațele încrucișate; a sta cu } \\
\text { mâinile în sân }\end{array}$ & B1 & parcial \\
\hline brazo & (no) dar el brazo a torcer & - & B2 & nula \\
\hline brazo & echar en brazos & a se arunca în brațele cuiva & B1 & parcial \\
\hline brazo & (esperar) con los brazos abiertos & a aștepta cu brațele deschise & A1 & total \\
\hline brazo & estar de brazos cruzados & $\begin{array}{l}\text { a sta cu brațele încrucișate; a sta cu } \\
\text { mâinile în sân }\end{array}$ & B1 & parcial \\
\hline brazo & (recibir) con los brazos abiertos & a primi cu brațele deschise & A1 & total \\
\hline brazo & (ser) el brazo derecho de alguien & a fi mâna dreaptă (a cuiva) & A2 & total \\
\hline brazo & abrir los brazos & a deschide brațele & B2 & parcial \\
\hline brazo & (no) bajar los brazos & - & B2 & nula \\
\hline cabeza & agachar la cabeza & a pleca capul & B2 & total \\
\hline cabeza & bajar la cabeza & a pleca capul & B1 & total \\
\hline cabeza & dar vueltas a la cabeza & a-și bate capul & B2 & parcial \\
\hline cabeza & $\begin{array}{l}\text { darse con la cabeza en la pared o } \\
\text { en las paredes }\end{array}$ & a se da cu capul de toți pereții & B2 & total \\
\hline cabeza & echarse las manos a la cabeza & a se lua cu mâinile de cap & B1 & total \\
\hline cabeza & escarmentar en cabeza ajena & - & $\mathrm{B} 2$ & nula \\
\hline cabeza & estar mal de la cabeza & a fi dus cu capul/pluta & $\mathrm{A} 2$ & parcial \\
\hline cabeza & (ir) con la cabeza muy alta & a-și ține fruntea sus & B2 & parcial \\
\hline cabeza & jugarse la cabeza & - & B2 & nula \\
\hline cabeza & (no) levantar cabeza & a (nu) se pune pe picioare & B1 & parcial \\
\hline cabeza & meter en la cabeza & a băga în cap & B2 & total \\
\hline cabeza & meter la cabeza & - & $\mathrm{B} 2$ & nula \\
\hline cabeza & meter pájaros en la cabeza & a avea gărgăuni în cap & B1 & parcial \\
\hline cabeza & no dejar títere con cabeza & a face totul harcea-parcea & B2 & parcial \\
\hline cabeza & $\begin{array}{l}\text { no tener más que serrín en la } \\
\text { cabeza }\end{array}$ & a fi prost facut gramada & B2 & nula \\
\hline cabeza & quitar de la cabeza & a-și scoate din cap & B1 & total \\
\hline cabeza & sentar la cabeza & a se așeza la casa lui /ei & B2 & parcial \\
\hline cabeza & (ser) cabeza cuadrada & (a fi) cap pătrat & $\mathrm{B} 1$ & total \\
\hline cabeza & subirse a la cabeza & a i se urca la cap & B2 & total \\
\hline cabeza & $\begin{array}{l}\text { tener la cabeza sobre los } \\
\text { hombros }\end{array}$ & $\begin{array}{l}\text { a avea capul pe umeri; a avea scaun la } \\
\text { cap }\end{array}$ & A1 & total \\
\hline
\end{tabular}




\begin{tabular}{|c|c|c|c|c|}
\hline cabeza & tener pájaros en la cabeza & a avea gărgăuni în cap & B1 & parcial \\
\hline callo & dar el callo & a pune osul; a-și toci coatele & B2 & parcial \\
\hline callo & pisar el callo & a călca pe bătătură; a călca pe coadă & B2 & parcial \\
\hline cana & peinar canas & - & A2 & nula \\
\hline cara & caerse la cara de vergüenza & a-i crăpa obrazul de rușine & B2 & parcial \\
\hline cara & cruzar la cara & a arde una peste faţă & B2 & parcial \\
\hline cara & dar la cara & - & B2 & nula \\
\hline cara & dar la cara por alguien & a-și pune obrazul pentru cineva & B2 & parcial \\
\hline cara & darse de cara con una persona & a da peste cineva & B2 & parcial \\
\hline cara & decir a la cara & a spune (verde) în faţă & B2 & parcial \\
\hline cara & echar en cara & a scoate ochii & B2 & parcial \\
\hline cara & plantar cara & a tine piept & B2 & parcial \\
\hline cara & poner la cara del revés & - & B2 & nula \\
\hline cara & restregar por la cara & a scoate ochii & B2 & parcial \\
\hline cara & romper la cara & a sparge fața & B2 & parcial \\
\hline carne & (poner) la carne de gallina & a i se face pielea de găină & B1 & parcial \\
\hline carne & poner toda la carne en el asador & - & $\mathrm{B} 2$ & nula \\
\hline carne & ser de carne y hueso & & B1 & nula \\
\hline carne & sufrir en su (propia) carne & a suferi pe propria piele & B1 & parcial \\
\hline carne & temblar las carnes & $\begin{array}{l}\text { a-I trece fiori reci; a-I trece toate } \\
\text { nădușelile; } \\
\text { a tremura ca varga }\end{array}$ & $\mathrm{B} 2$ & parcial \\
\hline carne & no ser ni carne ni pescado & a nu fi nici cal nici măgar & B2 & parcial \\
\hline ceja & arquear las cejas & a ridica din sprâncene & B1 & parcial \\
\hline ceja & meterse entre ceja y ceja & - & B2 & nula \\
\hline ceja & quemarse las cejas & a-și toci coatele & B2 & parcial \\
\hline ceja & tener entre ceja y ceja & - & B2 & nula \\
\hline cerebro & estrujarse el cerebro & a-și stoarce creierii & B2 & total \\
\hline cerebro & lavar el cerebro & a spăla pe creier pe cineva & B1 & total \\
\hline codo & empinar el codo & a trage la măsea & B1 & parcial \\
\hline codo & hablar por los codos & a turui ca o moară stricată & A2 & nula \\
\hline codo & romperse los codos & a-și toci coatele & B2 & parcial \\
\hline colmillo & enseñar los colmillos & a-și arăta colții & B2 & total \\
\hline corazón & abrir el corazón & a-și deschide inima & B1 & total \\
\hline
\end{tabular}




\begin{tabular}{|c|c|c|c|c|}
\hline corazón & partir el corazón & a rupe inima & B1 & total \\
\hline corazón & ser todo corazón & - & B1 & nula \\
\hline corazón & tener el corazón en un puño & a i se face inima cat un purice & $\mathrm{B} 1$ & parcial \\
\hline corazón & tener un corazón de oro & a avea o inimă de aur & A1 & total \\
\hline coronilla & estar hasta la coronilla & a fi sătul până în gât & B1 & parcial \\
\hline cuello & jugarse el cuello & - & $\mathrm{B} 2$ & nula \\
\hline dedo & chuparse los dedos & a se linge pe degete & B1 & parcial \\
\hline dedo & cruzar los dedos & a ține pumnii & B1 & nula \\
\hline dedo & hacer dedo & - & B1 & nula \\
\hline dedo & no mover un dedo & a nu mișca un deget & B1 & total \\
\hline dedo & no tener dos dedos de frente & a fi bătut în cap & A1 & nula \\
\hline dedo & pillarse los dedos & a-și prinde urechile & B2 & parcial \\
\hline dedo & $\begin{array}{l}\text { poderse contar con los dedos de } \\
\text { una mano }\end{array}$ & a număra pe degete & B1 & parcial \\
\hline dedo & poner el dedo en la llaga & a pune degetul pe rană & B2 & total \\
\hline dedo & señalar con el dedo & a arăta cu degetul & B1 & total \\
\hline diente & darse con un canto en los dientes & - & B2 & nula \\
\hline diente & enseñar los dientes & a-și arăta colții & B1 & parcial \\
\hline diente & hincar el diente & - & B2 & nula \\
\hline espalda & caerse de espaldas & a cădea pe spate & B1 & total \\
\hline espalda & clavar un puñal por la espalda & a înfige un cuțit în spate & B2 & total \\
\hline espalda & dar la espalda & a întoarce spatele & B1 & parcial \\
\hline espalda & echar sobre las espaldas & a-i pune în cârcă & B2 & parcial \\
\hline espalda & tener las espaldas anchas & a ține la tăvăleală & $\mathrm{B} 2$ & parcial \\
\hline espalda & cubrir las espaldas & - & B1 & nula \\
\hline hombro & arrimar el hombro & a pune umărul; a pune osul la treabă & B1 & total \\
\hline hombro & encoger los hombros & a ridica din umeri & B1 & parcial \\
\hline hombro & Ilorar sobre el hombro & a plânge pe umărul & B1 & total \\
\hline labio & dejar con la miel en los labios & a rămâne cu buza umflată & B2 & parcial \\
\hline labio & morderse los labios & a-si tine gura & $\mathrm{B} 2$ & parcial \\
\hline labio & tener los labios sellados & a-si pune lacăt la gură & B2 & parcial \\
\hline lengua & darle a la lengua & a da din gură & B2 & parcial \\
\hline lengua & irse de la lengua & a-I lua gura pe dinainte & B2 & parcial \\
\hline lengua & morderse la lengua & a-și mușca limba & B1 & total \\
\hline
\end{tabular}




\begin{tabular}{|c|c|c|c|c|}
\hline lengua & tener en la punta de la lengua & a sta pe limbă & B1 & parcial \\
\hline lengua & tener la lengua muy larga & a fi gură spartă & B1 & parcial \\
\hline lengua & tener la lengua muy suelta & a-i merge gura ca o moară stricată & B1 & parcial \\
\hline lengua & tirar de la lengua & a trage de limbă & B1 & total \\
\hline mano & escapar de entre las manos & a scăpa printre degete & B1 & parcial \\
\hline mano & llegar a las manos & - & B2 & nula \\
\hline mano & llevarse las manos a la cabeza & a-și pune mâinile în cap & B1 & parcial \\
\hline mano & morder la mano que da de comer & a muşca mâna care te hrăneşte & B1 & total \\
\hline mano & poner la mano en el fuego & a băga mâna in foc & B1 & parcial \\
\hline mano & poner la mano encima & - & B2 & nula \\
\hline mano & ponerse manos a la obra & a pune osul la treabă & $\mathrm{B} 2$ & parcial \\
\hline mano & tener las manos atadas & a fi legat de mâini și de picioare & B1 & parcial \\
\hline mano & tirar la piedra y esconder la mano & - & B2 & nula \\
\hline mano & echar una mano & a da o mână de ajutor & B1 & parcial \\
\hline mano & frotarse las manos & a-și freca mâinile de bucurie & B1 & parcial \\
\hline mano & lavarse las manos & a se spăla pe mâini & B1 & parcial \\
\hline mano & escaparse de las manos & a scăpa din mână & $\mathrm{B} 2$ & parcial \\
\hline mejilla & poner la otra mejilla & a întoarce și celălalt obraz & B2 & parcial \\
\hline nariz & arrugar la nariz & a strâmba din nas & B2 & parcial \\
\hline nariz & dar con la puerta en las narices & a trânti ușa în nas & B2 & parcial \\
\hline nariz & estar hasta las narices & a fi sătul până în gât & B2 & parcial \\
\hline nariz & hincharse las narices & a se face foc și pară; a-i sări muștarul & B2 & parcial \\
\hline nariz & importar tres pares de narices & a i se fâlfâi & B2 & parcial \\
\hline nariz & no ver más allá de sus narices & a nu vedea mai departe de lungul nasului & B2 & parcial \\
\hline nariz & tocarse las narices & $\begin{array}{l}\text { a sta cu mâinile în sân; a tăia frunză la } \\
\text { câini }\end{array}$ & B2 & parcial \\
\hline nariz & tocar las narices & a bate la cap & B2 & parcial \\
\hline nariz & meter las narices & a-și băga nasul & $\mathrm{B} 2$ & parcial \\
\hline ojo & andar con cien ojos & $\begin{array}{l}\text { a fi numai ochi și urechi; a fi cu ochii în } \\
\text { patru }\end{array}$ & B2 & parcial \\
\hline ojo & caerse la venda de los ojos & a se trezi la realitate & $\mathrm{B} 2$ & parcial \\
\hline ojo & cerrar los ojos & a închide ochii & $\mathrm{B} 1$ & parcial \\
\hline ojo & mirar con buenos ojos & a privi cu ochi buni & B1 & total \\
\hline ojo & no pegar ojo & a nu închide un ochi & B1 & parcial \\
\hline
\end{tabular}




\begin{tabular}{|c|c|c|c|c|}
\hline ojo & no quitar los ojos de encima & a nu slăbi din ochi & B2 & parcial \\
\hline ojo & no tener ojos más que para... & a nu avea ochi decât pentru & B2 & parcial \\
\hline ojo & quedarse con los ojos a cuadros & a face ochii cât cepele & B2 & parcial \\
\hline ojo & ser el ojito derecho & & A2 & nula \\
\hline ojo & abrir los ojos & a deschide ochii & B1 & parcial \\
\hline ojo & echar un ojo & a arunca un ochi & B1 & parcial \\
\hline ojo & mirar con malos ojos & a privi cu ochi răi; a nu privi cu ochi buni & B1 & parcial \\
\hline ojo & costar un ojo de la cara & costă (cât) ochii din cap & A1 & parcial \\
\hline ombligo & creerse el ombligo del mundo & a se crede buricul pământului & A2 & total \\
\hline ombligo & mirarse el ombligo & a tăia frunză la câini; a arde gazul & B2 & parcial \\
\hline oreja & agachar las orejas & a băga coada între picioare & B1 & parcial \\
\hline oreja & tener la mosca detrás de la oreja & - & B2 & nula \\
\hline oreja & planchar la oreja & a pune cornul în pernă & B2 & parcial \\
\hline oreja & poner la oreja & a trage cu urechea & B2 & parcial \\
\hline oreja & ver las orejas al lobo & - & B2 & nula \\
\hline oreja & tirar de las orejas & a trage de urechi & B1 & parcial \\
\hline pelo & caerse el pelo & a primi o săpuneală & B2 & nula \\
\hline pelo & poner los pelos de punta & a i se face părul măciucă & B1 & parcial \\
\hline pelo & no tener pelos en la lengua & $\begin{array}{l}\text { a spune verde în față; ce-i în gușă, și-n } \\
\text { căpușă }\end{array}$ & B2 & parcial \\
\hline pelo & tomar el pelo & a lua peste picior & A1 & parcial \\
\hline pelo & tirarse de los pelos & a-și smulge părul din cap & B2 & parcial \\
\hline pelo & no tocar un pelo & a nu atinge nici cu un deget & B2 & parcial \\
\hline pelo & no ver el pelo & a nu vedea la față & $\mathrm{B} 2$ & parcial \\
\hline pestaña & quemarse las pestañas & a învăţa pe rupte & B2 & parcial \\
\hline pie & buscar tres pies al gato & a căuta nod în papură & $\mathrm{B} 2$ & parcial \\
\hline pie & caerse el alma a los pies & - & $\mathrm{B} 2$ & nula \\
\hline pie & nacer de pie & a se naşte cu stea în frunte & B2 & parcial \\
\hline pie & sacar con los pies por delante & a scoate cu picioarele înainte & B2 & total \\
\hline pie & parar los pies & a readuce cu picioarele pe pământ & B2 & parcial \\
\hline pie & poner pies en polvorosa & a-şi pune picioarele la spinare & B2 & parcial \\
\hline pie & saber de qué pie cojea & $\begin{array}{l}\text { a ști ce-i poate pielea; a ști în ce ape se } \\
\text { scaldă }\end{array}$ & B2 & nula \\
\hline pie & tener los pies en el suelo & a fi cu picioarele pe pământ & A1 & parcial \\
\hline
\end{tabular}




\begin{tabular}{|c|c|c|c|c|}
\hline pie & no dar pie con bola & a o da în bară; a da chix & B1 & nula \\
\hline pie & no tener ni pies ni cabeza & $\begin{array}{l}\text { a nu avea nici cap, nici coadă; nicio } \\
\text { noimă }\end{array}$ & $\mathrm{A} 1$ & parcial \\
\hline piel & dejarse la piel & a se dedica trup și suflet & B2 & parcial \\
\hline piel & meterse en la piel & a se pune în pielea & B1 & parcial \\
\hline piel & salvar la piel & a-şi salva pielea & B1 & parcial \\
\hline piel & $\begin{array}{l}\text { vender la piel del oso antes de } \\
\text { cazarlo }\end{array}$ & a vinde pielea ursului din pădure & B2 & parcial \\
\hline puño & apretar los puños & a strânge din dinți & B2 & parcial \\
\hline riñón & costar un riñón & - & B1 & nula \\
\hline sangre & calentar la sangre & a fierbe /a clocoti sângele în vine & B2 & parcial \\
\hline sangre & llevar en la sangre & a avea în sânge & B1 & parcial \\
\hline sangre & subirse la sangre a la cabeza & a i se urca sângele la cap & B1 & parcial \\
\hline sangre & no tener sangre en las venas & a nu avea sânge în vine & B1 & parcial \\
\hline tripa & hacer de tripas corazón & a-și lua inima în dinţi & B2 & parcial \\
\hline uña & afilarse las uñas & - & B2 & nula \\
\hline uña & dejarse las uñas & a munci de-i sar capacele & B2 & nula \\
\hline uña & mirarse las uñas & a sta cu burta la soare & B2 & nula \\
\hline uña & sacar las uñas & - & B2 & nula \\
\hline uña & ser uña y carne & a fi prieteni la cataramă & B1 & parcial \\
\hline vena & cortarse las venas & a-și tăia venele & B1 & total \\
\hline yugular & saltar a la yugular & a sări la jugulară; a sări la gâtul & B2 & total \\
\hline
\end{tabular}


Distribución porcentual de los somatónimos

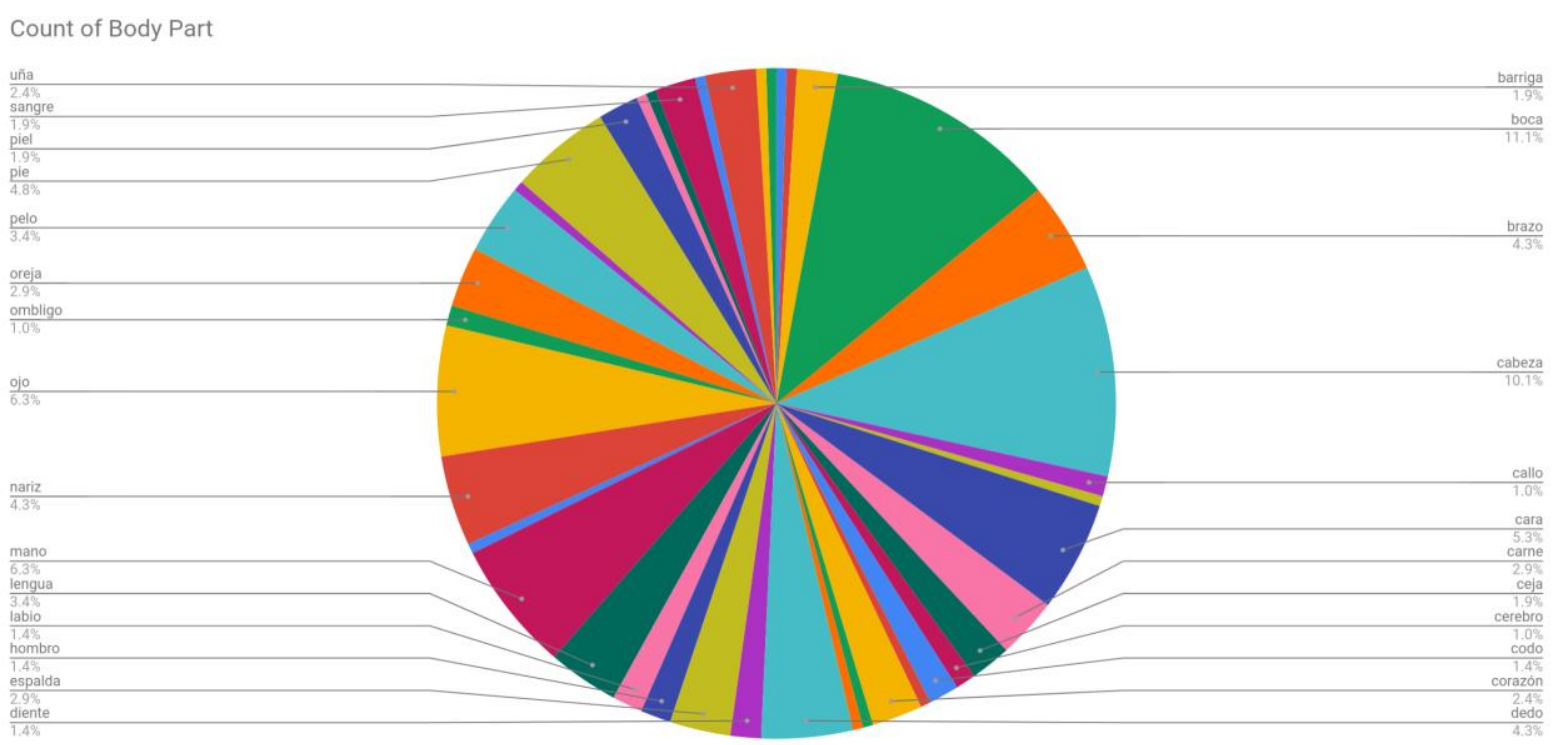

\section{Distribución numérica de los somatismos}

\begin{tabular}{|c|c|}
\hline Lexema & Unidad fraseológica \\
\hline barba & 1 \\
\hline barriga & 4 \\
\hline boca & 23 \\
\hline brazo & 9 \\
\hline cabeza & 21 \\
\hline callo & 2 \\
\hline cana & 1 \\
\hline cara & 11 \\
\hline carne & 6 \\
\hline ceja & 4 \\
\hline cerebro & 2 \\
\hline codo & 3 \\
\hline colmillo & 1 \\
\hline corazón & 5 \\
\hline coronilla & 1 \\
\hline cuello & 1 \\
\hline dedo & 9 \\
\hline diente & 3 \\
\hline espalda & 6 \\
\hline hombro & 3 \\
\hline labio & 3 \\
\hline
\end{tabular}




\begin{tabular}{|c|c|}
\hline lengua & 7 \\
\hline mano & 13 \\
\hline mejilla & 1 \\
\hline nariz & 13 \\
\hline ojo & 2 \\
\hline ombligo & 6 \\
\hline oreja & 7 \\
\hline pelo & 1 \\
\hline pestaña & 10 \\
\hline pie & 4 \\
\hline piel & 1 \\
\hline puño & 1 \\
\hline riñón & 4 \\
\hline sangre & 1 \\
\hline tripa & 5 \\
\hline uña & 1 \\
\hline vena & 1 \\
\hline yugular & 206 \\
\hline Total & \\
\hline & \\
\hline
\end{tabular}

Distribución de los somatismos por nivel (A1-B2)
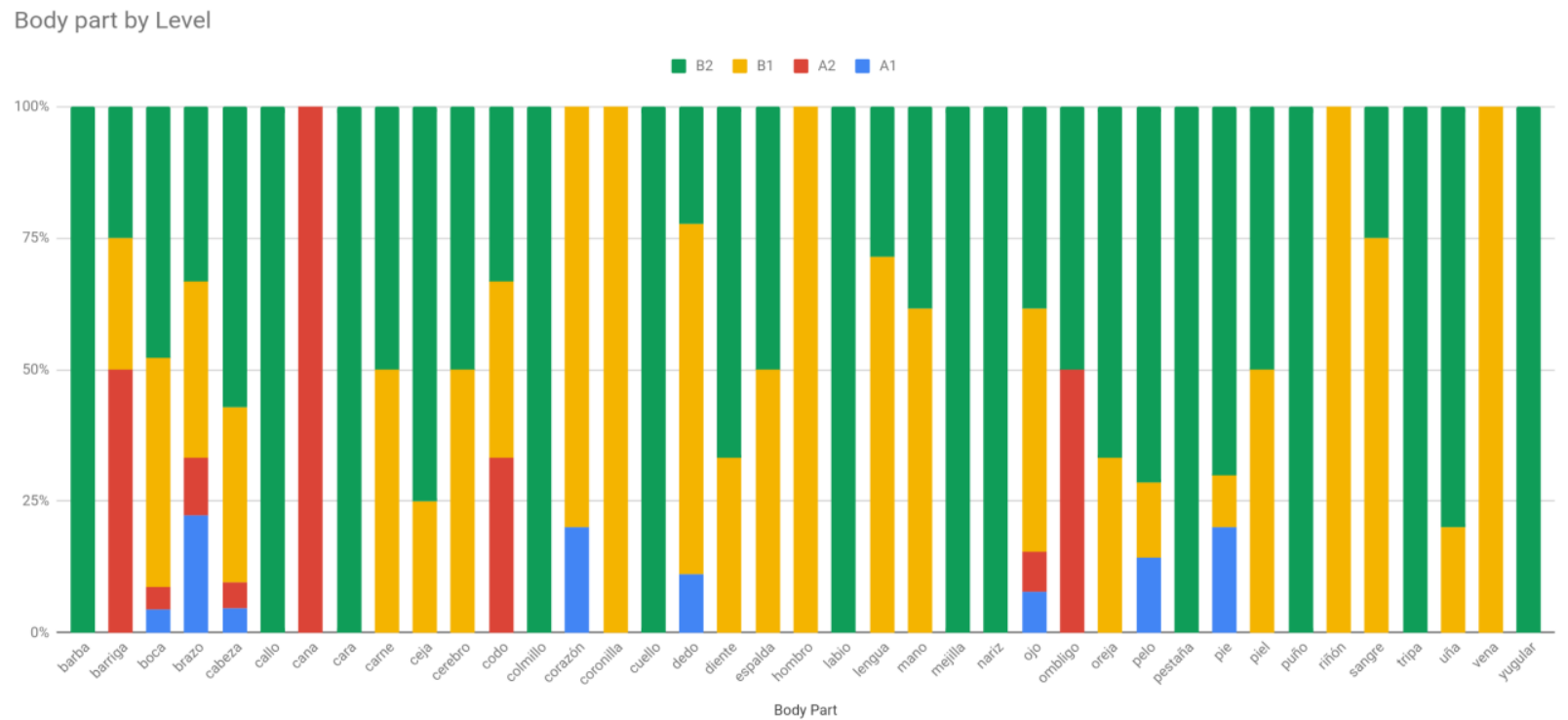
Tipo de equivalencia

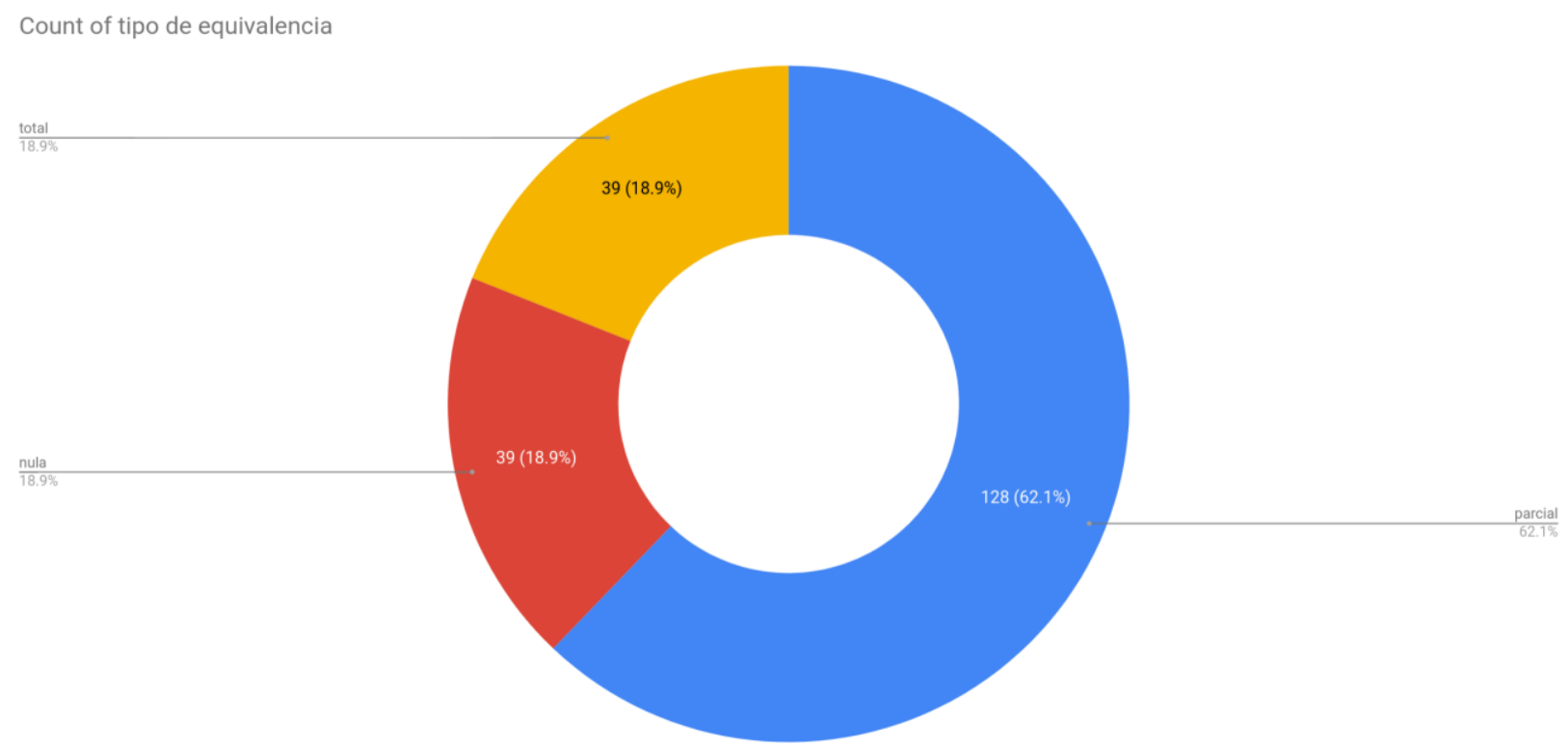

Distribución de los somatismos según la función comunicativa

Count of función comunicativa

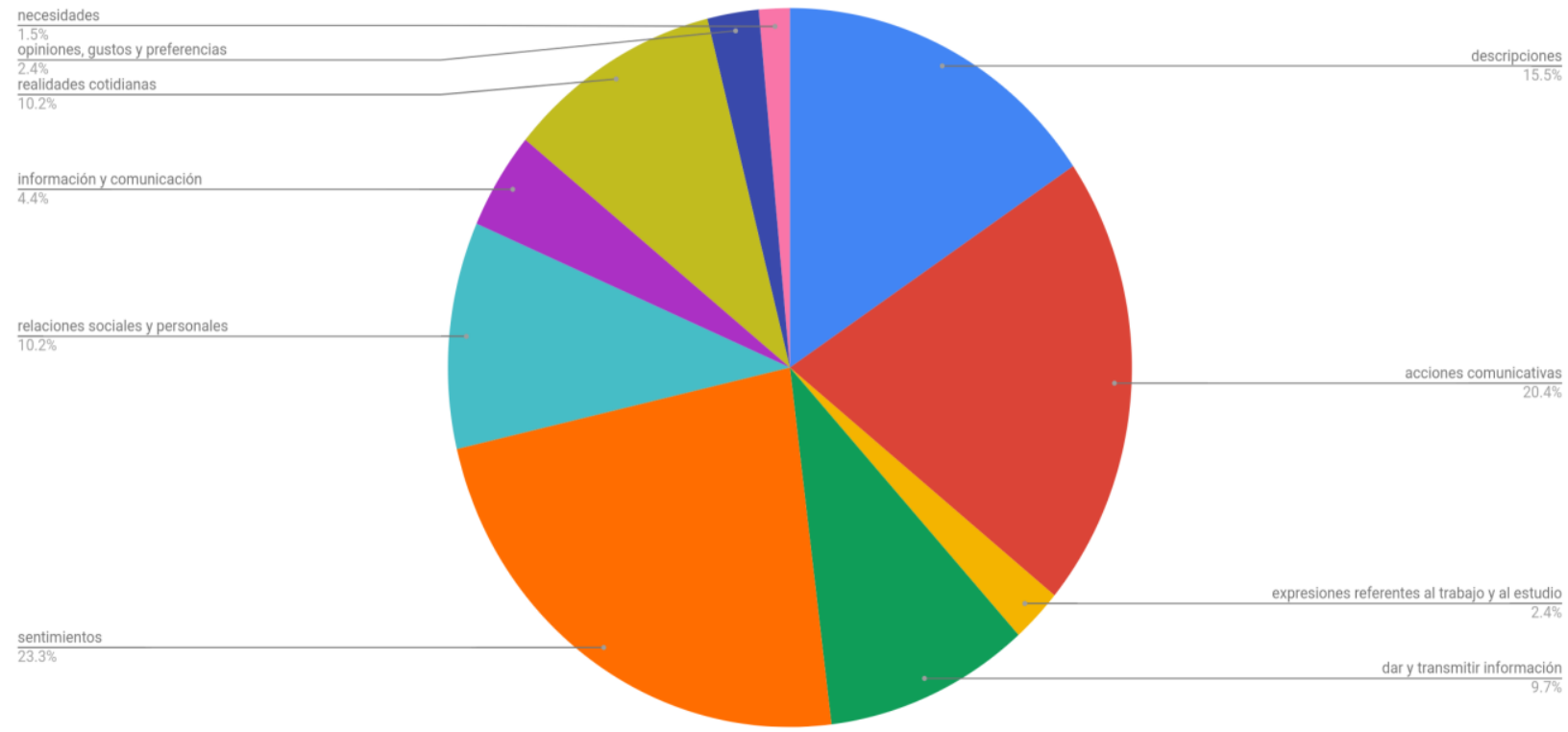


Distribución de los somatismos según la función comunicativa (descripciones)

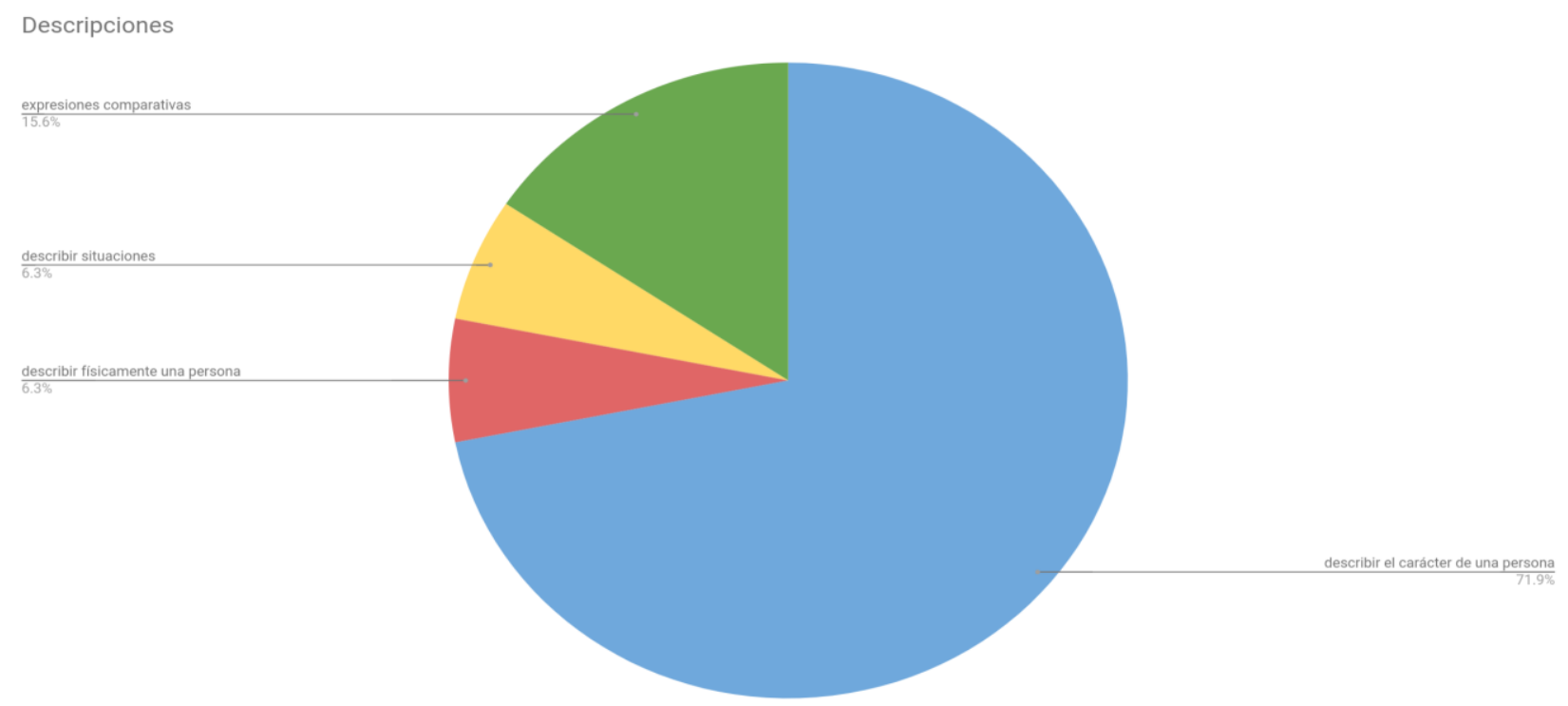

Distribución de los somatismos según la función comunicativa (acciones comunicativas)

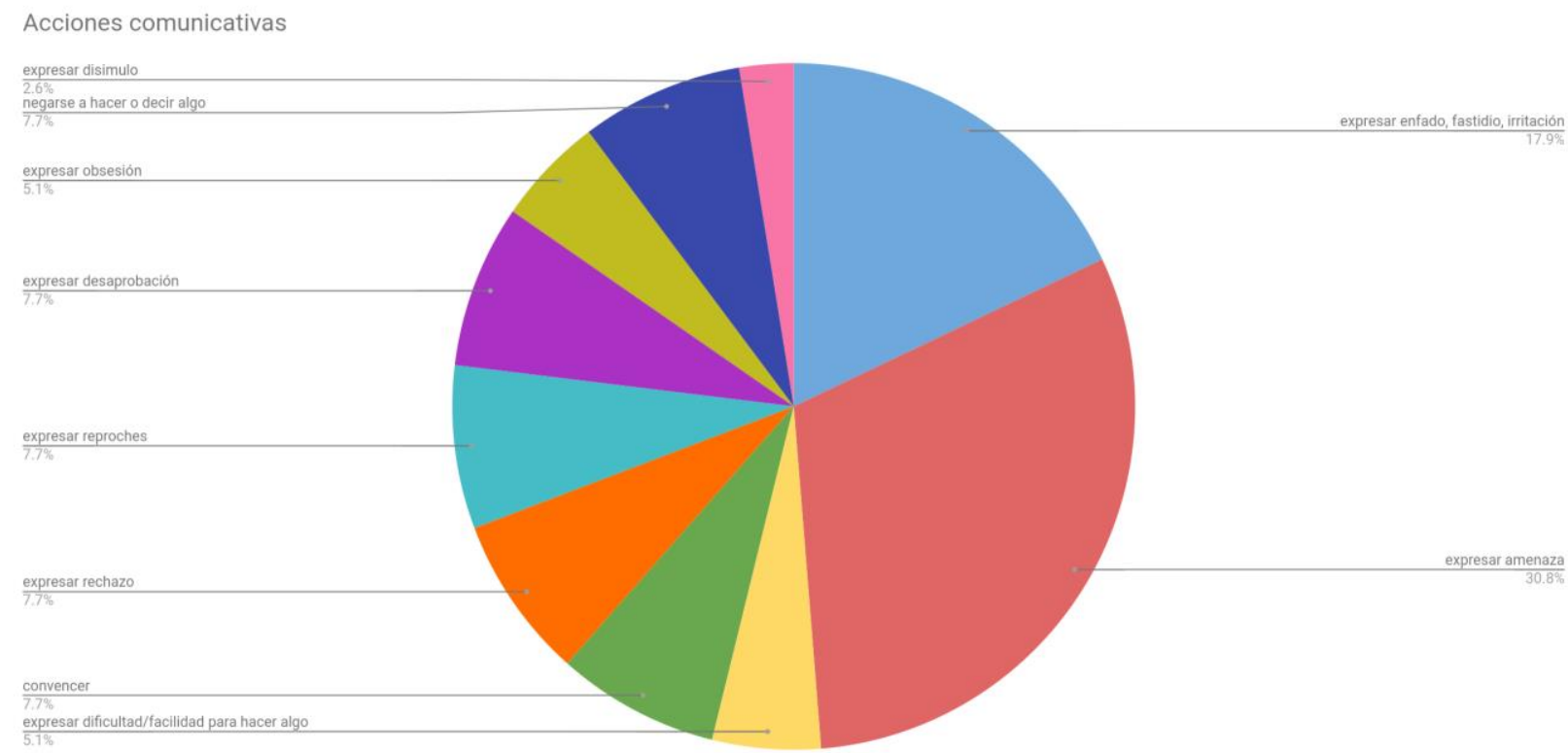


Distribución de los somatismos según la función comunicativa (sentimientos)

Sentimientos

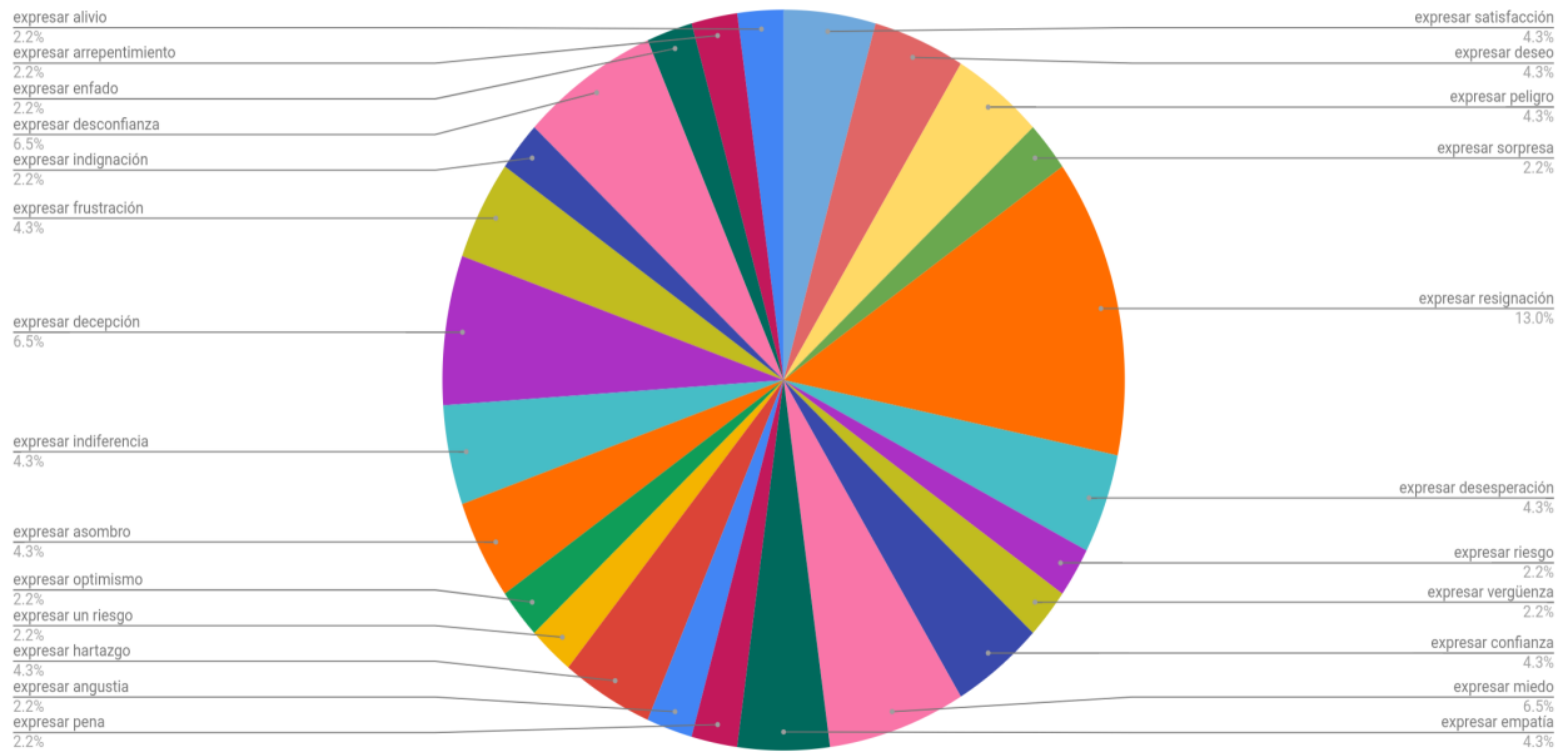

